

1

6 



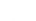

,

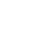
-

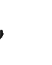



A TREATISE

oN

\section{Disputed Handwriting}

ANU THE DETERMLXITION OF

GENUINE FROM FORGED SIGNATURES.

\section{The Character and Composition of Inks,}

AND THEIR

DETERMINATION BY CHEMICAL, TESTS.

The Effect of Age as Manifested in the Appearance of Written Instruments and Documents.

BY WILLIANI E. HAGAN,

EXPERT IN HaNtWRTITING.

(ALL RIGHTS RESERVED.)

BANKS \& BROTHERS, NEW ÝORK.

AI,BANY, N. Y.

I894. 


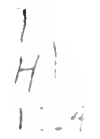

Entered according to Act of Congress in the year I 894 , by BANKS \& BROTHERS,

in the office of the Librarian of Congress at Washington.

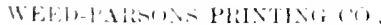

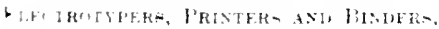

Albany, $x, y$ 


\section{Canses Celebres.}

THE MOREY LETTER.

THE DAVIS WILL CASE.

THE LE WIS WILL CASE.

THE GORDON WILLfCA SE.

THE THEODORE HUNTER WILL CASE. 



\section{TABLE OF CHAPTER CONTENTS.}

CHAPTER I. Introductory $\ldots \ldots \ldots \ldots \ldots \ldots \ldots \ldots \ldots \ldots \ldots \ldots \ldots \ldots \ldots$
CHAPTER II.
Forgeries, and the modern facilities for producing them - What
a majority of the more important ones consist of - The changes in the rules of evidence as to the comparison of handwriting by juries - The origin of the common-law rule, relating to expert evidence, its character and value -- Bank tellers and bank cashiers as experts in handwriting - Cause of opposite expert opinions . .......................

Page.

I 3-23

24-34

\section{CHAPTER III.}

Why persons write differently - How the writing habit develops with individual character - When and under what circumstances the writing habit becomes a reflex or mechanical capacity - Typical variation in writing of the same person Effect of practice and different systems of penmanship in modifying or changing individual habit $\ldots \ldots \ldots \ldots \ldots \ldots . . . . .$.

\section{CHAPTER IV.}

How individual habit becomes manifested in writing-Why there can be no rule for determining personal characteristics other than that which relates to their difference in each person's writing from that of every other - Personal characteristics in the writing of an individual always typical of each other, as to cause and why - The necessity of understanding the muscular functions of the hand and forearm to reach a proper understanding as to the cause of personal details in the writing - The function of hand and forearm in writing - The manner of moving and holding the pen determined by the appearances in the writing consequent upon it - Pen pres- 
PAGR.

sure as an modividual mamtestation in a person's writing constereal The chect 11 exentement. fatigrue, disease and old

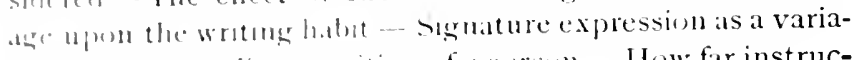

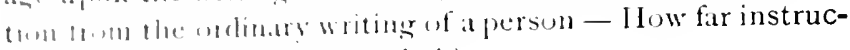
twm m.tb medly the witung habit. .............

\section{CHAPTER Y.}

The hafenence between what constitutes typical parallelism of the sme wrotr. and their simulation by another person -

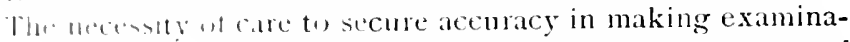
lamb and inmparisons of handwriting - The importance of howher proper stankards or admittedly genuine writing of the perom whese writing is being disputed - The date of all writura used for the purpose of comparison with relation to that it the disputen writing being examined - Traced signltwa and Juw produced - Some of the usual conditions of forgerl innatures considered - The use of the compound micresenge and the importance of its use in the examination of dispruted writing - The effect of age. disease and excitement to be taken into account in the examination of signatures - The analysis of personal habit in writing explained and illustrated in detail by an example - Why simulating cuphoties are limited - Weasure of accuracy attamableWritugr habits classed generically $\ldots \ldots \ldots \ldots \ldots \ldots \ldots \ldots$

\section{CHAPTER VII.}

Signatures comparerl with the ordinary writing of the same perw - The circumstances attending the production of sigmaturns as compared with those under which other than signiture writing of the same person is done - Modifications 1) the: hame habit of writing, their cause and character as applied t", the preduction of the Junius letters - Disguised handwriting is compared with habitual writing of the same perum l)ifficulties attending the examination of disguised handwritiug. and the identification of the writer of it by compurison liuder what conditions a perfect disguise of a person's handwriting mar be accompliched and the difficulties of dring it - Disguised handwriting as occurring in the case of $r$ whittiker and the process steps employed for its

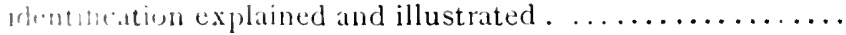


Lead-pencil writing and its comparison with pen-and-ink writing of the same person - What details of habit appearing in penand-ink writing which do not occur in lead-pencil writing, and the cause of their being manifested in the one and not in the other - The use of a rigid pencil as compared with that of an elastic pen, and the different effects appearing in the writing produced by them - Signatures written with a lead pencil have in them only such features of habit as are susceptible of imitation, and the difference in these respects from ink-written signatures of the same person - The resemblances which the pencil writings of different persons have, and why occurringThe effect which the character of the pencil may have in the appearance of the writing produced by it -- Traced signatures made with a lead pencil and the resemblance they bear to the genuine signature from which copied if well done- Why forgeries of pencil written signatures are difficult to determine.

\section{CHAPTER VIII.}

Inks and the circumstances under which a knowledge of their composition becomes important - The age of papers or documents determined by the appearance of the writing upon them - How written instruments manifest their age - The causes which retard or accelerate the changes occurring in their appearance - How the fading of inks relates to their composition - Inks historically considered - Ancient inks and their composition - Inks classed as solutions and as containing coloring matter in suspension - The effect of care and the custody of written documents as relates to accelerating or retarding the effects of time - The condition of the paper as affecting the changes produced in its age - The facility with which modern inks can be removed - The use of tinted paper as a means of protection - How machines which punch out value amounts are circumvented by forgers - Type-writer work and its safety when original copies are used, and the dangers attending the use of carbon

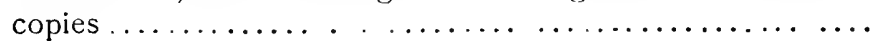

\section{CHAPTER IX.}

When and how the chemical testing of inks becomes importantHow, and with what implements the tests should be made, and by whom made - The identification of the reagents to 
be uned by jomt, establshung them to be what they purport

PAGE. (1) b. - luthuran o w the value of chemical tests as mat-

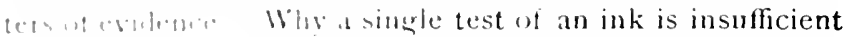

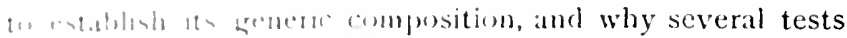
Whathe male - Where the kind of ink becomes importmety andent with the purported date of a written instrumat a the the when the ink was discovered with an mp.utunt ane rited - The effect of age upon writing when thr ank wath which the latter was produced is to be tested When wrome has been traced with a lead pencil and then wroten wer with nk, how the test should be made chemIcally (1) determine it - The effect of re:igents as applied to writings done with different inks and authorities cited with relatum there.t, Nigrosene inks ................ 


\section{P R E F A C E.}

To the lawyer having on trial a case in which the charge of forgery forms a feature, a knowledge of the facts relating to forged writings, and their production becomes very important. One understanding the causes conditioning the appearances of genuine, as contrasted with those of simulated writing, is better enabled to try a case of this kind intelligently than another, who has not a knowledge of these facts at his disposal. While it is not necessary that counsel or attorneys should become experts in handwriting to properly conduct trials of this kind, such of them as are acquainted with the authoritative experiences of those who have made such matters a subject of study, are better fitted to examine witnesses in a manner to make their evidence more clearly understood than others who have not this qualification. It has often occurred in the experience of the author when a witness at the trial of cases of this kind, that persons conducting the examination would put their interrogatories in such shape that they could not be fairly answered within the scope of the question, and at the same time convey a clear idea of the matter inquired about, from the fact that the interrogator did not have a proper understanding of it. While it may take a great deal of 
stuly to make a man an educated expert in hand. writing, it does not follow that a person cannot under. stuml the methods employed to reach conclusions in such investigations without being able to practically spply the process steps herein suggested, and a lawyer by understanding the methods can easily distin. gruish opinions founded upon a scientific basis, from those which are empirical and by cross-examination make the difference apparent.

Directly connected with the determination of individual habit of writing, there are other matters often calling for expert knowledge, and which, as developed in the experience of the author, the subjects are considered in the following pages. The real age, or the counterfeited appearances of age, which a document may have as to sustaining the question of its authenticity, and the genuine or forged character of the signatures appearing upon it at times become a matter of legal controversy, and the experiences of those who have had to investigate such matters become useful in reaching a proper conclusion concerning them. The effect which time has upon the ink with which the document in question was written, the kind of ink, how and why chạnges occur in ink writings as acted upon by time, are all of them features which at times become subject-matters for the consideration of courts and juries. Inks, and their composition, and how tested to properly determine their sameness or difference, as affecting their having been written with cotemporaneously when appearing in different parts of a document, are also 
matters at times requiring expert knowledge and experience to determine them as to character.

To bank officers and the tellers of moneyed institutions who are desirous of studying the phenomena which gives individual character to the writing of different persons, and by which alone the determination of forged from genuine signatures is accurately accom. plished, this book, if properly studied and with its contents made properly applicable, will prove of great value. To this class of persons a knowledge of inks, and their chemical character, as to permanency, and the detailed methods employed for raising the amounts of checks and drafts, will furnish valuable aid in making such examinations of suspected writings of this kind, and prevent the perpetration of fraud. 



\section{CHAPTER I.}

\section{INTRODUCTORY.}

Incidental to the study of a subject for over a quarter of a century, there results as a sequence of such employment a measure of education and experience relating to. and connected with what such a pursuit teaches; and these acquirements, so attained, better enable an individual instructed by them to understand the natural phenomena which the subject presents as to its realities, than when considered without the guidance of these qualifications. The most familiar conditions of nature, and particularly some of those which are seemingly simple in their every-day manifestation become complex when studied with relation to their organization and production; and in the examination of special subjects many apparently unimportant appearances take on a new aspect, and assume a character which would not be understood without knowing the relation such features may have, when as effects they are connected with cause. To the inexperienced eye of an observer the deviations in pen movement, which weave inwardly and outwardly in a line forming part of a letter, have no other significance than as an irregularity in the writing; but to the educated and experienced specialist who has studied the subject-matter relating thereto, such conditions occurring in the writing are indicative of muscular causes which are peculiar to the individual producing them, and are necessitated to so appear as a part of the writer's habit from the organization of the writer's hand. Ordinarily the peculiarities by which the writing of each person is made to differ in appearance from that of every other are 
considered in their greneral features of difference alone, and without connecting the apparent fact of their indivilual character with the cause of their manifestation. Experience in this field of study will from its teachings consider all the individuality apparent in the writing of persons, as the result of physical conditions by which the personality manifested in the writing is necessitated, as a matter of peculiar muscular coordination, with the latter as the cause establishing the habit, and the writing in its individuality as the effect.

Indirectly the subject of handwriting has been discussed and considered by medical writers and others in connection with what is termed Scriveners palsy or paralysis, as to the effect of the latter, and the cause of its appearance, but so far as relates to the determination of individual habit of writing from the phenomena presented by and accompanying its production apart from its form and general appearance, little has been written or published. In all the publications which have appeared with reference to determining the authorship of the letters of Junius, the conclusions reached, and the opinions promulgated concerning who was the writer of them, were based upon the characteristics of form and general appearances; and in none of them is the attempt made to ascertain the physical habit of the writer by a microscopic examination of the details appearing in the writing, and consequent upon it, as a matter of personality. When the letters of Junius were written, the conse-quill was the only implement employed, and this did not give to the writing the strongly marked details of physical habit which are manifested when a metallic pen is used.

To understand physical habit in writing, and to determine what its individuality consists of, is the problem 
presented for consideration in this treatise. The subjectmatter is not calculated to interest people generally; only occasionally will persons be found to devote sufficient time and study to the subject to become proficient in it; but to the earnest student who is fitted and educated for the work, the process steps, and the system of analysis proposed will prove full of interest. With others where rigidity of intellect has so fettered the faculties as to render them incapable of studying new and complicated subjects, or with those who are destitute of the education to intelligently apply the means and methods suggested, and who usually "damnant quod non intclligunt" the system will be of but little use.

During the very many engagements in expert work in that field where Chirography was the subject, and wherein by the system of examination and analysis hereinafter detailed, the Author has been enabled to determine with accuracy what seemed difficult and doubtful questions, the interrogation has often been made by those who appreciated such efforts. Why do you not publish your experiences and an explanation of the system by which you reach conclusions in regard to individual habit of handwriting? To these questions and requests the publication of this book is an answer.

The study of individual habit of writing for the determination of its individuality, with the incentive to the undertaking stimulated to attain definiteness and accuracy, opens a field for mental effot where those who enjoy the analysis of complications may find abundant material to struggle with, and wherein to possess the soul with patience is one of the first requisites. These conditions are not attendant upon the work where an assumed intuition or fancied innate capacity gives birth to opinions, and where a snap-shot view of 
the: writing is deemed sufficient to formulate a conclusion ats to its anumeness or simulation. Where the study is pursuced with the desire to insure accuracy, the process steps to be employed require the same kind of cxictness, and step-by-step verification that guides the mathematician in working out a calculation, or a chemist in making an analysis of a substance.

When it is understood that the field in which the stud! must be made presents in each case examined a peculiar set of facts which belongs to it alone; and that the habitual writing of different persons shows no parallelisms in those features which give individual character to it; and which causes the writing of each person to differ from that of every other; it follows that the study and determination of individual characteristics has to be made independently of every other consideration than those which the writing being examined presents, and as much so as in the study of any subject where every detail, and all the phenomena manifested in it, belong to it alone. As a sequence of this condition, no general rules can be formulated for the classification of individual peculiarities, but there can be indicated the use of such rules as designate a mode of procedure in making the examination.

Closely connected with the fact that no two persons writc with the same habit, is the cause why they do not: and why there should be developed in each person a cause that gives individual character to the writing habit. With the cause determined, the peculiarities appearing in each person's writings become typical of the cause and established as the product of the latter, in connecting the act performed with the personal way of ining it. Knowing that writing is accomplished as a muscular act done under the prompting of a mental 
impulse, it is, in its production by each individual, subject to the same differing conditions that are manifested when all other muscular acts done by different persons are compared; the cause being that in no two persons are the muscles which do the work, and the mental impulse which prompts their movement organized in such a manner as to produce the same coordinate action excepting in a general manner. This necessary difference occurring in all habitual writing constitutes the field in which the examination must be made to determine individual habit, and the analysis in each instance must be accomplished by ascertaining from the writing itself, the muscular coordination by which it was done, for the latter constitutes the habit, and the writing itself is but the effect and sequence of the latter.

To connect with the form of the letters the pen movement producing them, constitutes the general work of the analysis, and this involves in its application a very accurate study of the writing under the microscope. While the writing of a person may be very closely imitated so far as its pictorial appearance is concerned, the muscular habit of the writer whose signature is simulated cannot be; and the microscope enables the examiner to study the writing in a field where simulation cannot go. To the educated and experienced eye, signatures when thus studied should show all that is necessary to determine the muscular habit of the writer from the writing itself. Examined under these conditions the personal characteristics of the writing become concomitants of the cause producing them, and their variation (in view of the fact that they are never written precisely alike) cease to be real differences.

To the casual reader the minute details which indicate personal habit of writing, and the muscular coordination 
of each indivilual that are so small in their manifestation as (1) reguir. a microscope to determine them, may seem tow far wif in their measure to produce either reliable "vilknce, or satisfactory conditions under which to formul.1t: an opinion with accuracy; yet everything we see is mule up of atoms, and all the great substances to which names are siven are mere aggregations, in which the . Wums and their arrangement give character to the aggrewate. It is the same with that which constitutes indibilual hallit in handwriting, and gives character to it. fiald personal habit involves the production of details which are typical of the habit, and to identify them as the product of the latter and consequent upon it requires thit the eximiner is capable of determining them, and their connection with the cause of their production. While the subject involves the application of a kind of knowledge that can only be acquired by experience and faticnt investigation, the measure of accuracy within the reach of competent examination in this field of study is much greater than is generally believed.

In the study of chirography, until recently the form of the letters, their connection and general appearance was the only fiekl in which examinations were made to determine individual habit. The idea of connecting with the form produced by the pen, the personally peculiar muscular coordination of the individual by which the writing was done was not taken into account or conivlenel important; and thus the variations occurring fretwenn simatures of the same person abnormally producenl under the same muscular coordination, when compured with others of the same writer made with whinary emphasis, were very often considered real differences: and this tended to cmbarrass the judgment of such as were called upon to make such investigations. 
The general appearances of the writing being examined suggested resemblances or differences, but whether the resemblances were real or simulated and the variations positive differences, was largely a matter of guess-work. Hence signatures well simulated when compared with genuine signatures of the person whose writing was being disputed would be assumed to be genuine, from their resemblance, and signatures of the same person when compared with one another would from abnormal conditions of production be determined as the writing of different persons. Under an examination instituted in the higher plane of study herein suggested, while general appearances of signatures may be taken into account in making comparisons, the manner of making the letters, and the coordinate action of the muscles by which the form is produced, will be maintained in the following pages, furnish a far more reliable field for the determination of the personal characteristics which give to the signatures their individuality than the mere resem. blance in form; for while the latter may be imitated, the muscular coordination producing them cannot be.

The individualism manifested in persons as regards their acts, movements, general appearance, and mental processes are no more strongly marked as to personality than are the details which make up individual habit of writing, and which in their manifestation, like the former, have their origin under the operation of the same law which gives to the human form its personal characteristics in other respects. That the peculiar details which make up, and give individual character to the writing of each person are the resultants of physical habit cannot be reasonably disputed. The appearance when magnified of the details which cause each person's writing to differ from that of every other will indicate the cooperation of 
ine muscular factors producing them; and it would seem w be only a question of ability on the part of the examine making the analysis to determine from these details, at sepundess of such a physical cause, the muscular andination constituting the latter.

While humm julyment is not infallible, and the same suljective matuer presented to different persons for consileration will often furnish a means for disagreement of "pinion (particularly when the objective part of the subju bein considered. admits of a different understanding of what is seen) it would seem in the analysis of individ(1.1) h.1bit of writing when conducted in the same plane of stuly, and by examiners equally competent that there shuuld be but very little room for divergence of opinion. l'eculiar details appearing in the writing being examined, and found to be necessarily the concomitant of a manifested cause, concerning which as to kind and character there could be no mistake, it follows that when these peculiarities are considered as effects, that they must inlicate the cause alike to different observers equally compretent, and with such definiteness as to prevent disarecment.

The writing by an individual of his or her signature is a rery simple act after the habit of doing it is acquired, anl as to how its personality should be established in the writer by comparison is not only a learned and scientific sitisfaction as a matter of study, but it at times becomes imprortant with reference to the property interest the sicnature may create when affixed to an instrument in writing. If people wrote only their own signatures to papers to rive value to them, the question of determining the: individualism manifested in them would not become s) necessary it matter; and the scientific examination and identification of personal habit in writing as an acquire- 
ment, would find a place among those other studies in which the satisfaction of knowing the facts relating thereto is the only incentive to their attainment. But there are persons who are not content to write their own signature to papers of importance, but with dishonest intent essay to imitate those of other persons, and hence the identifi. cation of individual habit becomes important to protect property interests, and to punish fraud.

Based upon an experience derived from the examina. tion and analysis of thousands of specimens of writing in this field of study and research, the means and process steps herein suggested for determining individual habit of writing are not advanced as a mere theory, but as a system which when studied by the competent will establish its own claims to verity and reliability. Intelligently made applicable the method and procedure suggested opens a field for study where something tangible can be reached in the way of facts to verify an opinion, and to formulate a conclusion; but the Author is aware of the attending condition, that the measure of value attached to all opinions given and conclusions reached through the employment of the system herein proposed will depend upon the skill, and experience of the person making the examination, and the proper application of what is found to occur in the writing being examined. In the experience of the Author it has occurred that persons learned in the use of the microsrope would fail to connect with the physical cause of their production very plainly manifested, peculiarities in a signature. Seeing a detail that was peculiar to the writing of an individual and found to occur in all movements of the pen in typical delineation, the observer could distinguish the peculiarity, but why it should occur and what necessitated its appearance as a part of the writer's habit could not be under- 
stoud for want of experience, and an education that fitted the observer for the work.

Necessarily connected with the study of individual hatit as manifested in the writing produced by it is a knowledire of how individual habit is developed? Why must there be an individual habit manifested in the writing of each person? And a proper understanding of these conditions is essential to a correct consideration of what individual habit is, and how determined, before procecling to compare one writing with another, for the purpose of ascertaining whether that which is disputed is cenuine or simulated. A study and knowledge of these conditions is important in the fact that peculiarities appearing in writing are better understood and determined as to character when connected with the cause of their production; and a knowledge of how produced enables the examiner to distinguish them from like forms made by the pen under the operation of a different muscular coordination.

While the writing habit as acquired and specifically conditioned in each individual from physical causes manifests itself as well in the ordinary writing of persons as it does in their signatures, the latter are generally written with some peculiarity and more individual in character than other writing of the same person. This occurs from the fact that the signature represents the individual, and when signed to a paper of importance the intention to make its personality apparent becomes connected with its production as a matter of habit. With the writing of persons other than their signatures their is no incentive to give to it personal characteristics as to form and general appearance, nor is there any necessity for doing it. In a succeeding chapter this signature expression (so often occurring in the writing 
of individuals) and the relation it bears to the modification of personal habit of writing will be fully discussed.

The several branches of the subject are treated in the following pages in the light of the author's extensive experience, and while it is possible that conditions may be found to occur in the writing of a person where the means herein suggested may fail to connect the writing with the peculiarity of the muscular co-ordination producing it, yet such an experience has never occurred to the Author. Pen writing from the character of the implement used to produce it must indicate the manner in which it was held and operated, and while in this respect writing done with it differs from that produced with a lead pencil, and while the same rules will not apply to an examination of writing done with the latter that are applicable to pen and ink writing, yet even pencil writing, as will be afterward treated upon, generally has manifested in it details of habit by which the latter may be determined.

Individual habit of writing, as made the subject of the ensuing chapters, will be treated upon and principally discussed as relating to such writing when done with a pen and ink with accustomed effort and habitually, and not as relating to unusual or disguised handwriting, or to signatures written with a lead pencil. Other than signature writing and disguised handwriting will be treated in separate chapters.

William E. Hagan, Troy, $N$. $Y$. 


\section{CHAPTER II.}

FHRGIRIES, AND TIE MODERN FACILITIES FOR PRODUCING THISI-WHAT THE MAJORITY OF THEM CONSIST OF.-THE "HADMES IN THE RLLES OF EVIUENCE AS TO THE COMIMRIUN WF HANDWRITING.-TIE ORIGIN OF THE COMMON. L.WW RILI REL.ITING TU THE LATTER.-EXPERT EVIDENCE, ITS (IIIRACTER AND YALEE-BANK TELLERS AND BANK C.ISHHHR AS EXIPETS IN IIANDURITING.

The crime of forgery, like many other offenses against society and the laws enacted for the protection of the latter, has in recent years been compelled to seek out new avenues for its practice, to avoid those precautionary means which have been instituted to prevent its being successful, and where punishment is sure to follow detection. Few forged checks are now presented at banks or moneyed institutions for payment, unless they happen to come to the latter payable through exchanges from shop-keeper depositors; and this class of forgeries is generally the work of bunglers, and for small amounts. Occasionally endorsements of notes are forged, but in the matter of wills and notes against the estate of deceased parties, the number of forgeries seems to be increasing. The temptation to forge a will or note purporting to be that of a person who has died and 1. ft a large estate, is stimulated by the fact that for this class of forgeries, when detected, the perpetrators of the crime are seldom punished. As a sequence of this condition, forgeries of this class furnish the greater prart of the cases occurring in which litigation is had.

Not only have this class of forgeries increased greatly within the past few years, but those who commit the crime in the better conditions of its execution have 
Forgeries, and Facilities for Producing Them. 25

greater facilities at hand for accomplishing it than formerly. The steel or gold pen is a much better implement for the work than the goose-quill of fifty years ago; while materials for tracing and delineating the general appearances of a signature are very easily obtained by those who desire to use them for such a purpose. When the work of pen-artists and scriveners of the present day is examined, and particularly as shown in designs for stock certificates, testimonials, and other work of a similar kind, to the ordinary observer they are difficult to distinguish from engravings. It will be understood that the same means and better facilities which have developed this culture in the use of the pen for honest purposes, when used dishonestly have increased the ability to simulate signatures, and to make the determination of the fact whether they are forged or genuine more difficult than formerly.

It is well known that paper money imitations in the form of greenbacks have been produced by pen-artists in such perfect picturing as to defy identification as such in the ordinary field of examination. Copies of expensively engraved bank checks, having complicated designs, have been so closely imitated with a pen that ordinary observers could not tell them from the engraved specimens from which they were copied and pictured. While this development of ability has occurred with those making a study of this kind of work, there has been also a generally increased faculty on the part of all who write to control the pen with aptness and more complete command. Two hundred years ago there were but few people who wrote much or that used the pen to any great extent. But for the last three generations a large proportion of the people in all civilized countries have not only learned to write, but to write a great 


\section{2) Muner. Chavias in the Rules of Evidence.}

deal. Is a sequence of this condition many persons nut professional criminals are induced to commit forury on fincling out that they have the ability to simulate the sirnature of another, particularly when the tempta(ii)n to do it is coupled with the opportunity, and when the chances of detecting the crime and fixing it upon the perpetritor are made doubtful by surroundings.

Lntil recently, the comparison with disputed writing, of other witing known to be genuine, was not permitted under the common law in jury trials, unless the admitwelly genuine writing was in the case as a part of it, and ren now in some of the States of the Union this rule is still adhered to. This condition left available for evidence a very limited field of inquiry; and generally the unly cridence that could be used for establishing the senuine or forged character of a signature was the opin. ion of those who had become familiar with the writing of the person whose signature was being questioned, by having seen that person write. Witnesses whose evidence as to the genuine character of a signature is based upon having seen that person write, cannot be expected (1) judge as to its being genuine from anything but the seneral appearances of the writing, and as a forgery, to accomplish its purposes, must involve the imitation of the sisnature it is intended to represent, those forming in opinion from such a standpoint are easily deceived, anil much more so now than formerly, when forgeries are so successfully made as to deceive even the person whose name is simulated.

The English common-law rule as to the comparison of handwriting originated centuries ago, and continued to have force in England until I 854 , when by statute it was provided that writing proved to the satisfaction of the court to be genuine, might be submitted to the jury and 
by them used for purposes of comparison with disputed writing. This common-law rule (still in force in many of the States of the Union) originated in England at a time when juries could neither read nor write, and on this account were considered incompetent and unfit to compare writings when determining their genuine or forged character, and has strayed down into our times as one of the many excrescences that feudalism and igno. rance had from necessity grafted on to jurisprudence, and which has been remedied by subsequent enactment.

Under the old English common-law rule, and even now with the more recent statutory provisions operative as regards the comparison of handwriting by the jury, a witness having seen a person write his name ten or twenty years ago is sufficiently competent under the rule to testify as to the genuineness of a disputed signature purporting to be that of the same person the witness saw write years before; and evidence of this kind is very often introduced at the present time in the trial of causes; not only is this the fact, but there are even some judges and lawyers who still believe it to be the best kind of evidence. This class of proof, however honestly given, must be based on the condition alone that as the witness remembers the writing he saw done, the questioned signature looks like it. But as a forged sig. nature, to answer the purposes for which it was made, must from necessity look like that from which it was simulated; and as it frequently occurs that an expert forger will simulate a signature so closely that the very person whose name is simulated cannot tell the forged from the genuine, evidence of this class of witnesses would seem to have little value. It was to allow the introduction of what the courts of England considered better evidence that statutory provision was made for the comparison by the jury 
of the disputed writing wh the genuine: and this change a. m.ule ats an erolved necessity to meet conditions which hul mot dereloped, and were not in existence when the oll common-litw rule was alopted, and when juries andel not reand or write.

This change in the rule of evidence as regards the ampurison of handwriting, first adopted in England and linmer, and aftrmards in most of the United States, fremits the introduction of another class of evidence-thit of experts who have made the subject of handwriting a study, and who testify as a matter of opinion and without any personal lnowledge of the writing of the indivilual whose signature is being questioned, other than that derivel from an examination of the writing itself.

While this change in the rules of evidence would seem t) be a weat improvement upon the old common-law rule yet it is open to many objections in the fact that the same difficulties appear which accompany the trials of all cases where experts are called upon to testify as a matter of opinion; and more particularly so because there is no established rule or standard as to what constiutes an cxpert in handwriting. As a sequence of this cumlition the range of ability between the extremes of competency appearing is a wide one. Before an educatcel and learned court, able to distinguish between the competent and incompetent, there is less difficulty; but (1) the arcrage juryman this measure of ability is not talion inte account in reaching a conclusion. It often wecurs that experts who have had a wide range of andence, and possess every qualification to judge ind lliwently as to the character of the writing before the court, are contradicted by persons posing as experts whe hawe had little or no experience; and sometimes who lity claim to possess a supernatural grift in being able 
to tell genuine from forged writing by merely touching it.

Where the opinion of experts is given in court upon disputed signatures, it is not so much the opinion expressed as it is the facts made apparent in the writing by explanation, and upon which the opinion given is based which enables the court or jury to reach a conclusion that gives value to the testimony. These facts in their fair presentation makes the expert the amicus curice of the court in setting before the latter what the education and experience of the expert finds by analysis and comparison to exist in the writing, that the tribunal before which it is had may consider and take into account in reaching a conclusion.

Expert evidence given under the most honest convictions of its verity and conscientious regards to accuracy does not always receive the credence to which it is entitled, from the fact that this class of proof is so often coupled with conditions which give to it a partisan character. The earnestness and zeal shown at times by experts in emphasising all the apparent facts which tend to establish their opinion, and the avoidance of everything that might be considered as adverse to it, affects generally the value of all expert evidence, and so much so that all kinds of it are received cum grano salis. In estimating the integrity of this kind of evidence it would seem that honesty and fairness should be considered as necessarily enforced conditions to make the calling of the experts a successful one in a pecuniary point of view, yet this is seldom taken into account by those who sit in judgment upon it; nor is the fact that though experts may differ in opinion, they may each honestly testify to what is believed to be true.

The best appreciated standard of educated expert evi. dence is that which states the facts on which the opinion 
siven is based without bias, and in perfect fairness to inth sides of the controversy, no matter how strong maly be the conviction of the expert as to the opinion apressed, and while the latter may be defended by the recital of such apparent facts as go to sustain the views of the spert, yet the latter should be equally ready to allow whose conducting the cross-examination the benefit of all facts to which attention is called that tend to traverse the opinion of the witness.

While there is usually much that can be seen and explinined as to what the opinion given is founded upon, there are many features apparent to the experienced eye of an clucated observer that cannot be appreciated or understood by persons who have not made the subject being considered a study. Where the evidence of a chemist is given as to formulated reactions, and the process steps pursued in making an analysis, there is much which must be taken for granted if believed by those who are not chemists, and it is so with an analysis of handwriting made to determine its individuality, and there may be very important facts stated as occurring, which are only discernable by the eye of one experienced in making such examinations.

lersons who devote a large part of their lives to the study of special subjects must become learned in them, and when aicled by education and having capacity to understand what they see and learn, their ideas of a subject, if honestly given and without bias, may be useful to others in reaching a conclusion apon a matter pertaining to it who have not had this experience. While this is true in respect to all subjects where expert evidence may be of value, it is especially so as regards the determination of individual habit of writing which presents a field for study where peculiar education and experience are 
very essential to reach a correct conclusion in the matter of an opinion as to its genuine or forged character. Relating to the subject of handwriting as well as all others in which expert evidence is employed, it very often occurs that those having had the most experience as such will agree in their opinions and be arrayed upon one side of a controversy, and those with the least experience and fewest advantages to know of what they testify, will be found upon the other side; and then there comes from counsel supported by empyrical testimony the usual statement in summing up the case, that these learned experts do not agree. Occasionally it happens that even equally well-educated experts in handwriting will disagree, just as lawyers and even judges do sometimes in their interpretation of the law. As will afterwards be shown where the general appearance of signatures is the only field in which they are studied, formally written signatures may be given one set of experts from which to make the comparison, while those employed by the other side of the controversy will be given signatures to letters, or others written where the intention to give them personality was not necessary, and this procedure is apt to be misleading when signatures are thus studied, and leads to the development of opposite opinions.

Amongst the many who appear as experts in handwriting are bank officers; and when the conditions under which as a class they do business is considered there is but little that occurs in it to make them proficient in the art of determining individualism in signatures. The general appearance of signatures and the resemblance or difference they have in these respects when compared is the field in which their examinations are made, and this alone does not constitute safe ground for study and the formulating of an opinion; for both general appearances 
mb resemblances can be very closely imitated, and in such a mannep ats to cren deceive the very person whose name is simulated.

link tellers undoubtedly do acquire a certain amount of experience in letermining the genuine character or fornely of the signatures of persons with whose writing they are acyuainted; and yet very little money is paid ont wer the counters of banks on the knowledge which the teller has of the signatures of customers of the liank. Checks drawn to the order of strangers, if presented by the endorser, require the identification of the lattr. and checks for large amounts are seldom drawn paryble to bearer. Small checks, presented payable to bearer, when forged, are usually produced by novices or bunlers and are easily detected. Checks and notes coming in with exchanges have the collection endorsement of the bank sending them, and thus do not require critical examination. Checks deposited by customers of the bank containing the endorsement of the depositors require no more examination than to see that the endorsement is there. Thus it will be seen that while bank tellers may become acquainted with the general appearance of customers' signatures, this measure of experience so acruired by them does not necessarily qualify them to juctige of the signatures of persons other than those with whose writing they are acquainted; and from the further fact that they are not called upon to critically examine such other signatures. Hence the knowledge attained ly lank trllers does not fit them by experience to judge of the character of signatures generally, and the value of their evidence in these respects is greatly overesti. mated. This condition does not apply, however, to such bank tellers who, apart from the little experience thrir routine business gives, make signatures and the 
habit of persons in writing a study, and become proficient therein.

The cashiers and presidents of banks are sometimes called as experts to give evidence as to the character of signatures when their genuineness is questioned, and yet the experience these officers have to fit them to judge intelligently of such matters is very limited. The notes they receive and discount for the bank are taken and received more upon the financial standing of the maker or endorser, than upon any knowledge these officers may have of the signatures upon the notes. How far this class of bank officers are capable of judging of the genuineness of signatures, is best answered by the constantly occurring fact that when a series of forgeries are uttered in a community, the banks as victims become loaded with them. This would not occur were these officers who receive and discount the paper qualified to judge of the genuineness of signatures.

Writing teachers occasionally appear as experts, and the general idea would suggest that they should in their experience acquire a measure of knowledge that would fit them for the determination of individual habit of handwriting; and yet as a class they furnish experts of the least ability. Generally wedded to some particular system of penmanship wherein form alone is taught by exercises, they never get beyond this limit, and though they may be able to wield the pen so as to produce beautiful scrolls, birds and ornamentation, the physical causes which enter into and typify individualisms of habit they are not able to determine by analysis, and consequently conclusions reached by them or opinions given have but little value.

In addition to the differing measure of ability, experience and education occurring between experts in hand. 
writing tending to produce difference of opinion upon the crenuine or forged conditions of a disputed signature, there: are many accompanying circumstances in such cases tending to produce the same effect; and particularly where the seneral appearance of the writing, and the fictorial resemblance it bears to the genuine, is the only fich in which the examination is made. One of these comlitions occurs in the character and kind of genuine sinnatures used for comparison with the disputed writing. Standard signatures offered for the latter purpose are rencrally selected by those who have an interest in establishing the genuine or forged character of the disputed signature. In the experience of those who make such matters a study for the purpose of giving testimony in court, it will very often occur that each side of the controversy will furnish their counsel with only such sig. natures for use as standards from which to make the comparison, as will from their general appearance best faror their interests in the suit; and thus experts depending upon mere resemblances or general appearances alone in making the comparison, even when acting under the most conscientious motives, are led to disagree with others equally conscientious, who had a different class of standard writings for examination and comparison before coming into court and giving an opinion.

It frequently occurs that when experts are being crossexamined in court, that specimens of writing will be shown and handed them for inspection and opinion which they have not before seen or examined; and where the general appearance of the writing thus presented is all that the expert has to depend upon in formulating an opinion, conclusions reached under such circumstances are often erroneous. Where the expert is capable of determining individual habit of writing by a 
microscopic study of it, no opinion should be rendered until the expert has had the same opportunity to examine the writing so presented for the first time, in the same manner that the other writing in the case has been studied to formulate the opinion given.

There are so many conditions under which signatures of the same person are produced, that the variations manifested in them seem to be consonant with the impulse suggesting their production, as will be more fully considered hereinafter in another connection. Thus it will appear that signatures signed to checks, if written in a limited field as to room, or signatures written as indorsements, will differ in length and size from signatures of the same person when produced at the bottom of a bond or deed, or even a will, where there was more room to write them. Signatures to letters will very often differ in general appearance and resemblance from the more formally written signatures of the same person to papers of importance, such as bonds, deeds, wills, contracts or notes, where it is more essential that the personality of the writer appear in the signature. Hence when the informally written signatures to letters are given to one set of experts, and those making examinations for the opposite side of the controversy have standards consisting of formally written signatures from which to make the comparison, the foundation is laid for a disagreement; and this condition is particularly the case where resemblances or differences in general appearance is the only field in which the examination is made.

Where the resemblance and same general appearance is found to occur in a disputed signature that has a counterpart in the standard used for comparison with many who pose as experts in handwriting, it is deemed sufficient to establish the genuine character of the dis- 


\section{3) Why Geveral Aplearances are Deceptive.}

puted signature. With experts more experienced, and capable of analyzing writing in a higher plane of examination, while generàl appearances must be taken into account in formulating an opinion, to make this condition arailable in establishing the genuine character of the disputed signature, it must appear also that these resemblunces occurring in the writing being examined are proluced by the same physical habit; and for the reason that resemblances and general appearances are very easily imitated.

The measure of accuracy which may be reached as to the genuine or forged character of a signature when determined by analysis will depend upon the ability of the examiner to ascertain and determine the physical habit of the writer by the details appearing in the writing produced by it. Hereinafter when individual habit is more specifically considered as to what it consists of, and how determined, the measure of accuracy which may be attained in the examination of signatures will be more fully understood. 


\section{CHAPTER III}

WHY PERSONS WRITE DIFFERENTLY.- HOW THE WRITING HABIT DEVELOPES WITH INDIVIDUAL CHARACTER. - WHEN, AND UNDER WHAT CIRCUMSTANCES THE WRITING HABIT BECOMES A REFLEX OR MECHANICAL CAPACITY.- TYPICAL VARIATION IN WRITING OF THE SAME PERSONS.-.EFFECT OF PRACTICE AND SYSTEMS OF PENMIANSHIP.

The ability to easily and readily tell one person from another is an inherited faculty which all possess, from the infant a few days old to those of maturer age, and although the human face and form in its composition and make-up contains the same elements in each individual, yet among the millions of people living upon the earth, no two of them are exactly alike, and that they are not so is easily determined. No two persons walk, talk, or do any other act which calls for the co-ordinate action of a series of muscular factors in precisely the same manner, and for the same reason no two persons write exactly alike; and all individual habit in handwriting arises from the same predisposing causes as does the differentiation that produces personalities in other respects.

The development of a personal way of doing anything that calls for muscular response to mental monition becomes individual in its character from physical and mental causes, and the writing habit derives its individu. ality and development from the operation of the same influences. Unlike nearly all of man's other muscular acts, where inheritance manifested as intuition facilitates their acquirement, the writing habit does not take on reflex or mechanical conditions of use readily or uniformly; and this arises in a measure from the order in which the functions of the hand have been evolved. 


\section{is The Wrima: Comacities, How Developed.}

The time when man first began to write is hidden away in a remote antiquity, but the human inand as developed in function measurably gives the history of its organization, and thus connects its present condition with its uses in the past. The employment of the human hand for writing was not one of its earliest uses, and as a sequence its adlaptation for such work, while one of education, is not so casily acquired as are those muscular functions where inheritance aids their attainment. The grasping of prehensile functions were the uses in which the hand was first exercised by primitive man, and this kind of employment for ares had much to do with its present development; while those other muscular functions requiring aptness in the manipulation of tools and small implements like the fen, have mainly come through the more recent influences of cirilization, and the development of the arts calling for their exercise in this field of use. As an embryology developing stages significantly determine the evolution of the physical form, and the successive changes it has traversed in its elevation from a lower to a higher organization: so the functions of the hand in the order of their appearance and aptness show the relative periods of their development. Thus an infant but a few weeks old has the faculty of grasping objects in contact with the hand by the use of the prehensile muscles of the latter, though it can do but little else with them; and this indicates that these grasping functions are older and were earlier developed in the human hand than other muscular functions of the latter subsequently evolved by which, after grasping, the object held could be moved with precision and accuracy. These gripping or grasping capacities of the hand occur in every person in varied measure of strength and power, and for the reason that they are the muscular functions of the hand most used, 
and in writing with the pen are those which must grasp and position the latter. There are also developed in the human hand muscles which adapt it in connection with the prehensile functions for other uses than those of merely holding the pen; and when the grasping or prehensile capacities are employed, these more delicately organized muscles become subordinate to the former in performing all muscular acts requiring strength, or the development of power. When the hand is engaged in writing it is a question of personal muscular organization whether the prehensile capacities of the hand do the work, without the intervention of the muscles adapted for more delicate uses, or whether both act connectedly; and whether the prehensile functions of the hand cooperate with the forearm, and do not call into action the more delicately organized functions of the writer's hand, depends upon the individual condition of it as to muscular development.

When the rudimentary efforts are made in learning to write, generally the prehensile capacities of the hand are used to guide and move the pen as well as to hold it, although in some instances the beginner will use the prehensile muscles to hold the pen, and operate the latter by the forearm movement. It is under these conditions variously modified in connection with the mental monition prompting the act, that the preliminary steps for the establishment of the writing habit are individually exercised. Accompanying the acquirement of this habit there is intimately connected the individual measure of coordi. nate action existing between the powers to will and to do. Though the mind may suggest what should be done, the measure of responsive action in persons is widely different. Thus an individual might have a correct conception of the artistic effect of some eminent painter's 


\section{0 \\ How the Writing Habit Develops.}

work, and yet be unable to make a copy of it, though a life-time were devoted to the attempt. The human body through which the mental individualism is manifested is an entity in each instance as regards its appearance in those respects, which causes it to differ from every other one of its kind; so, also, is the mental force an entity in each instance, the one as the tenant and the other the tenement, and the manner in which they get along together with coordinate action is conditioned entirely by their organization and mutual adaptation. Thus, the measure of accord existing between the mental monition which prompts, and suggests the forms of letters as required, and the ability to make them as sug. gested must be a concomitant of the writing habit.

When learning to write, and until the habit is acquired, the same struggles occur between the powers to will and to do as are manifested in the efforts made by an infant when trying to reach and grasp something which it sees; the difference between the movement of the child in so doing, and those made by a person when learning to write, being merely that of degree. In illustration of this condition, if a person who has been educated to use the right hand alone in producing his or her signature, will make the effort to write one with the left hand, the efforts and struggrles between the mental monition which prompts the act, and the attempted execution of the latter, will in measure be the same in kind as those made by the infant.

I dozen or more children seated in a row at a desk, under instruction, going through the rudimentary exercises in learning to write, will give to an observer a good iclea of what causes the development of individual habit of writing. It will be noticed that no two of the children thus engaged will place themselves relatively to the desk in the same manner, if allowed to assume a position sug- 
gested by comfort and convenience; neither will any two of them hold the pen alike, and the measure of control which each of them has as regards the movement of the latter will be found to be different. If the observer will have the children each place the right hand upon the table with the palm resting on the latter, and look them over comparatively as thus placed, there will be found as much difference in the form of their hands examined, as in the faces of the children ; and it will be readily understood that a dozen or more of the latter learning to write from the same copies, and under the same teacher and system of instruction, will each develop a separate and distinct habit, and this will occur from the same cause that makes them talk, walk, or laugh differently.

The writing habit thus evolved from an exercise of the muscles of the hand, or the latter and the forearm under the restraints of instruction, is directed to the production, by the writer, of a copy-book form and style of the letters, and yet as a matter of free habitual writing, the faculty of doing so accurately is seldom if ever attained. Convenience and comfort as to the manner of holding and moving the pen become strong factors in the establishment of personal habit, and the differing muscular development in each person will assert itself, and make promi. nent its peculiarities.

When the writing habit is being developed by exercise, and under the restraints of instruction, its attainment is acquired by learning to copy the standard forms of letters; but after the muscles have become so educated, and the person has learned to write making such copies of the standard form of letters which the muscular coordination of the writer's hand necessitates, the habit generally becomes by practice and continued use in each person a mechanical or reflex capacity; that is, done without any 
copying effort or especially directed mental monition as to ketails, just as such other physical acts like walking are accomplished without apparent cerebration. While with most persons this condition of the writing habit is so dereloped, yet with many it always remains as a copying act, and the production of the letters when writing is accomplished by following a form present in the mind from memory.

The period at which the writing habit passes from its manifestation as a copying condition of its development to one where it operates as a reflex or mechanical act is not a fixed one, and depends largely upon the influences affecting each physical environment. With some persons it is never attained, with others the habit exists under both conditions of development. Accountants in writing down figures to represent amounts, and where accuracy is required, will generally produce them from a copy present in the mind as a thoughtful precaution; while all their other work with the pen will be done mechanically. Persons writing eccentric or peculiar forms of capitals for the embellishment of signatures will renerally produce them from an ideal form present in the mind, although the rest of the signature may be written mechanically. Artisans and farmers as a class, and particularly those who write but little, and generally nothing but their names, never learn to produce the latter as signatures mechanically, and they will write them in manhood and even in old age, with the same characteristics as they wrote them while children.

The development of the mechanical habit of writing depends largely upon the amount of practice in connection with the use of the writer's hand in such employ. ment, as well as upon the measure of coordinate action occurring between the powers to will and to do in each 
person. Thus one who has difficulty in producing with a pen what the mind suggests, must couple with the act the way of doing it, and such a writer cannot make the desired form without an ideal copy present in the mind. As a little child acquires the habit of walking mechanically as soon as the act can be accomplished without a specially directed monition as to how it shall be done, the same condition is in a measure true in the development of the writing habit as a reflex or mechanical capacity; although inheritance, manifested as intuition, comes to the aid of the child in the establishment of the walking habit, and does not, with noticeable effect, have any thing to do with the development of such a condition with relation to the acquirement of the writing habit. The attainment of the latter, whether in its development as a copying act or a reflex capacity, tends to the establishment of personal characteristics and their peculiar production, as much under the one condition of its manifestation as the other. When the writing habit passes from that form of it considered as a copying act, to become a reflex capacity, it carries with it those features of individuality which are forced into its composition from physical causes, there being no change in the act or way of doing it, farther than as relates to the mental processes which prompt its production.

The writing habit is much more easily acquired by some persons than others, and yet the manual dexterity of persons in other respects does not of necessity indicate an easy attainment of the writing habit as a mechanical or reflex capacity. Individuals whose muscles are highly trained, and more particularly in the use of small implements other than the pen, very seldom write a signature as a mechanical act. Thus artists who handle the brush so as to produce an effect that will 


\section{Inhringal Capheites tu Will and to Do.}

almost speak from the canvas, are very rarely able to write their sirnatures otherwise than as the copy of a form appearing in the mind at the prompting of memory; and it is largely so with engravers. This condition arises from educating the muscles to act in response to suggestion in producing a form that the artist's genius has conceived, or a form present in the mind of the engraver; and thus trained to act in one calling, the muscles follow the same routine of action and connected mental pro. cesses when writing.

As before detailed, there is as much difference between the relative capacities of individuals to do what the mind sugrests, as there are differences in physical personalities. II ith some beginners there is manifested great difficulty in controlling and moving the pen in a desired direction, with others there is less difficulty. All see the same imagre, and have the same idea of what should be done to copy it; yet they all make different copies of it. This varying condition arises from two principal causes, the primary one being that the hands, or the latter and the forearm of each of those doing the work rudimentarily under instruction are differently organized as to muscular coordination, and the second cause being the relatively different measure of responsive action in each person between the powers to will and to do; with this condition individually manifested in gradation between those measures where discordant action is merely apparent, and in the other extreme where the latter appears as approaching a palsied infirmity in character. Where there occurs the most prompt response to mental suggestion, the pen movement is more easily acquired by education and practice: but if the best coordination between the powers to will and to do is hampered by a deficient muscular function only such pen movements can be acquired by 
exercise and practice as are within the producing powers of the latter.

The first and rudimentary efforts made when learning to write with a pen are directed to the production upon paper of an image or object impressed upon the brain through the functions of sight. The details of this exercise combined with instruction have but one object, that of educating the muscles of the hand or the latter and the forearm to obey the will, and make a copy of the image. Having a representative form of letters by which they are known and recognized as such, their production and connection in a manner by which they may be read by others, as to what they express is the object of writing them. The same letters and arrangement of them when written by different persons to spell out the same words must have that resemblance to the representative form as will condition them to be recognized as such, and in these respects resemble each other, yet the same letters or signatures if written by different individuals (without any attempt at simulation excepting in following copy-book forms) will in each instance show evidences of having been written by different persons; and these differences as before explained will be due to an individual muscular habit in each of them. The representative form of the letters made by different writers while they must look alike in those respects which give alphabetical character to them, in other respects they will embody in their production by their variation from copy-book standard forms the peculiarities of each individual habit.

Instruction and studied restraint tend to educate the muscular functions of the hand, or the latter and the fore. arm to cooperate under the direction of the mental impulse; yet the resulting coordination from necessity will be that in which the best developed and individually 


\section{to The Develonime of Inimidual Habit.}

most responsive muscular functions in each person that are adapted to do the work will become prime factors in the act of writing, and these are relatively different in each person. With some individuals the forefinger is more responsive to intention when writing than the second fincer, with others the latter is more so than the index finser, and with many writers the index and second finger cooperate as one factor. These conditions together with the varied development of the thumb, and innumerable differences occurring in the muscular organization of the hand and forearm will be more fully considered when physical habit of writing is discussed apart from the conditions of its attainment.

Accompanying the development in the writing habit of those features which give individual character to it in each instance, there are as many personal conditions attendant upon their production as there are persons who write them, all of which can be determined by their appearance and their connection with the muscular coordination under which they are evolved. Certain peculiarly dereloped conditions accompany their manifestation in each instance, which can only be considered as to their character in connection with the individuality of the cause, wherein the latter as incident to their production explains and typifies their origin.

After describing the conditions under which the writing habit is developed, and in what manner it passes from being manifested as a copying act, to one where it is accomplished mechanically, there are other phenomena connected with its development which accompany its attainment, and become important to a proper understanding of its individualism. Prominently appearing in this connection is the variation which occurs in the form of the letters written under the operation of the same 
habit, the cause of their appearance, their character, and their connection with the well-known fact, that the same person never writes even an habitual signature so precisely alike as to have them exactly coincide in all respects. These variations of the same habit occuring in the form of the letters, originate during the development of the writing habit, and in the earlier stages of its attainment are more emphatic in appearance than after the habit has become more fixed; but they are a feature of all habitual writing in a greater or less degree of manifestation. In describing these features it becomes necessary to repeat somewhat the subject-matter considered in another connection to make the relation apparent in that now under consideration.

Individual habit in writing, when acquired, may be defined in the connection in which its variation is studied as a manifestation in each person's writing of peculiarities which cause it in appearance to differ specifically from copy-book standard forms of letters, and also to differ in like manner from the individual character of the variations in form which every other person's writing has when compared with the same copy-book standards.

All who are taught to read writing have to learn the representative form of the letters, and all who learn to form the letters have to be taught to produce them with such an approach to the standard style, that they may be recognized and read by others, and in doing which, individual habit is developed. Were it possible for every person who wrote to follow with accuracy the copybook forms of the letters, all definition of individual habit would disappear in this field of examination, and all persons would write alike. But from the fact before detailed this cannot occur, as in no two persons are the physical factors which do the work in writing developed 


\section{4. linivideal Haitt of Writing Defined.}

precisely alike, it follows as a sequence that this condition is a concomitant of the writing habit, and gives character to it, for as each person's writing differs from copy-book standards they also differ from each other.

$A$ standard form is given to the letters in writing copybooks and the form of these letters must be followed in creneral character in the production of a signature to have the letters spell out the name which as written they represent. The variations in form from copy-book stand. ards will necessarily be individual ones in each person's signature from physical causes, and the variations occurring in signatures of the same person if written habitually will be typical ones, that is while varying in form from others made by the same habit, they will indicate in their peculiarity that they are the product of the same muscular cause although modified in appearance. This variation from what would be a copy-book standard form being peculiar in each person's writing, constitutes the general appearance of its individuality, and is the field in which is manifested its difference from that of every other person's writing, and the variations which habitually written signatures of the same person have when compared with each other, will be found to be but modifications of the same peculiarities which give to them their individual character as produced with more or less emphasis. While no one writes his or her signature twice precisely alike, or so nearly so that if one of them be laid over the others that they will exactly coincide in all respects, they will be alike in those features which cause them to differ from every other person's writing, and in the variations which as individualisms they make from copy-book standard forms. These variations occur from several causes, the most common one being the differing conditions under which they are produced, 
which will be made the subject of description herein. after in another connection, and allusion only will be made to them now as relating to such influences which are connected with their development as a part of the writing habit and tend to their manifestation.

When learning to write, very prominent, irregularities will occur in the form of the letters, which under instruction and practice become toned down, so as to be less demonstrative and emphatic, although through the efforts made to approach the standard forms of letters, and after the habit has become established, signatures written with less than usual care are apt to revert to these earlier tendencies, which in either instance of their production would be typical of each other, whether produced with emphasis, or so as to be barely discernible. Assuming in this connection that a person in writing his or her signature to a paper of importance, and one in which it is the desire of the writer to have the individuality of the latter represented by the signature, it will be written at the dictation of habit, and in the writer's usual manner of producing it. Again assume this same person to sign a hurriedly written letter where the appearance of the writer's personality is not so important; these two signatures produced under different mental impulses might show manifest differences in their general appearance, and for the purposes of comparison in the latter field of examination alone might be misleading as to their indi vidualism; but if in this connection it is possible to determine the physical habit of the writer of them it will appear that all the variations of form apparent, are merely due to a relaxation of the restraint which practice had imposed upon the writer's habit, indicating a return to the earlier manifested irregularities of the writer which were developed when the habit was being established. These 


\section{Trpind Tariatuse uf the Same Habit.}

variations in the form and arrangement of letters manifested in signatures of the same person will be typical ones, originating from the same physical causes which crive individual character to the writing, and as thus determined cease to be real differences. IVhile this rule is applicable to that class of variations which are made with emphasis, it is also applicable to that class of them which are less prominently manifested, and generally relate to comparative measurement.

When it is understood that the features which cause each person's writing to differ from that of every other are lue to a different muscular coordination possessed by each person, the resulting individualism will be a concomitant of the cause giving it personal character and be typical of it; hence it follows that all the variations in form which are found to occur in signatures of the same person will be but mere modifications of the same personal characteristics originating from a common cause. These conditions occur in the writing of all signatures that are written habitually, and the rule applies to the signatures of those who write with ease and facility, as well as to others who produce them with difficulty.

The development in individuals of the writing habit thus necessitated to contain peculiarities which are caused by the differing physical habit producing them in each person, while evolving no perfect parellelisms, resemblances are sometimes found to occur in the writing of different persons. One class of these resemblances occur in a limited measure when the same letters are grouped together by different persons to spell the same word or name, and where the same representative form of letters must be used in the same connection, so as to present in substance the same alphabetical picture to the eye. In some instances resemblances are found to occur when 
different persons have been taught some like systems of penmanship in which unusual forms of letters are used as copies; and occasionally resemblances will develop in the habit of different persons where the writing of two of them will approach each other in those peculiarities which give individual character to them. These last-named cases very rarely occur, and though the writings may resemble each other somewhat in general appearance they are never found to be near enough alike to have the one taken for the other, when carefully and competently examined. The resemblances thus happening to occasionally appear in the writing of different persons vary materially in character from those produced by simulation, in the fact that where a signature is imitated the form of the letters, and their connection will be consonant with the habits of the simulator producing them; and unlike that of the writer making the signature from which the simulation was copied; in other words, the imitator must write them with a habit of his own and produce forms that are inconsistent with its capacities as to details when copying the forms incident to another habit.

Connected with the development of the writing habit, and to a certain extent the organization of its individual character is the influence and effect which enforced and persistent practice exercised under the arbitrary rules of differing systems of penmanship may have upon it. Under the old rules of fifty years ago the tendency of their enforcement was to develop in the prehensile faculties of the hand mainly the habit of writing. Under this old system the pen was directed to be held with its upper end pointing to the right shoulder and with the wrist resting flatly on the table. As thus held, the pen was operated entirely by the action of the common extensor and deep flexor muscular capacities of the hand and fore- 
arm, and these are the factors used for gripping objects and for strength. This condition limited and contracted the muscular functions of the hand in writing and made the exercise irksome and accompanied with discomfort to most persons, and much time was wasted in trying to teach beginners to write in a way that they could not do with ease.

Modern systems of penmanship couple with their instruction the adaptability of the differing muscular capacitics of individuals, and recognize in the practice taught these differing conditions; but none of these numerous systems can give to the muscles employed in writing capacities which they do not possess. By practice they may teach the individual coordination to make less prominent personal characteristics, and by use give to weakly developed muscular capacities, more aptness. Instruction cannot remedy, or by practice supply the want of a proper coordinate action between the powers to will, and to do, or have any more remedial effect than if applied to treat a palsied infirmity. A person having a thumb that is deficient in its abductor or adductor function, or an index finger that is limited in its extensor or flexor movements, or an inefficient development of the lumbrical muscles cannot have either of these wants supplied by any of the so-called systems of penmanship or the rules they establish for the development of the writing habit. 


\section{CHAPTER IV.}

HOW INDIVIDUAL HABIT BECOMES MANIFESTED IN WRITING.WHY THERE CAN BE NO RULE FOR DETERMINING PERSONAL CHARACTERISTICS OTHER THAN THAT WHICH RELATES TO THEIR DIFFERENCE IN EACH PERSON'S WRITING FROM THAT OF EVERY OTHER:-PERSONAL CHARACTERISTICS IN THE WRITING OF AN INDIVIDUAL ALWAYS TYPICAL OF EACH OTHER, AS TO CAUSE AND WHY.-THE NECESSITY OF UNDER. STANDING THE MUSCULAR FUNCTIONS OF THE HAND AND FOREARM TO REACH A PROPER UNDERSTANDING AS TO THE CAUSE OF PERSONAL DETAILS IN THE WRITING.-THE FUNCTION OF THE HAND AND FOREARM IN IVRITING.-THE MANNER OF MOVING AND HOLDING THE PEN DETERMINED BY THE APPEARANCES IN THE WRITING CONSEQUENT UPON IT. -PEN PRESSURE AS AN INDIVIDUAL MANIFESTATION IN A PERSON'S WRITING CONSIDERED.-THE EFFECT OF EXCITEMENT, FATIGUE, DISEASE AND OLD AGE UPON THE WRITING HABIT. - SIGNATURE EXPRESSION AS A VARIATION FROM THE WRITER'S ORDINARY WRITING.-HOW FAR INSTRUCTION MAY MODIFY HABIT.

Having explained how and why individual habit of writing is developed under the effort made to acquire it, and in a general way considered the conditions attending its attainment, the manner, in which its individuality becomes manifested, the connection between it and the cause of its appearance with the personality of the writing conditioned as an effect, should also be considered before proceeding to explain how the analysis of a signature is accomplished.

While all habitually-written signatures of the same person must resemble each other in general appearance, and while this latter condition must be taken into account in determining personal habit, the man- 


\section{5.t As Mang Writini Habits as Writers.}

ner of producing this general appearance is the field in which the examination should be made to properly establish its individuality, from the well-known fact that seneral appearances as manifested in a signature can be very closely imitated, and the habitual way of writing them cannot be. Thus conditioned as to the source of its individuality, the muscular habit producing the latter must be cletermined from the writing, by an analysis of its details, and the connection which the latter has with the cause of their appearance be pusitively established.

Inasmuch as each person has a peculiar muscular habit of writing, it follows that the same habit cannot exist in two persons developed in the same manner as to individualism, and that there must be as many personal habits of writing as there are persons who write. With this necessary and established condition confronting the consideration of the subject at the commencement, the seeming labyrinth into which an examination of the subject leads appears interminable, and the seeming difficulty of reducing to a system of study the mass of mate. rial presented looks formidable. To designate any special rules for distinguishing personal habit of writing would be as difficult as to formulate a law for the identification of individuals apart from their general features of difference, and yet the ability to distinguish one person from another is a common one, and possessed by everybody in a greater or less degree. Men all look alike in those typical features which distinguish them from other living forms, and thus all writing looks alike in the sense that the general and representative form of the letters must appear in it to have the writing read. Mankind have been taught by a transmitted and inherited ability to distinguish one person from another, and while almost every one can distinguish one person's writing from 
another, so far as they are unlike in their general appearance when written habitually, but the features which make up the differences when the writing of several individuals are compared are not so easily told with definiteness. To formulate any one rule for the determination of individual habit of handwriting would seem impossible from the fact that there can be no parallelisms between the writing of different persons, in those features which give individual character to it, and each one's writing becomes under examination an entity in these respects. While there can be no rule for the determination of parallelisms between the writings of persons where no parallelisms exist, there can be rules for discovering those individualisms constituting differences between the writings of persons, and the cause why there are no such parallelisms, and there must be such differences. With the fact established that a peculiar muscular coordination causes each person's writing to differ from that of every other, and which gives to the latter its personality, the latter as distinctly manifested in the effects produced become indicative of the cause, and the means for determining the individuality of the latter.

The peculiar features of all writing which give personal characteristics to it are in their appearance indicative of the muscular cooperation that produces them, and as a sequence must be typical of each other, as the product of the same cause. Thus features of peculiarity on the part of a writer in making a capital letter will indicate by its form, appearance, and details the cooperation of the factors that produce the latter, and which muscular coordina. tion when writing the smaller letters of a signature, would make them peculiarly in other respects as sequences of the same muscular effect, yet these features in either case, though different in appearance, would be typical of each 


\section{Detanls of Habit, Why Physically Typical.}

other, and as the concomitant of the same conditioning cause. With this phenomena accompanying the production of signatures understood as stated, the characteristics of individual habit are found to group themselves into a series of classes in each person's writing, that become typical of certain causes, wherein the muscular habit differently exercised in operating the pen with varied movement as to direction, gives them generic character as to derivation.

These classes of personal details occurring in each person's writing thus grouped as incident to the same influence, while varying in their manifestation according to the form produced, will in each instance of their appearance be compatible with, and within the capacity of the same muscular coordination writing them, and in their manifested details be indicative of the latter. Thus a peculiar form of oval in the body of a letter, or a loop at the top or bottom of a letter will in either instance be characteristic of, and incident to the same muscular capacity differently exercised. While this occurs when the forms of letters are considered generically as to character in the same person's writing, the same rule applies when the features of individual peculiarity are specifically examined in respect to the relation they bear to each other. Thus a peculiar emphasis necessitated to appear in a person's writing when forming the heavy downstroke in the standard of a letter " $h$ " would, when the same writer was making a curve in a downward direction to the left, produce an emphasis differing from that occurring in the "h," but necessarily typical of it as to cause.

These conditions as to the generic character of all individualism in connection with their appearance in like manifestation, and their typical character with relation to each other when produced by the same factors differently 
exercised as to direction and pen movement, will be found to occur in all habitually written signatures of the same person. These features constitute the basis upon which the analysis must be made, and include the details of form, execution, pen movement, and other conditions by which the individuality of the writer is made apparent, and are the elements from which the muscular coordination constituting the habit is determined.

To properly ascertain the handwriting in an individual manifestation of it, so as to trace effect back to cause, a knowledge of the physical organization of the human hand, and also that of the forearm are importantly desirable; for to appreciate effect in the better understanding of it, evidence and a knowledge of the cause are essential. In the developed capacity of the muscles operating the fingers and thumb of different individuals when writing, as in performing all other work requiring precision and action responsive to monition, there is a wide range of variation. With some persons writing is wholly done through the action of the deep flexor muscle, and the superficial flexor of each finger for bending inwardly the letters toward the palm, with the straightening out of the fingers produced by the common extensor descending from the forearm and its four tendons each connecting with a muscle inserted into.the back of the second and third phalanges of each finger. These are the muscles used for all prehensile or grasping movements of the fingers in connection with the adductor and abductor capacities of the thumb. When writing is done by these muscular factors, the pen is grasped by them, to be moved inwardly by the fingers, and outwardly and laterally by the thumb. In addition to the use of the before named muscular factors used to grasp the pen with many writers the lumbrical muscles situated in the 
palm, and each connecting with one of the branches of the deep flexor tendons in each finger, perform important functions in writing, which in their measure of aptness depends upon their relatively developed and responsive capacity in each individual. These lumbrical muscles in each finger form their dorsom connection with the extensor tenclon to bend the index and second finger at the first and second joint, thus adapting these fingers to perform their greatest acts of precision, and enable them to act in moving the pen laterally on the line on which the writing is clone, when the fingers have been drawn in toward the palm. These lumbrical muscles are highly developed in musicians who play the violin and guitar, and in persons who have the most perfect control of the pen in writing.

A knowledge of the functions, and relative capacity of the muscles of the hand and forearm, their movement and adaptation for varied coordinate action in writing gives to the examiner an advantage in determining indi. vidual habit from the details accompanying its production. Thus if there should appear in the writing of a person evidence that the pen was not held steadily, and if in its downward movement when writing; exhibited a tendency to rotate on the muscular cushion of the thumb, this fact would indicate that some of the muscular factors were deficient in prehensile function, and an examiner conversant with the relative duty of the factors upon which this work devolved would be enabled from the character of the detail produced to know which of them was deficient in function, and which fact determined as to cause would explain other phenomena in the way of personal details incident to such an influence and typical of it.

While the hand, arm, fingers and thumb contain the 
same number of muscles, having the same general function in each person, in no two individuals are these muscles developed alike in their capacity to coordinate, or in their ability to obey the monition of the will. Such as are leading factors in cooperating with others in performing certain acts and movements of the pen in one person will be developed in a subordinate capacity in another, with concomitant differences in coordinate work. These differences become innumerable when considered arithmetically, and a perfect parallelism in the writing of different individuals becomes an impossibility on account of this differentiation and its causes.

With this necessitated variation thus establishing indi. vidualism in the writing of persons, and its essential connection with cause, it will be understood how import. ant a knowledge of the physical organization of the hand becomes in determining personal habit of writing from the details manifested in it. Understanding that the writing habit consists of an individual coordination of muscular factors, with the details that give character to it considered as effects to determine the former by, from the appearance of the latter involves the intelligent study of those features constituting its personality in each case considered, with reference to how they were produced. While the appearances which give individuality to a signature must in each case be studied sui generis the manner of conducting the investigation may be explained by reference to hypothetical cases. If certain peculiar con. ditions of emphasis occur with uniformity in the writing of an individual with every like movement of the pen there must be a physical cause for its appearance, and with the latter determined and traced to the source of its production, a means is at the disposal of the examiner to trace up the cause of other peculiarities incident to such 


\section{Cunrumate Actun of the Muscular Functions.}

an influence. Thus where, in a person's writing, the second finger is in a peculiar manner more responsive to monition than the index finger in cooperating with the thumb to hold and move the pen, the second finger will become the controlling factor in performing certain move. ments of the pen; and from its relative position to the latter, and the thumb as held, it will produce certain appearances in all downward movements of the pen incident to such a cause. Having a knowledge of the functions of the factors into which tinis peculiarity intrudes the examiner is enabled to locate not only such a detail, but others consequent upon this condition of the writer's hand to classify them where typical as to origin. Each factor employed tends to individualize the work done by it with more or less emphasis, and produces details that are not only consonant with the function producing them, but to manifest them with individual characteristics.

In writing a signature there are brought into use a very complicated series of muscular factors and functions. When the writing is mainly done by the movement of the fingers and thumb without the intervention of the forearm movement any more than comes from the oscillation of the hand and forearm, the pen is usally grasped as a prehensile act by the thumb, the index, and the second fingers, and as thus held is moved over the paper with the ball of the thumb acting as a supporting cushion against which the pen bears when the fingers and thumb in cooperating action turn inwardly toward the palm of the hand, so as to make the downwardly extended and ordinarily heavy lines of the signature; while the lighter lines of the latter are produced through the upwardly and outwardly directed action of the thumb and fingers by which the pen is grasped. All the curves and lateral 
movements of the pen thus held when directed upwardly and slanting to the right are produced by the muscles of the thumb acting against the yielding functions of the fingers, in the direction of the thumb impulse; and all the curves in the letters forming the signature thus written as well as the lateral movements of the pen in slanting or curving to the left are produced by the action of the fingers against the yielding movement of the thumb in the direction of the finger impulse. In either instance where the thumb as one of the factors, and the finger cooperating together as the other factor to grasp and move the pen laterally as against each other, the facility with which the yielding of one set of factors to the other is harmoniously accomplished, the less prominent will be the delineation and emphasis of habitual details in this line of examination and the more want of harmony and coordinate action there is, the more prominent will be the details of personal habit.

When writing is mainly done by the flexure of the fingers and thumb the index and second finger usually act as one factor, in some of the pen movements and separately in others; while the thumb as the other factor operates in giving direction to, and in producing the bottom and upcurves of letters as well as the lateral movements of the pen to the right, when the prehensile muscular functions are employed; but every time a lateral movement is made one of these factors must yield to the other, and immediately change its action and function from that of a factor creating an impulse to a factor receiving one with reverse movement, and still retain its pressure in an opposite direction to that in which it is yielding with reverse motion to hold the pen in position. Every time each of these factors changes its function from one which creates an impulse 
with direction, to one that receives an impulse with reverse motion, there is a center or intermediate point caused by this change of function and condition, which will be visible in the writing and generally be accompained with an habitual detail.

While these conditions occur between the cooperating action of the index, the second finger and thumb when writing with their prehensile muscular functions, the fingrers themselves seldom act in harmony and generally do not cooperate without making details that are prominently characteristic of the writer; in fact their want of harmonious action when occurring produces very positive details of personal habit. When yielding to the thumb impulse by a movement to the right in one direction of curve the index and second finger may do so gracefully, and without marked discordance; but when thus operating to produce a longer curve, or one in another line of direction the fingers may yield grudgingly and irregularly. Again where the form of parts of the letters of a signature are produced by the movement of the fingers downwardly to the left, although the thumb may yield without discordance, yet between the fingers there may be struggle as to which shall do the major part of the work, and this want of accord will be peculiar in each person's writing, and where occurring, cause the appearance of details having strong individual characteristics. This want of harmonious cooperation on the part of the index and second fingers will be found to more prominently occur in the downwardly projected and heavy lines forming the staffs or standards of letters, and when appearing will be individually peculiar in details of production. The index finger is generally more facile in its ordinary work than the second finger from having a muscular faculty developed in its organization that is not found in the 
Coordinate Action of the Muscular Functions. 63 second finger, but this additional function is of little use in writing.

While this condition as regards the individual action of the fingers in producing habitual details is found in all writing, the thumb and the manner in which its abductor and adductor functions are individually developed causes to appear in the writing well-defined evidences of habit, particularly when the writing is mainly done by it and the fingers. Its position as a factor in the combination is a prominent one, in giving character and form to all curves in the writing extending from left to right, all upcurves connecting the letters, and all loops produced at the top and bottom of the latter. These as thus described are the general functions of the thumb in writing, but they are so widely different as developed in different persons, that the detalls of habit originating from its individuality are innumerable, and definite as to character.

The fingers have muscular functions adapted for a strong prehensile work, and the development of strength in connection with the forearm, and they have other muscles adapted for the more delicate duty of playing upon stringed instruments, sewing with a needle, and the manipulation of small implements requiring precision of movement; but in the organization of the thumb the muscular functions of the latter developed for grasping and prehensile effort are the same ones that are employed in writing. As a sequence of this condition it will be readily understood that the measure of development as to character which fits the muscles of the thumb to perform their part in grasping a sledge hammer is widely different from that which adapts them to move the pen, and that between these. two extremes of capacity there must necessarily be a wide range of aptness in different persons. As a sequence of this condition of the thumb 
64 Cingingate Action of tile Muscular Functions.

when the prehensile functions of the hand are alone employed in writing, it as a factor tends to the production of the more prominently manifested details of personal habit, some of which will appear when giving direction to the pen movement, and in others where it demonstratively interferes with the operations of the fingers.

The work of the thumb as a factor (when the writing is done by the prehensile faculties of the hand through their flexure) occurs where its impulses give direction to the pen movement in forming the curves at the bottoms of letters projected to the right; also in operating the pen to form the up-strokes, and the lines connecting the letters as well as in producing the terminal of the final letter of a signature. The thumb in addition to the foregoing by its movement produces the up-strokes in forming all such letters as " $y$," " $\mathrm{g}$ " and " $\mathrm{h}$ " where extending either above or below the line on which the signature is written. When the thumb is operated in connection with the fingers to produce the heavy down-strokes of letters where extending below the line of the writing, there generally appear two or three details that are importantly characteristic of personal habit; one of them indicative of the flexure of the thumb at the first joint, one at the coming in of its flexure at the second joint, and another indicative of the manner of using the adductor function.

All writing done with the pen necessitates the employment of the prehensile functions of the hand to grasp and hold it, and when these same muscular functions by their flexure are used in the act of writing and are combined with the employment of the lumbricale muscles, the effect of the latter as manifested will appear in the lateral morements of the pen with the letters produced usually made more full and rotund than in standard forms. The 
use of the lumbrical muscles enters into the production of what is termed backhand writing wherein the horizontal axes of the letters is increased comparatively, and by which the writer is enabled to put shading into the bottom instead of the sides of letters.

When writing is mainly done by the forearm movement of the pen with the fingers and thumb as prehensile factors operating to merely grasp and hold the pen with the latter moved over the paper by the hand as sliding back and forth thereon, the letters will be more broadly rotund in their curves than when written by the flexure of the grasping muscles; while the density of shading will generally vary but little as between what should be the heavier, or light lines of the letters from a copy-book standpoint. While this is the usual condition of all writing done by the forearm movement yet there are some writers who are capable of combining with the forearm movement of the pen enough flexure of the thumb and fingers to give a measure of shading to the down-strokes of letters.

When the forearm movement is employed in writing the elliptical or rounded form given to the letters are produced with the pen bearing upon the paper in one position, and without flexure when forming the tops and bottoms of letters where curved, with the angle which the point of the pen makes with the paper a constant one. When the pen is operated by the flexure of the thumb and fingers as its point is drawn in toward, or forced outwardly from the palm of the hand, its angle with relation to the paper is a constantly changing one, and the two differing conditions of pen movement are easily determined by the manner in which, at the point whereat, the splits or nibs of the pen cross each other when forming the top and bottom curves of letters. 
The position with which the pen-holder is grasped relatively as to distance from its writing point, where resting upon the paper, has much to do with giving habitual character to the writing, and this pen grasp of the holder is conditioned in every person's writing from physical causes. When the writer has long bony fingers with weak development of lumbrical muscles, the writing will be mainly accomplished by the use of the prehensile capacities of the fingers and thumb, and this will necessitate a much higher grasp upon the pen-holder than where the lumbrical muscles are aptly developed. This condition of pen grasp tends to the production of angularity, and is accompanied by other peculiarities incident to such a cause. The manner of holding the pen as appearing in the writing of different persons, become habitually developed at the dictation of comfort and convenience; that is, each person holds the pen in such position as is necessitated by the muscular organization of the writer's hand. The manner in which the pen is held as regards the position of the nibs or split-points relatively to the paper on which the writing is done, tends to the production of strong personal characteristics. When the pen, at the dictation of habit, is held with the split-points resting evenly and squarely upon the paper, and with the concavity of the pen facing evenly towards the palm of the writer's hand, in the standards or staffs of letters the splits or nibs of the pen will be in horizontal alignment at the tops of the latter, and they will cross each other at the middle of the top and bottom curves of letters. When the pen is held with its concavity facing off to the left from the palm, then the left-hand one of the two split-points will be higher than the other at the tops of all standards or staffs of letters, and just the reverse will be found to occur as to the relative position of the splits when the pen is held and oper- 
ated with its concavity facing off to the right of the palm.

When the writing is done with the top of the pen slanting off away from the right shoulder in direction, one of the split-points will precede the other in every upward movement of the pen, or when the latter is moved downwardly, and produce a detail incident to such a cause at the top and bottom of every letter made by it. Where the finish at the top of a letter is a mere line, and made without a loop and produced by the pen as so held, one side of its upper end will be higher than the other, and angular thereat, and when a bottom curve is made in a letter with a pen so held, the split points or nibs will not cross each other until the formation of the succeeding upcurve is commenced, and the curve at the bottom of the letter finished. These conditions of habit are common ones, and are stated that they may be understood as such; and are only useful for comparison in cases where other and more positive personal characteristics accompany their production as sequences of the same cause, and where they appear in a standard signature and do not occur in a disputed signature, or when found in one of the latter and not in a standard signature.

The two split-points of the pen with which a signature is written are very important factors in determining the details of a writer's habit. When pressure is applied to the pen in writing, the points elastically spread out to make the downwardly directed heavy lines of the signature, and run close together or side by side, in the upwardly directed movement of the pen to make the finer lighter lines; and where they cross each other at the roundings of the curves of letters, or where the pen movement changes from one direction to another; as well as at the initial movement, they record every break or tremor 


\section{Detalls of Hanit Ploduced by the Pen-Splits.}

where the action of the muscular factors doing the work is habitually unharmonious. Not only are the before-named features produced in the writing by the nibs or splits, but the latter inclicate with accuracy the manner in which the writer was educated to hold and move the pen. Thus if the pen is held with its outer end slanting to the right, awa from the right shoulder, the right-hand one of the splits will, from such a position, make a deeper furrow in the paper than the left-hand one, and more ink will settle into it from its greater deptlı; and as another indication of such a position of the pen, the left-hand edges of the writing of all curves will be more ragged and rough than the right-hand one. When the pen is held with its outer end slanting toward the left shoulder the reverse of these conditions will occur; and when held with the outer end pointing toward the right shoulder the furrows made by each of the split-points will have the same depth.

The measure of pressure with which the pen is caused to bear upon the paper on which the writing is done should be always taken into account, in the comparison of signatures, as this is regulated and made necessary in each person's writing as to character from physical causes, and has much to do with establishing the habit of the writer. The measure of pen pressure also gives pictorial effect to a signature taken as a whole, and though the letters of the latter may be skeletally imitated in form and arrangement, yet if the simulation is wanting in density of lines and shading when compared with the writing from which it was copied, the difference between the two is readily discerned. In addition to the general measure of pen pressure found to occur throughout the writing of a signature, there must also be taken into account, in determining individual habit, the measure of comparative density occurring between the lighter and 
heavy lines of a signature, the points at which the shading emphasis commences and ends, and the facility with which it is accomplished.

Persons who have the best coordination between the powers to will and to do in writing, use less pen pressure upon the paper than others who must grasp the pen rigidly to have it obey the will, and the consequent muscular actions of the hand or forearm which moves it. When the pen is grasped rigidly it responds to all the tremors occurring from want of harmonious action on the part of the muscular factors operating it, and of times to the arterial pulsation, and the vibration which the latter gives to the hand. When the hand is held with a grasp that is not rigid it is more easily operated and with less pressure upon the paper when writing. Persons who grasp the pen rigidly do so as a matter of necessity because a certain measure of muscular tension is required to enable them to hold it, and without which firm grasp they would have much less control of its movement. The same cause which necessitates the heavy pressure of the pen upon the paper, also makes essential the rigid grasp of the pen, so as to control its movement, and the production in the paper of a deeper furrow than would occur were the pen easily held without rigid grasp. This varying condition of physical habit as affecting the habit of persons in writing is manifested in differing measures of emphasis and originates when not caused by a palsied infirmity, in the differing capacity existing in individuals between the ability to will and to do, and in the measure of promptness with which monition or intention is followed by responsive action.

The measure of pen pressure which is habitual to the writer of a signature is to a certain extent manifested in the general appearance of the latter, and the pictorial 
Measure of Pex Pressure, How Determined.

imagre which it presents to the eye of an observer, although for accurate determination it should be examined microscopically with the writing so placed as to be seen as a transparency with a strong light behind it, and by which the relative proportion of pen-furrow depth occurring between the lighter and heavier lines of the signature being examined can be determined. When writing is done upon paper with a two-nibbed pen, the ink settles into the furrows made in the paper by the latter, and the measure of density relatively to the depth of the furrow is generally susceptible of measurement by an educated and experienced observer. In estimating the pen pressure as a detail of personal habit it will not do to depend wholly upon the width or density of the lines occurring, because a signature when written with a soft and very elastic pen would form the lines with more width and density of shading than if written with a pen that was stiff and less yielding; the proportion of furrow depth as between the heavier and light lines of the writing would be the same if written by the same person, whether a soft and elastic pen, or a stiff one was employed. This feature of habitual pen pressure is one of the greatest obstacles in the way of successful forgery, and in most cases where attempted, a second effort has to be made by going over the writing again to finish the simulation with approaching resemblance.

When a signature is written habitually with the fingers, the thumb and forearm cooperating together, the per. sonal details of habit are quite as well defined as when written by the flexure of the fingers and thumb; and this occurs from the fact that the greater the number of factors cooperating in the work, the tendency is to increase the number, and to make more emphatically manifested personal characteristics of habit. Not only this occurs as 
a sequence of the coming in of the forearm movement, but a signature so written will in every instance show a more radical departure from copy-book standard forms, and consequently will have more strongly-developed evi. dences of individuality in these respects.

While the foregoing is true as to signatures written with the combined movement of the pen by the fingers, thumb and forearm the same rule in a varied measure applies to the personal characteristics appearing as details when the writing is done mainly by the forearm, with the fingers and thumb performing the prehensile function of holding the pen, in connection with the application of the shading emphasis given to the lines by the flexure of the grasping functions. Where the writing impulse comes wholly from the forearm and without the use of those muscular factors which exercise their flexor functions in close proximity to the pen grasp, the details of habit are more strongly marked in their individual character from the greater distance occurring between the source of the motor influence, and the pen point by which the writing is done; and consequently signatures written by the employment of the forearm will make greater deviation from copy-book forms, than when produced by the flexure of the prehensile functions of the hand, and in these respects more intensely individual in character and definition.

There are occasionally found persons who write their signatures with the pen held so as to pass out from between the index and second fingers, in a position to bear against the muscular cushion or ball of the thumb for support and connected action with the latter. This condi. tion of pen grasp relatively to the muscular factors which operate it, generally has the effect to cause the shading emphasis to appear in all the bottom curves of letters, 


\section{Chikicteristics of "Back-HaNd" Writing.}

tangential to the line on which the signature is written. When writing is clone with the pen so held the index finger is passive, and the details appearing will be indicative of the cooperation of the middle finger and thumb, and be personal in character as these factors so coordinating have individual peculiarity. This condition of pen-grasp generally has the effect to cause the shading emphasis to not only manifest itself at the bottom of letters, but to occasionally extend into the up-stokes and gives to the letters a convolute or vine-like appearance, and in which the vertical elipticity is less than when the pen is held between the index finger and thumb, and operated by the flexure of the grasping functions, or when held by the latter, and operated by the forearm. Writing of this character generally becomes habitual from physical causes, and is usually the result of a condition of the writer's hand, wherein the index finger is deficient in grasping function, and where the muscular functions for lateral movement of the pen are highly developed, and more so than those of the writer depending upon direct flexure for their impulse. When a signature is thus habitually produced from the position in which the pen is held and the necessary oscillation of the hand accompanying such method of writing, the details which give to the writing its individuality become very characteristic.

In thus discussing what individual habit of writing is, and how determined, there are so many varied conditions under which the writing is done that should be considered, and particularly the causes affecting its variation, and the differing measures of emphasis manifested in its individual features. While signatures of the same person, when written habitually, are always typical of each other, they are never written so nearly alike that when laid one over the other they will exactly coincide as 
before stated. This modification in the writing of signatures by the same person results from the varying circumstances and surrounding conditions under which they are written, together with the constantly varying measure of responsive capacity existing between the power to do, and the suggestion or monition prompting the act. These conditions cause many of the variations or modifi. cations appearing in signatures of the same person, and the measure of responsive capacity varies with the physical condition of the individual so as to produce, with greater or less emphasis beyond their usual appearance, those peculiar features due to the muscular habit of the writer. As before stated, the writing habit of each person develops the representative forms of the letters in such approximation to copy-book forms as the muscular coordination of the writer's hand will permit, with the variations therefrom in their execution typical of each other, and the habit of the writer making them. As a sequence of this condition, it occurs that with less than usual control of the pen movement, these individual variations from copy-book forms will appear with more empha, sis, although typical in kind and character with those which were produced when the capacity of the writer was normal, and enabled to exercise more control of the pen movement.

Thus considered as to the more demonstrative variations occurring in signatures of the same person caused by other than normal conditions of muscular action, it is also a concomitant of their production that signatures of the same individual when consecutively written, and apparently under the same conditions and surroundings, never exactly coincide; although their variation will be less than when written at different times under the influence of abnormal tendencies. This want of exact duplication and parallelism in signatures of the same person 


\section{it Ihy Slonatukes of the Same Persons Vary.}

is best explained by an understanding of what would have to occur to accomplish it. When the almost innumerable conditions surrounding the combination and sub-combination of factors which do the work are taken into account, the chances of reaching exact duplication extend into that realm of arithmetical progression where millions run into billions, and the latter into trillions.

The abnormal conditions under which signatures of the same writer are caused to vary demonstratively in the production of personal characteristics originate under differing influences, all tending to have a like effect; and more particularly as having this tendency are those occasioned by excitement, fatigue, disease, old age and loss of nervous power; all of which in varying measure act to intensify and make more prominent those features of personal habit which education and practice had toned down, and made less demonstrative in appearance. In other words, with less than usual control of the pen the writer is apt to revert to those rudimentary prominences which characterized the efforts made when learning to write, and which, under the influence of instruction and effort, have become less emphatic.

Assuming in illustration that in consequence of a peculiar organization of the muscular functions of the hand or forearm that a person when making the writer's best approach to the representative form of a capital letter "O," was compelled to produce it so as to give to one side of it an angularity of more or less development instead of producing it elliptical; this same writer who under the influence of instruction may have reduced this tendency so as to be merely discernible, would when writing to form this letter under the influence of excitement, or other like cause, make this angularity with more than usual emphasis, in consequence of having less con. 
trol of the pen movement. In further illustration of the effects of excitement upon the writing of an individual, if the latter will write an habitual signature immediately before, another immediately after having rapidly run up and down a long flight of stairs, it will be found, on examining the two signatures thus produced, that the last one written will show that the personal details of the writer's habit, which give individuality to it, are made much more prominent in their manifestation than in the signature first written, when the writer had more control of the pen; and that all those peculiarities in which the writer's habit differs specifically in the form of the letters from copy-book standards will appear with greater emphasis.

While excitement has the effert to thus intensify all the individual characteristics of the writing habit for the reasons before given, the same effect is generally manifest by fatigue, and ofttimes by increasing age, and the decline of nervous power in consequence of the latter. If the signatures of a bank cashier written at the close of a day's work in signing bills are compared with those written in the fore-part of the day when the muscular functions doing the work were fresh and rested, those of them last written will show more prominently the details of personal habit than those first written. With increasing age and a decline of nervous power there follows as a sequence less ability to hold and control the pen in writing, and this is accompanied in the latter with increased emphasis and appearance of those features belonging to the writer's habit, although the measure of this tendency as a concomitant of age is not a fixed one. It frequently happens in the writing of persons advanced in years, and in which declining muscular power and control is strongly manifested, that the writer again becomes 
76 Efrect of Sickness Upon the Writing Habit.

a child between the struggles to will and to do, and reproduces the irregularities of form that came with the early efforts made when learning to write.

The effect which sickness or disease has upon the writing habit of persons in the production of their signatures is too varied to be discussed with anything like an accurate consideration of the subject. Some persons suffer greater prostration of nervous power than others under the influences of the same illness; and occasionally persons having strong will power have the ability to write their signatures with habitual regularity, when others under the same conditions of pain and suffering would be incapacitated for writing in any manner. Rheumatism may so cripple the fingers and hand of a person that the latter cannot write at all; and again this form of disease in its more moderate forms of manifestation may in various ways act to modify and change a person's writing, so as to make such of it, when produced under its influence, quite different from that done by the writer when free from the infliction. A gouty deposit at the joints may so stiffen the fingers and thumb as to materially change the personality of the signature, when compared with such of the latter as were produced by the same writer before being thus afflicted The most common effect of disease (other than rheumatism) when accompanied with loss of nervous power upon the writing of a person is very much the same as that before described as occasioned by fatigue.

In addition to the deviation from a representative form of the letters in writing a signature necessitated by the physical habit of the writer, signatures are sometimes written with some peculiarity as to the form of some of the letters of which they are composed, and more par. ticularly the capital letters and their connection, that is not common in general appearance to other than signa- 
ture writing of the same person. This signature expression and variation from the other writing of the same person when occurring, originates seemingly as a matter of the writer's fancy and is generally employed to give to the signatures an ornamental and individual significance, or to make them complicated, and difficult to imitate; and this in effect is often carried to such an extent as to make them obscure and difficult to decipher; but the forms of letters so used in the production of a signature will embody merely such of them as are within the compass and capacity of the writer's habit, and the eccentricity of the forms displayed will be generally an intensified variation from the representative form of the letters, which is natural to the writer made ornately, and given a finish by practice. The condition of signature writing will be more fully considered in connection with another branch of the subject to which it more intimately relates.

In connection with the general features that make up the writing habit as developed differently in individuals there are many other features than those already enumerated which should be taken into account as important, and among them are the effects of the appearance at times in the writing of the arterial pulsation. This occurs more frequently in writing of women than men, and particularly in the writing of persons having bony hands with little development of muscle, and who write with the wrist resting flatly on the table. This effect, when occurring, will appear to have been produced by a lateral vibratory movement of the pen where at the time in contact with the paper, so as to create an irregularity thereat, but as these latter occur in any part of the writing where the pen happens to be at the time of the pulsation, in appearance they differ from details manifested with regularity in connection with certain muscular acts, and 
are easily distinguished from the latter and other details consequent upon habit.

The measure of slant or slope of the letters, and the angle which the latter make with the line on which the signature is written, as well as the measure of ellipticity with which the curves of the letters tangent on the line of the writing, are largely the result of physical causes, and as manifested become very strongly indicative of personal habit. In addition to the foregoing, the angle or slant which the downwardly directed stiokes of the pen make relatively to the angle of the up-strokes, and with the line on which the signature is written, become importantly a feature of individual habit of writing; also when the latter is done by the flexure of the grasping functions, the rela. tive measure of ellipticity or curve occurring between the down-curves produced by the pen under the finger impulse, and the up-curves of the thumb impulse, or where the latter moves the pen to form lines connecting the letters, or in producing the terminal of the last letter in like manner manifest individual features of habit.

Instruction and persistent practice under the promptings of the latter act to change individual habit of writing as to its general appearance, and may to a certain extent modify the coordinate action of the muscles, so that the cultivated habit will differ somewhat from that which had been acquired when learning to grasp and operate the pen, in a manner that the muscular factors of the writer had assumed under the dictation of comfort and convenience; but the cultivated habit will be in a measure typical of the earlier acquired habit in its characteristics, and unless practised and used to a considerable extent, is apt to revert to its former condition and appearance. This feature of the writing habit is more strongly manifested in writing other than signatures, and is illus- 
trated by taking the writing of persons produced under the restraints of instruction, that done early in life before the effect of the latter was made apparent, and that written in old age; and on comparing the several writings it will be found to occur that the writer as advanced in years has in a measure returned to the earlier acquired habit. When writing signatures, where the tendency is generally manifested to give to them a representative character, the individuality expressed in them is not so much or so often affected by instruction as other writing of the same person. Writers usually adopt a form of signature at a time when business matters require its use in a representative character, and although they may adopt by instruction and practice a change in their writing other than signatures they will continue to write the latter without modification to any extent.

In defining individual habit in writing the causes of its appearance by way of illustration concerning the conditions of its manifestation in connection with the suggestion where to look for them, as developed in the experience of the author, have been given more to elucidate and make clear the processes of examination to be employed in the analysis of a signature than as presenting a specific course to be followed by others engaged in the work; but to name all the various features which must be taken into account when making an examination of a signature to determine the individual habit of the writer of it, is impossible. Each person writing must be examined by itself as an entity; taking into account its general appearances, with the details producing the latter traced to a physical cause, wherein as a result of the latter, the details become typical of the cause and are consonant with it. 


\section{CHAPTER V.}

THE DIFFERENCE BETWEEN WHAT CONSTITUTES TYPICAL PARALLELISIS OF THE SAME WRITER, AND THEIR SIMULATION BY ANOTHER PERSON.-THE NECESSITY OF CARE TO SECURE ACCLRACY IN MAKING EXAMINATIONS AND COMPARISONS OF HANDWRITING.--THE IMPORTANCE OF HAVING PROPER STANDARDS, OR ADMITTEDLY GENUINE WRITING OF THE PERSON WHOSE WRITING IS BEING DISPUTED. - THE DATE OF ALL WRITINGS USED FOR THE PURPOSE OF COMPARISON WITII RELATION TO THAT OF THE DISPUTED WRITING BEING EXAMINED. - TRACED SIGNATURES AND HOW PRODUCED. SOME OF THE USUAL CONDITIONS OF FORGED SIGNATURES CONSIDERED. - THE USE OF THE COMPOUND MICROSCOPE, AND THE IMPORTANCE OF IT IN EXAMINING DISPUTED WRITING.-THE EFFECT OF AGE, DISEASE, AND EXCITEMENT TO BE TAKEN INTO ACCOUNT IN THE EXAMINATION OF SIGNATURES. - THE ANALYSIS OF PERSONAL HABIT IN WRITING EXPLAINED, AND ILLUSTRATED IN DETAIL BY AN EXAMPLE.WRITING HABIT GENERICALLY CONSIDERED.

Having considered in the preceding chapters why individual habit in writing becomes a necessary concomitant of the latter ; and having also explained why there can be no positive parallelisms in writing other than that of the same persons, and that there must be positive differences between the writings of different persons, it follows when a disputed signature is compared with genuine ones of the writer, whose name the disputed signature purports to represent, that if habitual parallelisms are found to occur in both the disputed and genuine writings in typical delineation, the integrity of the disputed signature becomes established; and the reverse condition is made apparent, when instead of such parallelisms positive differences are found to occur between the disputed and genuine writings being examined. 
The determination between what constitutes typical parallelisms as occurring in signatures of the same person, and the differences appearing in a simulation of the same signature produced by another, demonstrate the development of two habits of writing, one of them being done as an accustomed act, in which all the details of its production are consonant with the muscular habit causing their appearance, and in the other where the form produced as an imitation is not consonant with the muscular coordination by which it is accomplished. Thus A., in producing his signature, is compelled to use the forearm movement of the pen in writing it, and B., who simulates the signature of A., cannot use the forearm movement of the pen, but must employ the fingers and thumb to do the work by the flexure of these factors. While B. may make a good pictorial simulation of the signature of A., it will have to be done by an entirely different habit of holding and moving the pen; and B., to use the latter aptly to make the imitation, is necessitated to employ the pen as accustomed, and this will incorporate into the simulation the details of habit which belong to B., and the forgery will be destitute of the features that in detail are characteristic of the writing of $A$. These conditions in which mere resemblances in form, and general appearances are contrasted with those features which are positive parallelisms typically considered, together with the method of making these facts when appearing, and the subject-matter of the preceding chapters applicable for the purposes of analysis and comparison, will constitute mainly the subject of the present chapter. It is in this field of study only, that tangible conditions on which to base an opinion are reached, and though the process-steps by which facts are developed in this line of investigation may seem difficult, they will only appear so to such 
persons as will not, or cannot, give to them the study to make them available.

In the examination of writing where the question to be determined is whether signatures which are disputed as to their genuineness were written by the same person that wrote those produced as standards, or admittedly genuine signatures of the writer whose signature is in dispute, great care should be taken in making the examination if the results of the latter are to be given as an opinion in court. As in analytical chemistry each step in the work must be conscientiously proceeded with at the commencement, to insure accuracy at the end of the investigation; and the examiner who desires to reach a correct conclusion in determining the personal habit of the writer must verify all the step-by-step disclosures which the analysis reveals, with such positive connection that a conclusion at variance with that one reached would be an impossibility. Each developed fact must be compatible and in harmony with all others; there must be no hypothesis at the commencement, and the examiner must depend wholly upon what is seen, leaving out of consideration all suggestions or hints from interested parties; and if possible it best subserves the conditions of fair examination that the expert should not know the interest which the party employing him to make the investigation has in the result. Where the expert has no knowledge of the moral evidence or aspects of the case in which signatures are a matter of contest, there is nothing to mislead him, or to influence the forming of an opinion; and while knowing of the case as presented by one side of the contest might or might not shade the opinion formulated, yet it is better that the latter be based entirely on what the writing itself shows, and nothing else. 
Proper Signatures to Use for Comparison. $\delta_{3}$

In making an analysis to ascertain the individual habit of the writer as developed in signatures produced by the latter, signatures of the same person are better standards for comparison than other writing of the same individual; for the reason that generally they are written in a measure different from ordinary pen work of the same person. Sometimes, however, signatures are written habitually with the same details of form and production as other writing of the same individual, and this is more particularly the case with persons who write but little else than their signatures. The conditions attending the production of signatures as compared with those under which ordinary writing of the same person are produced, will be made the subject of part of a succeeding chapter.

In most examinations of disputed signatures to ascertain whether they are genuine or forged, the result reached as a matter of opinion is attained by a comparison made between the contested signature and standards or admitted writing, furnished by the party to the contest at whose request the examination is made, and before such standards have been proved to the satisfaction of the court to be the genuine writing of the person whose signature is disputed. While counsel and attorneys may be ever so honest, their clients, if trying to sustain a forgery, can make the attempt to deceive the expert as well as the counsel in the standards produced for comparison, and the examiner who would reach a fair conclusion must avoid all chances of being deceived, so as not to be the means of misleading others by the opinion which he may give when on the witness stand. Hence, too much care cannot be exercised in the examination of the signatures produced as standards from which to make the comparison as to their character, their relative importance in personality to the papers on which 
they appear, the time at which they purport to have been written as compred with the date of the contested signature; and where there are several standards presented for comparison they should be by analysis determined as the writing of the same person before comparing them with the contested writing.

These preliminary steps are very important from the fact that persons who will commit forgery will resort to forgery to sustain themselves (particularly where the amount involvect is large) and in view of the additional fact that it is quite as easy a matter to produce good imitations of the disputed signature as it was to produce the latter. Hence all signatures examined as standards should be privately marked by the examiner, and in such a manner as to be positively identified when called upon to testify, and all opinions should be withheld until the standards are proved to the satisfaction of the court to be the genuine writing of the person whose signature is questioned.

It very often occurs in the experience of those who make examinations of handwriting preparatory to giving evidence in court, that the party who employs the expert will only furnish such standards for comparison as in appearance best sustain their interest and view of the case; and where the general appearance of the writing is the only field into which the person making the examination can go intelligently for study, this proceeding is very misleading. Where the examiner is educated to determine by analysis the muscular habit of the writer, and whether the general appearances of the signature are real or simulated, a conclusion as to the genuine or forged character of the signature in question is much more likely to be correct.

Another very important condition to be considered is the date at which the standard signatures introduced for 
Date of Standard and Disputed Writings. 85

comparison were written, relatively to the date of the paper on which the signature in dispute purports to have been produced. Standard signatures introduced for comparison to properly serve their purpose should have been written within three or four years of the date when the disputed signatures purport to have been written, as the greatest limit of interval that is safe to insure accuracy; and the nearer the standards approach in time the date of the disputed writing the better, unless it is made to clearly appear that the writer's habit has not changed. In the case of aged people a much shorter interval of time between the date of the stand. ards and that of the contested writing is at times necessary to insure accuracy in the examination and comparison. Where the standards are many years older than the date of the questioned writing, the chances occurring from changed habits of life, loss of nervous power, the effects of accidents and disease, with other conditions that might affect physical habit should be taken into account. How far such causes may have become operative in changing the character of the person's writing are best ascertained by comparing signatures of the same person recently written with those produced earlier in life. Where persons are well advanced in years so as to be within the precincts of old age, even a year might change the general appearance of a writer's signature to a considerable extent. When an opinion has to be based upon signatures as standards showing a long interval of time between the date of their production and the date of questioned signature, unless it can be shown that the habit of the writer has not been affected materially by age, such an opinion must be more or less modified as to positiveness.

If the written instrument to which the signature in 


\section{S6 Fokmhly and Ixformaly Made Writings.}

dispute is appended to a will, deed, note, check, endorsement, contract or other written instrument of like importance, which woukl call for the execution of the writer's signature in a formal manner; or a paper in which it was essentia! that the writer's personality should appear in the signature with representative form, the proper standards in such cases are the signatures of the writer produced with like import as to their execution, or written under conditions where it was equally important that the writer's personality should be represented therein. As a matter of experience it generally occurs to those who examine a series of signatures produced by the same writer when affixed to deeds, bonds, mortgages or other papers of like character under the form of an acknowledgment, that such signatures will be found to be very uniformly written; and seemingly as if the mental impulse prompting their production had the effect to make them so appear.

Signatures produced upon letters written to members of the writer's family or letters of friendship written to others than relatives, as generally made, are not proper standards for comparison with a disputed signature of the same person to a will, or other paper of like importance, when the general appearances of the signature as to form and pictorial effect is the only field of examination, from the fact that it is not necessary that signatures to letters should be formally written, and the mental impulse prompting the act cloes not suggest the importance of producing them with representative character. In evidence of the indifferent and generally careless way in which letters of the kind named are signed, an examination of a large number of them will show in the writing of each individual a wide deviation in general appearance from signatures of the same person that were formally written. Where the habit of the writer is strong and demonstrative 
as to its individualisms, the latter may be determined by the microscope to even include a variety of typical forms, but where the general appearances of the signature are the only features from which to establish resemblances or differences by comparison, any conclusion reached in this field of examination alone must be open to serious question as to accuracy.

It would seem at times as developed in the experience of those who make the individualism of handwriting a matter of extensive study, that some persons will write their signatures in a usual or unusual way so far as general appearances are concerned, under the influence or character of the mental promptings which make the production of the signatures necessary. When the signature is written as a willing act, and at the dictation of a mental impulse that is satisfactory to the writer it will be produced formally, and with its usual significance as to its individualisms; but when grudgingly done, or as an unsatisfactory act, signatures produced under this condition of mental prompting will sometimes show a manifest departure from the general appearances in the writing of the person as usually done, and seemingly as if so made for the very purpose of having them disputed at some future time. Thus a person grudgingly writing a signature as endorser for the renewal of an accommodation note which attending circumstances suggest the endorser will eventually have to pay ; or a person affixing his or her signature to paper or written instrument against the will or interest of the signer; or a person signing a will when ill or advanced in years at the pressing importunities of members of the testator's family present to the prejudice of absent relatives, and when conscious of being influenced to wrong the latter; will very often (when writing their signatures under such circumstances) seemingly produce 
them purposely with such variation as if to have their authenticity questioned at some future time. This condition appearing in signatures so written when compared with formally produced signatures of the same person is a perplexing one to examiners, who alone depend upon mere resemblances or differences in form upon which to base an opinion, as to their genuine or forged character. A conclusion reached from such a comparison alone can have but little value, and an opinion so formulated, if given with any positiveness, must be deemed empirical if considered honestly rendered. It being understood that a person desirous of avoiding the general appearance and prominent characteristics of form appearing in their usual signature may do so in a measure ; yet it rarely occurs that such writers are able to do any thing more than to make changes in the form of the letters; and generally these variations, when studied in a higher plane of examination than that of comparative form, will be found to be but modifications of the usual form, and in connection typically with the habit which produces the usual, or unusual forms in signatures of the same person, written under the prompting of differing mental impulses. In this latter field of examination reasonable accuracy may be attained as to the genuine or forged character of such signatures, when compared with formally written ones of the same person.

In detailing matters which experience suggests as importantly connected with the examination of disputed signatures, there are none more essential to a proper consideration of the subject than an understanding of those characteristics often appearing in forged signatures, and by which, in a measure, they are distinguished as such. When these features, occurring as a concomitant of most forgeries, are understood, their appearance may suggest 
a short and easy route to reach a conclusion; yet the careful and conscientious examiner will, even with these indications present in a disputed signature, institute a very careful and detailed study of the latter by comparison with the standard writings; and with as much effort as if these indications of forgery were not present. To make these features positive evidence, each other developed detail must also tend to the same deduction, and each detail must be compatible with every other feature, and all point to the same conclusion.

As forgers differ in their capability as to accuracy in simulation; all grades of its proficiency come up in the experience of those who, as experts, are called upon to make such matters a study. At one extreme will be found to occur signatures written with but little effort to imitate the genuine signatures they purport to represent ; with all the intermediate grades of imitation extending to the other extreme, wherein a skillful forger will, by practice, so simulate the signature of a person, and with such close resemblance that the very individual whose name is imitated cannot, independently of attending circumstances, tell the forgery from a signature which he knows he has written.

Among the most common forgeries of signatures are those which have been traced from genuine ones, and these are produced in various ways; the most common method being to place the genuine signature over a plate of glass horizontally arranged, with a strong light behind it, or against the window pane, and then to place over the signature so positioned the paper on which the forgery is to be made. When this has been done, the two papers are held in contact firmly, the pen is dipped in ink and moved over the paper, guided by the lines of the genuine signature beneath, which show through the superimposed 
paper, and hy means of which the form of the signature is transferred to the paper, which is exteriorly placed.

While this process of tracing produces very nearly the proper form of the signature thus copied, and if well done by the forger the copy will in general appearance, and to a certain extent, resemble in outline the signature from which it was thus traced, there are usually apparent in all simulitions thus made, peculiarities indicating the manner in which they were produced, and by which they can be illentified as such. One of the most prominent features of forgeries thus made is the general sameness of the writing ap apearing in the uniform width of the lines, and the omission of the usual shading emphasis. The cause of this appearance is the absence of habitual pen pressure, and the necessitated slow movement of the pen held closely in contact with the paper, and by which a uniform and steady flow of ink is deposited thereon; thus making what should be the heavier and lighter lines of one width, and density as to shading. This method of tracing is that resorted to by novices and is seldom employed by expert forgers.

Another condition appearing in all traced signatures is the absence of all evidences of pen pressure when examined as a transparency; this deficiency occurring as consequent upon the manner of moving the pen over the paper, with the slow copying effort before described; and while signatures thus made may resemble the one from which copied, the only likeness they have is that of pictorial resemblance, and it will be found to be destitute of all the appearance and indications of habitual writing in other respects.

Another method of tracing signatures is frequently resorted to by persons adept in the art, and this consists in making a lead pencil copy of the genuine signature by 
holding the latter against a window pane beneath the paper on which the forgery is to be produced; tracing the outline of the signature by means of a pencil, and then with pen and ink to write over the pencil copy; but as this method necessitates the use of an india-rubber eraser to remove the suplus black-lead where not covered by the ink, evidences of the use of the rubber will be found to occur, and traces of black-lead can be found by the microscope. While these appearances and conditions are common to traced signatures, there are in addition to their presence generally found evidences of pauses made in the writing, the effect of which will appear not as shading of the lines, but as irregularities or excrescences thereon produced by resting the hand in its movement, and by which at intervals more ink flowed from the pen than would occur, when the latter was being moved habitually over the paper.

Where two signatures of the same person exactly coincide when one is laid over the other in parallel arrangement with a strong light behind them, this condition of their appearance is very positive evidence that one of them was traced from the other, and is a forgery, as it is impossible for such a circumstance to occur in the writing of two signatures produced habitually. In the Silvania Ann Howland case there were found to occur as added to a will three codicils each of which had affixed thereto what purported to be the signature of the testator, and which three signatures when examined as transparencies were found to exactly coincide in all respects as to form and general appearance. A calculation made by Prof. Pierce, a learned and well-known mathematician of his day, as to how often it was possible for such a circumstance to happen with habitually produced signatures, he gave it as his opinion under oath, from actual calculation, 


\section{2 \\ Characteristics of Forged Signatures.}

it could only happen once in two trillion eight hundred and sixty-six billion times.

Forged signatures often show a copying effort that is manifested in the details of their production. These evidences generally appear, in some instances, as pauses made in the lines connecting the letters of the signature, where the pen rested while the eye of the forger was directed from the writing being done to the copy, that the writer could fix in the mind the form of a succeeding letter. These pauses appear in different measure of prominence in different forgeries, and there is no rule as to their measure or appearance. With some simulators, the pen rests with considerable emphasis, and with others it is lifted from and returned to the paper while the eye of the writer goes back to the copy. With others there will appear but little hesitancy; and some forgers, well skilled in the art, will, by practising the simulation until they have the form of the genuine signature well fixed in the mind, become enabled to produce a forged copy of a genuine signature that will show no pauses; hence the absence of pauses is not proof of the genuine character of a signature. Another common characteristic of forged signatures, and particularly such of them as are not traced and are produced by persons not skilled in the art, is found in the studied appearance which they have, as if written under restraint, and without the apparent freedom consequent upon habitual writing; and still another characteristic of forged signatures that are not traced from a genuine signature is that they are written with greater length in proportion to the width and height of the letters, than occurs in the genuine signature from which they are copied in imitation. This want of proportion occurs generally from making the lines connecting the letters of the signature longer than those of the copy. 
While these characteristics are common to forged writing, to make them available in formulating an opinion from an analysis they must be substantiated by every other detail occurring in the writing. It must clearly be kept in view that general impressions derived from a cursory examination of a disputed signature should have no weight in the mind of the examiner, before proceeding with the analysis; as such an impression is apt to lead the investigation into a particular line of research, and it should be understood that the work of the examiner must relate to the comparison of the details in each of the writings as to their correspondence or difference.

In thus considering forged writing, and in detailing some of the most common features which are found to occur in it, as developed in the experience of the author, it must not be understood that all the phenomena attending the production of forged signatures can be given. Inasmuch as each person has a peculiar muscular coordi. nation that is manifested in the production of habitually written signatures, so each forger, from the same cause, has an individual habit that must be used when simulat. ing; hence there will be as many styles of writing manifested in the production of forgeries as there are forgers to produce them. No rule can be laid down for the classification of their peculiarities, excepting as hereinbefore stated, and as occurring from the measure of accuracy with which the simulation appearing in them is done. Each case of disputed writing must be examined by itself, and while there are certain process-steps to be followed which experience suggests, as facilitating the analysis, yet the examiner must wholly depend upon what is seen in the disputed signature that is, or is not found in the admittedly genuine writing of the person whose signature is questioned, and the comparison of the one with the other. 


\section{Use of the Microscope a Necessity.}

In all examinations of questioned signatures to determine the individual habit of the writer, the use of the compound microscope is a necessity to obtain the best field for study and analysis, for the reason that the most important details are ofttimes so minute that they cannot be seen with the naked eye in sufficient size to determine their individual character with accuracy. While a magnifying glass or a Coddington lens may be used to a moderate extent, the former has but a limited field that is in focus without distortion, and the Coddington lens is not easily held in position steadily for continued observation and study; neither has it the requisite power for the work. The lower powers of the compound microscope are best available for the examination of signatures, for the reason that when the higher powers are used but little of the signature is in the field of vision, although the power of the lens may be increased when some particular point or feature in the writing requires greater enlargement for more perfect definition. The higher powers of the microscope are sometimes used to ascertain the character of inks with which writing is done, and also to determine the character of the paper on which a signature is written, which at times becomes important. For all practical uses of the microscope in the examination of signatures, the ranges of object enlargement occurring between a three-inch and an inch objective will be found to best answer the purpose, as the various powers of these lenses become important in making the analysis. The microscope stand that is best adapted for use in this work is that designed by C. E. Hanneman of the city of Troy, N. Y., and which is made by Zentmeyer of Philadelphia. This stand has no stage when used for examining writings, although it is adapted to have a stage attached for ordinary work. It is made 
with an extension tube that is projected downwardly, and the apparatus is so arranged that with a pane of glass laid over the signature, the stand is placed on the glass, whereon it can be moved back and forth without creasing or marking the paper on which the signature is written. Where the ordinary microscope stage is used, the writing has to be folded and creased in being placed upon the stage in a position to be examined, and this procedure is objectionable as it tends to injure the paper. By attaching an elbow and interiorly placed prism to the upper end of the tube used in the Hanneman stand, and the eye-piece on the outer end of the elbow, the examiner seated in a chair can study the writing for a long time without fatigue, which is a matter of great importance where prolonged efforts are necessary.

While it is a fact that the microscope and a knowledge of its uses is of the greatest importance in ascertaining the character of signatures, where the question of their being forged or genuine is the object of the examination, it does not follow that because a person is learned in the use of the microscope in other fields of research that he is therefore qualified to be considered an expert in handwriting. A peculiar education made practically applicable by experience in this latter field of study is absolutely necessary to determine with accuracy what the microscope reveals, and its importance to give value to any conclusions reached by its use. The connection of effect with cause, and the determination of the latter as a matter of individualism cannot be accomplished merely from what is seen under the microscope. The examiner must by experience and education be fitted to ascertain from personal characteristics manifested in the writing of a signature what necessitated their appearance as a mat. ter of individuality. 


\section{General Appearances When Misleading.}

When comparing a disputed signature with a series of admittedly genuine signatures of the same person whose signature is being displited, the general appearances and pictorial effect of the writing will suggest as the measure of resemblances or differences predominates, an impression upon the mind of the examiner, as to the genuine or simulated character of the signature in question; and it is under the influence of this impression so made in this field of examination alone, that originate most of the errors in judgment that occur with persons posing as experts, without the requisite experience or qualification to fit them for the work. When it is understood in this connection that to make a forgery available for the purposes of its production, it must resemble in general appearance the writing of the person whose signature it purports to represent, it follows as a reasonable conclusion that resemblances in general appearances alone must be secon. dary factors in establishing the genuineness of a signature by comparison; and the fact that two signatures look alike is not always evidence that they were written by the same person.

To distinguish with any degree of certainty the differences manifested in the general appearance of a series of signatures written by the same person, and that resemblance produced by simulation of the same writing (if well done) is a very difficult proposition to determine; and examiners having the most experience will as a rule be guarded and careful in giving an opinion based on any conclusion reached in this field of study, without further verification. As an illustration of the uncertainty of an impression produced by the general appearances, and close resemblance of signatures even to an expert obser. ver is manifested, when the fac simile signatures of the signers of the Declaration of American Independence, as 
executed by different engravers are examined. On comparing each individual fac simile made by one engraver, with the fac samile of the same signature made by another engraver, they will be found to exactly coincide in general appearance as to form and pictorial effect, and so much so that the fac similes of the same signature made by different engravers cannot be told one from the other. On examining them by the use of the microscope they may be very easily determined as the work of different persons. While this is likewise true of the resemblances in general appearance which a disputed signature may have when compared with a genuine signature of the same person, it is also true that the measure of difference occurring in the general appearance of a disputed signature when compared with genuine ones of the same person are not always evidence of forgery.

As hereinbefore considered and explained there are many conditions affecting the production of signatures habitually and uniformly, apart from the causes which prevent a person from writing signatures twice precisely alike under the influence of normal conditions of execution. These conditions tending to modify individual habit should be taken into account when making examinations for the purpose of distinguishing typical variations from simulation. The effect of fatigue, excitement, haste, or the use of a different pen from that with which the standards were written are well-known conditions operating to materially affect the general appearance of the writing, and may have been in one form or another an attendant cause when the questioned signature was pro. duced, and thus have given to the latter some variation from the signatures of the same person, executed under the influ. ence of normal surroundings. Hence, to know whether these differences are the result of circumstances other than 
normal conditions in the production of the questioned signature (considered to be genuine), or are caused by a forger's inability to make a good simulation (with the signature in question considered a forgery) become very important elements of study in making the analysis. Too much care cannot be exercised, and all the contingencies that could have happened to vary the general appearance of the questioned signature should be taken into account at the commencement of the examination, before any impression as to the genuineness or forgery of the signature in question is allowed to lead the mind of the examiner making the investigation with general appearances the only step in the analysis; unless the disputed signature bears no more resemblance to the genuine writing of the person it purports to represent than the signature written by another person would have without simulation. In the latter case, however, it would be a safer proceeding to verify this difference in the general appearance of the two signatures by a microscopic examination rather than to depend upon it to formulate an opinion.

Having thus considered some of the peculiarities occurring in forged signatures, and some of the essential requirements to be taken into account when making examinations of them to distinguish simulated from genuine signatures, in illustration of the system to be employed there are produced photo-engraved copies of two checks. One of the latter, and that shown on plate I, being a fac simile representation of a check which was in possession of a forger, and that appearing upon plate II, being a check and signature which was simulated from the other; and these illustrations are supplemented by a description of the method of analysis employed to determine the forgery. The details of personal habit are shown as 
enlarged upon plates III and IV, the latter being a fac simile of the forgery, and the former that of the genuine signature of the check shown upon plate I, "with the writing appearing as it is seen under the microscope when enlarged about sixteen times. Plates V and VI represent in fac simile the movement of the pen-splits when writing the word "Cipperly" with the writing examined as a transparency by the use of the microscope, and enlarged by the latter; that appearing on plate $\mathrm{V}$ representing "Cipperly" of the genuine signature, and that upon plate VI the word "Cipperly" of the forgery. Plates VII and VIII represent fac similcs of the word "Cole" taken in the same manner as the fac similes upon plates V and VI. The illustration upon plate VII representing the word "Cole" of the genuine signature, and that upon plate VIII the word "Cole" of the forgery.

Enlarged photographs when taken properly show writing in about the same field of observation as the microscope focussed to the same enlargement, with the exception that as the writing is being examined and studied under the latter, the definition is better, and particularly more so than when bromide prints are used instead of ordinary photographs, and though photoengravings are not so well adapted for making examinations as photographs, they are better adapted for illustration herein, and are employed on this account.

The simulation thus selected for the purposes of illustrative analysis was successfully produced and uttered by one Lyman who was one of the ablest of forgers, and for the perpetration of which crime he was tried, convicted and sentenced to prison where he died before the term of his sentence expired. The capacity of this man Lyman in the use of the pen was simply wonderful, and his powers of copying and closely imitating 
signatures was extraordinary. The very check on which the foryed signature is shown is drawn by him with a pen, and so close and deceptive was this imitation of the senuine check that until an expert examination had been male of it by the use of the microscope, the bank officers and others supposel that the forger must have come into the possession of a blank check printed from the same stone as the genuine check from which it was simulated.

In thus selecting for illustration and analysis one of the most accurately simulated signatures, executed by one of the most expert of forgers, the intention is to indicate with what accuracy examinations of this kind can be made, the value of evilence based upon them when conducted in this field of study; and also to show that although a forger may simulate a signature so closely as to deceive the person whose name is simulated, the forger cannot incorporate into the imitation the details of habit belonging to the writer whose name is forged, and the best that the most expert forger can do is to imitate general appearances, and thus produce in the forgery a pictorial rescmblance to the signature from which it was simulated.

When the two signatures thus illustrated are compared and examined as to their general appearance, they will be found to differ no more from each other than some of a series of genuine signatures of the same writer will vary when compared. While there are some differences in the form of some of the letters of the genuine signatures when compared with the forgery, yet greater differences were found to occur when a series of signatures produced by the writer of the genuine signature in ques. tion were compared with each other; so that this measure of difference in form could not have been taken into account to determine whether the signature illustrated in 


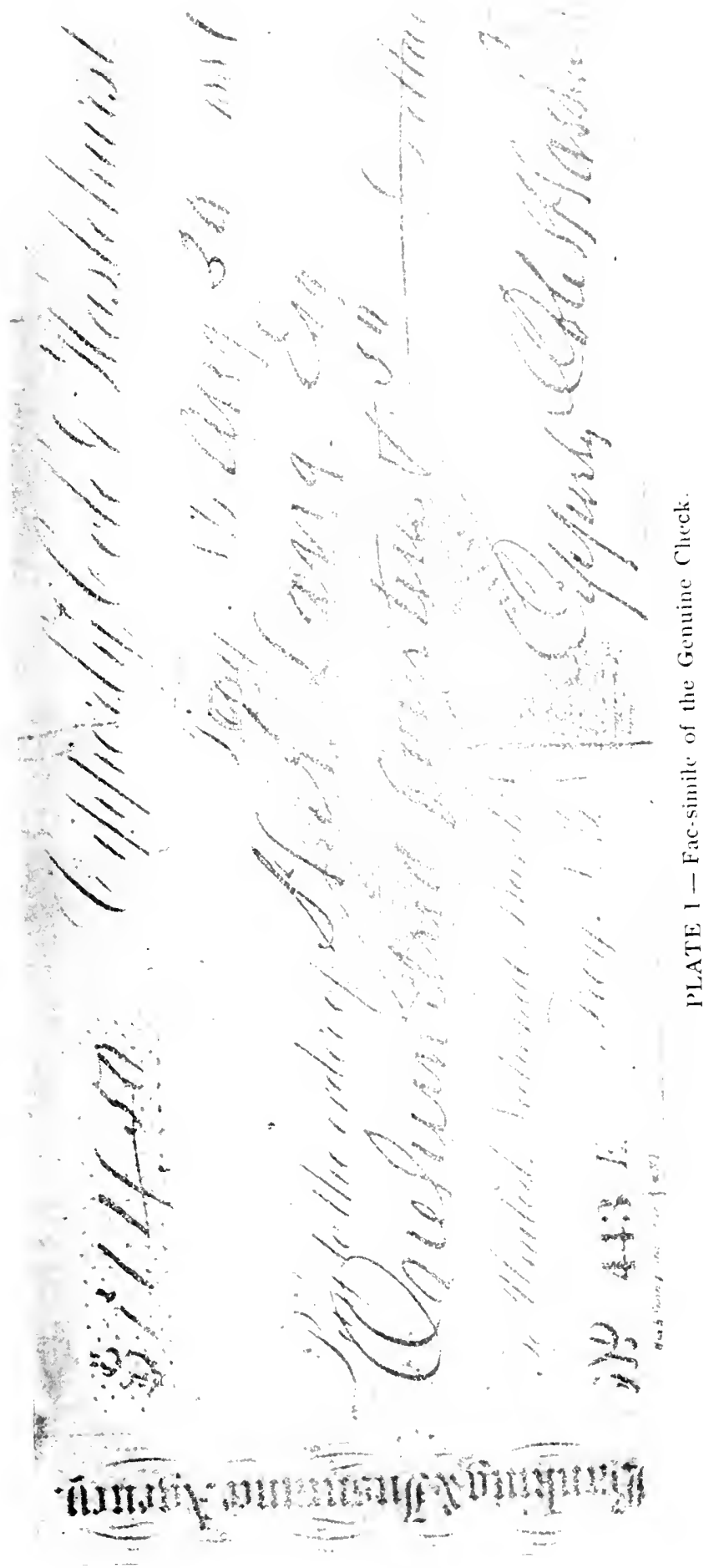




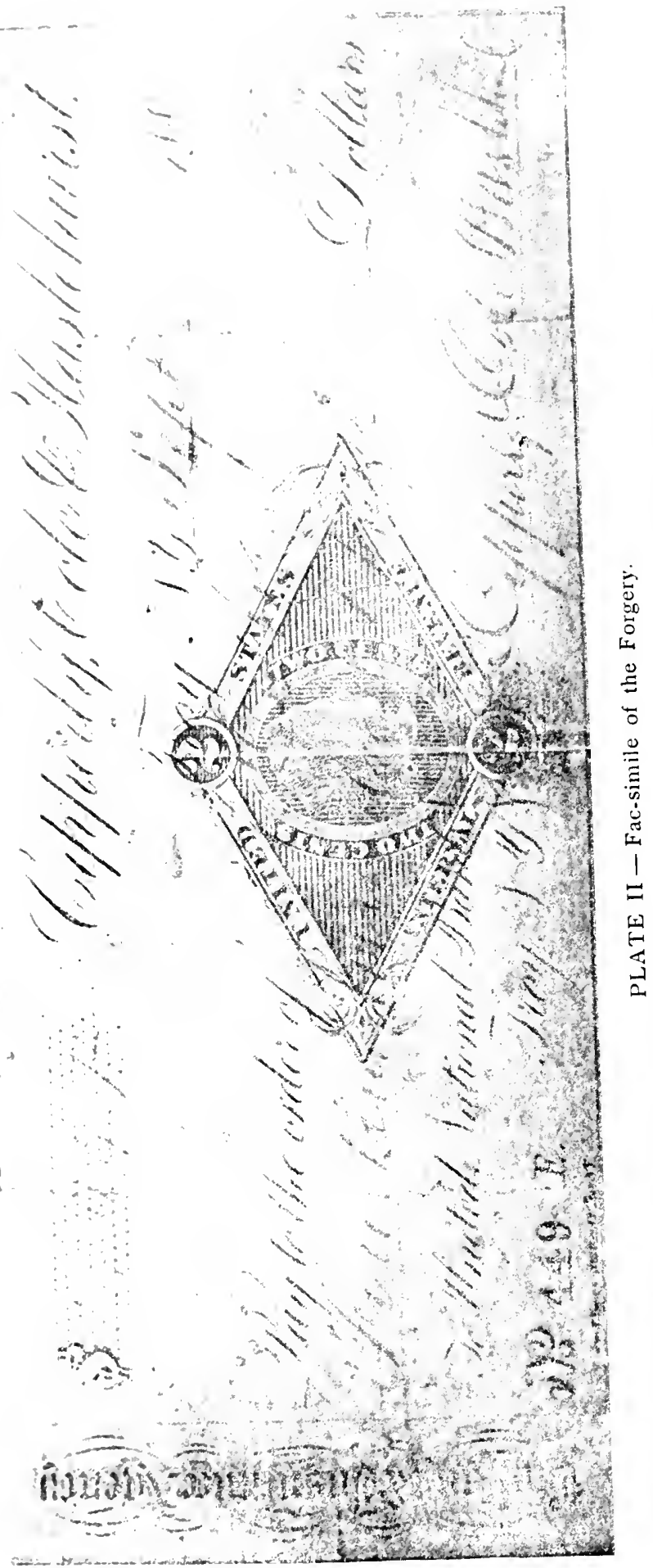




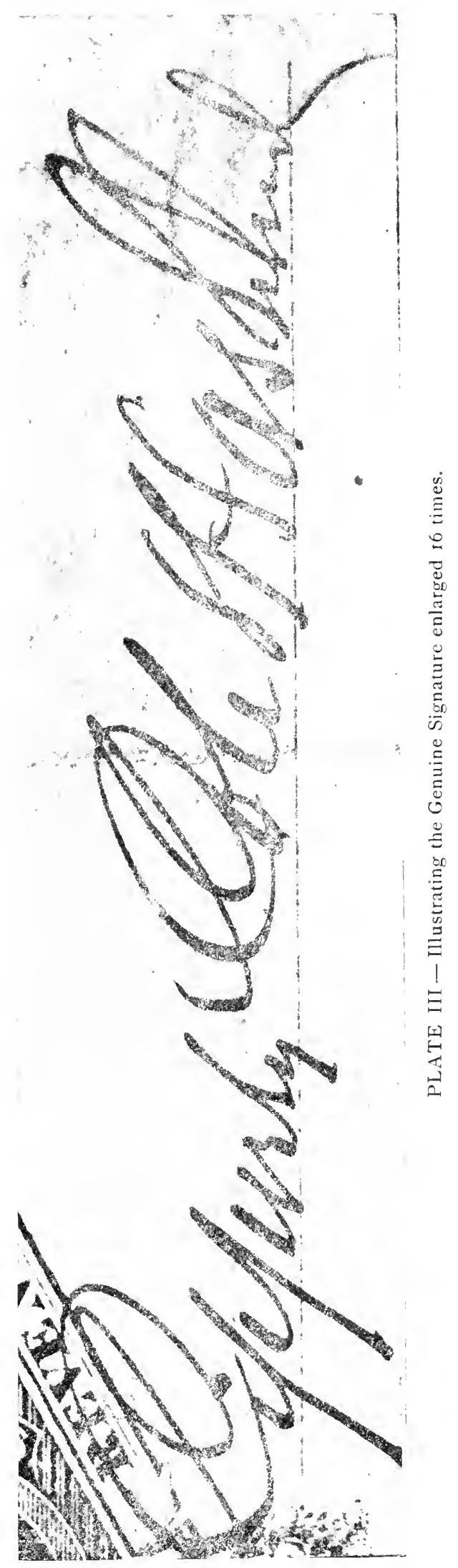




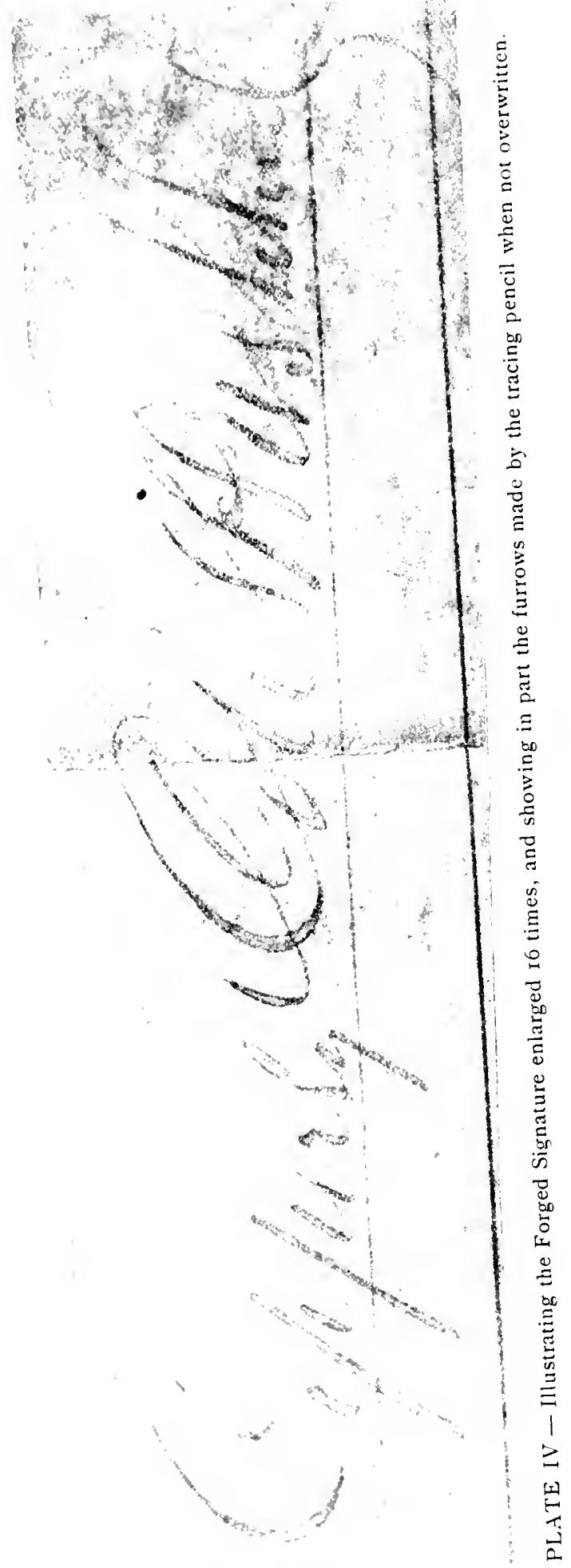




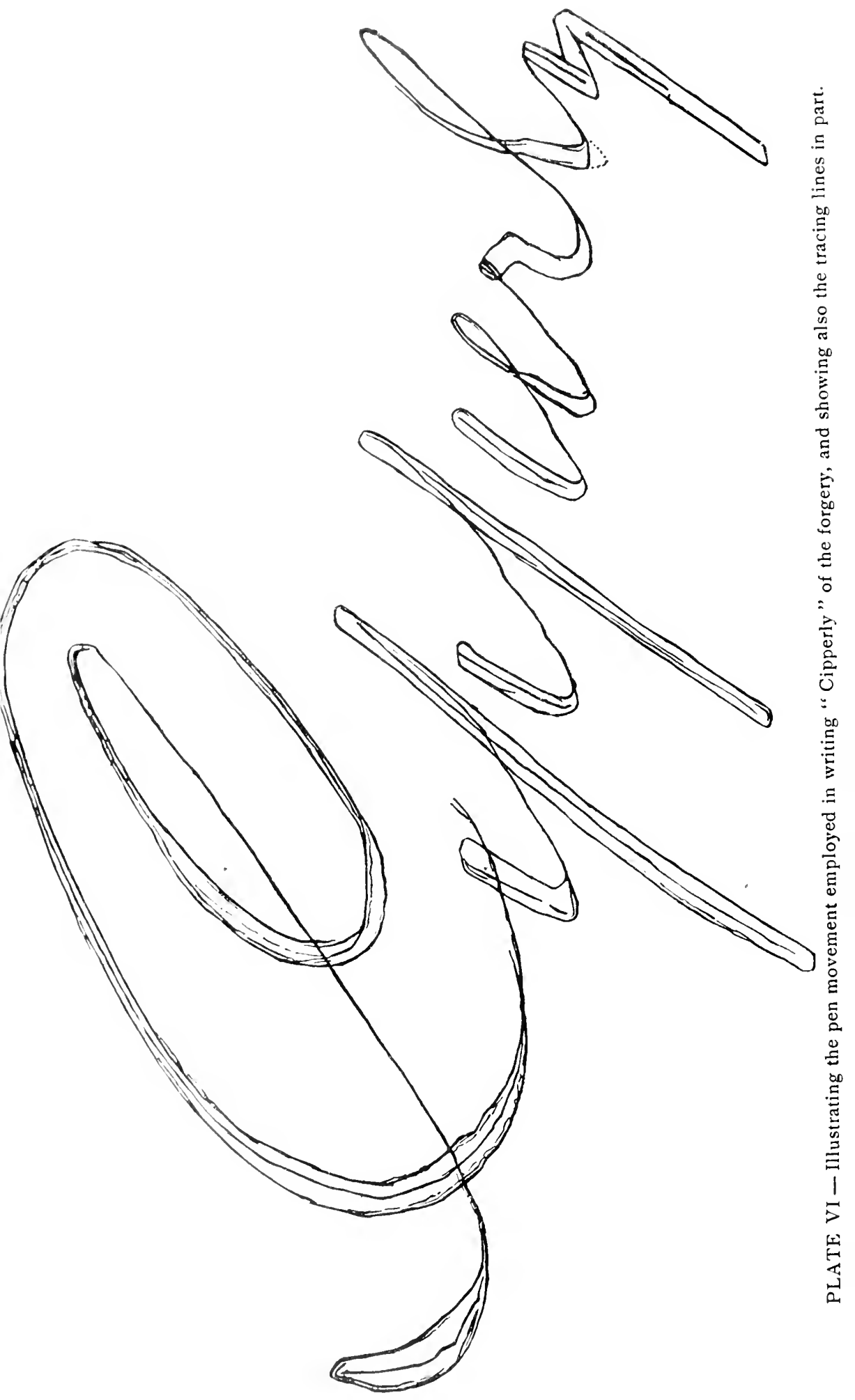




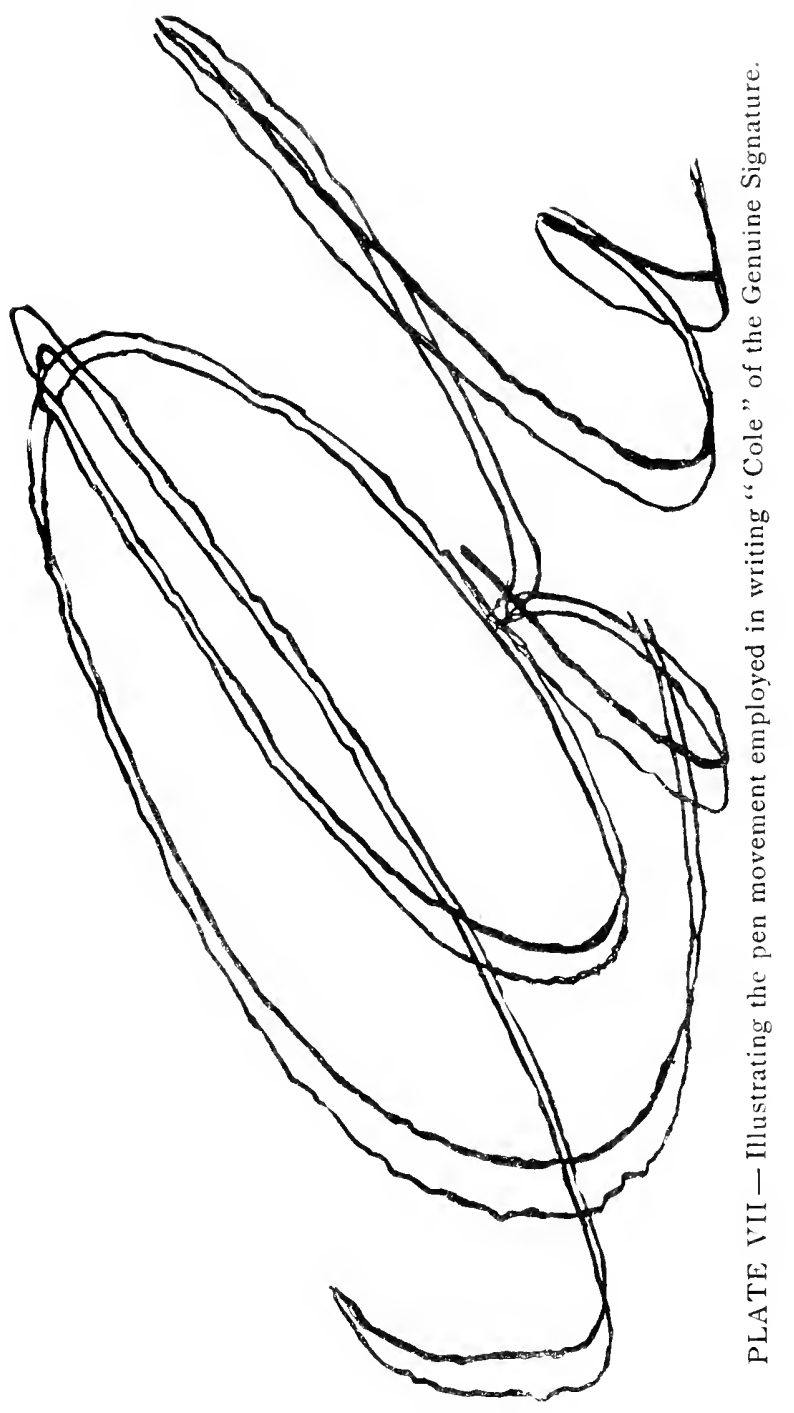




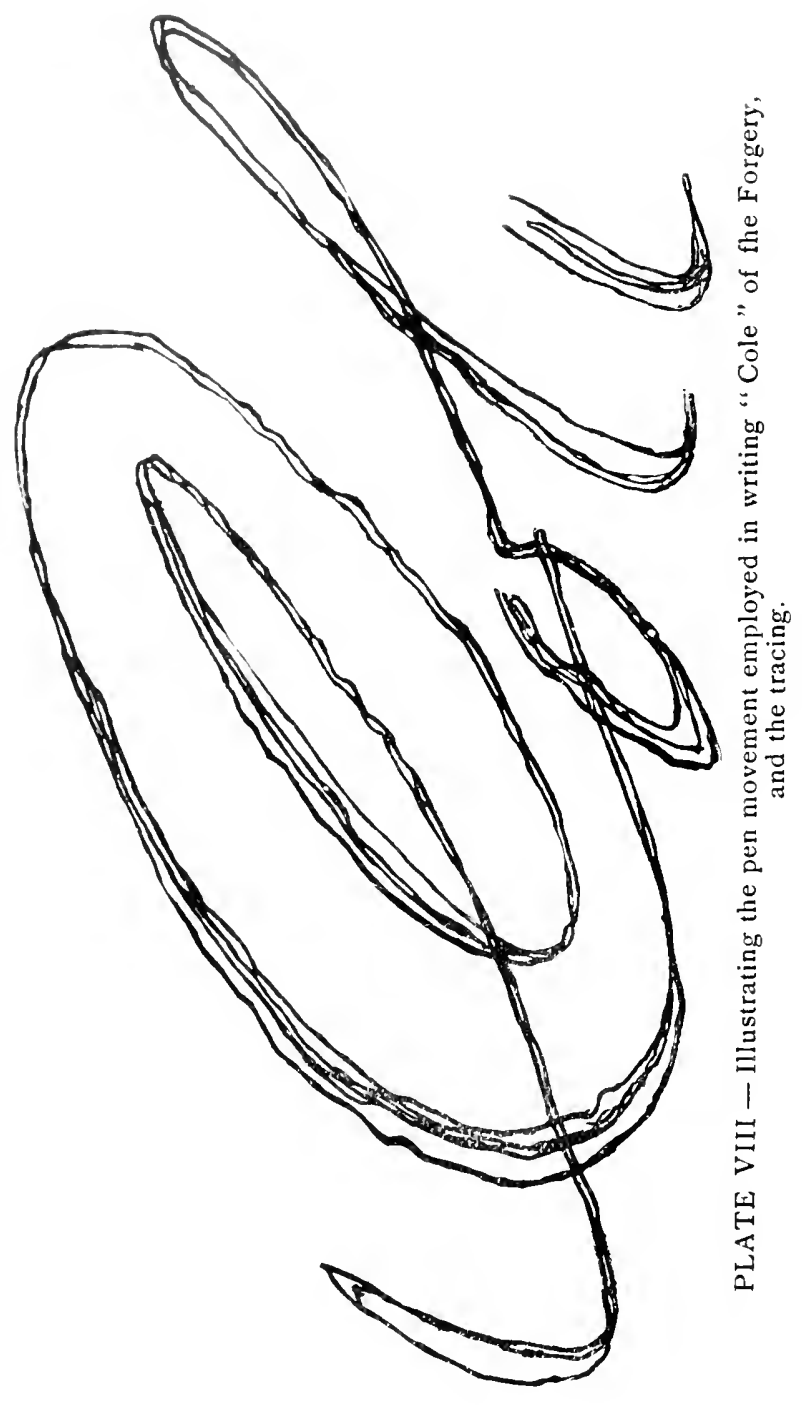


fac simile upon plate II was genuine or forged, when compared with that illustrated upon plate I.

So thoroughly are the general appearances of the genuine signature simulated in the forgery illustrated, that when some thirty odd checks signed by the same party who wrote the genuine signature from which the simulation was made, were laid in a row so that the signatures upon each underlapped that upon the check immediately above, with the forged check one of the thirty, quite a number of snap-shot experts, including the writer of the genuine signature, made the effort, not one of them picked out the right one as the forged check. This occurred, however, before the ink with which the forged check was written had faded to the extent that it had when photo-engraved for use herein.

On examining the illustrations shown upon plates $\mathrm{V}$, VI, VII and VIII, in which skeletal appearances of separate parts of the genuine and forged writings are illustrated, they are seen as they appear when examined as a transparency by the aid of the microscope with a strong light behind the paper, and in a field of examination where the skill of the most cunning forger cannot go in imitation. These illustrations show accurately every movement of the pen, and the position which the splits, or nibs of the latter occupy in each movement; not only this is made clearly manifest, but these representations establish as a matter of fact that the two signatures were written by two differing and well-defined physical habits; one of them being capable of making letters of the form appearing in the genuine signature by an habitual movement; and the other to produce a skeletal representation in form, and in sequence to go over the work a second time to put on the shading emphasis.

The physical habit of the writer of the genuine signa- 
102 Analysis Made for Determining Habit.

ture illustrated upon plate $\mathrm{I}$, as manifested by the details of its production, indicate that in making some of the letters of the signature they were formed by the forearm movement of the pen; while other parts of it were produced by the flexure of the prehensile muscular functions of the fingers and thumb; as if the writer having in mind a representative form that was to appear in the signature as a matter of fancy or selection, was compelled to adopt such a method of producing it, as was adapted to the organization of the writer's hand, and which will be more fully considered hereinafter.

When the writing of the genuine signature illustrated as a whole upon plates I and III, and skeletally in parts upon plates $V$ and VII is examined to ascertain the individual habit of the writer of it, the following facts become apparent at the commencement of the analysis; that although the letters of which the signature is composed are most of them connected, they are in the main produced by separate efforts, in each of which the pen is raised from off the paper upon the completion of the letter and then returned again to produce a succeeding letter; and so that when thus returned to contact with the paper it would override the up-curve line of the letter last produced, and thus make the connection of such parts of the signature as where the letters join; while in other parts of the genuine signature these breaks are shown as occurring independently of any effort to have the connecting lines intersect a succeeding letter.

The letters "C" in "Cipperly" and "Cole" of the genuine signature illustrated upon plate I, do not connect by a continuity of effort with the next succeeding letter, although made to intersect the latter. The letter " $i$ " in "Cipperly" and its up-curve terminal line was produced, and the pen lifted from the paper, and then returned to 
the latter to make the staff or standard of the first letter "p," with the top of the latter over-riding the top of the curve leading up to the letter "i." In the same manner the body part of the first letter " $p$ " was produced, and its up-curve continued to where the staff or standard of the second letter "p" should commence; and then the pen was again raised from off the paper, and returned to the latter so as to extend over the top terminal of the preceding up-curve where commencing to make the staff or standard of the second letter "p." This same condition is also apparent in the formation of the letters " $\mathrm{e}$ " " $r$ " " $l$ " and " $y$ " of "Cipperly" and in most of the letters occurring in "Cole" and "Haslehurst" of the genuine signature shown upon plate I.

These conditions thus manifested in the genuine signature are positively ascertained by the movement of the split-points or nibs of the pen, and, as shown in the skeletal illustrations upon plates V and VIII, which represent them as enlarged and as examined by the microscope, with a strong light behind the paper. These details become important at the commencement of the analysis, for they appear all through the genuine signature, and must have their origin from one of two causes; one being that they were so made as a matter of the writer's fancy or choice, or, the other, that desiring to use such forms of letters, the writer was compelled to produce them in the manner in which they appear from physical causes. If originating from the latter there will be found other details of habit necessitated to appear which will be typical of them.

From the relative position which the pen-splits must have had in the formation of the letters " $\mathrm{C}$ " of the genuine signature, where the lines, as produced by their move ment, indicate shading; and where the pen-splits spread 


\section{iof Analyis Mane for Determining Habit.}

apart by pressure to produce the latter, and where they cross each other at the top and bottom of these letters to produce curves thereat, it is very plainly indicated that the pen was held nearly vertical without slant towards the shoulder of the writer, but slightly inclined to the right from a perpendicular. This position of the pen when forming the letters " $\mathrm{C}$ " of the genuine signature is also made apparent in the relative position of the penslits as they are moved to form the up-curves of these letters, and the shading therein, which could only have been applied by pressure and not flexure, from the vertical position in which the pen was held, with its concavity facing to the right. It also appears from the details that when the pen was operated to form the letters " $C$ " of the genuine signature it was caused to bear upon the paper at the same angle during the movement for their production, and, consequently, it must have been rigidly held by the prehensile grasp of the fingers, and, as so held, operated by the forearm movement.

When a slanting and elliptical form of letter like the letters " $C$ " of the genuine signature is made by the flexure of the thumb and fingers, instead of by the forearm movement before described, it will be readily understood that the angle at which the pen bears upon the paper is a constantly changing one; for the splits of the pen must be drawn inwardly toward the palm of the writer's hand when making the down-strokes; laterally moved to the right or left when producing the bottom curves, to the left when forming the top curves, and outwardly away from the palm when giving direction to the up-strokes of letters; with the grasp of the pen forming a pivotal cen. ter around which it is operated to write by the flexure of the thumb and fingers. On examining the skeletal representation of the pen movement occurring in the produc- 
tion of the genuine signature it will be found that all the details present indicate the production of the letters " $\mathrm{C}$ " by the forearm movement, with the pen held as before described.

After the production of the letters " $\mathrm{C}$ " of the genuine signature as thus determined, the letter " $\mathrm{i}$," the first letter "p" and the staff or standard of the second letter " $p$ " were also written by the forearm movement, but with the pen slanting toward the right shoulder of the writer, and with its concavity facing slightly to the left. The whole of "Cole" was written with the forearm movement, with the pen held as in writing "ip" and the staff of the second letter, "p," in "Cipperly," with the exception of the capital letter "C" in "Cole," which was produced in the same manner as occurring in "Cipperly," before described. The " $\& \mathrm{H}$ " of the genuine signature as well as the bodypart of the "a" in "Haslehurst" were written with the forearm movement, the pen being held and operated as when writing "ole" "of Cole," the "ip" and staff of the second letter, "p," in "Cipperly," with all the remaining parts of the genuine signature done by the flexure of the fingers and thumb, and without the intervention of the forearm movement.

In the production of the before-named parts of the genuine signature by the forearm movement, other than the letter "C," an examination shows that the pen was held, while being so operated, with its outer end and that nearest the body of the writer slanting toward the shoulder of the latter, with its concavity facing somewhat towards the left, instead of towards the right, as when making the capital letter "C." This condition of pen grasp and the determination of the method by which it was operated, is ascertained by the pen-split furrows, and the position they have relatively to each other, when pro- 
ducing the tops of, and the bottom ends of the staffs or standards of letters, and the position of the splits where they cross each other, relatively to the curves made in the body-parts of letters, where, upon the line on which the signature is written. Upon an examination of the bottom ends of the staffs or standards of the letter "p," it will be seen that the left-hand one of the two splits descends lower than the right-hand one; and at the tops of these staffs, or standards, of the letters " $p$," the righthand one of the splits commences to form its part of the letter higher up than the left-hand one. These details so occurring could only have been produced as they thus appear by the pen, held as before described, with its concavity facing to the left. Having shown that when the pen is held nearly vertical and operated by the forearm movement to produce curves in the tops and bottoms of the letters " $C$ " of the genuine signature, that the splits cross each other after the curves are made, it follows that with the pen operated by the forearm movement when slanting back toward the body at its outer end, and with the concavity of the pen facing to the left, that the pen splits from necessity when making curves that tangent upon the line on which the signature is written must cross each other at the commencement of the up-curve, and this is just the condition found to occur in those portions of the genuine signature which have been considered as written by such a pen-grasp and forearm movement of it. It also occurs in the curves of the body-parts of letters where tangential to the line on which the sig. nature is written that the pen was held rigidly, and nearly vertical by the prehensile grasp of the fingers and thumb to produce the capital letter " $\mathrm{C}$ " of the genuine signature, and so held was operated by the forearm movement as determined from the manner in which the 
pen-splits cross each other in the production of curves as so differing from those produced in the same parts of letters when made by the thumb and fingers, with these factors by their flexure at the joints moving the pen around the curves at a constantly changing angle to the paper, and with the pen-grasp forming a pivotal centre for the movement.

Having shown the two conditions of the forearm movement appearing in the writing of the genuine signature as determined by the details accompanying their production; on an examination of other parts of the signature and features of individual character present, it will be found that some of the letters, and particularly those which have been determined as produced by the two modifications of the forearm movement of the writer, have well-defined bottom curves where tangential to the line whereon the signature was written, while in other parts of the signature there are details occurring which indicate their production by the muscular flexure of the fingers and thumb, and particularly in those parts of the signature where, in place of curves at the bottom of letters, there are angles. From an examination of the genuine signature and its differently written parts, it is very plain that the whole of it could have been produced by the forearm movement, with well-defined bottom curves, if the writer had desired to so produce it, yet it is apparent that such was not the writer's intention, and that to give to the signature a desired representative character the writer produced all the firm signatures written by him in this manner, as an inspection of a large number of them made by him demonstrated very clearly.

Finding angles at the bottoms of letters in some instances, and curves in the same relative position in other parts of the signature, would not necessarily deter- 


\section{los Analysis Made for Determining Habit.}

mine that in the one case they were produced by the forearm movement, and in the others by the flexure of the thumb and fingers. If the angles and curves being considered were all produced by the forearm movement, they would show details consonant with such a production of them; and if the angular pen-work of the genuine signature being considered is accompanied by the appearance of details indicating their origin in the thumb and finger movement of the pen, that are incompatible with the forearm capacity, the appearance of such details will establish their production by the former.

It being understood that the bottom curves of all letters written by the flexure of the grasping muscular functions of the thumb and fingers are produced by the thumb as a factor of impulse in moving the pen to the right as it bears against the fingers, with the latter yielding in the direction of the thumb impulse in a downwardly directed movement to the right, and in an upwardly curved direction, so as to continue as an upstroke, or on an incline for connection with the com. mencement of a succeeding letter, or to finish a terminal one, it follows with this understanding made applicable that the thumb impulse, when performing either of these movements of the pen, is actuated by its individually peculiar adductor muscular functions, and whether curves or angles are formed at the bottom of letters must depend upon the thumb capacities exercised in making such movements, and in their adaptability to coordi. nate with the fingers in doing the work. The fact that the writer could produce well-defined curves at the bottoms of the body-parts of letters by the use of the forearm movement does not establish that the same writer could make them by the cooperative action of the 
thumb and fingers; for the manner of producing them by the two methods is entirely different. When curves of this class are made towards the right hand by the muscular action of the thumb and fingers with the former, the factor of impulse, the pen is moved inwardly towards, laterally to the right, and outwardly from the palm of the writer's hand by the flexure of these factors at their joints; and this muscular action is accompanied by the appearance of details very different from those manifested in the corresponding parts of letters, when the latter are made with the pen grasped as a prehensile act and moved by the forearm, as before described.

On examining the bottom curves in the body-parts of letters, as occurring in the letter " $\mathrm{i}$ " and first letter "p," shown in the illustration of the genuine signature upon Plate I, and its enlarged representation upon Plate $\mathrm{V}$, it will be seen that the pen-splits cross each other at the commencement of the up-curves instead of after the latter have been formed, and as manifested in the production of the letters "C." It will also be observed that the concavity of the pen, when forming the body-parts of the letters " $i$ " and the first letter " $p$," faced somewhat to the left when commencing to make; and during the production of the body-part, by the downward movement of the pen until just before reaching the bottom, when the pen was caused to rotate on the muscular cushion of the thumb (against which it was pressed by the fingers) so that the concavity of the pen was caused to squarely face the palm of the writer's hand, producing a detail thereat designated in enlarged representation at Plate $\mathrm{V}$, and this is a peculiarity which occurs in all the habitually produced signatures of the writer.

When the bottom curves of the letter " $i$ " and the body-part of the first letter " $p$ " in "Cipperly," and the 
body-part of letter "a" in "Haslehurst," of the genuine signature, are compared with the corresponding parts of the "e," "r," and of the "l" and "y" of "Cipperly," and the staff of the "a" in "Haslehurst," of the same signature, there are not only wide differences in the form. of the letters found to occur, but where curves are used at the bottom in some of these letters, angles are formed to take the place of curves in the others. As either of these forms. occurring at the bottom of the body-part of letters, could have been produced by the forearm movement, they are only important in connection as a peculiarity of the writer's habit of writing signatures, and the details consonant upon their production, which estab lishes that the curves were produced by the forearm movement, and the angularity by the flexure of the thumb and fingers.

Referring to the letters " erly," including the body-part of the second letter "p," illustrated upon Plate I, it will be observed that, after making the staff of the first letter "p," a well-defined pause occurs in the writing of the genuine signature, and that the pen was lifted from off the paper, and from this point, as the pen is returned to the paper to complete the signature, the angularity at the bottom of the body-part of letters commences, and the same condition occurs in the writing of "Haslehurst," after the oval body-part of the letter "a" is made. It will also be seen that from the commencement of this angularity the size of the body-parts of letters decreases as the signature extends to the right, the cause of which will be explained in another connection. In the writing of the part "erly" and "lehurst," including the staff of the letter "a," preceding the latter there are very positive evidences that the thumb of the writer of the genuine signature was a muscular factor in other than prehensile 
uses, and that it was peculiarly deficient in adductor function.

It will be readily seen that the staffs of the letters "p" of the signature illustrated upon Plate I, are carried down below the line on which the signature is written to about twice the distance manifested in the downward extension of the staff of the letter "y," and that they are so extended without irregularity or evidences of discordant muscular action in making the movement; but when the bottom of the downwardly extended staff of the " $y$ " is examined under the microscope there is a detail occurring at the bottom terminal, indicating that a struggle occurred thereat between the muscular factors, which were thus impelling the pen downwardly, and that factor against which it was bearing when thus operated; and this latter factor was the writer's thumb, which, in performing its functions in responsive cooperation, should curve inwardly towards the writer's palm. The staffs of the letters "p," as has been shown, were produced by the forearm movement, and have unusual length of downward projection, and in the production of which the thumb of the writer merely exercised its grasping func. tions without flexure; and in view of the resistance which the thumb made in the downward extension of the staff of the " $y$," it is very clear that its functions were very differently exercised than when forming the staffs of the letters "p." The detail illustrating this struggle, and want of harmonious action on the part of the thumb when resisting the incurving of the fingers to make the staff of the letter " $y$," is illustrated at Plate $V$ in enlarged representation, and is just such a one as would be produced by the thumb when resisting the incurving of the fingers towards the writer's palm, and which could only happen as it appears, by the action of the thumb and 


\section{ir 2 Analosis Mane for Determining Habit.}

fungers. This detail, occurring at the bottom of the letter "y." was found to be manifested in all signatures of the writer, and in typical character as to cause.

When the staffs of the letters "l" in "Cipperly" and "Haslehurst" of Plate I, are examined and compared with the "l " in "Cole," of the same signature, it will be seen that as the pen was moved to make the downwardly extended heary strokes of these letters, there are apparent differences, and evidences that they were not written by the same manner of holding and moving the pen. In the letter "l" of "Cole," the heavy down-stroke made by the pen is regular in its curve and slope, and was manifestly produced by the forearm movement of the writer, from the relative position of the pen-split appearing in its formation as before described. In the other letters "1" of the genuine signature considered in this connection, there is a bulge or incurve to the right in the down-stroke near their bottom terminal; and as thus appearing they indicated that as the pen was moved downwardly against the drawing inwardly of the thumb, that the latter instead of yielding to the finger impulse resisted it so as to produce the incurve or bulge to the right. This detail being considered with relation to the one at the bottom of the letter " $y$ " before described, becomes typical of the latter when connected with cause.

The fact is also apparent that the angularity manifested in the body-parts of letters as indicated in the signature illustrated upon Plate I (where the up-strokes from each letter intersect with the top of a succeeding letter, excepting that of the terminal letter), commences in the formation of the body-part of the second letter "p" of "Cipperly," and after making a pause thereat, the pen was raised from off the paper, and when returned by the writer to the latter to complete the word "Cipperly," thereafter the size 
of the body-parts of letters commence to decrease in vertical and lateral measurement until the terminal " $y$ " is about half the size of the body-part appearing in the second letter "p," and the same condition occurs in the production of parts of "Haslehurst," which have been considered as written in the same manner. This decrease in the size of the body-parts of letters where extending from left to right is common to all writing done by the muscular flexure of the fingers and thumb, when a series of letters extending from left to right are produced with the hand resting stationary upon the table. This appearance of writing so produced occurs from the fact, that these muscular factors operating by their flexure have to reach farther from the resting point of the hand to do the work, and consequently become more and more limited in movement as the reaching distance at which the writing is done becomes greater. The letters immediately in front of the hand will be larger than those farther off to the right, and the size of the let. ters will from necessity diminish as the distance which the fingers and thumb have to reach increases. In producing "Haslehurst" after writing "\& $\mathrm{H}$ " the letters "a" and "s" as before described, then another pause was made before commencing the letter "l," and the hand of the writer was moved to the right. Both of the letters "l" in "Haslehurst" show the incurve to the right caused by the want of adductor function in the writer's thumb, and from this point the body-parts of the letters commence to decrease in size as extending from left to right, just as they do in the production of a part of "Cipperly" as before described. The terminal of the genuine signature made in lineal connection with the final letter " $t$ " shows a detail wherein the pen is shown to have been caused to rotate in the finger and thumb grasp by the unyielding 


\section{Axalyis Made fur Deterianing Habit.}

lisposition of the writer's thumb. While this angularity. alpearing in the genuine signature could have been produced by the forearm movement of the writer so far as relates to its general appearance, it is very plainly apparent that it was not so written from the presence of details which establish it very positively as done by the flexure of the fingers and thumb. These details so appearing are considered as typical of each other, though differently manifested, and they originate from a muscular cause that is peculiar to the writer's hand. Having a thumb that was deficient in adductor function the writer could not move the pen by its flexure to produce curves in the body-parts of letters where tangential to the line on which the signature was written; and could only operate it when forming these parts of letters by carrying it up from the bottom of one letter to the top of another on an angle. All the details relating to a comparison between the curves appearing at one part of the signature in the body-parts of letters, and in the same parts of letters where made angularly indicate that the curves were produced by the forearm movement of the pen, and the angles by the flexure of the thumb and fingers.

The physical habit appearing in the genuine signature illustrated upon Plate I, was peculiar as regards some very unusual extensor abductor capacities of the writer's thumb, and as developed in the great length of the loops of the letters "h" and "l" in "Haslehurst." In the formation of these loops the up.strokes of the pen are projected upwardly with unusual length and in harmonious cooperation with the extensor capacities of the fingers, until in forming the down-stroke under the finger impulse, the writer's thumb as deficient in adductor function commiences to resist the finger movement, and thus forces into the staffs of these letters the incurve before alluded to. 
Thus while the writer's thumb was deficient in adductor function its abductor capacities were developed in an unusual measure.

As a summary of the foregoing examination and analysis, it appears that the writer of the genuine signature illustrated in fac simile upon Plate I, produced it under three differing muscular operations of the hand; one of them in which the pen was grasped as a prehensile act by the fingers and thumb, with the concavity of the pen facing to the right, held nearly vertical, and operated by the forearm movement, with the writer's hand as thus actuated sliding back and forth over the table to form parts of the signature; another condition of muscular coordination in which the pen was grasped by the prehensile functions of the hand, with its outer end slanting towards the right shoulder of the writer, with its concavity facing to the left, and operated by the forearm movement as before described to produce other parts of the signature; and still another method in which the pen was grasped by the prehensile functions of the fingers and thumb, and operated by the flexure of these factors to complete the remaining parts of the signature. These features of muscular cooperation constituted the habit of the writer in producing and giving to the signature of the latter such an individual character as was desired; and the details before named as accompanying its production appear as effects of such muscular coordination and incident to it, and there are no details or features suggesting any other.

Having thus analyzed the writing appearing in fac simile upon Plate I, and having ascertained the personal habit of the writer of it by the details appearing in the production of it, when it is compared with the signature illustrated in fac simile upon Plate II, the following conclusions are 


\section{ig Axalysis Made for Determining Habit.}

reached. Is to general appearance, and in signature expression there is very little difference between the two writings, and although not exactly the same in form, they are found to be as much alike in these respects as were a series of genuine signatures produced by the writer of that appearing upon Plate $I$, when compared with each other. I) isregarding the faded appearance of that shown upon Plate Il, and not knowing that one of them is a forgery, they must in that field of examination where resemblances and general appearances are alone considered, be regarded as the writing of the same person. While the loop of the letter "C" in "Cole" does not extend up through the top of the letter as in the signature shown upon Plate I, yet on examining a series of signatures written by the same person who wrote that appearing in fac simili upon Plate I, it was found that the letter " $\mathrm{C}$ " was as often made as appearing in the signature of Plate II as otherwise.

In connection with the general appearances of these two signatures, it will be remembered, as hereinbefore stated, that the writer of the signatures illustrated upon Plate I, could not pick out that appearing in fac simile upon Plate II as the simulated one, when the latter was placed among some thirty odd signatures upon checks signed and written by him and laid in a row with the signature upon each check so placed underlapping the one above it; and quite a large number of bank experts tried to do the same work as to selection, and failed. In view of these facts, the general appearances of the signature shown upon Plate II as a simulation was so well done as to defy detection in the ordinary field of examination, a fact which should be remembered when this disputed signature under a microscopic examination loses all the effect of resemblance; and when every feature which in 
general appearance caused it to look like the one from which it was simulated becomes established as the work of another habit, and the writing of a different person.

Having thus examined the signature illustrated in fac simile upon Plate II, with it considered as a disputed sig. nature, and having made a study of it in that field where many who assume to act as experts can only go to formulate an opinion as to the genuine or forged character of signatures; and finding nothing in the general appearances of the disputed signature to lead to the conclusion that it was not written by the same person who wrote the signature illustrated upon Plate I, to sustain this conclusion a general and preliminary examination of the signature in question should be made microscopically, for if both signatures are the writing of the same person, the resemblances found to occur in them will be found to have been produced in the same manner, and to contain the same details of personal habit.

On placing the signature illustrated upon Plate II under the microscope, and on using a low power of lens, it is found that the letters "C" of "Cipperly" and "Cole" were produced by first going over the paper with a lead pencil to line out the form of the letters, and afterwards the latter were written over with ink, so as to follow the pencil lines, and then again with ink to put on the shading or heavier parts of the letters. Continuing this preliminary examination it also appears that the rest of the word "Cipperly" was first lined out with a lead pencil, and then written over with ink; and the same conditions are also found to occur in the production of "Cole" and "Haslehurst," although the lead pencil lines have not been followed with accuracy in all cases where written over with ink, and more particularly in the loop of the letter "C," and the " 1 " in "Cipperly," as well as 


\section{1 is Axalysis of the Forgery as Illustrated.}

in the "a," the " 1 " and " $h$ " of "Haslehurst," where the ink does not cover the lead pencil outlining, and in some of which places it remains intact. In the letter " $\mathrm{C}$ " of "Cole," the leat pencil furrow remains, although the black lead has been removed by an eraser.

I inding this condition to occur in the signature illustratect upon l'late II, the question of its being a traced signature is suggested, and also that of comparative measurement to determine it. On applying a pair of measuring compasses to the pencilings appearing as palimpsest writing in the signature upon Plate II, and also to the same parts of the signature upon Plate I, they are ascertained to not only exactly coincide as to length and size, but the several parts of the disputed signature, when measured and compared with the genuine signature, are found to be the same in length and size, although where in inking in the pencilings the latter have not been closely followed, there are found to be some differences. Where the palimpsest, or underwriting, as determined by the pencil furrows made in the paper is measured, there is exact coincidence with that of the grenuine signature, and as shown by the calculations of Prof. Pierce in the Silvania Amn Howland will case the chance of such a condition occurring in habitual writing is too remote to be considered.

Thus it appears that the disputed signature illustrated upon Plate II is a traced signature, and further, that it was traced from the signature illustrated in fac simile upon Plate I, which was in the possession of the forger. But, to pursuc the investigation still farther, an examination microscopically should be made of the details of habit appearing in the disputed signature, to show their difference from, or their resemblance to, those appearing as manifested by the muscular habit of the writer of the 
genuine signature; and this is done to show that although a forger may make a picture of a genuine signature, the pen must be operated by the forger in an habitual manner, as the muscular functions of the simulator's hand have been educated to act to make an imitation, and which involves the production of details belonging to the simulator's habit, and which are different from those developed by the habit of the writer of the genuine signature.

It appears when these two signatures are examined and compared under the microscope (apart from the traced features of the forged one) that the details of physical habit manifested in the latter are totally unlike those of the genuine signature, as determined by the analysis set forth in the present chapter. These differences are well defined in their character, and in all their features indicate the employment of a physical habit of writing, radically unlike that developed in the genuine signature. Thus, the letters "C" of the forgery are clearly shown to have been made by the muscular flexure of the fingers and thumb, instead of with the pen held nearly vertical and operated by the forearm, so welldefined a condition of the writing occurring in the formation of these letters " $C$ " where appearing in the genuine signature. It will be remembered that these letters were produced in the genuine signature with the pen held nearly vertical in position, with its concavity facing to the right, by which the heavy shading of the down-strokes occurred below the transverse centres of these letters, and by which the pen so held and operated caused shading to appear by pressure in the up-strokes, and as being rigidly grasped by the prehensile functions of the fingers and thumb without flexure was caused to bear on the paper at an angle that was constant. In the forged sig- 


\section{Analysis of the Forgery as Illustrated.}

nature the ink writing was done by the slow process of going over the pencilings with the concavity of the pen facing the writer's palm, having its outer end slanting towards the right shoulder of the writer, and operated by the flexure of the fingers and thumb, to bear upon the paper at a constantly changing angle, with the splits of the pen running in contact, without spreading, to put shading into the up-strokes. Thus, while a resemblance is manifested in the letter " $C$ " of both signatures, this likeness was produced in a very different manner.

On examining the enlarged representations of the two signatures upon Plates III and IV, where they are shown in a measure as they appear when seen under the microscope, it will be observed that in the forged signature, upon Plate IV, that the letters " $\mathrm{C}$ " were touched up by the pen to complete the shading emphasis, for this second ink application of the pen overlaps the first lining out-done by the latter; in fact, as thus seen in the enlarged representation at Plate IV, it is evident that three efforts were used to produce the letters "C;" one of them when the signature was traced with a lead pencil; another, when first gone over with ink, and a third when the shading was applied, the latter application of ink giving to the writing, when magnified, a patchwork appearance. There are no evidences of any such work being done by the writer of the genuine signature when producing the latter.

In the writing of the connected letters "ipperly" of the forgery the pen was not lifted from the paper, and the down-strokes and up-strokes were produced by a continuous effort and movement of the pen; while in the same part of the genuine signature the pen was raised from off the paper at each termination of its up-stroke, as has been before described. In the letters "e" and "l" in "Cip- 
perly," of the forgery, well-defined loops are found to occur, and, in which respects, the simulator did not follow the tracing accurately. There are no loops in these letters of the genuine signature. In the formation of the letter " $y$ " of the forgery the pen is not raised from the paper until the latter is completed, and its details of production in other respects are different from those appearing in the same part of the genuine signature. In the latter the up-stroke from the preceding letter, "l," is carried up to where the first down-stroke of the " $y$ " commences, with the pen then raised from off the paper, and again returned to the latter to make the down-stroke so as to override the previously formed up-stroke, with the latter formed so as to intersect the first down-stroke about midway between its top and bottom. In the forgery the up-stroke of the "l" is carried up to where the first down-stroke in the body-part of " $y$ " is to commence, and the pen is then moved sidewise, and pressure applied to it, as moved downwardly, to form the first member of the body-part, without lifting the pen from the paper, and with the up-stroke of the "l" connecting with the first member of the " $y$ " at the top of the latter, instead of intersecting it about half way between its top and bottom.

In the production of the connected letters "ole" the writer of the forgery not only run away from the leadpencil tracing, but began the letter "o" with the concavity of the pen facing clear around to the right, so that the splits of the pen did not cross each other until after the bottom up-curve had been commenced, and although a good simulation of the letter "o" was made as to form, it will be easily determined, on a microscopic inspection, to have been produced by an entirely different operation from that employed to write the same letter in the genuine signature. It will be seen when examined as enlarged 


\section{Axhlysis of the Forgery as Illustrated.}

that the letter "o" of the genuine signature was made by the forearm movement, and with the concavity of the pen facing off to the left. which caused the splits to cross each other at the bottom of the curve, instead of after the curve had been macle. The letter "l" in "Cole," of the forgery, is shown as made with a well-defined loop at the top, and a continuous movement of the pen in connection with the up-stroke of the preceding letter; while there is no loop in the top of the "l" in "Cole" of the genuine signature, and in making which the simulator did not follow the tracing. It will also be observed that after making the letter "o" with the concavity of the pen facing to the right, it was, by the simulator, returned to its usual position, facing the writer's palm, to produce the succeeding letter "l."

In the forged writing of Haslehurst, the same differing detıils of habit occur as when the other parts of the genuine signature before described are compared with the forgery. These differences appear in the letter "h," which have been described as occurring in writing of the "l" in "Cole," and in producing which, as in the other in the other instances alluded to where the tracing was not closely followed. Another feature of prominent differcnce appears in the production of a loop at the bottom of the character " \&," which, as appearing, necessitated the adductor uses of the thumb in which the hand of the writer of the genuine signature was deficient. The letter "a" of the forgery is wanting in the well-developed details of habit manifested in the writing of the signature from which the simulation was made, and which have been described as having been produced partly by the forearm movement and the remainder by the flexure of the fingers and thumb, while in the forgery this letter was wholly produced by the continued flexure of the grasping 
factors. The letter "s" in the forgery has a well-defined loop at the top, while the same letter in the genuine signature is made without it, and in producing which the forger run away from the tracing previously made with a lead pencil.

The forger made a good fac simile of that part of the signature represented by "lehurst" so far as the general form and size of the letters constitutes a simulation; but in writing them over with ink the microscope reveals that the tracing was not accurately followed, although the correct form was lined out for the ink overwriting. The furrows made by the lead pencil where not covered by the ink are very plainly visible under the microscope, and some of them appear in the fac simile of the forgery appearing upon Plate IV. It will be seen on making a microscopic examination of the standards or staffs of the letters " 1 " and "h" of "Haslehurst," appearing in the genuine signature as made with an incurve due to the want of adductor function in the writer's thumb do not appear in the forgery as inked over, although they are very well lined out in the tracing. These letters " 1 " and " $\mathrm{h}$ " in the forgery have their top loops made with the ornate finish and copy-book style of the same letters appearing in the engraved representation of the firm name at the top of the check, and in which respects the forgery is not so good a simulation of the genuine signature; as where the tracing of the latter has been more accurately followed. While the general appearance of that part of the signature in which "lehurst" has been imitated is well calculated to deceive, when it is examined by enlargement all this resemblance disappears as the manner of writing it is compared with that of producing the same form, so clearly demonstrated as occurring in the genuine signature. Well-defined curves are found at the bottom 


\section{Analysis of tile Forgery as Illustrated.}

of all of the body-parts of letters in the forgery, features of writing which were not within the capacity of the writer of the genuine signature, who when writing by the flexure of the fingers and thumb was compelled to make angles at the bottom of the body-parts of letters instead of curves; and that these factors were used by the writer of the genuine signature in producing all those parts of the latter, other than those in which the forearm movement was employed, has been well established. From the foregoing description of the writing habit by which the forged signature was produced, and the differences manifested in it when compared with the one from which it was simulated, it will be readily understood that these differences occur from two very unlike methods of producing the same form in both of them, and that these differences are not manifested in their general appearance with enough significance to say from an examination without enlargement that the one is a simulation of the other and a forgery: This condition illustrates fully the necessity of determining the habit of the writer of a signature by microscopic examination, wherein the skill and observation of the expert can enter a field of research where simulation cannot go, and where only definite and accurate conclusions can be reached.

A very important and well-defined condition of forged writing is clearly illustrated by the preceding analysis, and as before alluded to as a feature of it; that a forger when imitating the signature of another must use his own writing capacities as they have been educated to cooperate and move the pen to make the imitation with any approach to resemblance. It appears in the case analyzed that with the form of the genuine signature correctly lined out upon the paper before him, the forger as necessitated to use his own writing habit when inking in the tracing, was 
under its influence, as asserted, compelled to deviate from the tracing, and impelled by its impulses to make prominent peculiarities of his own habit as features of detail. This forger so expert with the pen that he could produce in such close imitation the simulation of the check on which the forgery appears, could not follow the tracing, so strong was his individual habit in its tendencies when writing.

In this connection the question may suggest itself. Why cannot the forger imitate these details of habit which are found to occur in the genuine signature, and by which its individuality is determined? This interrogation is answered by the apparent fact which will appear in considering the matter, that the features determined as characteristic of the personal habit in the genuine signature are ascertained, and made visible under the microscope, and most of them are too minute to be imitated with a pen and ink even aided by their enlargement; and to this condition there is supplemented the other fact, that to imitate even such details, the forger can only operate the pen as his muscular functions have been educated to coordinate habitually, and this involves the production of details that are incident to its employment. In attempting to assume the habit of another when writing (were it possible) the intention must take from the writer all facile use of the pen under the assumption of an unusual way of operating it, and which if attempted would incapacitate the forger for imitating form with any approach to resemblance; and then as each individual habit is the result of physical causes inherent in the writer, these conditions cannot be assumed by another person.

The palimpsest writing or tracing evidence while very plainly visible under the microscope could not be seen or 
noticed without the latter when the signature was examined in an ordinary field of vision. Some of these evidences are visible where the forgery is shown in fac simile as enlarged at Plate IV, and in which the writing is seen as a transparency, and under which condition it was photographed to produce the fac simile alluded to. In some places the pencil tracings are seen intact, in others the pencil furrows have cast a shadow, which, by means of a strong side light, was caught in the photograph and macle to appear in the illustration.

In the analysis thus described and illustrated, a conclusion is reached, concerning the accuracy of which there can be no question, and although the work examined was the production of one of the most expert of forgers, and the details upon which the conclusion is reached are no more distinctly made apparent than will occur in most of the cases presented for examination; although but few of them will appear where the simulation was so well done, as the one illustrated, or where the forgery is more positively determined.

Connected with the examination of signatures under the system of analysis herein proposed and illustrated, there is suggested the inquiry, Can this accuracy always be reached? This question is fairly answered that it can be if the examiner is competent to make it, and to intellisently understand what the microscope reveals. The whole procedure and the correctness of all conclusions reached depend upon the examiner's ability to understand the cause of what is seen; how and by what means that which is seen is produced; and whether the resemblances which a disputed signature bears to an admittedly genuine signature are the products of the same physical cause in both, or whether these resemblances are merely simula. tions in the disputed signature, made by the muscular 
habit of another person. The field of examination proposed is, however, one in which inexperienced eyes may fail to see the effect of what the microscope reveals; and even when seeing it aright the examiner, for want of experience and education in this system of study, may be unable to trace what is seen to an individually developed cause, and consequently err in any conclusion reached. While this accuracy seems within the reach of competent analysis, the results of the latter are not always easily made plain to courts and juries. In some cases where the courts will permit it, the expert witness may fully explain upon what he bases his opinion, but it oftener occurs that the trial judge will limit the evidence down to a very narrow scope, and the mere relation of such facts as the jury can see; and where a forgery is well executed, the difference in general appearance between it and the genuine writing of the person whose signature is questioned, when compared, is small; this limit put upon expert evidence by the trial judge takes from the effect of the testimony all the benefit of an explanation of the facts upon which the opinion is founded. Juries are generally allowed to examine enlarged photographs of the writing, and sometimes to see it under the microscope, but even when so doing, what they see unexplained cannot be appreciated intelligently; and unless taken for granted as meaning something which the experience of the expert who gives the opinion understands, and which they, without such an education, could not be expected to do, that which the photographs show and the microscope makes visible is just as likely to be misleading as otherwise. The commonlaw rules of evidence have undoubtedly been evolved from the necessities attending their use, yet in cases of the kind being considered when rigidly enforced by the trial judge the whole effect of an educated explanation of the appa- 
rent facts is often prevented, and the opinion of the educated and experienced observer, who may have devoted a life-time to a study of the subject, is made to stand on the same level as the charlatan.

After having illustrated by analysis the method employed in determining the individual habits of the writers as relating to the two signatures examined, the method of proceeding to do similar work in other cases will be more clearly made apparent, and better understood by the process-steps therein employed, than by naming any special methods differing in character to be employed in other cases. In connection with the fact that the analysis of each person's signatures must be made suigeneris, and that there can be no rule for classifying the differences between the writings of different persons, it must also be explained and understood that there are certain conditions of the writing habit which become classed generically. Thus there are three well-defined methods of writing, into which are grouped the various and differing ways of exercising them, as they are developed in individuals. One of these consists in writing with the pen grasped by the prehensile functions of the hand, and operated by the forearm movement; another in which the pen is grasped by the prehensile functions of the hand and actuated by the flexure of the fingers and thumb; and still another, in which the pen is grasped by the fingers and thumb, and is operated by the flexure of these factors in connection with the use of the lumbrical muscles. When either of these generic conditions of pen movement are exercised by the writer, its use tends just as much to the development of personal details as the others, and these details, while showing the generic character of the writing in those respects being considered, will be strongly individual in their tendencies. 
The first step in making the aurarysis in view of these generic conditions is to ascertain which of them was employed by the writer, and afterwards to study the individual character of the details incident to their use; and the peculiar manner in which the generic method adopted by the writer becomes individual in character as to manifestation. While the forearm movement of the pen, or with the latter operated by the flexure of the fingers or thumb, or with the latter factors combined with the use of the lumbrical muscles constitute the three general divisions under which all movements of the pen when writing are accomplished, each person in adopting either of them habitually will employ that one of them which is best adapted to the physical organization of the writer's hand, or that of the latter and the forearm. Thus in the analysis made and illustrated, it was found that a peculiar condition of the writer's thumb as appearing in the writing of the genuine signature, forced into parts of the latter details that were indicative of it when used in connec. tion with the flexure of the fingers, and which compelled the writer, when desiring to make a particular form of capital letter, to employ the forearm movement of the pen to accomplish it; and that when using this generic method of operating the pen the writer was compelled to employ it in a manner which produced strong evidences of its individuality, and in using the forearm movement to write other parts of the signature than the capitals it was employed in a different manner, than when writing the latter, and produced details which determined the difference.

Referring to the analysis made and illustrated, it will be remembered that the forearm movements of the writer were determined as such from the position which the pen-splits occupied relatively to, and when operating 


\section{Writing Habit Generically Classed.}

to form parts of the letters, and as to how the concavity of the pen faced when writing, was ascertained by the position of the pen-splits as appearing at the top and bottoms of the staffs of letters, and this, as a conclusion, was verified by examining the relative depth of the furrows made by the splits in the downwardly-directed penstrokes as the concavity of the pen faced to the right or left. The vertical position of the pen when using one modification of the forearm movement was determined by the apparent fact that in the letter " $\mathrm{C}$ " of the genuine signature analyzed, the shading by pressure was found to occur below the transverse centers of these letters, and shading was also apparent in the up-strokes, which could only have been produced with the pen held nearly vertical, with its concavity facing around towards the right. These facts, and the additional ones demonstrated by the relative position at which the pen-splits crossed each other at the top and bottom curves of these letters "C," not only confirmed the fact that the pen was held nearly vertical, but that it bore upon the paper at an angle that was constant. Thus, the writer of the signature made the subject of analysis and illustrated upon Plate I, used the forearm to produce these letters " $\mathrm{C}$ " in a manner which was peculiarly individual to give to them the desired representative character. Such parts of this signature as have been considered as produced by. the flexure of the fingers, in connection with the thumb of the writer, were ascertained and determined to have been so made, from the manifested decrease in size of the letters where extending from left to right, and the character of the writing thereat where indicating that a part of it was produced directly in front of the writer's hand, and the remainder by reaching off from the resting-place of the latter to write with a limited scope of 
pen movement, and which necessitated a diminishing size of the letters and made the angularity more acute to the line on which the writing was done. In addition to these features there were also found to be manifested in this part of the genuine signature, details which indicated that the writer's thumb was a factor in producing them in other than prehensile functions. These facts determined the generic character of that part of the genuine signature, considered as done by the flexure of the fingers and thumb, and the details manifested in its angularity, the making of each letter separately, by raising the pen from off and then returning it to the paper, together with the very prominently manifested details appearing as forced into the writing by the want of adductor function in the writer's thumb, and how this condition of the latter affected and interfered peculiarly with the flexure of the fingers when operating the pen sustained the before-named conclusion.

These generic methods of operating the pen, as adopted by individuals, while they may cause the writing of persons to approach each other, they never lead to parallelisms in other respects in such measure of development as to be misleading, and the details of personal habit manifested in the writing of different persons produced by a generic method of operating the pen will appear with as strong evidences of individualism, as when races of men are considered Philogenetically and then specifically as to individuality.

From the foregoing it will be understood that the first step in making the analysis of a signature is to determine the method in which the pen was held and operated, and the succeeding one will be to ascertain from the details by which this fact is determined, the individual character of the latter, as manifested in their peculiarity, the latter 


\section{Individuatity of Generic Details.}

showing in what manner the muscular functions of the writer cooperated to produce them. A determination of these features will connect personal characteristics with the cause of their development, and enable the examiner to enter that labyrinth into which the investigation extends from this point, and wherein the individualisms of each person's writing become different from that of every other, and for the determination of which no rules can be established.

The foregoing analysis and its illustration makes manifest how and in what manner signatures may be exam. ined to ascertain the individual habit of the writer of them, and the means and process-steps to be employed in determining their simulation by another person. When, however, other than signature writing is made the subject of study, there are attending conditions which have to be taken into account, which do not occur when signatures are the subject of analysis, and these features and their connection with other than signature writing, are made the subject of the next succeeding chapter 


\section{CHAPTER VI.}

SIGNATURES COMPARED WITH THE ORDINARY AND OTHER WRITING OF THE SAME PERSON.-THE CIRCUMSTANCES ATTENDING THE PRODUCTION OF SIGNATURES, AND THOSE UNDER WHICH WRITING OF THE SAME PERSONS OTHER THAN SIGNATURES ARE DONE.- IIODIFICATIONS OF THE SAME HABIT OF WRITING.-THEIR CAUSE AND CHARACTER ILLUSTRATED AS APPLIED TO THE JUNIUS LETTERS.-DISGUISED HANDWRIT. ING AS COMPARED WITH HABITUAL WRITING OF THE SAME PERSON.-DIFFICULTIES ATTENDING THE EXAMINATION OF DISGUISED HANDIVRITING, AND THE IDENTIFICATION OF THE WRITER OF IT BY COMPARISON.-UNDER WHAT CONDITIONS A PERFECT DISGUISE OF A PERSON'S HANDWRITING MAY BE ACCOMPLISHED, AND THE DIFFICULTIES OF DOING IT. - THE DIFFERENCE BETWEEN MODIFICATIONS OF A WRITER'S HABIT AND DISGUISED WRITING EFFORTS OF THE SAME PERSON.-DISGUISED HANDWRITING AS OCCURRING IN THE CASE OF "CADET WHITTAKER," AND THE PROCESS STEPS EMPLOYED FOR ITS IDENTIFICATION EXPLAINED AND ILLUSTRATED.

In the preceding chapters the writing habit, as exercised in the production of personal signatures, has been more importantly considered and discussed, than where employed in the writing of individuals other than signatures; and for the reason that the character of the latter much more frequently becomes a subject of inquiry and investigation, as to their being what they purport to be, and it only occasionally occurs that the ordinary writing of individuals becomes the subject of dispute as to its personality; and which, when happening under such con. ditions, does not attain, as a matter of investigation, the importance attending the determination of the genuine or forged character of signatures. Generally the question 


\section{3t Mritixg Other Than Signatures.}

as to the individuality of writing otlier than signatures becomes a matter of legal adjudication in criminal cases, although it sometimes becomes important in others; and occasionally, as a matter of curiosity for study and conjecture, such as was made during the latter part of the last century in England to ascertain who was the author of the Junius letters, by their penmanship.

While the same general methods apply to the study of the ordinary writing of a person which are employed in the examination of signatures, to ascertain the personal habit of the writer; between the production of the two writings by the same person there may be, and very often is manifested, an habitual difference; that is, a person may usually write his or her name as a signature in a manner that renders it different from the habit used by the same person in other than signature writing; when having by practice cultivated a method which gives to the signature produced by it such a form and appearance as will suit the fancy of, and be within the muscular capacity of, the writer.

This manifested intention to give individuality and peculiar expression to their signatures, induces many persons to introduce into their composition pen movements and forms of letters which are not common to their ordinary writing, and with the intention seemingly to make their personality more prominent than if written as they write every thing else. The signatures of the late F. E. Spinner, so well known from their appearance in fac simile upon government bills, are marked examples of this kind: and although each signature written by him, apart from fac simile representation, was the counterpart of every other of them in habitual detail, they were quite unlike his ordinary writing; and the latter was as uniform in its details as to muscular coordination as was the writ- 
ing manifested in his signatures. This condition was conspicuously manifested in both kinds of writing done by him, and each modification of habit was clearly shown to be within the compass of the same muscular factors differently exercised. It will be understood that a peculiar muscular coordination may be operated in a variety of ways as to the form of the letters produced by it, all of which will be indicative of the muscular factors doing the work, which, in the one case, will take on such character as to demonstrate what the same factors can do, when differently operated, as sequences of such a capacity. Thus a person having an unusual measure of adductor and abductorability developed in the muscular function of the thumb, when combined with a highly organized development of the lumbrical muscles of the index and second finger, would, when writing ordinarily, manifest this capacity with emphasis, and its presence would establish the ability of the writer to produce in all lateral movements of the pen, to the right or left, prominences and peculiarities in a personal signature which would be typical of the cause, while the apparently different writings of the same person would in fact be indicative of the same muscular coordination exercised to produce differing forms of letters.

The individualism manifested in the writing of persons other than their signatures, while conditioned by a differently exercised capacity of the same muscular func. tions, is usually more emphatically shown in the latter than in the former, as there is an object in making the signatures prominently characteristic of the writer, while in the production of the ordinary writing of the same person there is no such incentive, it being done by the coordinate action of the muscles in a manner that best suits the convenience and comfort of the writer. This 
signature expression is generally accomplished with stronger evidences of habit than the other writing of the same person, and although often with prominent measure of difference when compared with the latter, there being no rule as to its appearance or the measure of its development. Some persons write their signatures as they do all their other writing. Differing from the latter in their ideas of making their signatures peculiarly individual in character, others will form the capital letters of their signature by a method of holding and mov. ing the pen which is unlike that used in their ordinary writing, and produce the remainder of the signature with their usual effort, while others will write the whole of their signature in a manner that is totally unlike their ordinary writing in appearance, just as fancy may have suggested a form and style that suits the individual, and which the latter has adopted and made physically habitual by practice. This condition so often occurring establishes the rule which should apply in making analysis of signatures to determine individual habit, that only signatures should be used for purposes of comparison, unless it appear that the writer of the disputed signatures usually wrote the latter as when writing. ordinarily and without signature expression.

This general condition attending the comparison with signatures of ordinary writing of the same person, necessarily includes the execution of both of these kinds of writing, though considered separately to be within the compass of the writer's muscular eapacity. This also necessarily determines each of these manifestations of it as produced under the operation of the same causes which give to it individuality in other respects. Although each of the forms appearing as modifications may differ from each other in a measure, any unusually 
developed functions, marked peculiarity or muscular incapacity of the writer's hand will incorporate into the modified writings executed by it details, that will be typical of it.

The attending circumstances under which signatures are written become quite different from those surrounding the production of ordinary writing of the same person, both as regards the mental processes suggesting the act, as well as the execution of it. When the hand is engaged in writing a letter, more time is required in its employment than in the momentary effort in signing a note, check or other writing of like character, and consequently a method of holding the pen may be adopted for signature writing, which could not be continued for any length of time without labored effort and attendant discomfort. Not only this occurs, but the mind of a person writing a letter is occupied with the subject of and composition of the latter, and as to how it is written is hardly a matter of cerebration. The ordinary writing of individuals is usually accomplished as a mechanical or reflex act, with the forms of the letters making such an approach to standard styles as is within the capacity of the writer's habit. When writing a signature with the intention to give it expression, and by a different method of moving the pen, the mental suggestion not only prompts the performance of the act differently from that attendant upon the use of the ordinary habit, but designates a way of doing it.

The ability to modify the writing habit from the ordinary habit in the production of signatures with personality, also extends in some instances to other than signature writing, and in which the ordinary writing is made the subject of modification, although not for the purpose of giving it individuality. When this faculty is developed, 


\section{$13 S$ Tine Alility to Modify the Writing Habit.}

it will generally be found to occur with those who use the pen a great deal, and who to a certain extent may change the pen-grasp to relieve a too long-continued strain upon one set of muscular factors. Occasionally scriveners who have to use the pen continuously for hours, to relieve the constant and long-continued strain upon the muscular functions of one pen-grasp, are able to change it to another, if within the writer's ability. Thus after using the index and second fingers in connection with the thumb until this condition wearies the muscles, a change may be had by passing the pen up between the index and second, or between the second and third fingers, either of which changes of pen-grasp, and the movements consequent upon it, will produce details in the writing, which will be characteristic of that modification of the writer's habit thus employed. These modifications of personal habit may each of them be distinctive as to general appearances, and measurably so as to details; or they may be typical of each other, but when occurring under either of these conditions of production, they will take on such a character as is consonant with the muscular organization of the writer's hand, and be within the peculiarities of its muscular capacity. Thus a person who in writing changes the position of the pen relatively to the finger-grasp must still use the thumb in the same manner in either instance, and the individual details produced by the latter will be typical of each other in both writings. So where in the organization of the writer's hand, the second finger is more facile and more directly responsive to monition than the index finger, all modifications of the writing produced under such conditions will be typical of the cause, although the factors as so organized may be differently operated.

It will be understood from the foregoing that the indi- 
viduality of signatures and the personality manifested in them, is much more easily determined than that occurring in other than signature writing of the same person. This arises from the fact before explained that individuals generally write their signatures with the intention to give them personal character and appearance, and this procedure leads to their like production; while in the writing of persons other than their signatures, the only influences tending to the establishment of individuality are those unconsciously evolved, without any especially directed mental monition as to the appearance of personality, or characteristic parallelism.

This condition of writing other than that appearing in signatures, while necessitating the use of the same processsteps in making analysis of signatures, surrounds the work with more attendant difficulties in the one case than in the other. In examining signatures a few of the latter will answer the purpose of standards for comparison, as it rarely if ever occurs that people will modify their signatures to any extent in appearance or detail; but in examining the ordinary writing of persons the question of intentional modification has to be taken into account, and the examiner should have before him enough writing of the person whose pen work is in question to cover all possible modifications of it. While true that all modifications of the same person will embody details that will be typical of the muscular organization producing it, to insure accuracy this condition should be verified by an examination of enough of the writing, to ascertain whether the writer had the capacity to adopt modification, and if so, whether such of the latter embodied the features of the writing in question as to habitual tendencies.

The ability developed in one person to write with two 
habits neither of which is properly a disguised effort, and with one of them a modification of the other, is strikingly apparent when the writing produced during the last century under the nom de plume of Junius is compared with that of Sir Philip Francis, as both writings are illustrated in fac simile in a book entitled "Handwriting of Junius," by Chabot, edited by Twistleton, and published by John Murray of London in 1871 .

To assume that a writing produced with more than usual uniformity, and without wandering effort, is a disguised writing would seem to be the application of a misnomer to it if so entitled; this seems to be the only feature on which to reasonably disagree with Mr. Chabot, in view of the fact that if a person has the ability to write habitually in two different ways, neither of them can properly be called a disguised writing. It very frequently happens that persons will write so as to give the letters the usual copybook form as regards slant and ellipticity, and the same person will also write back-handed as it is termed, and with both of these methods habitual. The form of the letters in the fac simile writing illustrated in Chabot's book is all there is on which to form an opinion, but the evidence of form all tend to verify Mr. Chabot's conclusion that the Junius Letters were written by Sir Philip Francis.

That there are two conditions of the writing habit of one person apparent when the writing of Francis is compared with that of Junius is very plain; but another conclusion is also clearly indicated, that one of these habits is a mere modification of the other, from the manifesta. tion in both writings of very strongly and peculiar developed muscular conditions of the writer's hand. All the features of form upon which Mr. Chabot bases his conclusions, and designates as parallelisms become manifested 
as these demonstrative muscular functions peculiar in character appear in both writings, and which, though exercised differently in the two habits, in both give typical evidence of cause.

These writings as presented in fac simile in Chabot's book can only be made the subject of examination as to the form of the letters, and their connection, and not microscopically as to details by which the form was produced, from the absence of the originals, excepting where, without the microscope, the direction of pen movement is clearly incident to individual muscular function as to character and kind. Understanding that when writing with the flexure of the fingers and thumb by which the pen is grasped (as manifestly both of the writings being considered were produced), all movements of the pen made to the left are caused by the impulse given to it by the second finger, which when grasping it bears upon its right-hand side; and that all the curves and lateral movements of the pen to the right are caused by the adductor functions of the thumb, any prominently manifested muscular peculiarities which are unusually developed as to capacity in an individual, will in either of these pen movements before named, or when the second finger and thumb coordinate to move the pen inwardly towards the palm, show in the writing evidences of this emphatic development.

That the writer of the Junius papers possessed both of these peculiarly individually developed second finger and thumb capacities is very clearly manifested in the fac simile writing of Chabot's book ; and while this is true of the writing over the signature of Junius it is equally true of the writing of Francis as therein illustrated; although when writing as Junius while the demonstrative adductor thumb capacity is apparent all through the writing the 
second finger emphasis only appears occasionally when the writer lapses from one habit into another, from Junius to Francis.

The two habits of the same writer, as manifested in the fac simile writing thus illustrated, are produced by two different methods of holding and operating the pen, to give to them a modified appearance. The writing designated as that of Junius has less slant or slope than that designated as the writing of Francis, so far as the staffs or standards of letters are compared; and there is more modification when the writings are compared in this respect, than when the down-curves to the right, and the lines connecting the letters in the two modifications, are compared. It will also be observed that when writing as Junius the body-parts of letters are made smaller than when writing as Francis, thus indicating the employment of less flexor function. With the individually manifested adductor capacity of the writer's thumb, made apparent in both writings, and the individually developed second finger function appearing only, characteristically, occasionally in the Junius writings, it is very clearly apparent that some other factor than the second finger was prominently employed when writing as Junius, and this factor must have been the index finger, from the reduced measure of flexure occurring in forming the body-parts of letters; although at times the second finger would break in with a lunge to the left in precisely the same manner when writing as Francis. That the writer of both of these fac similc representations was the same person so far as the same can be determined from the fac similes in Chabot's book, seems very clear, and that when writing as Francis the second finger cooperated with the thumb, and when writing as Junius the thumb and index fingers were the prime factors of muscular impulse. 
The fact that some persons may write with modification and measurable variation of appearances being established, the conditions under which it is done should be well understood to distinguish such efforts from those made by persons to dissimulate or disguise their writing. Modifications of the writing habit manifested by the same person are, as has been shown, generally typical of the same muscular causes, and when occurring in the same person, they are usually as much habitual in one modification as another. Hence neither of several modifications in the habit of the same writer can be considered as a disguised or dissimulated effort, but each of them, where existing, must, as a practiced acquirement, be deemed an habitual one.

As in the examinations of signatures made to ascertain their individuality, the use of the microscope is essential, its employment becomes equally important when examining other than signature writing with the same object in view. The process-steps are very much the same as regards both kinds of writing, and relate to a determination of the writer's habit, from the manner of producing the forms of letters, the details indicating the pengrasp, and the pen movement manifested in the writing, in connection with such peculiarities as the individual muscular coordination of the writer may necessitate the appearance of. As the writings of persons other than their signatures vary much more in appearance than do the latter from each other, a greater amount of time and study is required to properly make an analysis of them. The number of forms and the details accompanying their production is much less when making an analysis of a signature than where the general writing of a person is the subject of examination; and the range into which the latter must extend is more varied and complicated than 
in the other. There must be constantly kept in view the fact that the ordinary writing of persons is not intentionally given any of the representative character apparent in signatures, and that all the features which appear in other writing than the latter which will cause it to differ from that of every person, must be those necessitated to be so manifested from the effects of individual habit and produced involuntarily. As a sequence of this condition, parallelisms, or differences occurring when comparisons are made, will require more study for their determination than if the writing was intentionally produced with representative features.

The capacity to modify the ordinary writing, as occurring in different persons, has been explained, and in connection with this faculty as a conditioning cause, there must be taken into account when making comparisons, the tendencies which surroundings may have upon the production of the writing, whether apparently written hurriedly or carefully, under the effect of excitement or when composed, together with all the other before-named contingencies affecting the writing of signatures. While accuracy is within reach in most examinations made to determine the author of other than signature writing, by comparison, the conditions surrounding its production are at times so complicated as to put a limit upon the value of any opinion or conclusion reached in regard to it. This condition, when existing, will be found to occur where the writing was so influenced or affected in character by surroundings, as to obliterate all positive evidence as to its individualism. Thus, a person writing with a defective pen, or one which would catch in the paper when held as the writer was accustomed to use it, and which compelled the writer to adopt an unusual method of holding it, to be able to write at all, would, if present as interfering 
causes, render the determination of individual habit not only difficult, but such influences might be so intensified in effect as to render it impossible, although such cases would be the exception, rather than the rule as ordinary handwriting is usually produced.

Where, in other than signature writing of individuals, an effort is made to disguise the personality of it by doing the writing in an unusual manner, greater difficulties are encountered when endeavoring to ascertain its individuality by comparison, than where as in habitually produced signatures there is manifested the intention to give to the writing a personality; or, as in other than signature writing, where the details of individual habit are found to occur with small measure of emphasis. When checks, notes, deeds, or wills are signed, the signatures thereto, as has been detailed, are written in the ordinary manner of producing them, and seemingly as if to represent the person making them. They are so written at the dictation of habit for the purpose of giving them a personality. So, when other than signature writing is done, its habitual tendencies of form and detail will appear in it with more or less emphasis, but when the latter writing is accomplished by a studied effort to make it appear as unlike the natural habit of the writer as possible, new complications enter into the examination and analysis of it, by which accurate results relating to the determination of the writer of it by comparison, are made more difficult to reach than in the other instances named.

In the analysis of disguised handwriting instituted for the purpose of ascertaining the author of it by determining the habit of the writer, one of the usually attendant difficulties is the obtaining of proper standards for comparison. The representative character of a series of individually written signatures carries with it in appear- 


\section{How Disguised Writing Manifests Itself.}

ance and detail a peculiarity of definition having welldefined habitual parallelisms, while in the examination of other than signature writing the standards used for comparison vary in their manifestation of habitual details, and consequently there is necessitated in some instances the examination of such a number of standards as will include all possible variations of the suspected writer's habit, for the field into which the examination extends is not one of simulation, but just the reverse of the latter, and comparison in some cases can only be properly made when all the modifications of a suspected writer's habit are before the examiner for study, and such standard specimens are at times difficult to obtain. Where, however, the writer is not an adept with the pen, a single specimen will often answer the purpose.

Where the intention to disguise a person's writing is made, there is usually no difficulty in determining its character as such, from the writing itself, but to connect its wandering unhabitual manifestations (if well done) with the conditions appearing in other writing used as standards for comparison, with enough definiteness to identify the dissimulator, is a proceeding attended with difficulty, and particularly so where the examination and comparison made is limited to the general appearances and form of the letters alone, and independently of how procluced.

The capacity to disguise writing depends largely upon the ability of the individual attempting it to keep constantly present in the mind the intention, and if the writer can do so with every movement of the pen, personal habit will not appear in the dissimulation, so far as its general appearances are concerned; and the identification of the writer of it by comparison with other writing of the same person will be rendered impossible in this field of exam. 
ination, thus establishing a condition in which seemingly a perfect disguise of a person's writing may be accomplished. Knowing, however, that any peculiar condition of the writer's hand as to muscular function will necessitate the production of details which are typical of the latter, whether the writer produces usual or unusual forms of letters, it generally happens that all erratic or eccentric movements of the pen in disguised writing from necessity will be of a character connecting their production with the physical habit of the writer of them. While what seems a perfect disguise in general appearances of a person's writing is possible, the probability of its occurrence is rendered doubtful from the fact so well established by experience, that the writing habit when acquired by practice, and made peculiar in each individual from physical causes is persistent in its habitual tendencies, and although the effort be made to adopt an unusual method of writing for dissimulation, the habit in which the writer has been educated to write (unless the simulation consist of but few words) will unconsciously assert itself in spite of the efforts made to avoid its appearance. In this connection the difference between what have been described as modifications of individual habit, and the attempts to dissimulate in writing and prevent the presence of individuality in it, should be understood as meaning in its application in the one instance, the production of writing in an unhabitual way; and in the other, as referring to modifications of the same writer constituting differences, but habitually manifested. These conditions as thus explained should be kept in view, when considering the effect of the intrusion of what is habitual when writing with dissimulating inten. tion.

The differences between habitual modifications of the writing habit of an individual, and the efforts made to 
avoid the appearance of personal characteristics originates from the unlike conditions under which they are accomplished. When writing habitually the work is either that of a mechanical or reflex capacity, exercised without thought as to how it shall be done, or by the copying of a usual form of letters present in the mind from the operation of memory. When the effort is made to disguise the habit of the writer by the production of unusual forms of letters, the intention will direct the hand into a wandering movement, wherein the letters produced are not only unlike in themselves, but are accompanied with details of form which are destitute of parallelisms; that is, if the writer be capable of keeping the intention to dissimulate constantly operative, and this peculiarity of disguised writing is by these features very positively determined as such. In habitual writing the details will all be typical of the muscular coordination, producing them as a matter of parallelism ; in dissimulated writing (if successfully done), the writer in avoiding habitual tendencies must assume unaccustomed conditions of writing, and in the production of which the pen from necessity will be operated with a wandering irregularity.

When dissimulation of the writing habit is attempted, the act calls for the assumption of an unusual way of holding the pen in operating it to form the letters, or an habitual way of operating it for the production of unusual forms of letters, either of which conditions necessitates a struggle between the assumed method of holding and moving the pen, and that in which the hand has been accustomed to write. The usual and habitual way of forming letters gives to them parallelisms in all like movements, and these the dissimulator must avoid producing by making them different, without any accustomed guidance as to what this difference shall be, excepting that it must be 
unlike that ordinarily produced by the writer. If the object can be kept constantly coupled with intention, so far as the writing of a few words are concerned, the general appearances of the writer's habit may be avoided; but where the act requires a more extended or prolonged effort (as in the writing of an anonymous letter of some length), it rarely occurs that the dissimulator can prevent the tendency of reverting to habitual tenden. cies. These intrusions of personal characteristics will not usually appear at the commencement of the writing, nor generally at the beginning of words when the intention of the writer is more carefully kept in mind; but as the writing progresses towards its end, when the hand of the dissimulator becomes weary of the restraints imposed by the unnatural and assumed movement of the pen, it lapses into habitual tendencies in spite of the effort made by the writer to avoid their appearance. Disguised handwriting, as thus considered, cannot consist of that which is habitual, as has before been discussed in connection with the production with the famous letters of Junius, and to so name them would seem to be improper, and as much so as it would be to assert that because a person usually writes his or her signature differently from their ordinary writing, that the signature is written in a disguised hand.

Such disguised handwriting as calls for study and examination to ascertain the author of it, generally appears in anonymous letters; and so widely different are the influences which prompt their appearance that no rule can be established, nor any principle be considered, as to the effect which motive may have had in their production. Unlike the temptation to forge signatures for gain, such of them as necessitate legal consideration have their inception under the influence of revenge, 


\section{Motive Features of Disguised Writing.}

hatred or jealousy. When written under the prompting of either of these motives, the composition of the letter is apt to employ the writer's attention quite as much if not more than the intended dissimulation, and the apparent evidences of personal habit will crop out in the writing. By far the larger number of this class of cases will occur uncler the promptings of the before-named influences, although they occasionally appear in what are termed "blackmail" character, but in whatever shape or uncler what circumstances they are produced or written, the ability to dissimulate, as existing in different persons, shows a wide range of variation. Persons who write with a mechanical or reflex capacity are more likely to revert to habitual tendencies when attempting the dissimulation of their writing, than persons who write with a copying effort. In fact, the writer who uses the pen but little, is often better adapted to put a deceptive and prominent measure of distortion into the forms of letters than one who writes with a reflex or mechanical effort, and who has been taught, as a matter of manual practice, to make representative forms.

One curious feature of anonymous letters as they occur in the experience of experts who have occasion to examine them, is the fact that females as a general rule will write the most vulgar ones, and their production in this con. dition is not limited to the social position or standing of the writer. It frequently occurs when jealousy prompts their appearance that females surrounded by refinement and having good social position will write them in language the most obscene. Whether the vulgar emphasis is given to such letters to throw off suspicion, or originates under the influence of passion morbidly excited and uncontrolled by the restraints of surroundings is a ques. tion. When anonymous letters are written by men in 
a majority of cases the reverse is found to be the rule, and the composition will exhibit a tendency to give to the writer a position of consequence, and to magnify his standing and influence, as if seemingly to impress upon the recipient of the letter the importance and power of the writer.

From the conditions surrounding the production of disguised writing, and its character as before explained and described, it will be readily understood why it is more difficult to determine the writer of a specimen of it with the efforts of the latter directed to make the dissimulation as unlike the habitual writing as possible than where sig. natures are the subject of analysis; and wherein either habit or simulation are employed to make them look alike; and yet the process-steps to be employed are about the same up to a certain point. In the case of signatures the examination relates to the manner of producing the form of letters, whether exercised habitually or in simulation; in analyzing disguised writing the manner of producing an unhabitual form by an habitual method of holding and moving the pen is one of the important steps, and this is' supplemented by a determination of the relation which a distorted form of letters has to an habitual one of the same writer when produced in each instance by the same muscular coordination differently exercised. When, however, the dissimulation is attemp. ted by adopting an unhabitual method of holding and moving the pen, then the analysis must go further and grope for facts to find what there is, if anything, manifested in the habitual writing of the suspected person which is indicative of peculiarity in the physical organization of the writer's hand, which would become operative in the assumed pen movement to give personal character to it; and thus connect the disguised writing 
with that of the suspected person. Where the attempted dissimulation is poorly done, and strong evidences of habit are apparent, there is but little difficulty in reaching a conclusion, but where the disguised writing shows a wandering movement of the pen that is destitute in parallelisms of form to connect the production of a disgruised writing so done with the habitual writing of a suspected person by the features of physical habit manifested in both writings, accurate determination is difficult of attainment.

Understanding that an unusual and unhabitual method of holding the pen must produce appearances in the writing which will be totally unlike those of the same writer using the pen in an accustomed manner, the only features which will occur to connect the disguised efforts with the usual writing of the same person in general appearance will occur where unconsciously the writer reverts to the usual and habitual manner of producing the same form of letters in both writings. If the dissimulator is able to keep the object constantly coupled with intention, this tendency to lapse into the production of habitual forms may be avoided so far as general appearances are concerned, and the detection of the individual. ity of the writer in this field of examination be prevented. While this condition confronts the examiner when considering the measure of accuracy to be attained by the analysis, and the difficulties of reaching it, the probabilities of such positive dissimulation ever being accomplished are made very remote, when the chances of its occurrence are taken into account; but if happening with the examination limited in its application to the pictorial effect of the writing, the chances of reaching accuracy in determining the author of the dissimulated writing by comparison are rendered very doubtful. While these 
conditions confront the examiner they are not always beyond the reach of competent analysis even where the writer is enabled to avoid the production of the usual characteristics of individual habit, so that the pictorial effect of the dissimulation is in general appearance totally unlike the usual writing of the dissimulator, for it very often happens that the wandering efforts of the latter will be of a character that are positively indicative of, and necessarily the product of some peculiar muscular condition of the writer's hand, and which in the dissimulation are but exaggerations in emphasis, of features that are typical of the same cause appearing in the ordinary writing of the dissimulator.

All persons who write, as has been already explained, do so by an individual muscular habit which is peculiar as to capacity in each person, and when learning to write, some of the more prominently developed muscular factors which do the work are inclined to do more than their proper share of it, by making peculiar emphasis in such movements of the pen that they actuate, and which by practice and the restraints of instruction, the writer has been taught to avoid producing, when following copybook forms of letters, but of which muscular peculiarity rudimentary traces remain in the habitual writing though toned down in their emphasis by practice. With this condition prevailing in the writing habit of a person, when a wandering movement of the pen is attempted, and the accustomed method used for such a disguising effort, the writer will usually revert to the production of these same features, with varied measure of emphasis, which by practice and the restraints of instruction have been made less demonstrative in the habitual writing of the same individual. Although these forms thus exaggerated, when used for dissimulation, will show varied meas- 


\section{$15+$ How Habitual Detalls Will Appear.}

ure of prominence in their manifestation they can usually be traced to, and determined as typical of the rudimen. tary traces appearing in the habitual writing of the dissimulator. Thus where in the writing capacity of a person the second finger is more facile than the index finger it will from its position, relatively to the thumb in grasping the pen, give emphasis to all movements of the latter directed to the left hand in forming parts of letters, and although this condition may not be demonstratively shown in the ordinary writing of the individual, yet with the restraints which practice and the effect of instruction removed, the wandering form of letters resulting from the dissimulating effort will be emphatically in the direction which such a muscular peculiarity would institute, and be typical of it. So a person having a thumb that was peculiarly deficient in adductor or abductor function, of which evidences appear in the ordinarywriting of an individual, would, when writing with dissimulating intention, make wandering forms of letters that would be typical of such a muscular condition of the writer's thumb.

While these features will occur in the best dissimulation of the writing habit, in connection with a peculiar organization of the fingers and thumb of each individual as to muscular function, similar tendencies are manifested when the pen is grasped by the prehensile functions of these factors, and actuated by the forearm movement with dissimulating intention. With the pen thus held and operated, any manifestation of peculiarities which are indicative of an individual muscular coordination, and which can be determined by rudimentary traces in the ordinary writing of a person will generally appear in typical character with exaggeration in the dissimula. tion made by the same writer.

The most difficult disguise of the writing habit to 
The Ability to Will and to Do-Its Effect. i 55

analyze for the purpose of identifying the writer of it by comparison, is that kind which is produced by the substitution for the habitual thumb and finger movement of the writer, of an unhabitual forearm movement, or the reverse of these conditions as to educated habit by the use of the one for the other. But, even writing produced under either of these conditions by the substitution of the unhabitual for the habitual generally exhibits a tendency to revert to the making of habitual details, in spite of the effort used to avoid doing so. Theoretically it would seem possible to produce, under the operation of either of the assumptions of unusual and unhabitual methods of using the pen, a perfect disguise of the writ. ing habit, yet experience establishes the fact with those making a study of such subjects, that it rarely occurs, particularly where there is enough of the writing to tax, for any length of time, the dual mental effort of keeping the disguising intention operative, and at the same time giving thought as to what is to be written.

When writing habitually in the production of a letter the pen work requires no more mental effort than does the act of walking, and the mind of the writer may be wholly employed in the subject-matter and its composition, but where trying to write unhabitually the intention must be kept constantly in mind, to make the dissimulation, and at the same time the writer must be thinking of what is to be written. It will be readily understood in this connection that writing done as a reflex capacity necessitates the production of forms without any mental effort as to how they shall be made, and what is written, as the subject is the only tax upon the mind of the writer so employed. When the intention is to disguise the writing, not only what is written, but how what is written shall be done, become imperative conditions to the per- 


\section{Whex Results of Axalysis are Doubtful.}

formance of the act, thus developing two different phases of mental employment which must operate simultaneously and in opposition to the tendency and influence of the practised habit to intrude its peculiarities.

Although these conditions are present with more or less emphasis in all efforts made to disguise personal habit in writing, and there are in most cases coming up in the experience of those who are called upon to examine writing of this kind, evidences which lead to an accurate identification of the writer's habit by analysis and comparison, yet it is a field where the most experienced are in some cases compelled to give modified opinions as to positiveness, or no opinions at all. Unlike the examinations of signatures which are purposely written to represent individuality with habitual characteristics disguised, handwriting occasionally presents conditions, wherein there is but little shown to connect the author of it by comparison with other writing of the latter, although such a manifestation would be the exception, rather than the rule in regard to it. When the writer has peculiar conditions of muscular coordination which are demonstratively apparent in the usual writing of the same person, these features will extend into all dissimulating efforts of such a writer, and be indicative of it; but, where the writer is enabled to use the pen with but little evidence of discordance or peculiarity, the best efforts of dissimulation are accomplished, and the determination of the author of the writing by comparison is made difficult.

From the foregoing description of the causes attendant upon the production of dissimulated writing, and the phenomena appearing in it as the effects of disguised intention, it will be understood that there can be no rules established for the classification of the appearances accompanying it, excepting in a general way; from the fact that 
there are as many methods of disguising writing as there are persons who do it. It will also be apparent after under. standing the conditions under which dissimulated writing is produced, that while the same process-steps which are used in the analysis of signatures so far as the use of the microscope is concerned must be employed, the examination from necessity must extend into the study of wandering forms in letters, and the trend into which the tendency to make them with emphasis is manifested, and from them to ascertain by what muscular coordination they were produced, and the relation which they bear to the muscular habit developed in the writings used for comparison. Although these features require the same study as do the variations of personal signatures (in the fact that they are never written twice precisely alike), in disguised writing the study becomes more difficult and complicated from the fact that personal signatures are always typical of each other in habitual delineation, and in disguised writing the wandering pen movements are produced with intentionally formed differences, extending into a field where to ascertain their individuality (which if determined) will be found to occur, cloaked over with appearances intended to prevent recognition as to personality.

Although it is impossible to designate a method to be followed in making an analysis of dissimulated writing in all cases that will occur, from the fact that each individual manifestation of it differs from that of every other, nevertheless there are certain generic relations which dissimulated writing bears to habitual writing of the same person, which have been made apparent in the author's experience, which in their presentation may suggest to others making such examinations a method of procedure where the analysis extends beyond, and becomes more 


\section{Features thit he Generically Habitual.}

complicated than the process-steps employed in the examination of signatures. These features, where generic conditions are manifested, occur when any of the muscular functions of the writer's hand, emphatically peculiar, are employed to produce eccentric or erratic forms of letters with dissimulating efforts. Thus, where in the habitual writing, when clone by the flexure of the fingers and thumb, there are manifested evidences of an emphatic development of adductor thumb function, the trend of the wanclering efforts would be in the direction of its action, with the employment of this function as a factor of impulse. Hence the exaggeration or wandering features of the dissimulation would largely occur in all the movements of the pen to the right. In the bottom curves of letters, the lines connecting the letters, and their spacing, where the abductor functions of the writer's thumb had unusual extensor capanities as developed in the habitual writing, the erratic movements occurring from such a muscular function would appear in the great length of the staffs and loops of letters, and their distortion. If the writer's thumb had limited adductor functions, its extensor capacities would be limited, and the trend of this function would be to reduce the letters in size, as compared with the habitual writing of the same person. If in the writing done by the flexure of the thumb and fingers, the writer had any unusual development of the lumbrical muscle of the second finger, with the latter a factor of impulse in dissimulation, the exaggeration and wandering would be manifested in making all the curves in the writing to the left distorted by an unusual rotundity.

This condition appearing in all disguised writing establishes the fact that the intentional efforts made to produce it by giving to the letters an unhabitual form, 
mainly originates in connection with the use of those muscular functions of the hand or arm which are individually peculiar to the writer; and although they may, when recognized, appear rudimentarily in the details produced by them as toned down in emphasis by practice and the restraints of instruction in the habitual writing, or demonstratively therein, they will be in either instance of their development, the muscular functions exercised to give character and direction to the improvised distortion of form appearing in the letters.

From this condition of dissimulated writing it will be understood that there is much more to be studied, and the examination of it to determine its individuality must extend farther and into much more complicated surroundings than where signatures are the subject of analysis. This extension of the area wherein the examination must be made is one where the most experienced will go cautiously. The difficulties attendant upon the determination of what the writer could or would do under the operation of the same muscular coordina. tion when dissimulating, from what was done by the same person when writing habitually, at times causes the most experienced to grope with the matter presented as one walking in the dark. The tracks made by a man having a peculiarly deformed foot, when walking shoeless upon the sand, could be readily identified as to their personality; but if shoes were put on the feet it would be impossible to determine the tracks as made by the same person unless there was something in the gait of the latter which was demonstratively peculiar, and which gave character to the tracks in either instance.

To more fully explain and make clear the method employed, and the connected process-steps used in making an analysis of disguised writing for determining the 
author of it, a celebrated case is selected for illustration and description; and this is chosen more particularly from the fact that the conditions surrounding the examination were such as to put expert evidence to a very severe test. The case alluded to is the well-known one of Cadet Whittaker which occurred at Vest Point in I880. It will be remembered in connection with the latter, that Whittaker alleged that an outrage had been perpetrated upon him by the cadets who were hostile to him on account of his African lineage. He produced a note of warning which he claimed to have received prior to the time of the alleged outrage, but the receipt of which he did not acquaint the officers of the post until after the wrong claimed to have been inflicted on him was done. From other circumstances connected with the case, the authorities at West Point believed that the claimed outrage was his own work, and that he must have written the note himself, and in consequence of which a Court of Inquiry was ordered to investigate the matter. As the handwriting of the note claimed to have been received by Whittaker is the only feature that is important herein, the other circumstances connected with the case are omitted.

To furnish writings for comparison with the note of warning each of the cadets to the number of two hundred and forty-seven, were required to write with a pencil a sentence, the composition of which was arranged to contain the words and letters occurring in the note of warning, which were repeated several times. These slips of paper containing the standard writings of all the cadets were numbered by the recorder of the court, and a record kept by the latter as to the writer of each of them. To prevent communication between the experts employed in the examination as to the characteristics of any of the specimens or standards, the numbers were changed for 
each expert, so that neither of the latter among the several employed knew the writers by the same numbers as the others; and the experts were compelled to examine the writing at different times and separately, and without conference or communication with each other. Thus it will be seen that the experts could not know the writer of any of the standards. These two hundred and forty seven specimens of the cadets' writings, together with the note of warning, were placed before each expert for examination and report. These proceedings as thus instituted were well calculated to put expert evidence on trial as to its accuracy, and serve to fairly contradict the untruthful statements made by a leading New York city physician, who, in a lecture delivered by him, stated that the experts in the Whittaker case were led to believe that Whittaker wrote the note of warning, more from the influence of surroundings, and that of persons interested in such a conclusion, than from any thing appearing in the writing. In giving an account of the manner in which the examinations were conducted before the Court of Inquiry at West Point, the author states the facts as they occurred in his own experience, and from what he learned after the trial was concluded, from the other experts engaged in the case, upon whom the same conditions of examination had been imposed.

This note of warning was written with a lead pencil, and including the address upon the envelope contained fifteen words. There was but little matter to disguise, and the chances of perfect dissimulation of individual habit were on this account made more easy of accomplishment. The analysis made and conclusions reached as hereinafter given, were mainly taken from the memoranda made by the author at the time of his examination of the subjectmatter at West Point. From reading newspaper accounts 
of the alleged outrage before going to the Court of Inquiry, the sympathies of the author were strongly with Whittaker, assuming the statements published to be true concerning his treatment; but the examination was so arranged that neither sympathy nor sentiment could exert any influence as a factor in prejudicing a conclusion either one way or the other; and so fairly was the trial conducted that the author did not know until the Court of Inquiry announced its decision, that the writing which he had picked out from among those given him for compari-
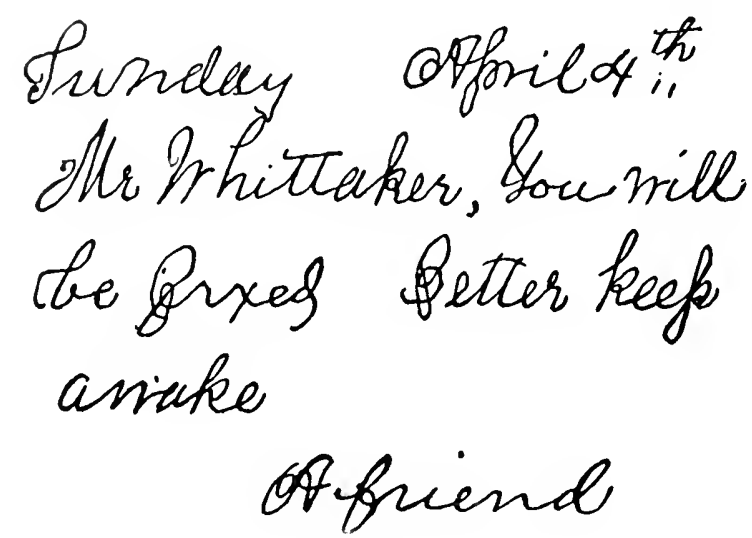

PLATE IX - Fac simile of the pretented note of warning.

son, and identified as written by the writer of the note of warning, that was done by Whittaker himself. In the subsequent proceedings when Whittaker was tried by court-martial at his own request, and the same conclusion was reached by the latter that was rendered by the Court of Inquiry, as regards the authorship of the note, the experts examined the writing as in other cases.

The note of warning which Whittaker assumed to have received is correctly represented by the fac simile appearing upon Plate IX, and the examination of it, as made when Whittaker was being tried before the Court of 
Inquiry at West Point, developed the following conditions: A preliminary inspection of the note led promptly to the conclusion that it was written with dissimulating intention, from the wandering movement of the pencil appearing in the initial efforts in the production of the following letters: the " $\mathrm{S}$ " in "Sunday," the " $\mathrm{M}$ " in "Mr.," the "Y" in "You," the "B" in "Better" and the letter " $\mathrm{b}$ " in the word "be." In all the instances named the commencements of these letters showed wandering efforts. Not only this was ascertained, but it was manifested that the intention to dissimulate was better kept in mind when commencing words than when finishing them, a very common condition of disguised writing; for it was very plainly apparent that in the terminals of all words, as well as the production of other than capital letters, the pencil seemed to have been operated habitually and quite uniformly. It was also found that the letters " $\mathrm{tt}$ " in "Whittaker" and "Better" were produced with uniform characteristics of form, and the same conclusion was reached as to the letters " $\mathrm{p}$ " in "April" and "keep," and also the letters "a" in "Sunday," "Whittaker" and "awake." These parallelisms suggested habitual tendencies from their uniformity. After making this preliminary examination of the note and what appeared to be wandering and dissimulating efforts, and such features as had parallelisms of personal habit, the examination was continued with specific relation to the muscular coordination of the writer, and the conclusion was reached that not only all the parallelisms indicated that their production was accomplished by one peculiar coordination of muscular factors; but that all the wandering movements were within the compass of the same habit and indicative of it. To understand how such a conclusion was reached will be better understood by explaining the method 
employed for determining it and in what manner the few words constituting the note indicated it, and to do which the relation which the pencil grasp and its movement bears to the appearances produced should be explained.

It will be understood that with the pencil grasped by the thumb, the index and second fingers that the position of the pencil relatively to these factors, as thus holding and operating it, is as follows: The second finger bears against the right-hand side of the pencil, and the latter is a rigid and non-elastic implement having no yielding nibs like the pen. The index finger bears mainly upon the top of the pencil and the thumb upon the left-hand side of it. Under this condition of grasp and operated by the flexure of these factors where the pencil is forced emphatically to the left in forming letters, it is so moved by the second finger as a factor of impulse, and this bears upon the right-hand side of the pencil; and, when directed demonstratively towards the right, the pencil is thus operated by the thumb as a factor of impulse, which, in so doing, bears upon its left-hand side; and when the pencil is moved inwardly toward the palm of the writer's hand, it is so actuated by the incurvating operations of the fingers and thumb acting together. Applying these rules, as regards the pencil movement and grasp to the parallelism occurring in the writing of the note, it led to the conclusion that the second finger and thumb of the writer appeared to have done nearly all the work, as factors of impulse, and that the features of emphasis appearing in the letters which indicated this condition also established the fact, as a condition of the writer's hand, that the index finger was deficient in function as to flexure, and yielded to that more positively manifested in the second finger for all movements of the pencil in which inward flexure was required. Not only this feature 
was strongly apparent in the writing, but it was found that the second finger of the writer had unusual functions in connection with an abnormal length of thumb, and these indications were determined and made apparent by the following features occurring in the writing of the note.

On an examination of the letters "p," occurring in "April" and "keep," which were found to be habitually alike, it appeared that the staffs or standards of these letters were made to have broadly rounded loops at the top, indicating a strong second finger movement towards the left, and a corresponding movement in the upcurve, wherein the thumb, as a factor of impulse, directed the pencil from left to right with emphasis. The lower ends of the staffs of these letters "p," where below the line on which the body-part was written, were found to have broadly rounded curves, produced by a movement of the pencil from right to left, which could only have been produced by the second finger as a factor of impulse, and the same condition appears as applied to the top loops of these letters. The staffs of these letters " $\mathrm{p}$ " and their accompanying loops were ascertained by an examination of the connection manifested where function gives character to form, to have been produced by the peculiarly individual action of the writer's thumb and second finger. This conclusion was reached from the character of the pencil move. ment as to direction, and emphatic measure of capacity when actuated by the thumb impulse to produce the upstroke forming a part of these letters; the coming in of the second finger impulse when directing the pencil movement to form the top of the upper loop in rounded curve to the left with emphasis; the movement of the second finger to the left when forming the rounded curve at the bottom loop of these letters " $p$;" and the coming in of the thumb impulse to make the up-stroke of these bottom loops; in 
all of which movements of the pencil, the thumb and second finger of the writer are shown to have emphatic devel. opment of individuality. These features all of them manifest a characteristic capacity to move the pen horizontally when operating the latter at some distance above or below the line on which the writing was done, and could only have been so produced by the flexure of these factors with the pencil grasped by them at transversely opposite holding points, and this indicated an abnormal length of thumb as a peculiarity of the writer's hand.

These same conditions of muscular habit described as appearing in the formation of the letters " $p$ " were also found to occur in the letters " $\mathrm{d}$ " and " $\mathrm{f}$;" while the letters "a," "e," "w," "i," "l " and " 11 " in their form were compatible as to production by the same peculiar muscular functions. After tracing these apparently habitual parallelisms to the muscular cause which made them peculiar, an examination was made of the wandering movements occurring at the beginning of words, and the conclusion reached in regard to them determined that these disguising efforts were all of them typical of the same individually peculiar thumb and second finger movement which has been described as producing those parts of the writing already considered. Thus the irregular loop at the top of the letter "S" in "Sunday" the initial irregularities manifested in "Mr," "be," "fixed" and the staff of the letter " $B$ " in "Better" were at the time of making the examination determined as typical of the same form appearing in the staffs of the letters " $p$ " before described, but made irregularly, with wandering intention. These prefixes all of them are made in lineal connection with the letter to which they are appendages, and each of them consists of a reversing cyma-recta curve made more pronounced than where produced habitually 
in other parts of the writing. The curls appearing at the bottom and left-hand side of the capital letters "A " on a microscopic examination were found to have been made, and added to these letters as an after thought, and the same was found to have been the case with the top loop on the standard of the capital letter "Y" in "You," but even when this appendage was subsequently put on, the added loop by examination was found to have been made by the same second finger and thumb movement as was employed in forming the initial curve in the letter " $f$ " of "fixed." Thus the features of disguise became typical of each other, and of those parts of the writing wherein habitual parallelisms were apparent. The top lobe of the letter "B" in "Better" found its counterpart in the initial movement producing the " $f$ " in "fixed," while the staff of this letter " B" was found, as explained in another con. nection, to be but a modification of the muscular pen movement employed in producing the letters "p."

The tops of the capital letters "A " appeared to have been made by the second finger and thumb movement of the pencil, from the emphasis given by their horizontal extension to the left at their commencement, and from the parallelisms apparent in the production of these letters in connection with the same conditions as occurring in the top loops of the letters "p," the top of the letter "f" in "fixed," and the top lobe of the letter " $B$ " in "Better" were considered to have been made habitually. This same muscular coordination was found to have been employed in making the standards of the letters "d" in "Sunday," "friend," "fixed" and in the letters "k." All the broad curves of letters where tangential to the line on which the writing was done, gave evidence of a highly developed adductor function in the writer's thumb; and the character of the loop of 
the letter " $h$ " in "Whittaker" and the length of its standard or staff, indicated in its production an unusual extensor thumb-capacity and function.

From the apparent fact that the thumb and second finger did most of the work as factors of impulse, and that the index finger did not manifest itself distinctively, and from the manner in which the centrally located and rounded loops of letters such as were found to occur at the junction of the two lobes of the letter "B" in "Better," the " $\mathrm{f}$ " in "fixed" and in the body-parts of the letter " $k$," it was plainly manifested that the writer's thumb must have extended down along the pencil toward its writing point to a position that was transversely in line with the engagement which the second finger made to grasp it, thus indicating that the writer's thumb had abnormal length, and which necessitated a better coordination with the second, rather than the index finger.

After having reached the foregoing conclusion as to the physical habit of the writer manifested in the note of warning, the examination of the two hundred and forty. seven specimens of pencil writing submitted as standards was entered upon, and at the end of the second day's employment in the work of analysis and comparison, one of the specimens was selected as having been written by the same muscular habit that appeared in the note of warn. ing. The one identified was numbered I 89 , as designated numerically for the author's use, and this specimen is reproduced in as close fac simile representation as possible upon Plate No. X, but owing to the fact that it was written with a pencil, and had been handled a great deal at the Court of Inquiry, and subsequently at the trial by Court-Martial, before being photo-lithographed for use at the latter, portions of it that were almost obliterated had to be restored by retracing. While this is true as regards 
Case of Cadet Whittaker.

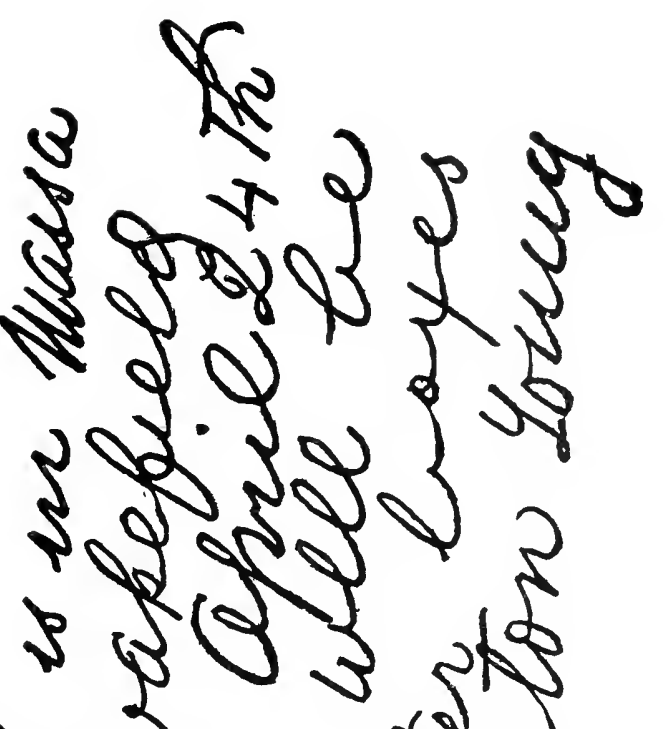

ए 300

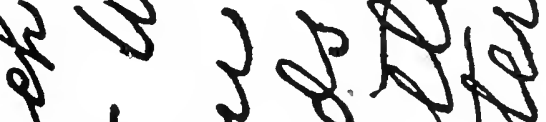

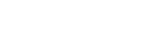

3 y 30,50

2502,5

2 की 8

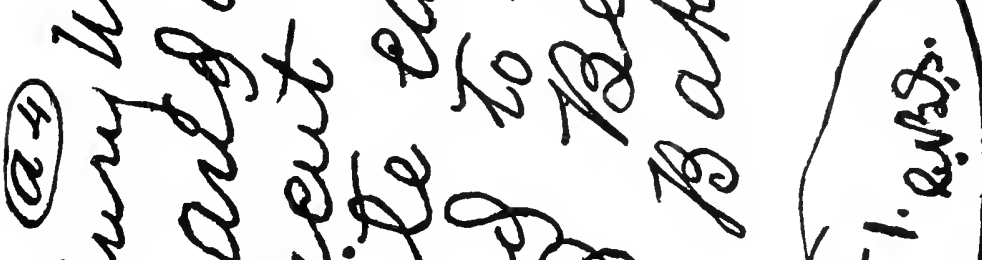

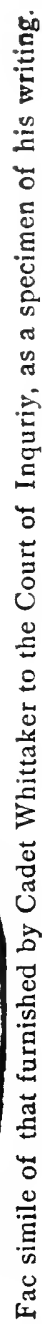

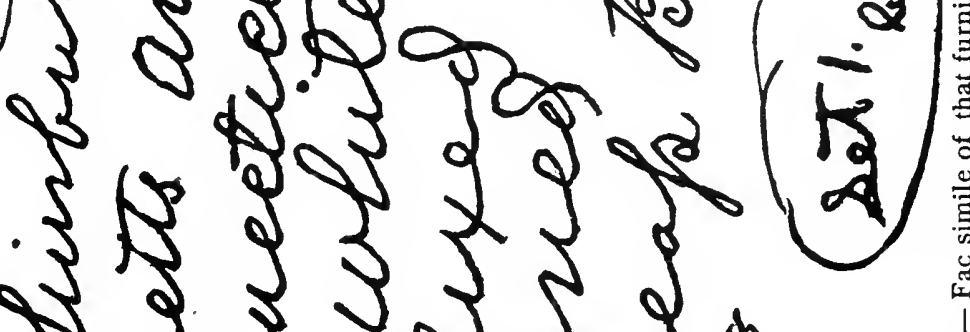

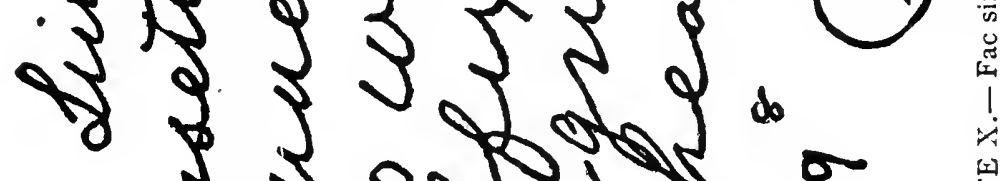

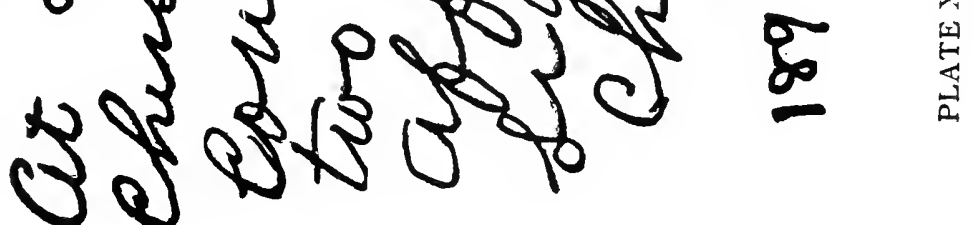


a portion of the specimen, the greater part of it is correctly shown in fac simile. An examination of this slip made at the time the investigation was being conducted by the Court of Inquiry indicated that a much better disguise of the writer's habit appeared in it than was found in the note of warning.

Desiring to secure accuracy, and to avoid all possible chances of error in every way, after deciding that this specimen No. I 99 was written by the same muscular habit as that which appeared in the note, the author addressed a letter to the Recorder of the Court asking for some more writing of the person who wrote $S_{9}$, and at the same time requesting that it be sent mixed with other specimens of cadets' writing which had been done before the date of the alleged outrage. In reply to this request there were sent several hundred sheets of writing, which had been cut from out the books in which the cadets took down notes of lectures in pencil. From the latter the author selected four sheets containing writing which the author positively identified as having been written by the same person who wrote the note of warning. Having, as the author thought at the time, so thoroughly ascertained the physical habit of the writer of the note, and desirous of knowing whether or not the pen-writing of the same person could be determined from what this physical habit would necessarily make apparent in it, a request was again sent to the Recorder of the Court for pen-and-ink writing of the cadets, with some of that written by the writer of No. I 89 mixed with the speci. mens furnished. A large number of sheets of such writing were returned in answer to the request, and from among them the author selected two sheets of pen-andink writing, which, in his opinion, were written by the same curiously-organized hand that had written the note 
of warning. In each instance the specimens selected as the writing of the person who wrote the note of warning (as the author afterward learned) were the writing of Cadet Whittaker.

Among the two hundred and forty-seven specimens of writing used for comparison, there were two of them which in some of their features of form made an approach in resemblance to the writing of the note; but on a careful examination it was found that these resemblances were produced by a different habit of writing. On an examination of the specimen illustrated in fac simile designated as No. I89, and shown upon Plate X, there was but little in its appearance that could connect the writer of it with the production of the note, excepting the evidences indicating that the same muscular coordination had been employed to produce the latter and this specimen. There were some apparent resemblances occurring in the appearances of the letters " $d$, , " $p$," "B," the " tt's," and the letters " $k$," but it was the manner in which these resemblances were produced, which indicated their identification as the work of the same person. It was the peculiar muscular character of the writer's hand which gave to these features their individualism. When disguising the forms of letters appearing in the writing of specimen No. I 89 the broad sweep given to the pencil movement where forming the bottom curves of letters tangential to the line on which the writing was done, indicated the same highly developed adductor thumb functions, so also did the lines connecting the letters; while the broad sweeps of the pencil to the right or left in forming the tops of letters, in connection with the individual manner in which the thumb and second finger cooperated to make the top and bottom loops, and the interior loops appearing in the body-parts of the letters "f," "p," and "B," were features 
that could not be mistaken as to identity or the origin of their personality.

From the analysis of the writing thus illustrated and described, it will be understood that it was not wholly due to the fact that the writing of the note and that in specimen No. I 89 was mainly done by the second finger and thumb of the writer that the individual habit of the writer was determined, but from the manner in which these factors did coordinate peculiarly, that the personality of the habit was established; and that the abnormal length of the writer's thumb necessitated its cooperation with the second rather than the index finger. As it afterwards appeared during the trial that Whittaker wrote with the pencil passed up between the index and second finger, and there grasped by the latter and the thumb, the author's conclusion as to the condition of the writer's hand formed from a study of the writing produced by it was fully substantiated.

The question will be suggested in connection with the analysis and conclusion reached in the Whittaker case, whether it is possible to attain the same measure of accuracy in the examination of disguised pencil writing generally, and the answer must be, that it is not. The conditions surrounding the production of the Whittaker note were just such as favored the accurate determination of the writer's physical habit; and these related to the organization of the writer's hand, which in actuating either the pen or pencil gave such strongly marked evidences of individual character to its movements, and in such measure of emphasis, that their production could not be avoicled by the efforts of dissimulating intention. The generic character of the muscular functions of Whittaker's hand being determined by his habitual writing, and its individuality by the emphasis in which these generic 
functions were exercised, as is usually the case, the forms introduced by him for dissimulation, were all of them made to appear as wandering efforts occurring in the same direction of pencil movement, wherein the generic functions became specialized through the organization of the writer's hand. Such individually demonstrative conditions of muscular function when writing are not common, but when occurring they are easily and positively determined. The finding of the Court-Martial sustained that of the Court of Inquiry, which held that Whittaker wrote the alleged note of warning himself. When in a succeeding chapter wherein lead-pencil writing is made the subject considered, the difficulties attendant upon determining the inclividuality of the writer of it will be made more clearly apparent. The experts employed in this case were A. Southwarth of Boston, Daniel T. Ames of New York, and the author, the two former concurring in opinion with the latter. Dr. Piper of Washington, and one Simpson, an ex-bank teller from Brooklyn, N. Y., acted for the defence, and the latter were aided with ability by David N. Carvalho of New York city, as expert counsel. 


\section{CHAPTER VII.}

LEAD-PENCIL WRITING, AND ITS COMPARISON WITH PEN-ANDINK WRITING OF THE SAME PERSON. - WHAT DETAILS OF HABIT APPEAR IN PEN-AND-INK WRITING WHICH DO NOT OCCUR IN LEAD-PENCIL WRITING, AND THE CAUSE. - THE USE OF A RIGID PENCIL AS COMPARED WITH THAT OF ELAS. TIC PEN AND ITS EFFECT AS APPEARING IN THE WRITING.-SIGNATLRES WRITTEN WITH A LEAD PENCIL HAVE IN THEM ONLY SUCH FEATURES OF HABIT AS ARE SUSCEPTIBLE OF IMITATION, AND THEIR DIFFERENCE IN THIS RESPECT FROM INK-WRITTEN SIGNATURES. - THE RESEMBLANCE THAT THE PENCIL WRITING OF DIFFERENT PERSONS HAS, AND WHY IT OCCURS. - THE EFFECT WHICH THE CHARACTER OF THE PENCIL MAY HAVE IN THE APPEARANCE OF THE WRITING PRODUCED BY IT.- TRACED SIGNATURES MADE WITH A LEAD PENCIL, AND THE SIMULATED CHARACTER THEY BEAR TO THE GENUINE IF WELL IMITATED.

Writing which is habitually produced with a lead pencil will show in its appearance features that are peculiar to the individual doing it, and these personal characteristics are sometimes very prominently apparent. They have their origin from the operation of the same causes which manifest habitual details when the pen is used, although they are fewer in number than when the latter is employed and they are not so strongly indicative of personality, while the field in which they appear and wherein determined is more limited in scope. The features which give individual character to lead-pencil writing mainly relate to the form of the letters and their connection, wherein these manifestations are rendered peculiar from the influences of the same muscular causes which are operative when either of these writing implements are used, but the individual peculiarities in form 
thus appearing will be modified as produced by the pencil when compared with those of the same writer made with a pen, though in a measure typical of the same cause. Apart from these resemblances of form there is little else to depend upon when examining lead-pencil writing to ascertain the habit of the writer from its comparison with other writing of the same person done with a pen. As a sequence of this condition, the field available for the identification of personal habit by analysis becomes limited, when the one kind of writing is compared with the other. This limit, as will be readily comprehended, originates mainly from the differing character of the two implements used in producing the writings, one of them the pen, having an elastic point made with nibs or splits by which the varying density of the lines formed with the pen flexure indicates where and through what muscular means the emphasis of shading is given to the letters, and by the details consequent upon their movement, the position in which the pen was held, and from the manner in which the curves are produced determines the muscular coordination by which the writing is accomplished. With the use of the lead pencil there can be little if any shading or emphasis produced by an elastically applied pressure, with the appearance of the details of habit consequent upon it, neither can the manner of holding the pencil be accurately determined from the writing any farther than is shown by the forms of the letters, and the indications belonging to the latter where demonstratively peculiar to the writer of them.

All the minute and positive details of personal habit which are produced when writing is done with a pen, and which characteristics are indicative of the individual measure of control, as existing between the capacities to will and to do, are not generally present when the writing 


\section{iz6 Pencil and Pen-and-Ink Writing Compared.}

is done with a lead pencil in place of the pen. The former when employed in writing bears upon the paper with a constant and steady pressure, while the pen with its elastic split-points operates with a constantly varying pressure, and thus a person who is compelled to write tremulously with a pen may not manifest this tendency in the least when writing with a pencil. The lighter pressure upon the paper necessitated when using the former, is not required when writing with the pencil, and the latter may be rigidly grasped to bear upon the paper with sufficient pressure to give steadiness to its movements; and thus tremulousness manifested in the pen-and-ink writing of the same individual will not appear in the writing of the same person done with a pencil. These and other differing conditions occurring between writing produced with a pen and that done with a pencil, narrows down the field in which examinations may be made, to put a limit upon the value of all conclusions that may be reached, when pen-and-ink writing is compared with that done with a pencil to establish its individuality. When habitual penand-ink writing is compared with pencil writing of the same person, resemblances in form and general appearance will be usually found to occur, but when examining the two writings so produced, to establish whether or not they are the writing of the same person, these like features cannot ordinarily be depended upon alone, and particularly if the pencil writing in question relates to signatures, in which they are so easily within the reach of simulation. When these features of form and general appearances are demonstratively peculiar in their personality, and indicative of some strongly manifested muscular coordination that is intensely individual in character, such features enable the examiner to identify the habit of the writer, whether using either pen or pencil, excepting so far as relates to 
Pencil and Pen-and-Ink Writing Compared. i 77

the question of their simulation, and their production with a pencil by another person.

When lead-pencil writing is compared with other leadpencil writing, to ascertain its individualism as to habit, while the field available for examination and study is somewhat greater than when pencil writing is compared with pen-and-ink writing, still this condition does not furnish the same measure or kind of developed facts upon which to base an opinion as when pen-and-ink writings are compared with each other. Most of the details appearing in the latter are distinctively indicative of personal habit, and but few of them occur in pencil writing; while those apparent in the latter will relate to the form of the letters, and their connection alone. This deficiency in the appearance of personal details occurring as a condition of pencil writing is caused by the differing operation of the two implements by which the writing is produced, and which has been before described. In view of this fact, when an examination of a signature written with a pencil is made to ascertain its genuine or forged character by comparison with other signatures, none of the latter should be used as standards for the purpose excepting those produced with a pencil, for the reason that should there be any marked peculiarity or signature expression in the ink-written signature, the use of the pencil to produce it might so modify or change its appearance as to be misleading.

Signature writing and other writing than the latter done by the same person with a lead pencil will bear about the same relation to each other in their individuality as when the pen is used, that is, a person writing a peculiar signature with a pen, when producing one with a lead pencil, and writing both habitually, will usually follow the same general form in the one instance as the other, although from the differing character of the implement 


\section{i ts Eraect of a Rigin Pexcil axi Elastic Pen.}

used the one produced with a pencil will ordinarily appear as a modification of the other in form, yet the measure of difference may be such as to give to the one produced with the pencil an unlike appearance when compared with the other. The pen-and-ink writing of persons other than signatures, when compared with that done with a pencil, will usually show the same generic differences that their signatures do when those written with a pen are compared with those produced with a pencil.

This generic difference will be manifested in the effect caused by using a rigid pencil to make certain forms of letters instead of an elastic pen, and the manner in which the same muscular coordination will individually act under the changed character of the implement used. In illustration, if a writer habitually using a pen with a heavy pressure in the down-strokes of letters to produce shading, should, when writing with a pencil, still continue this shading pressure, the tendency would be to make all the down-strokes of letters where the shading would occur with more rotundity of form and curve to the left than would occur when the pen was used under the same pressure, and this would constitute a generic difference between the pen and pencil writing of the same person as to cause, and a manifestation of what will occur where the use of the pencil tends to modify the form of letters produced by it.

Signatures written with a lead pencil do not ordinarily show the details of habit available for comparison through which positive conclusions are reached, and the personal characteristics of form appearing in the letters composing a signature so produced are susceptible of a very close imitation by tracing and otherwise. These features of a signature make up its general appearance when written with a pencil, and give to it the pictorial effect it presents 
to the eye, but they are too easily simulated to be depended upon alone in formulating an opinion as to the genuine or forged character of the writing. Pencil sketches of objects in perspective are very easily made, and the much more simple act of producing a pencil copy of a signature by the use of the same means will be readily understood and appreciated. These conditions, present in all cases were signatures written with a pencil are to be examined, necessarily limit the approaches to accuracy in reaching a conclusion as to the habitual or unhabitual character of the writing appearing in a ques. tioned signature so produced, and although they do not render the attainment of correct deductions impossible, they do establish the general rule of doubt in such cases, and the effect of which must be taken into account in estimating the value of all opinions based on such examinations.

While this general rule applies to, and should not be overlooked, there are exceptions to it which should also be considered. That the simulation of signatures written with a lead pencil may be so well done as to defy detection is possible from the fact that the pencil does not detail anything in the signature but what is within the range of successful imitation, yet when the attempted simulation is poorly done, and where the forger produces form of letters that are not only unlike those of the standards, but resemble those which are habitual with the simulator; or where some peculiar characteristics belonging to the standards are ommitted in the disputed writing, and other forms which are not habitual with the writers of the standards are used in their place; or where it is aparent that in the writing of the standards there are certain peculiarities of form which are forced therein from physical causes, and which do not occur in the disputed signa- 
iso Habitual Detalls of Pen and Pencil Work.

ture; in such cases reasonable accuracy may be had in formulating an opinion when the examination relates to the comparison made between signatures written with a lead pencil.

Where the lead-pencil writing to be examined is other than signatures, and when the question of simulation cannot come into the case as a matter of investigation, reasonable accuracy may be had at the hands of competent examiners in determining by comparison the writer of an anonymous letter, or other writing; and the same is true as regards the identification of the writer of dissimilated or disguised writing done with a lead pencil; and particularly when the writers show in their habitual writing done with a pencil any marked peculiarity of muscular coordination. It is also true that while many of the details of habit consequent upon writing with a pen, do not appear in writing done by the same person with a pencil, the latter from its construction and adaption also produces details by which an habitual form of pen writing is modified in an individual manner from the rigidity of the pencil and given features that do not appear in the pen-and-ink writing of the same person. As a sequence of this condition, to insure accuracy in making examinations of pencil writing to determine its individuality, only the latter kind of writing should be employed as standards.

In all lead-pencil writing there is a tendency to resem. blance even when produced by different writers, and this sameness in appearance is other than that occasioned by the representation of the letters in their alphabetical character; and it occurs from the effect consequent upon the use of the pencil as a writing implement. These approaches in general resemblance originating from the employment of the latter are sometimes more strongly 
Kind of Pencil and the Detalls Produced. i8I

marked in their manifestation than at others, yet there is more or less of this tendency apparent than occurs when the pen-and-ink writings of different persons are compared. The fact that the pencil is a rigid implement, and is not subject to the flexure occuring with the use of the pen, when the former is employed by different persons, its use tends to the production of sameness in appearance as regards the density of the lines forming parts of letters, the absence of shading, and individual character which this emphasis gives to pen-and-ink writing. The monotonous density and uniformity which occurs in all pencil writing, and the little difference between what should be the light or heavy lines, as compared with pen-and-ink writing, constitutes a uniformity occurring in all pencil writing, and is a condition of it which is very misleading to inexperienced examiners.

The kind and condition of the pencil with which the writing is done has much to do with its appearance, and the development of the individual modification of the forms of letters, which are found to occur in the pen-andink writing of the same person. If the pencil with which the writing is done be a hard one having a sharp point, the writing executed with it will appear very different from what it will be when produced by the same person if using a soft pencil and a bluntly rounded point. When the hard and sharply-pointed pencil is used the loops of the letters will usually be formed distinctively so as to be characteristic of the writer making them; but the same person when using a soft pencil having a broadly rounded point will so write with it as to have all the loops of letters disappear in the greater width and density of the lines producing corresponding parts of letters; and this will be necessitated by the broadly-rounded writing end of the soft pencil. While this condition of the pencil 
writings of the same person causes them to vary materially in form from those produced by a pen, it also causes pencil writings of the same person to differ essentially from each other in appearance, thus making the question as to their resemblance or difference dependent upon the kind and condition of the pencil with which the writing was done.

There are manifested certain differences between the pen-and-ink writing of the same persons which are common ones, arising from causes before explained; but with all the contingencies taken into account, this tendency to differentiate is greatly increased when the lead pencil is used instead of the pen. Among these conditions so generally apparent is the fact that most persons when writing with a lead pencil will give to the letters more vertical length, make them larger, and with less space between them, and the words will be farther apart than when writing with a pen. Another fact is commonly apparent that persons who when writing with a pen will give considerable slant to the letters will, when writing with a pencil, produce the same more upright and with less inclination. Another feature that is quite common in its manifestation, and that before alluded to, wherein persons emplcying a heavy shading emphasis in their penand-ink writing, will employ this impulse to make parts of the letters that are usually shaded when writing with a pen more rotund when using the pencil.

In addition to the foregoing conditions of pencil writing and the variations consequent upon its production, is the well-observed fact that some persons when writing with a pen will operate it by the flexure of the fingers and thumb, and when writing with a pencil will employ the forearm movement to operate it instead of the latter. This change of method, when employed, leads to the production of so much variation in the form and general 
appearance of two writings of the same person thus made, that there may be but little if any resemblance between them when compared.

With some writers, whether the pen or pencil is used, the coordinate action of the muscular factors which do the work will be so intensely individual in character that it can be identified when either pen or pencil writing produced under such conditions are compared with each other. Belonging to this class of writers are those persons who never have learned to write mechanically, and who write but little, and always by copying forms of letters as present in the mind from memory. Also belonging to this class of writers are those who have some prominently deficient muscular function pertaining to the grasping and moving of the pen or pencil, by which very emphatic and personal conditions of habit become mani. fested. This class of writers will be generally very demonstrative in the production of individualisms, even when the letters are produced with a pen or pencil; the only feature to be considered when examining such writings for the purpose of identifying their personality is the question of simulation.

Recognizing the fact that perfect simulation of a signature written with pen and ink is an impossibility, and that in the hands of a skilful forger a pencil-written signature can be so well simulated as to defy detection, in all cases where the question of imitation could possibly occur this contingency must be kept constantly in mind. There are two general conditions of motive prompting the simulation of lead-pencil writing. One of these is manifested when signatures are forged, and the other where writing is imitated to fix the authorship of it upon some other person than the one producing it. So far as the simulation of the few letters composing an ink-written signature 


\section{$1 S_{4}$ Tracings reom Pencil-Written Signatures.}

is concerned (with a genuine one before the writer from which to do the tracing), the work may be done by a skilful forger with a lead pencil very accurately, from the fact that the general appearances of the signature is all there is to imitate when the pencil is used; but where an anonymous letter is to be written in simulation of another person's writing, there are greater difficulties for the imitator to contend with, unless the latter has a complete copy from which to trace the writing. When parts of a letter are traced from a copy in the hands of a simulator, and there are other words intervening of which the imitator has no copy, the discordance and patched up character of the writing will be apparent and easily discern. ible. Where the simulator has all the words in the form of a copy from which to do the tracing, the imitation may be well done and calculated to deceive.

The best simulations of pencil-written signatures are those which are traced from a genuine one; they are most easily produced and most deceptive in character, from the very close resemblance which may be given to them. Forgeries of this class if well made will show no evidences of their being such, excepting that they will exactly coincide and correspond in measurement with that one of the genuine signatures from which the tracing was made, which fact alone would be conclusive evidence of forgery, as the writing of two signatures precisely alike is not possible if produced habitually. When ink-written signatures are first traced with a pencil as simulations and then inked over by a second effort with the pen, as has been shown, they will bear strong evidences of their being so made; but when traced to be used as forgeries of pencil.written signatures, they may be so well done as to defy detection in the absence of the signature from which they were copied. 
It rarely occurs that signatures are written with a pencil to papers of importance, and when so occuring, if contested as to their being genuine, great care should be exercised in their examination, and unless they are plainly different or alike the standards with which they are compared, examiners having the most experience in this field of study will be the least positive in opinion as to their genuine or forged character. Signatures written with a pencil, when disputed as to their genuineness, generally present one of the two conditions of being unlike, or as having resemblance to the standard writings when compared; and whether these differences arise from their having been produced by different persons, or from varying conditions surrounding their production by the same person, or whether the resemblances occurring are those resulting from their habitual production as genuine writing of one person, or their simulation by another, are the questions to be determined. In view of the conditions under which pencil-written signatures must be produced, these propositions present for solution many features that tend to limit the attainment of accuracy. Only where the disputed pencil-written signature is wholly unlike the genuine ones of the writer it purports to represent; or if it has a studied appearance that types it as unhabitually written; or resembles in some of its features the admitted writing, and is very different in others, or where its variations from the standard forms are typical of the same muscular coordination as that of the writer of the standards, in such cases reasonable accuracy may be had in determining the genuine or forged character of the disputed signature; but where the disputed pencil-written signature looks quite like the genuine writing of the standards as regards the form, spacing, and slant of the letters, and where the variations 
186 Where the Results of Analysis are Doubtful.

in form which appear when the two writings are compared may have been produced within and under the action of the same muscular coordination, and the apparent differences may have been caused by the use of a differently pointed pencil or a hard or soft pencil, conscientious judgment in the light of experience will dictate a modified opinion and without positiveness. Where the pencil-written signatures being examined very closely resemble each other, and knowing that accurate simulation is possible when so made, the only conclusions that can be reached must include in their expression the contingency of being mistaken.

In thus detailing in a general way the conditions surrounding the production of lead-pencil writing as developed in the experience of the author, only such features of it as are commonly apparent in it can be given; for the individuality of pencil writing like that of pen-and-ink writing, causes each case to stand alone in those conditions which give personal character to it, although not so positively in the one case as the other. The occurrence of circumstances under which lead-pencil writing becomes a matter of legal contest are rare, yet they do happen, and from the manner in which evidence relating to their genuine or forged character is often given, is at times surprising. Generally those who have had the least experience will be most positive in their opinions; while others who have devoted a life-time to the study of the subject matter will be the least so. That the conditions under which lead-pencil writing is produced, the contin. gencies attending the identification of individual habit, and its determination from an attempted simulation of it may be clearly understood, is the object of the present chapter. 


\section{CHAPTER VIII.}

INKS, AND THE CIRCUMSTANCES UNDER WHICH A KNOWLEDGE OF THEIR COMPOSITION BECOMES IMPORTANT.-THE AGE OF PAPERS AS DETERMINED BY THE APPEARANCE OF THE WRITING UPON THEM.- HOW WRITTEN INSTRUMENTS MANI. FEST THEIR AGE.- THE CAUSES WHICH RETARD OR ACCELER. ATE THE CHANGES OCCURRING IN THEIR APPEARANCE.HOW THE FADING OF THE INKS RELATES TO THEIR COMPOSITION. - INKS HISTORICALLY CONSIDERED. - ANCIENT INKS AND THEIR COMPOSITION.-INKS CLASSED AS SOLUTIONS, AND AS CONTAINING COLORING MATTER IN SUSPENSION.THE EFFECT OF AGE UPON INKS, AND AT WHAT PERIOD THE LIMIT OF THEIR CHANGE IS REACHED. - THE EFFECT OF CARE AND THE CUSTODY OF IVRITTEN DOCUMENTS AS RELATES TO ACCELERATING OR RETARDING THE EFFECTS OF TIME.-THE CONDITION OF PAPER AS AFFECTING THE CHANGES IN IT PRODUCED BY AGE.- THE FACILITY WITH WHICH MODERN INKS CAN BE REMOVED. - THE USE OF TINTED PAPER AS A MEANS OF PROTECTION.- HOW MACHINES WHICH PUNCH OUT THE AMOUNTS ARE CIRCUMIVENTED BY FORGERS.-TYPEWRITER WORK, ITS SAFETY WHEN ORIGINAL IMPRINTS ARE USED, AND THE DANGERS ATTENDING THE USE OF CARBON COPIES.

The composition of inks often becomes very important in connection with the papers or written instruments by which the latter or the signatures upon them are produced to establish their authenticity. It also becomes important at times to ascertain the age of papers through the appearance of the ink with which they were written, and while these matters cannot always be determined with accurracy, in most cases an old writing can be easily told from a recent one. Papers or written instruments purporting to be older than they really are, and in which the effects of age have been counterfeited by purposely 
iss How Inks Fade and Paper Shows Age.

soiling them, or in which an aged appearance has been produced by the use of chemicals, are subjects often requiring the attention and adjudication of courts of justice. So also as regards wills purporting to have been executed many years before being offered for probate, deeds of property, receipts for the alleged payment of money, and the cancellation of moneyed obligations occasionally appear in legal contests affecting property rights, all of which require examination as to their character and age, and in the determination of which expert evidence becomes important.

All written instruments as they grow older manifest their agre in various ways, the change of color and browning of the paper and the fading of the ink being the most prominent features to indicate the effect which time has had upon them. The conditions surrounding the care of papers and instruments of writing have much to do with the permanency or fading of the ink with which they were written, yet changes do take place under all conditions of care, and the measure of change appearing in them is in most cases indicative of their age, particularly when other than carbon inks are used in their production. All the inks in which logwood forms the coloring matter alone fade in a peculiar way, and differently from tanno-gallate of iron inks, while the well-known blue inks, so generally used during the early part of the present century, are affected differently by age from either of those before named, and the same is true of the sulphindylic acid inks of the same period, but all of them indicate in a greater or less degree conditions from which to judge of the age of the writing. The logwood inks fade by turning a yellowish-brown; the Prussian blue and oxalic acid inks of fifty years ago take on in fading a bluish-grey, and the sulphindylic acid inks when combined with ferric 
sulphate turn a reddish-brown, while inks of the latter group when containing nut-galls as one of the ingredients become a pale brown under the effect of age.

The most permanent inks are those containing carbon in suspension, and these were the inks used by the Ancients, their stability as to color being due to the fact that carbon of the form used in their production is not affected by light, or the action of the atmosphere. These carbon inks as described by Dioscorides were made to contain three parts of lamp-black (carbon) and one of gum; the latter being dissolved in water to make a thick mucilage into which the carbon was mixed and held in suspension. Pliny also historically alludes to the use of the coloring matter of the cuttle-fish (sepia) for writing ink. The ancient carbon inks in some respects resembled the copy. ing inks in use at the present time, in which carbon in the form of lamp-black is suspended, and in their composition they were very much the same as India ink, when rubbed up with water and used for drawings.

The inks in use during the first half of this century, as well as those in use at the present time, are best arranged for description by being divided generically in two classes; in one of which are placed those considered as true solutions, and in the other those in which the coloring matter is held in suspension by gum or mucilage. Of those classed as solutions were the inks made from the Stephenson formula and its modifications. These inks in kindred variety were largely employed about the beginning of and down to about the middle of the present century, when they went out of use; they were true solutions, and the writing done with them appearing a dark blue when first written, and immediately turning to a deep black. Another ink manufactured by Stephenson and others was produced by dissolving Prussian blue in a weak solution of oxalic 
acid, and this was also a true solution, the writing produced by it remaining a bright blue until acted upon by time or heat, the latter agency obliterating it. Among the solutions most generally used were those made from logwood, and set with chromate of potash. These inks, when written with, gave a dense blue-black color, and were in general use during the early part of the present century, and continued to be employed in a limited meas. ure down to the latter part of it. Lastly, as classed among the solutions, there came into use inks made from nigrosine, a soluble form of black aniline, and these inks with the latter as a base or body, are very generally in use at the present time on account of their cheapness and the facility with which they can be compounded. These nigrosine inks came in to use in 1870 , al though other forms of black aniline had been used for making inks several years before the discovery of nigrosine.

Of those classed as containing coloring matter in suspension are those termed tanno-gallate of iron inks, made from a decoction of nut-galls, and set with ferric-sulphate, and they are the inks of this class most generally used. As a matter of fact, historically, their employment dates back several centuries. These inks are sometimes made by reducing the amount of nut-galls and substituting logwood to cheapen the cost of their production, and occasionally lamp-black is added to better adapt them for copying uses. Another kind of inks occurring in variously modified formula, and belonging to this class, were those made from a decoction of nut-galls and set with the salts of Vanadium; and in addition to those already named there were others termed Alizarine inks, in the manufac. ture of which there was employed a solution of indigo in sulphuric acid, to which iron filings were added, with the mixture allowed to stand, from which the supernatant 
liquor was drawn off, and thickened with gum to prevent the coloring matter from being deposited. Besides those already named as belonging to this class, were the carbon inks before alluded to, and inks made from a decoction of Archil, and set with ferric-sulphate.

To give the formula for the production of these inks would not seem necessary, and all that seems really important for the purposes herein considered is to class them generically as to their character and ingrediential composition. All inks made from nut-galls and ferricsulphate would yield the same results when tested qualitatively, whatever proportions of these same materials were used in their preparation. So inks made from logwood and chromate of potash, or from Archil and ferric-sulphate, would show when tested what they were produced from, whatever the proportions of these ingredients were employed in making them; and the same would be true of the sulphindylic acid inks, and also those made from prussiate of iron and oxalic acid.

While this is true as to the qualitative tests, it is equally true as to the effect which age and surroundings would have upon the inks with which the writing was done; and although these effects might vary as to the intensity with which they were manifested, they would be generic in kind. Thus all inks in which ferric-sulphate were used would turn brown by oxidation, and the measure of the latter would depend upon circumstances. So all logwood inks would, as affected by time, become a yellowish brown under its influence in measure as modified by surroundings.

The advent of metallic pens, which supplanted the use of the goose-quill as the latter had the stilus of the Ancients, necessitated changes in the composition of inks, and particularly such of them as were acid in their composition, from the corrosive effect the latter had upon the metal of 
which the pens were made; hence the sulphindylic acid inks as first made by Stephenson and others went out of use, and their place was supplied by the logwood inks, and those made from nut-galls variously modified to adapt them for use with metallic pens. The latter made their appearance during the third decade, and came into general use about the middle of the present century.

Inks containing coloring matter in suspension have been found to be the most durable, and much more so than those classed as solutions. All of the latter permeate the paper on which they are used more than the others, and consequently are in a better condition to be acted upon by time on this account. When writing is done by the use of inks which deposite the coloring matter upon the paper, a portion of the liquid enters the latter at the edges of the writing, and this liquid portion so conditioned is acted upon more readily by the agencies of time, while the body of the writing changes more slowly; but where the ink is a solution of color it permeates the paper so as to be wholly acted upon more rapidly by those agencies tending to fading and obliteration. Inks that are absorbed by the paper are much more readily affected by conditions of the latter than those which are deposited upon the paper; and while the agencies in the latter tending to accelerate fading act upon all kinds of inks excepting those made from carbon, they act with more force upon the ink solutions than upon those in which the coloring matter is held in suspension.

Having thus considered inks as regards their history, composition, and in a limited measure the chemical changes made to appear in writing done with them by age, the causes which accelerate or retard these changes are numerous, and so irregular in their development as to prevent the establishment of any rule as to the measure of their 
How Fading of Inks is Indicated by Age. 193

occurrence. Thus writing having the general appearances of age as apparent in the fading of the ink, may be readily distinguished when compared with that recently written, but whether ten or twenty years older than that with which it is compared is a more difficult problem to satisfactorily determine. The kind of ink used in the writing of a document may connect the production of the latter with the period when such inks were employed, yet this alone would not establish the age of the written instrument, for the ink could have been recently made for the very purpose of deception, but the fact that a peculiar kind of ink which was in general use years before showed the concomitant effects of age in the changes which the writing of the document had undergone, would tend to connect the execution of the paper with the period when like inks were generally employed.

The difference between a written document that purports to be older than it is and what its real age is, may be difficult to determine with accuracy, but the counterfieited appearances of age when applied to a written instrument are generally easily distinguished, so that competent evidence as to the fraudulent character of such a writing should have value, although it may not be possible to establish the exact age of the paper as to production.

Where inks containing coloring matter other than carbon in suspension are used, at the edges of the writing, the liquid is absorbed by the paper so as to penetrate and flow into the latter. This action of the paper filters out the suspended coloring matter so that the liquid entering the paper at the edges of the writing consists mainly of the chemical agencies used in setting the color, and consequently these portions of the writing are those first acted upon as regards change or fading. While this is the 


\section{I94 Period When the Fading of Ink Ceases.}

case with tanno-gallate of iron inks, like conditions are manifested when those made from logwood are employed. At the edges of the writing in which tanno-gallate of iron is used, the liquid filtered when passing in to the paper is a solution of iron (for all inks of this class contain ferric sulphate in excess), and this liquid where thus absorbed by the paper will turn brown by oxidation before the other parts of the ink are acted upon to any extent. With the logwood inks the chromate of potash absorbed at the edges of the writing by the paper becomes in a measure converted into a carbonate by the action of the atmosphere, and the hematoxylin of the logrwood takes on a yellowish brown. These changes at the edges of the writing make themselves manifested in from seven to ten years, after which the whole body of the writing passes through the changes more slowly.

There seems to appear in all writing done with other than carbon inks, and particularly with that kind of inks made from nut-galls and ferric sulphate, a measure of change up to a certain period, after which the fading ceases and the color does not change any more. Thus when a letter written with nut-gall ink by George Washington, and dated in $178 \mathrm{I}$ (in the possession of Seymour Van Sanvoord, Esq., of Troy, N. Y.), is compared with specimens of writing done by B. Van Horike (also written with nutgall ink), in $1_{6} 6_{2}$, and in the possession of the Troy Young Men's Association, the inks in both writings have faded to about the same extent, although the Van Horike writing is about twice as old as the Washington letter. Taking into account this fact and knowing that under the most favorable circumstances the ingredients of which the ink in these writings is composed that it would take at least fifty years to have produced their present appearances, such an opinion as a matter of evidence would be 
good, but as to how much older than that, would be mere guess-work unless there was something else than the appearances of the ink upon which to base an opinion. In the possession of the author there are two letters written by himself about forty years ago, in the production of one of which nut-gall ink was used, and in the writing of the other a logwood ink was employed, both of which inks were made by the author, and the letter written with nut-gall ink has faded just about as much as that of the Van Horike specimen and the Washington letter before alluded to.

While it is thus impossible to reach accuracy as to the age of writings, which have passed through all the changes which an age of two or three centuries may have caused to appear in them as indicated by the fading of the ink with which they were written, yet as to the interim between the time of writing them, and when they will reach the limit to which the fading extends, a reasonable estimate may be made as to their age by examination; particularly when the writing shows at its edges a commencement of fading, or where the less densly written portions have commenced to fade, and the remainder is still unaffected to any extent. An examiner knowing the kind of ink with which a document was written, and the general condition of its care, has a good basis upon which to make the estimate as to its age and the value of the latter as a matter of evidence will depend much upon the skill, education and experience of the examiner. In all old writings where the fading out has reached the limit of its progress all the parts of the writing have about the same shade; but where the fading is progressing, the parts most readily affected reach the limit of their change before the others, and it is in this field of examination that appearances are found to occur upon 
196 Whex Chemical Tests of Ixk are Necessary.

which an estimate must be made as to the time that had clapsed between the production of the writing and the development of the apparent changes.

When examining writing for the purpose of reaching a conclusion as to its probable age, it is important usually that a chemical test of the ink with which the writing was done should be made when practicable; for while the kind of ink may be unimportant in determing the age of the writing considered alone, and with relation to the time when those of its kind were in use, yet having a knowledge of the ingredients of which the ink was composed, the effect which time would have upon it can be more closely estimated, and the measure of change cal. culated to better advantage. It being known that inks of some kinds fade more rapidly than others under the same conditions, because of the greater or less effect which light, moisture, and atmosphere have upon the different materials of which they are composed, a person knowing the kind of ink with which the paper or instrument, being made the subject of examination, was written, is much better enabled to reach a conclusion as to its age than when making a study of the subject matter without such knowledge.

The manner in which a paper or written instrument has been kept, or cared for, and the form of the paper are important considerations to be taken into account when examining it to ascertain its age. If the subject matter of the investigation be a will, bond, deed, or other document having a like form and folds, it is necessary to examine the ink and paper of the inwardly folded surfaces in comparison with those upon the exterior and much more exposed surfaces as to the effect produced upon the paper and the changes that both have undergone. Thus, if the ink be of a kind which light causes 
to fade, the writing upon the outer folded surfaces will be more affected by this agency than that upon the inner surfaces; and the same rule applies as to inks in which varying hygrometrical causes are more active upon exposed surfaces than upon those where the ink is by the folds of the paper better protected from this influence. The place in which the document has been kept, as to being damp or dry, has much to do with the changes occuring in the ink and paper, as well as giving character to them. Writing kept in a constantly damp atmosphere will not usually fade so rapidly as in one where the conditions alternate between dampness and dryness, although it may affect the paper and its sizing, as will be subsequently alluded to.

A microscopic examination should be made of all writing wherein the age of the latter is a subject of investigation, for the purpose of ascertaining whether at the time the writing was done, the ink employed was dense and heavily deposited on the paper. If the ink be of that class in which the coloring matter was held in suspension, the deposit will be there retained by the gum minus its original color. If the ink with which the writing was done was a solution of coloring matter, and the color was dense at the time the writing was executed, it will in its faded condition still cover the paper, so as to prevent the latter from showing through the faded writing; but if the ink was pale at the time the writing was done, the paper will show through the faded-out ink.

Among the causes tending to accelerate the changes which ink undergoes as affected by time and surroundings is the condition of the paper upon which the writing was done, and the kind of material used in sizing it, as well as in tinting it, when colored; and to what extent the agencies used in bleaching the paper while in the pulp state have been washed out or retained. Thus, if paper turns 
yellow with age, which can be ascertained by a comparison with the most exposed parts of those more protected, the fact is developed that the lime used in the form of a chloride to bleach the pulp has not been wholly removed by washing. and this condition of the paper would indicate that the facting out of the ink had been accelerated on this account. Paper tinted with ultra-marine or French blue, which was much used during the middle of the present century, and is at the present time employed to a limited extent in the manufacture of account books, accelerates the fading of logwood inks, but has little or no effect upon those made from nut-galls. Paper that has been sized and calendered, when kept in a dry atmosphere serves in a measure to retard the fading of all inks, from the fact that the latter do not penetrate the paper to the same extent as when unsized and uncallendered; but sized and calendered paper when exposed to continual dampness hastens the fading of ink and causes the growth of mould.

When a written instrument has been wet and stained to give to it an aged appearance, such treatment causes the writing to settle into the paper, and thickens up the latter, thus producing just the opposite effects that age will cause. In all writings in which the effects of age are honestly manifestated, the ink appears to stand out in relief upon the paper, and this condition and appearance is caused from and by the constantly changing action of the atmosphere as to humidity. Every time that the air contains an increased humidity the paper takes up moisture and expands in proportion to the amount absorbed, and when a dryer condition of atmosphere prevails, it contracts in parting with the absorbed moisture; and these constantly occurring conditions of expansion and contraction tend to draw the paper away from the ink, until the writing done by the latter appears in relief upon the paper. When a 
recently written instrument is wet after the writing becomes dry enough to prevent the spreading of the ink, the ten. dency is to loosen up andraise the fibre of the paper, and this gives to the writing the appearance of having settled down into the paper.

It often becomes important as a matter of evidence to determine whether all parts of an instrument were written with the same ink as the body of it; or as to whether the signatures of witnesses to a will were written by the use of the same ink, as affecting their having been cotemporaneously written. When competently done, chemical tests may be made of the ink in such cases which will determine the matter with accuracy; but it so often occurs that these tests are incompetently made that there is a general prejudice against having them done. A small portion of a letter is all that is required to be operated upon, and if the chemical agency employed produces the same effect in both tests, an additional one should be made with another reagent to verify the first one made, to insure positiveness. In a succeeding chapter the testing of ink by chemical agencies will be more fully considered.

All the modern inks, with the exception of those containing carbon in suspension, can be easily removed by chemical agencies, and while the latter furnish a means for the removal of blots, they also give to persons desirous of falsifying entries and footings a means for temporarily covering up fraudulent work; and the facility with which ink can be removed enables other dishonest persons to easily remove the amounts which are written in the body of checks and drafts for the purpose of inserting others expressing greater money values. These chemicals are peddled by itinerants, and are to be found in every drug store. To guard against these facil- 
ities and means for committing fraud, checks, drafts and sometimes notes are printed upon tinted paper, which latter, under the action of the agencies used to remove the ink, is bleached out white, so as to readily direct attention to the changed appearance of the paper, and in most cases this tinted paper answers the purpose for which it is designed. But it is also well known that where some kinds of this paper are used the ink can be removed and the tinting of the paper restored without restoring the ink. Generally where the ink writing has been removed by chemicals the pen tracks of the writing can be made to appear by photography, although not always. The pen furrows made in the paper can usually be seen under the microscope, and to cause them to appear by photography the paper on which they are mani. fested is placed back of a glass in an ordinary print frame with enough pressure applied to make the paper smooth beneath the glass; and during the exposure to direct, by means of a mirror, a strong side-light upon the paper, so as to have the pen furrows in the paper make a shadow, which latter will be caught by the negative, and appears in the prints made from the latter. This can always be done when the writing removed was made under pen pressure sufficient to cause furrows to appear in the paper.

As an additional means of protection against frauds of this character the figures representing the amount for which a check or draft is drawn are by a machine punched out of the paper with the dollar-mark preceding the figures representing the money amount; but even this procedure does not afford protection against the raising of the amount by skilful operators which it would seem to provide; for recently, in a number of instances, it has occurred that the figures following the initial ones next to the dollar-mark have been cut out of the paper, 
and by working down very thin the edges of the latter where cut out, to insert a patch very dexterously and to punch from it ciphers, by which a draft drawn for sixteen dollars was made to read, as punched, sixteen hundred dollars, with the writing in the body of the draft raised to correspond in amount. This fraudulent work has been very successfully operated, and so closely and accurately done as to require a microscope to detect it.

To properly test inks so as to determine whether they can be removed, freshly prepared Labaraque's solution of chloride of soda is applied to the ink by means of a camel's hair brush, allowing the applied liquid to remain for a moment and then remove it with a clean blotter, repeating this operation until the coloring of the ink is re. moved; this should be done without rubbing the paper. Ink freshly written with is more easily acted upon by this reagent and more readily removed than where the writing has become dry and hard, but it will remove the coloring from all modern inks in use excepting those containing carbon in suspension. These latter inks when properly prepared are just as fixed and permanent as printing inks, and are the only inks that should be used in the writing of books of accounts, records, and in expressing the value of amounts in checks, notes, drafts and other papers where alterations may be made in the interests of crime or fraud. The fact of the permanency of these carbon inks is illustrated when the appearances of writings done during the 7 th, 8 th and 9 th centuries are compared with others of the $15^{\text {th }}, 16$ th and 17 th centuries; the inks of the latter periods having been made from nut-galls and iron, and those of the earlier periods by the suspension of carbon in liquids. While the latter have retained their color and freshness, the others have faded and at times become almost obliterated by the 26 
action of time. The great advantage of using carbon inks is not that of their permanency, but the fact that chemicals do not act upon them for their removal, and the insertion of other written matter to take the place of that obliterated.

Carbon inks are not much used from the fact that to prevent the carbon from settling, so much gum is required that they do not flow freely from the pen, and they are apt to become thick and difficult to write with. To prevent carbon inks from being affected by the action of the atmosphere or wetting, when properly prepared they should contain shellac dissolved in the water wherein the carbon is suspended; the shellac having been made soluble therein by means of borax or potash, aided by heat, with the carbon subsequently added and thickened by gum. When carbon inks are thus prepared and written with, they cannot be removed or changed by washing them, and they are not acted upon by any of the chemical agencies which remove other inks. When parchment was used for all writing purposes centuries ago, and carbon inks were employed, it is occassionally found to occur, when examining such old documents, that the same sheet of parchment after having been employed for one purpose as a written document, and had served its uses as such, the ink would be by the economical monks washed off, and the same sheet be rewritten upon for another purpose with traces of the palimpsest writing still remaining indistinctly visible. While inks could thus be removed from parchment, it would be very difficult to accomplish such a result by washing these carbon inks when used upon paper, on account of the constituent difference between the paper and parchment, although, unless the carbon ink was prepared with shellac, it could be rendered indistinct by wetting and rubbing it. 
With the advent of the typewriter machines the calling of the scrivener and engrossing clerk is fast disappearing, and with their departure the contingencies occurring as to the stability of written documents, in all respects save that of signatures, is becoming no longer a matter of thoughtful care. With the use of the typewriter, all first impressions (not carbon copies) can be made as durable as when printer's ink is used, and all possibility of their alteration by chemical agencies is avoided. But to accomplish this condition of safety, the ribbons or ink-imparting material should be made to deposit carbon in as near an approach to printer's ink in composition as possible. The carbon copies made by manifolding, while not acted upon by chemicals, can be very easily removed by means of a rubber or cloth eraser, and on this account should not be depended upon for matters of record. Not only can portions of a document be removed, but other matter may be inserted in the place of that erased and the whole purport of the instrument changed.

All typewriter machines, even when using the same kind of type, become more or less peculiar by use as to the work done by them. One of these characteristics which each machine manifests is that produced by varying alignment, in which some of the type make peculiar imprints which very positively connects the work done with the machine by which it was produced, and this occurs more particularly to such of them as have been used for some time, and so distinctly marked does this peculiarity become connected with the printing done by each machine that little skill is required when comparing the work done by a dozen of them to pick out that produced by each of them. A knowledge of this fact sometimes becomes important in tracing up the source of an anonymous letter printed by a typewriter machine. 
204 Character of Inks as to Their Being Tested.

Having thus considered inks as to their character and history in a general way, the methods and applied means for testing them as developed in the experience of the author (educated as an analytical chemist), and as set forth in well-known and standard authorities, will form the subject of the succeeding chapter. 


\section{CHAPTER IX.}

WHEN AND HOW THE CHEMICAL TESTING OF INKS BECOMES IMPORTANT.- HOW AND WITH WHAT IMPLEMENTS TIHE TESTS SHOULD BE MADE, AND BY WHOM MADE.-THE IDENTIFICATION OF THE REAGENTS TO BE USED BY PROOF ESTABLISHING THEM TO BE WHAT THEY PURPORT TO BE.-AUTHORITIES AS TO THE VALUE OF CHEMICAL TESTS AS MATTERS OF EVIDENCE,- WHY A SINGLE TEST OF AN INK IS SUFFICIENT TO ESTABLISH ITS GENERIC COMPOSITION, AND WHY SEVERAL TESTS SHOULD BE MADE.- WHERE THE KIND OF INK BECOMES IMPORTANTLY CONNECTED WITH THE PURPORTED DATE OF A WRITTEN INSTRUMENT AS TO THE TIME WHEN THE INK WAS DISCOVERED, WITH AN IMPORTANT CASE CITED.THE EFFECT OF AGE UPON WRITING WHEN THE INK WITH WHICH THE LATTER WAS PRODUCED IS TO BE TESTED.WHEN WRITING HAS BEEN TRACED WITH A LEAD PENCIL AND THEN WRITTEN OVER WITH INK HOW THE TEST SHOULD BE MADE TO DETERMINE IT.-THE EFFECT OF REAGENTS UPON DIFFERENT INKS AND AUTHORITIES CITED WITH RELATION THERETO.

In all chemico-legal cases where the results attending the testing of inks become important as a matter of evidence before courts and juries, there is but little chance for difference of opinion between experts equally well educated and competent, although persons posing as experts in such matters without the requisite education and experience may not only deceive themselves but be the means of misleading others. All who are conscientiously actuated in making such examination will prefer to have the employment of the tests surrounded with all the safeguards and evidences of competency which can be imposed to secure accuracy and exactness, and will make no objection to their strict enforcement. 
One of the first and most important considerations to be taken into account in testing writing with chemical agencies is the purity and character of the latter which are to be employed; they should be proved to be just what they purport to be before making the tests, and the latter should be made in the presence of the court and jury. For the purpose of applying the reagents to the writing, a glass or quill pen should be employed, although a clean camel's hair brush may be used, and where the latter is the implement selected, it should be washed in the presence of the court and jury before making the application. The glass or quill-pen are either of them more desirable instruments for the use than the brush, from the fact that by their employment a single line may be drawn across the letter selected for the test, and much less of the writing defaced than where the brush is the implement used. Metal pens must not be used under any circumstances, as they are readily acted upon by the agencies employed, and in a manner that would render doubtful any results attained. In connection with the application of the reagents employed, is the use of a clean blotter which has been tested as to its being free from lime, the function of the blotter being in its application to arrest the action of the reagents and their absorption when applied to the writing.

Before proceeding to detail the manifested effects of different reagents, some authorities are given with reference to the advantages to be derived from such investigations, the measure of accuracy attainable, through their application in such cases; and these authorities are more particularly selected with reference to the high character and generally recognized abitity of those establishing them.

William Thompson, F. R. S. E., a well-known scientist of England, in a discourse before the Manchester Liter- 
ary and Philosophical Society, and which is reported in the Chemical News, of London, Vol. XLII, page 32, gives great weight to the reliability of chemical tests made to ascertain the character of inks. He states that he found no difficulty in determining the inks of different manufacturers made at different times by means of chemical reagents, although the inks had in some instances been diluted with beer, tea, or coffee, and written at different times. Thompson gives a long list of reagents to be employed, naming dilute sulphuric acid, sulphurous acid, solution of oxalic acid, solution of caustic soda, solution of oxalic acid saturated with lime, solution of calcium chloride, solution of stannous chloride, and solution of stannic chloride. He directs that several letters of the writing to be examined have applied to them any series of these reagents, that they be allowed to act upon the writing for a few seconds, then to remove them by the application of a clean blotter; and if the effects produced by these reagents is the same in both instances, the identity of the inks in two writings is established. Allen's Organic Analysis, Vol. III, page I 28 , is given as an authority as to the effects of reagents when applied to writing done with different kinds of inks, and the determination of their character qualitively. As to logwood inks, reference is made to Bloxam's Chemistry, edition of 1890 , page 678 . As to the composition of inks and their numerous formula, the reader is referred to "Ure's Dictionary;" for those in use generally about the middle of the present century, to "Workshop Receipts," edited by R. Haldane, and published by Spon \& Co., London, and to the "Techno-Chemical Receipt Book," edited by Brant \& Hall, and published by Sampson, Marston, Searle \& Rivington, London, for the formula of inks in general use at the present time. 
When an examination is directed to ascertain whether the writing occurring in the body of a written instrument was all produced by the same kind of ink, or when the question to be determined is whether the signatures to a written instrument were each produced with the same kind of ink as the other parts of it, a test made by a single reagent is not sufficient, as before stated, to reach a correct conclusion. This occurs from the fact that even a different ink will sometimes give a like reaction under the application of the same reagent ; hence, to insure accuracy, there should be several reagents employed, and the inks under examination should each be tested by the same series of chemicals, with each of the latter in each instance of its application producing its peculiar reaction, to establish that the ink with which the writings were done are the same, and with unlike effects to establish their difference. Thus if the writings under examination when tested by hydro-chloric acid showed the same reaction in each instance of their application as relating to this reagent, and when oxalic acid or stannic chloride was applied the writings in each instance showed the same effect, and when any other of the series of reagents each produced the same result peculiar to the chemical employed, the sameness of the inks with which the writings were done would be established, and with unlike reactions their difference would be determined. When done expertly these tests can be made without defacing to any great extent the writing to which they are applied.

Where the question arises as to the kind of inks and their determination as to generic composition, there is required a different application of chemical knowledge, and a recognition of the qualitive character that the tests made by the use of reagents indicate, which is not called for when their sameness or difference is the subject 
of inquiry. Where the investigation is instituted to determine whether inks with which writing was done are the same or different in composition, and which on being treated with reagents developed like or unlike conditions, the composition of the inks was unimportant, but where it becomes necessary to ascertain whether a will purporting to having been executed in 1886 , was written with logwood or nigrosine inks (with the latter unknown until I 870), the process-steps and reagents employed require in connection with their use a knowlege of what the action of the reagents used would be, to determine the ink to have been made from one or the other of these substances, with this knowledge supported by standard authorities.

Thus in an alleged draft of a will produced in evidence in the Gordon will case tried before Chancellor McGill of New Jersey, in $189 \mathrm{I}$, in which document red ink had been used for interlining portions of the writing which it was assumed had been done about the same time the draft of the will was made, the proof was that this red ink so employed was manufactured from eosine, a coal-tar product and something which had not been discovered until some years after the time the alleged copy or draft of the will and its interlineation, this evidence being given as an opinion by the expert supported by standard authorities and substantiated by chemical tests made in the presence of the court. In cases of this kind chemical knowledge of what the effect of reagents when applied to ink writings will be in determining their generic composition, becomes important.

When the formula of inks is determined it has to be done by analysis, and by which not only the qualitive character of its ingrediential composition is ascertained, but their quantitive measure is determined. When writ- 
ing is tested by reagents, all that can be ascertained is the qualitative character of the materials used to produce the ink by which it was written, and the formula as to the proportion of ingredients used does not enter into the examination excepting as to kind. To facilitate making tests of ink by which writing has been produced, inks are classed generically as to composition, that is they are grouped and arranged with reference to their containing certain well known basic ingredients that are common to all of the genera in which they are classed. Thus inks made from nut-galls and feric sulphate will be classed as tannogallate of iron inks, and when tested they will indicate their composition no matter what the proportion of the same ingredients are employed to make them. So inks in which other vegetable substances are used in place of nut-galls and are blackened by ferric sulphate will, when tested, not only indicate the latter but also the presence of some other elements than nut-galls. As relating to all tests made of ink writings, the reactions taking place through the use of reagents attain their specific character as a matter of experience to those making them, and thus become established as chemical facts, and these are generally supported by standard authorities, excepting in some cases where the application has not occurred often enough to become a part of the written law of chemistry. In such cases the effects produced must be taken on the statement of the expert as to their verity if made applicable.

When making qualitative tests of ink writing through the operation of chemical reagents, there are attendant conditions which at times should be taken into account, and prominently among them as having a modifying effect is the age of the writing. Thus a very old writing originally produced by a tanno-gallate of iron ink may 
have become so changed by the action of time as to merely show the presence of iron in the form of an oxide, with no traces of the nut-galls apparent. So an old writing done with logwood ink may show nothing but the pale yellow stain of the hematoxylin, and without any traces of the chromate of potash by which it was originally turned black; a suplhindylic acid ink may show nothing but the iron oxide from the same causes.

While these conditions are common to the inks of all old writings, others of a more recent date as regards the measure of promptness with which reagents act upon them are affected by age. Thus writings ten years old are not generally so responsive to the action of reagents as those which are two years old, even when the inks with which they were written had the same ingrediential composition, although the reactions will be the same in character, but they will be modified as to the intensity of their reaction. The measure of density with which the ink being tested was deposited on the paper, and whether thick or thin at the time the writing was done, will cause the intensity of the reactions to vary quantitatively rather than qualitatively; the thicker ink manifesting a more intense effect generally than thin or pale ink of the same kind when tested chemically.

The great number of formulas in use for the manufacture of ink will prevent giving a tabulated statement of tests to be applied to determine that of each manufacturer excepting as classed generically, and even if the kinds of ink most generally used were coupled with a tabulation giving the effect which reagents would have upon writing done by them, there would still be difficulties attending its use to have such tabulation answer in all cases as an authority. The varied conditions under which inks are kept and used, the character of the paper on which 


\section{2 i 2 Tests Should be Made by Competent Persons.}

the writing appears, and the manner in which it has been cared for, all tend as conditions to vary and modify the action of reagents; hence, the effect of the latter could be only established in a general way, and such tabulation as relating to the effect of reagents upon the several kinds of well-known inks in the hands of inexperienced and incompetent persons might prove misleading. When chemical tests of ink are to be employed, they should be applied by persons competent to make them, and to judge of the results attending their application; and such persons being well acquainted with what the effect resulting from the use of reagents should be, would not require any tabulation of specific reactions to even determine the inks of different manufactures from each other, though generic in kind. Thus all inks of a certain manufacturer when made from the same formula would, under the application of reagents, give results as modified by surroundings which an experienced chemist would determine as the same reactions, and though qualitatively the same, they might vary enough in appearance as to mislead an inexperienced person depending upon a tabulation of tests as authority.

When writing has been traced with a lead pencil and then inked over with a pen so as to completely cover the tracing, to determine its production in this manner the ink should, on a portion of the writing, be decolorized by the application of chloride of soda or chloride of calcium in solution, and as the carbon or black-lead of which the pencil writing is composed, is not acted upon by chemical agencies, the pencil marks will be found intact after the color of the ink has disappeared. To restore the ink (if having an iron base) the paper operated upon should be placed while still moist over the mouth of a Florence flask containing hydro-sulphuret of ammonia, which has been 
sufficiently heated to vaporize and come in contact with the paper, and which procedure will immediately restore the ink color. This test was first applied by David N. Carvalho of New York city, in a suit where the question arising was whether a certain writing made the subject of legal investigation was traced with a pencil before written over with ink.

All the inks made from nut-galls and set with ferric sulphate are partly decolorized and turned grey by the application of hydro-chloric acid, and a reddish grey by oxalic acid. The presence of iron in inks of this class in the form of a sulphate is ascertained by applying hydrochloric acid, allowing it to remain on the writing a few seconds, then removing it with a clean blotter, and immediately applying, while the paper is still moist, ferro-cyanide of potash, when the ink changes instantly into a deep blue, the reaction leading to the production of Prussian blue. This test for iron applies to all inks in which it is used as a sulphate, and very positively distinguishes inks of this class from those made from logwood and set with chromate of potash. All writing done with ink containing nut-galls is turned a deep reddish brown on the appli. cation of potassic hydrate.

Inks which when written with have a bright blue color that turns black soon after, generally consist of a solution of Prussian blue mixed with a decoction of nut-galls, and to which ferric sulphate is added. When tested with oxalic acid they turn from a black into a bright blue; they take on a deep reddish brown when tested with potassic hydrate, and the presence of the iron in the form of a sulphate is determined by the test given before.

According to Allen, before alluded to, writing produced by the use of an ink made from aniline black is turned a reddish brown by the application of hydro-chloric acid, 
and is not affected by other acids; they are readily decolorized by bleaching agencies, and when fading under the action of the latter assume a grey color. If during the action of the bleaching agencies, the progress of the latter is arrested by the application of a blotter, and stannic chloride is applied, the ink momentarily assumes a pale green color. Nigrosine inks, as made and as appearing on the market, vary much in their reactions under the application of the same reagents, from the different manner in which the nigrosine is produced by different manufacturers, and it is difficult to define any one reliable chemical test for their determina. tion by such means, although there is a very simple test by which writing produced by their use can be deter. mined. This consists in wetting them with water and gently rubbing them, when they dissolve as usually made, and in dissolving off from the writing turn a dark blue; thus distinguishing them from inks containing carbon, which, under the same manipulation, are a dead black. When, however, nigrosine is dissolved in a solution con. taining shellac which has been saponified by an alkali, water will not dissovle it, but with diluted alcohol applied it will, and produce the same results.

While there are many established and well-known kinds of ink in use, those made from well-established formula are constantly being superceded by others, and to enumerate them and classify them, or even a part of them, would require more space than can be appropriated to the work. The matter of their production, and the methods for determining their composition, qualitatively, is all that can be given. Among them there is at present none of them but which in the hands of a competent chemist can be identified and their qualitative composition determined with accuracy. 


\section{CAUSES CELEBRES.}

The circumstances attendant upon the production of forged documents and papers are so often but mere repetitions of others which have preceded them as regards inception, motive and the methods connected with their production, that there is suggested by this condition the perpetuation through compilation of some of the most important cases of this character, in connection with their illustration in fac simile, so that as history repeats itself in the same respects, their description and illustration may be referred to. The cases selected for this purpose have been chosen more from their character as "Causes Celebres" rather than from any relation which they bear to each other, either as to conception or motive. They are not all of them manifestly the product of the same promptings. but some of them are typical in character, and evidently born of like conditions of suggestion. At the time the "Davis Will Case" became prominently known in Montana and throughout the United States, the "Gordon Will Case" and another of like character appeared shortly afterward in New Jersey, all of them purporting to date back twenty odd years before the time they were offered for probate, and involving the disposition of millions of dollars. That the appearance of the one suggested the emergence of the others would seem a proper conclusion.

Independently of making a good imitation of a signature there are usually conditions made necessary to have the forgery answer the purposes designed, and which, as 
developed in individual cases of like character, take on parallelisms in these respects. Generally the features which make cases typical as to kind occur from the fact that the attempts made to establish the forgery as genuine require like efforts in the way of proof, and this is particularly the case where the names of deceased persons are forged to notes, and for the collection of which suits are brought against estates. To account for the ownership and making of notes of this kind, it will, in various forms of manifestation, occur by implication or attempted proof that the deceased had given the note to compromise some wrong-doing which it was desirable should not be known to relatives and the public; some affair in which a woman was a party, or other escapade which, as will be alleged, the deceased, at the time of its occurrence, was anxious to conceal, and, as a concomitant of this class of forgeries, this condition is a very common one. Generally notes of this kind have their emergence without regard to the social position of those who produce them for collection; they are rarely the work of professional criminals, and are often found to be in the possession of assumed innocent holders who occupy a seemingly respectable position in community.

In the experience of experts who have had a wide range of employment in the examination of disputed handwriting, and wherein the often occurring forgery of notes against the estates of deceased parties become litigated, it has occurred at the trial of these cases frequently that on changing the names of the parties, and the witnesses, the attempted proofs will be so much alike that the testimony given in one case will be the counterpart of that presented in the others. It will generally appear in pretended evidence that a payment had been made on the forged note according to an indorsement thereon, and a 
witness will testify to having seen the payment made at the time it purports to have been done; and thus cases of this kind become typical in character as to their inception and the means employed to sustain their production.

Where large property rights are at stake, particularly in the distribution of estates, it will strangely appear at times how emphatically interest will warp judgment, and how easily seeming respectability will be led by it to do disreputable acts. Persons who throughout a lifetime have looked upon crime with apparent disgust will become interested in promoting its successful exercise, where the subject is a will of doubtful character, and by the provisions of which they are to be benefited pecuniarly. Where wills are forged the work is often done by persons who have no rights in the estate of the deceased by inheritance, but who do the forgery and sell the fraudulent will to those who have. Where an assumed injustice to some of the heirs of an estate occurs from the purport of the real will of a testator, and another will of a later date turns up mysteriously, the tenor of which suits the interests of the dissatisfied heirs, conscience eases itself with the solace that though questionable in character the later will merely corrects an imagined wrong, and those benefited by the forgery become champions to sustain it.

It is developed as a matter of experience with those who are constantly engaged in the examination of forgeries of this class, that the latter when of any magnitude are rarely the work of professional criminals; in fact a large majority of the cases occurring are found to appear where the perpetrators are socially in a position to make their work best available for use; and it often happens that the social standing of an accused is allowed to shield and cover up a fraud of this character, and from this cause the crime oftener originates under the surroundings of good social 
standing than otherwise. Unlike other crimes that demoralize men and make them known as criminals, forgery in a large majority of cases entrenches itself behind an apparent respectability, and under the assumed protection of which the perpetrator of it expects to escape detection. This condition applies generally to the forgery of wills and the signatures of deceased persons to notes.

Forgery when perpetrated by persons who occupy good social position has its inception and is committed under one general idea, that in doing it no wrong is intended, and although the conditions under which it developes are somewhat varied, the idea of its being a crime is hardly taken into account. The transition from an assumed high moral perch to that of degradation by the commission of it apart from its exercise as a professional act, is often an impulsive one at first, and particularly where the forgery is the endorsement of a note, and the act is usually coupled with the intention of wronging no one. The first effort is usually made to tide over an emergency which the forger hopes to take care of before the maturity of the note on which the forged name appears. Once done its repetition becomes easier, and conscience solaces itself with the idea that something will turn up to prevent detection. This is the history of most cases where persons occupying good social position make the plunge and become criminals without intending to defraud any one. Where wills are forged by parties in interest, the crime has its inception in the idea that the forgery merely corrects what seems to be a wrong in the mind of the forger, and thus conscience is appeased, and the crime is self-condoned.

Historically, the cases illustrated and described have significance as representing in what manner their emergence took place, the conditions which seemingly prompted their production, and how incentive coupled with intention 
led to their occurrence and gave character to them. While crime of this kind as a phase of human effort does not always follow a beaten path, the study of the phenomena associated with its development tends to educate those upon whom the duty devolves to thwart its purposes or to punish the perpetrators. 


\section{THE MOREY LETTER.}

During the political campaign preceding the election of General Garfield as President of the United States in ISSo, about two weeks before the election in November of that year, there appeared in Truth, a newspaper pubished in the city of New York, a letter purporting to have been written and signed by General Garfield, addressed to one H. L. Morey of Lynn, Mass, and relating to the question of Chinese labor; a fac simile of which letter is represented on Plate XI, and upon Plate XII there is a fac simile of a letter from General Garfield denying its authorship, and pronouncing the letter a forgery.

This "Morey Letter," as it was entitled, caused a great deal of excitement at the time of its advent, and as political bias influenced the judgment of leading politicians, opinions as to its being forged or genuine became very earnestly expressed, and with oppositely formed conclusions, as party lines tended to divide and color them; but after election, and when considered apart from the influence of misguided partisan feeling, the fact of its being a forgery was generally acquiesced in, even before its character as such had been positively determined. Believing some of those persons, who in stating that they considered the letter to be genuine writing of General Garfield, were honest in their conclusions, its appearance gave an object lesson as to how much political bias will at times shackle judgment, and put a limit upon the value of all opinions formulated under its influences.

When a genuine signature, or the habitual writing of a person other than the latter is compared with simulations 


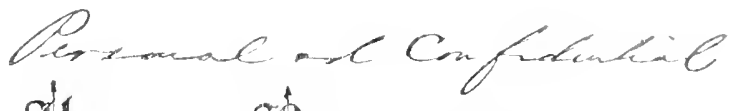

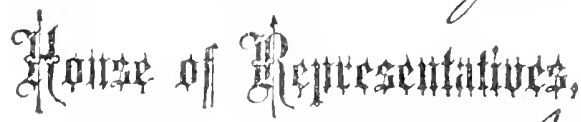 \\ Wastuington, D. G. Alacy 25, 1880}

Aras Sais

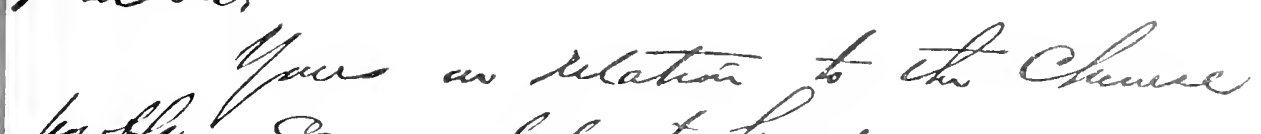

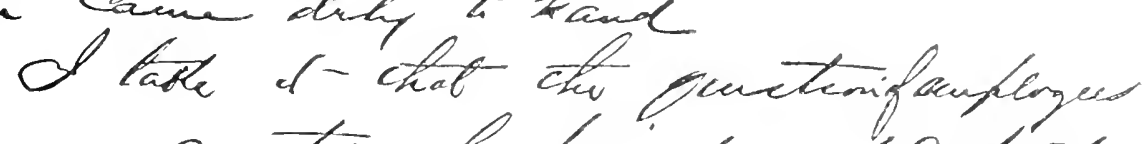

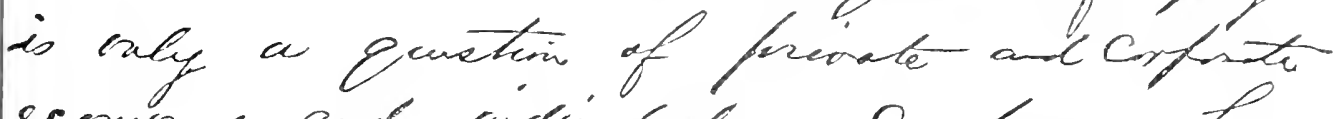

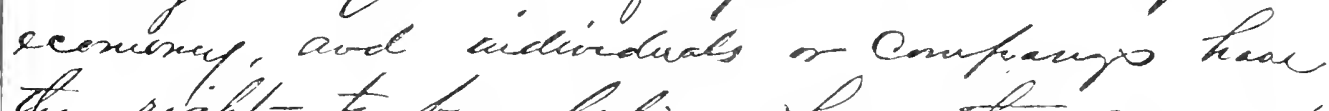
the righll- to buy labin whine ching can yet it chorfuat.

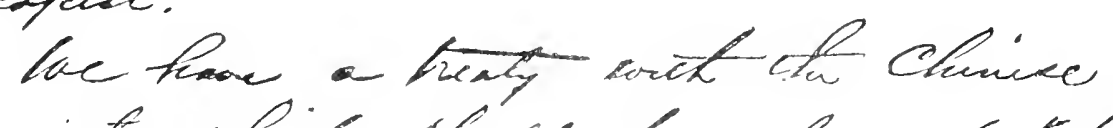

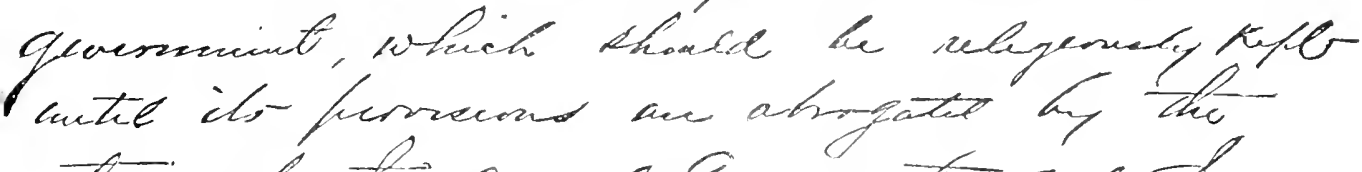

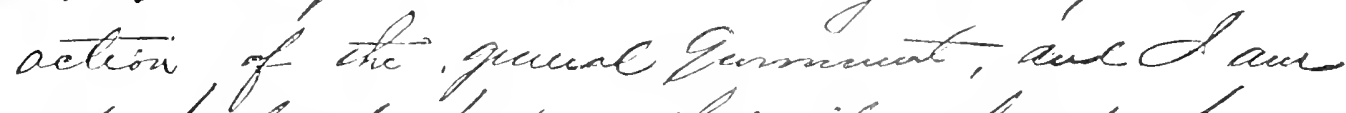

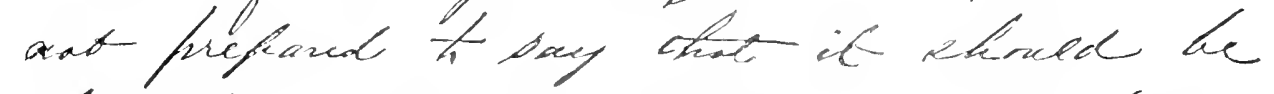

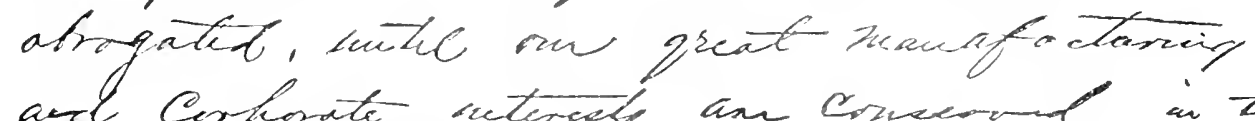

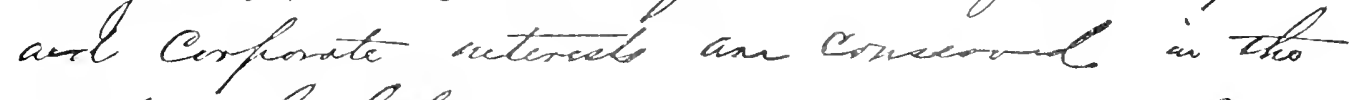
wathe of lachos,

A. D. Howey

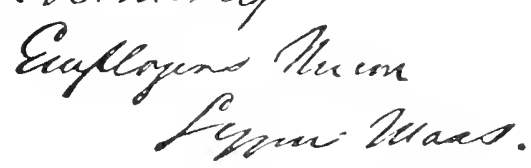

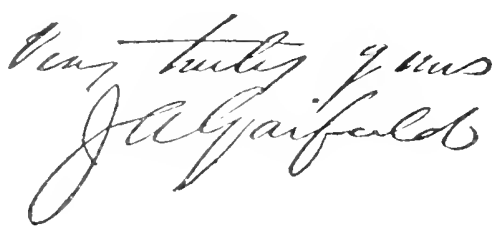

PLATE XI - Fac simile of the forged Morey letter. 
мемтов.оніо. Lec 23, 1880.

How Brunchale Gurele

Chaiman Ress. Rat. Cosmuate

24. Fifte levenue NY.

Que div:

Sn suy disfeatihes

of yesteday and this Evenng (while one alec reut you by mail chase Acmomed the mricy letter as a bace forqery. Sta stiffid and bra. läl centimentos Snever Expressel. nor Enteicained- The lithagraphis capy thoswe a very Chunsy atteugt A mitale suy, Beminanship and Aipratine. Suy one who is fauilin with my Cundersiting weil motauity Qee tha (Bteleteris epurian Den Bugly ifons

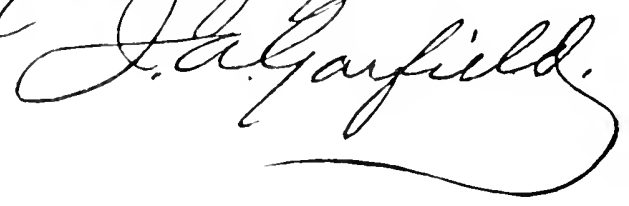

PLATE XII - Fac simile of the genuine writing of the late President Garfield. 
of it with many persons the fact that the writings look alike is deemed sufficient to base an opinion that they are the writing of one person, entirely overlooking the condition that to answer the purposes of a simulation it must look like the writing from which it was imitated, and this was just what occurred when the signature to the Morey letter was by some persons honestly assumed to be genuine. This error is one of frequent occurence, and very often misleads persons who think they know, and do not know how to determine the resemblances produced by simulation from that due to its habitual production in writing done by the same person. The Morey Letter passed into history as a fraud, and when subsequently its writer was run down and identified through the persistent efforts of John I. Davenport, no one was surprised at the result, for with the exception of identifying the author, public opinion had long before decided the letter to be a forgery.

Studied expertly the letter appearing in fac simile upon Plate XI contains within itself and apart from its comparison with any other writings internal evidence of its being spurious. Its patch-work appearance, the production of letter-forms that are not consonant with the habit producing others, all of which conditions lead to one conclusion, that the simulator had in possession a genuine signature of General Garfield's, and a small amount of his other writing, for the only imitations relate to such letters as appear in the signature and the words "truly yours;" but in producing the letter appearing in fac simile upon Plate XI, when writing other forms of letters than those in the possession of the forger, the latter had to use forms which were habitual to him. Thus it is very plain that the simulator had nothing from which to imitate the forms of the connected letters "th" as they are 
found to occur in "the," "that," or their," and wherever these letters appear they are formed without studied effort.

The word "problem," written immediately below "Dear Sir," is in part written with the natural habit of the writer, and the remainder with a simulating effort, thus "pro" is written studiedly and the remainder "blem" naturally. If the words "until," line 10 , "action," line II, immediately below the former, and the word " not," line 12 , below " action," and the word " abrogated," at the beginning of line $I \hat{3}$, are compared, it will be readily seen that "not" and "until" were written by one studied effort, and "action" and "abrogated" by an habitual effort, so unlike are they in appearance.

When the letters "J" and "a" in "Jan," at the top heading of the letter upon Plate XI, are measured, they are found to exactly coincide in width and depth with the same letters in the signature, showing that one of them was traced from the other, or both were traced from the same signature. After writing "Ja" of the date it will be seen that the rest of "January" was abbreviated and a.final letter " $y$ " formed like that occurring in "yours." On an examination of the word "individuals," occurring at line 5 of the forgery, it appears that in writting "duals" as a part of that word, the letters composing that portion of it were badly connected and show a studied patch-work effort. The simulator had no letters h, p, c, m or n, nor capital letters M, H, D or S of Garfield's writing, for where these letters appear in the forged letter they are made in the habitual form of the simulator, and without studied appearance. In making all downcurves of letters tending by direction to the right, as in the final "d" in Garfield, the letters "1," "a " and "s," when either of the latter is a terminal letter, that the simulator's best efforts appear. 
At the time of the investigation before Judge Noah Davis, in November, 1880, Experts Daniel G. Ames, Albert Southwarth, Joseph E. Paine and the author, were called as witnesses, all agreeing in their testimony that the writing of the Morey letter was not that of General Garfield, and the signature thereto a forgery. The author at that time gave a modified opinion as to the writing of the letter being that of Kenward Philp, from the fact that the examination had to be made in a crowded court room where the light was such as interfered with the use of the microscope for close work. The writing in parts did resemble that of Philp, particularly the words "Personal and confidential" at the top of the letter. The author was not a witness before the grand jury which indicted Philp. All the notes taken down at the time of making the examination were lost when the building in which the author's office was located was subsequently destroyed by fire, so the results of the microscopical examination cannot be given.

There is but a very small portion of the writing represented upon Plate XI which resembles that illustrated on Plate XII, excepting the signature and the "Ja" in "Jan" before alluded to. Where the letter forms of Garfield are used in the forgery other than the signature they are put into words with such a studied effort as to be distinctively indicative of their character, and the. effect of combining simulated letters with others that are not imitations gives to the writing an irregularity and general appearance quite different from that of the writing shown in fac simile upon Plate XII. All the efforts manifested in the latter that indicate uniformity of effort as to habitual tendencies are wanting in the other. But the most striking difference occurs when the habit of the writer who produced the letter represented by fac simile 
upon Plate XI, is compared with that of Garfield as shown upon Plate XII : all the forms of letters shown in the latter are clearly made with the pen grasped by the fingers and thumb, and moved by the forearm, while in the other all the pen movements are very clearly produced by the Hexure of the fingers and thumb. In the fac simile of Garfield's writing the pen pressure is uniform, indicating that it was moved over the paper without flexure of the thumb and fingers which held it, and the appearance of shading as a sequence of the latter. In the fac simile upon Plate XI, the lines alternate in density with light up-strokes and heavy down-strokes, indicating flexure of the factors which moved and guided the pen to make manifest this shading.

To an expert eye the signature of Garfield upon the fac simile illustrated upon Plate XII, bears on its face the appearance of tracing, and particularly in the production of the " J," the " $f$," the " 1 " and the final " $d$," and these same indications are found to occur when the words "truly yours" are examined. As a photo-lithographic fac simile shows the pictorial effect of the writing of which it is a copy, and does not show in detail the move. ment of the pen-splits, a proper analysis of the writing in the absence of the original cannot be given in detail, excepting as relates to the form of the letters and the evidences they give of the muscular habit by which they were written. 


\section{THE LEWIS WILL CASE.}

Romance could hardly have developed under the stimulus of a novelist's fancy a more cunningly developed conspiracy than that which was finally unravelled and made manifest in the trial of the before entitled case. All the details of the conspiracy were arranged with so much shrewdness and with such plausable pretensions that at times even those who had believed the efforts of the alleged widow contestant to be fraudulent, began to think they might be mistaken; so appropriately did all the details of proof, as arranged by the conspirators, answer their purpose. The incidents attending the trial, and the circumstances by which the designed fraud was discovered, are in a condensed form detailed as follows :

A miserly mulatto, Joseph $\mathrm{T}$. Lewis, for many years a resident of Hoboken, N. J., died at his home in the latter place in 1876 , at the age of eighty-seven years. $\mathrm{He}$ had been well known by his neighbors and by moneyed men as wealthy; he was something of a dandy in his dress, affected to patronize art, and was a character in his way. He left a will which provided, after paying a few small legacies, the remainder of his estate, amounting to over a million of dollars, should go to the United States government, and by the latter be applied toward the payment of the National debt. His African lineage made him an earnest supporter of the north during the war of the rebellion, which in connection with his hatred of slavery that the war had abolished, was thought to have been the incentive prompting this disposition of his property. 
The testator was shown, upon a thorough investigation made by E. DeGilmore, to have no direct heirs, although there were some claimants. On a careful search suggested by letters and other papers found among his effects, which were kept at the Manhattan Bank in the city of New York, it was ascertained that he had corresponded with persons living at Jamacia, West Indies, and thither, as dispatched by the executors of the will, DeGilmore went on a tour of research. Reaching his destination he put himself in communication with a local lawyer by the name of Nathan, and the latter on making inquiries took him to see an aged and well-known negress, from whom DeGilmore was enabled to get at the early history and parentage of the deceased millionaire. It was ascertained that Lewis was the son of a Hebrew by the name of Joseph T. Levy, and his mother was Jane Wright, a mulatto, who was also the mother of several other illegitimate children by other parentage than Levy; and it was with these persons that Lewis had in the past corresponded. DeGilmore also ascertained that Levy took the testator when a boy to the city of New York, and after giving him some education at school, that he bound him as an apprentice to an engraver, giving to the boy the name of Joseph T. Lewis. He became a resident of Hoboken in 1820 , and resided there until the time of his death. In a short biography of Lewis published in the New York Sun the following occurs :

"He dressed in well-fitting clothes and was scrupulously neat. In one hand he carried a cane and under his left arm was invariably a black umbrella on fine days in winter and a yellow one in summer weather. A flower usually decked his button hole in summer. He seems to have had a few intimate friends, among them the gentle. men named as his executors, and Herman Batjer, of New 
York, and General Hatfield, of Hoboken, but he was a mystery to them all. His conversation showed that he had travelled in Europe and South America. He displayed some familiarity with art and was a member of the National Academy of Design, and frequently was delighted to do amateurs small favors in the way of tickets. He was simple in his tastes and habits, but was not averse to letting it be known that he could be a gourmand on occasion. His opinions, shrewd and generally sound, were always strongly and sometimes testily maintained. His investments were almost uniformly successful, because he was careful and methodical, and never speculated. $\mathrm{He}$ never bought real estate. His whole fortune at his death, over a million and a half of dollars, could be carried in his hat."

The Lewis will had been drawn in the office of ex-Attorney-General Gilchrist, and the latter was engaged by the executors to sustain it; the DeGilmore before alluded to was a clerk in Gilchrist's office. Notice of the will being contested having been served, the Chancellor referred the matter to Master in Chancery See, of Jersey City, to take testimony; and while DeGilmore was at Jamaica, W. I., getting the history of the testator, a putative widow, Jane $\mathrm{H}$. Lewis, with her son Thomas, appeared as one party contestant, with Thomas and John Carhart, brothers, claiming to be nephews of the deceased, as another contestant party; and counsel also appeared to represent the claims of the Jamaica parties. The claims of the Carharts were very soon disposed of, and so were those of the testator's half-brother and sisters, but those of the pretended widow were not so easily put aside. She was a woman about forty years of age, of respectable appearance and carriage, and she told what seemed to be an apparently plausible story as to who she was and where 
she came from, although she declined to give her resi. dence. She stated how she came to be acquainted with Lewis, the details of his courtship and how at first she rejected him and afterward accepted his proposals. She produced a marriage certificate to sustain her allegation, and this document, apparently regular on its face, purported to have been made and dated November IS, I858. This certificate stated that Jane Hastings and Joseph T. Lewis were married according to the laws of the State of New Jersey by Justice of the Peace Ethridge M. Fish. The paper was signed by the latter, and, as it purported, was witnessed by George Brown and George R. Bradford, the latter testifying as to being at the wedding to which the certificate referred.

The pretended widow supplemented the production of the marriage certificate with a statement of how and why she was compelled to separate from Lewis after living with him about six months. She stated that he had deceived her and disguised his African lineage by shaving off his wool and wearing a wig, and that he used rouge to disguise his complexion, and that he was cruel and unkind to her. She produced one Schmidt, claiming to be a commission merchant doing business at i $S_{\text {I }}$ Pearl street, New York, who testified that he had seen her at the testator's house in Hoboken, and that he had been introduced to her by Lewis as his wife, and there was other evidence of like import. A New York lawyer named Caldwell testified that he had frequently visited Lewis at his house and had seen Mrs. Lewis there. This Caldwell further testified that at one time he had commenced proceedings on behalf of Mrs. Lewis for a divorce, but that a settlement had been made between the parties at his, Caldwell's, office. The case of the pretended widow at this point seemed so strong that R. W. Russell, counsel for the Jamaica 
claimants, admitted that her position could not be shaken.

This condition of the case as thus developed puzzled the executors and they put a detective on her track, but she so magician-like managed her coming and going that it was some time before they were enabled to track her to where she boarded. But it was finally discovered, and also that she was in communication with one Marcus $\mathrm{T}$. Sarcia, who had been repeatedly charged with forgery. Another fact was also ascertained that she was holding communication with a Dr. Park, who, under the pretense of learning the facts of Lewis' life for an article to be published in Harper's Magazine, had been furnished as much of its history as Joshua Benson of Hoboken, a neighbor of Lewis, could give him. It was also ascertained that Justice of the Peace Fish had, before his death, moved to Iowa, and while there had been associated with Sarcia, at that time living there, and employed in the office of the recorder of Pocahontas county. It was proved that Sarcia had been seen to be employed in tracing the signature of Fish by holding the paper against the window pane. There was a large quantity of Sarcia's writing at the recorder's office, and all who were familiar with it gave it as their opinion that the pretended marriage certificate was in the handwriting of Sarcia; the latter having left Iowa on account of the suspected forgery of some bonds. The son of Fish testified that the signature to the marriage certificate was a forgery, and not the handwriting of his father, and also, that the latter was not a justice of the peace in 1858 .

It was proved by the proponents, through the testimony of Mr. Cassillear of the Bureau of Engraving at Washington, that the engraved plate from which the pretended certificate of marriage was printed, had been altered in 
I S62, and differed from the one used before that time. In answer to this testimony the contestants produced other marriage certificates printed from the same plate as the one produced by the pretended widow, also dated in I $S_{5} S$, and they offered to prove by the registry of St. Andrew's church, that persons married there in I 858 , had been given certificates printed from the same plate, and they produced one Frank Fleet, who had such a certificate which had been witnessed by one William Arnoux. The latter, Fleet, and Elijah Caldwell, testified to the genuineness of the certificate which was dated in 1858 , and gave in apparently reasonable statements the circumstances attending the issuing of these marriage certificates.

While the trial was progressing the pretended widow was asked by her counsel if she had any material evidences in the way of tokens or relics to show that she had ever lived with Lewis as his wife, and thereupon Mrs. Isabella Harper, a boarding-house keeper, testified to having in her possession an old pillow-case containing a considerable quantity of old laces and scraps of silk, which pillow-case and contents Mrs. Lewis had while boarding with the deponent and which she had left there when she went away. On request the deponent produced the pillow-case before the master, and it was found to have been marked in a good imitation of the deceased's writing. Amongst other articles which the pillow-case contained were several receipts for money paid for board by the pretended widow, and these were signed by Mrs. Harper's daughter.

The trial was a long one and over three thousand pages of testimony were taken upon the subject of the marriage alone, but every effort made by the proponents was met by a countering one on the part of the contestants. It 


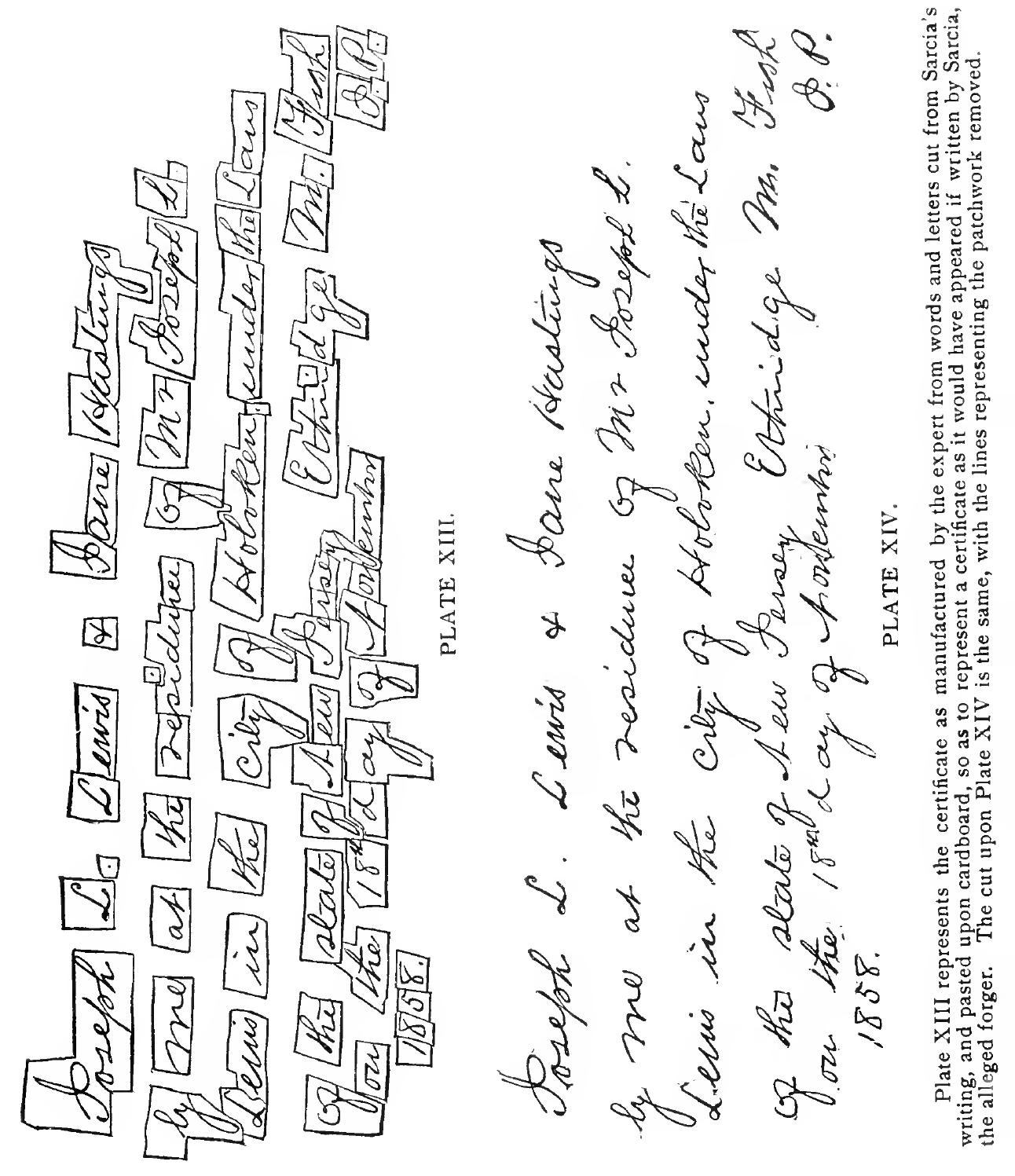




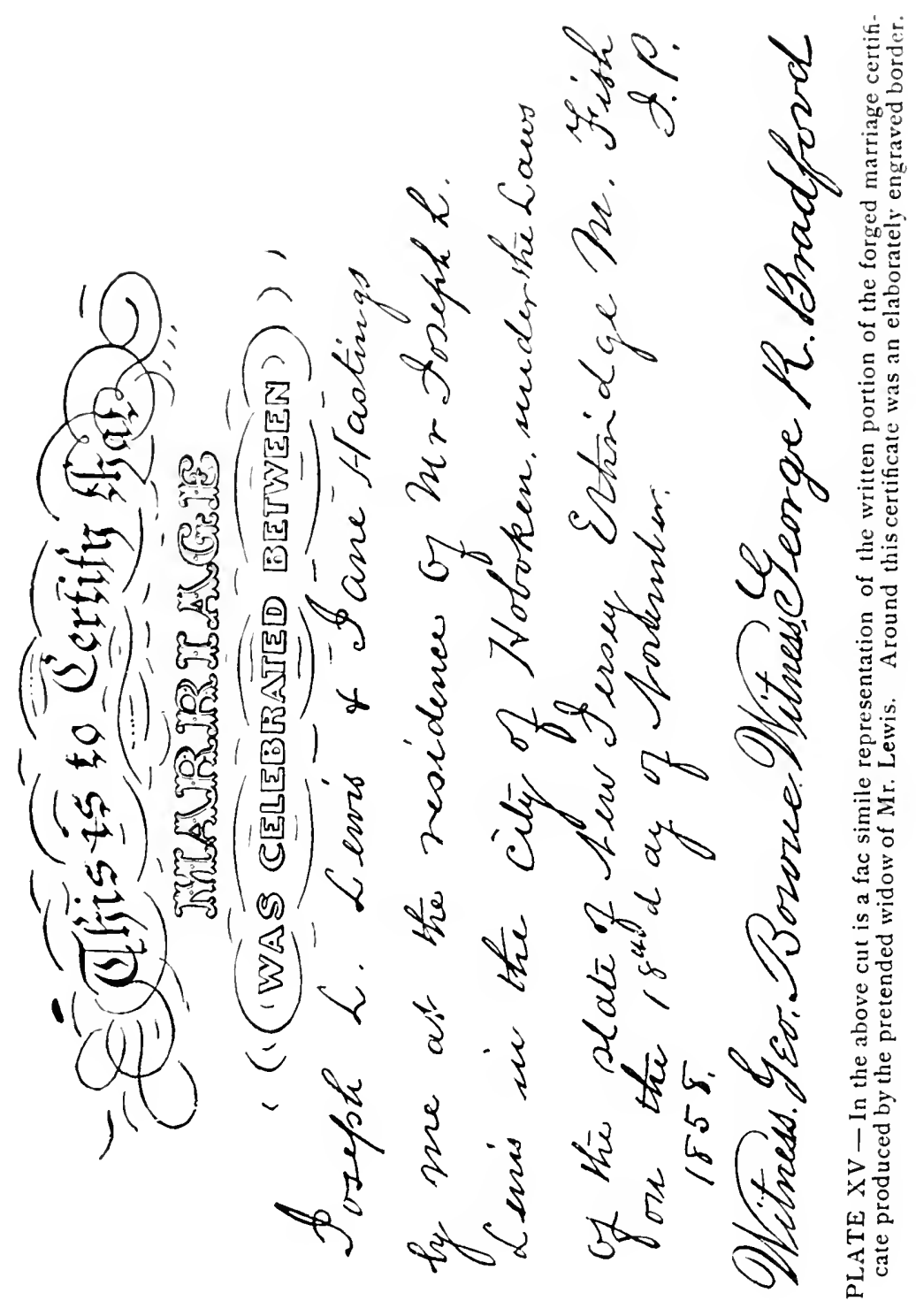


was at this stage of the trial that Joseph E. Paine, of Brooklyn, then a well-known expert in handwriting, and since deceased, was called into the case. On examining the marriage certificate produced by the pretended widow, and on comparing it as to the writing employed to fill it in, with that of Sarcia, the expert pronounced it as his opinion that all the writing on the certificate of marriage other than the witnesses' signatures was that of Sarcia, and from specimens of the latter's writing, which he procured to be photo-lithographed for the purpose, he produced the fac simile appearing upon Plates XIII and XIV, the one furnished by the pretended widow being shown at Plate XV.

About this time Frank Fleet, being taken very ill and believing that he was about to die, made a confession that he had been persuaded to swear falsely as to the marriage certificate to which his name appeared as a witness. As the case was now attracting a great deal of attention from the publicity given to it in the newspapers among the persons attracted by the sensational character of the case to attend the trial, there was one who thought he identified, in the pretended widow of Lewis, a woman who had in I874 personated a Mrs. Jennie Hammond in proceedings for a divorce, instituted by a pretended husband, in which a well-known gentleman of wealth was named as co-respondent, with the object of blackmailing the latter. This being communicated to District Attorney Keasby he secured the attendance of witnesses to identify the pretended widow of Lewis as Mrs. Jennie Hammond. John Dos Passos, a lawyer of good standing and respectability, and who had defended the gentleman made the subject of the blackmailing suit, on seeing the woman identified her positively as the one who had personated Mrs. Jennie Hammond in the suit 
alluded to, and his brother and clerk gave testimony of like character. They produced her letters and correspondence relating to the divorce suit. Matters had now assumed such a shape that respectable counsel would no longer act for her, or attempt to maintain her claims. Within a short time after this false personation had been proven she made a formal renunciation of her claims as the widow of Lewis. She confessed the whole matter, and stated that her real name was Lewis, and that she had been persuaded to do what she had done in the matter under the direction of Dr. Park, and that he was the chief conspirator.

There were nine persons indicted for their connection with the attempted fraud, six of them were tried, convicted and punished by fine and imprisonment; Dr. Andrew F. Park receiving the longest term. The pretended widow pleaded guilty and was used as a witness against the others. The author in the compilation of the foregoing facts is indebted largely to the Penman's Jour. nal of New York City, edited by Daniel G. Ames. 


\section{THE HUNTER WILL CASE.}

Theodore Hunter was a bachelor farmer living near Port Henry, Essex County, State of New York. He employed a housekeeper named Anna Murray, who acted as cook in preparing all the food he ate. There was also employed about the house a young girl named Mary Stanton. Hunter was taken suddenly ill with symptoms of poisoning He had medical attendence, died suddenly and was buried. Soon after his death, Anna Murray offered what purported to be a will of Theodore Hunter for probate, by which will with the exception of one thousand dollars left to Sarah and Chilton Trimble each, the remainder of the estate amounting to about twelve thousand dollars was bequeathed to Anna Murray, who was also made sole executrix.

After the burial of Hunter, relatives living in distant parts of the State became suspicious, they had the body of Hunter disinterred, an inquest was held, and Anna Murray was arrested and indicted by the grand jury for murder. An analysis of the stomach contents of the deceased developed the presence of metallic arsenic in quantity sufficient to have produced death. The chemical analysis was made by Dr. William P. Mason of Rensselaer Polytechnic Institute. At the first trial of Anna Murray it was proven that she had sent Mary Stanton to buy arsenic, and the druggist refused to sell it. The accused then sent a written order alleging that she wanted to kill rats with it, the arsenic was given Mary Stanton on the order, and she delivered it to Anna Murray; and 
this occurred before Hunter was taken sick, and died. It was also proven that prior to Hunter's cleath the accused had called upon Mr. Stokes, a lawyer of Port Henry, and asked him to prepare a draft of a will, which he did, retaining a carbon copy when printing it on a typewriter. It was also proven that the alleged will was with the exception of the names therein mentioned a copy of that which Anna Murray had obtained from Stokes.

Immediately after Hunter's death, Anna Murray filed a petition for the probate of the alleged will. It was contested by the heirs at law. Proceedings for taking testimony were commenced May I8, I $89 \mathrm{I}$, and terminated September 16, same year. The surrogate of Essex county decided the alleged will to be a forgery, but did not promulgate his decision until after the close of the first trial of Anna Murray for murder. The jury disagreed at the first trial of the accused and acquitted her at the second trial. She had in the meantime been indicted for forgery. The defense on the trials, proved by the undertaker who had prepared Hunter's body for burial, that he had used exteriorly upon the body a solution of arsenic, and this raised the question of doubt in the minds of the jury, and they gave the prisoner the benefit of it; although such an external use of arsenic could not account for the presence of metallic arsenic in the stomach of the deceased. The people were represented by the district attorney of Essex county, A. K. Dudley, and ex-Judge Smith of Elizabethtown, and the defense by P. C. McRory, and Hand, Kellogg \& Hall of the same place. Evidence that the will was a forgery and was done by Anna Murray, was introduced by the people as establishing a motive.

Portions of the alleged will are shown in fac simile upon Plate XVI and also fac simile representations of 


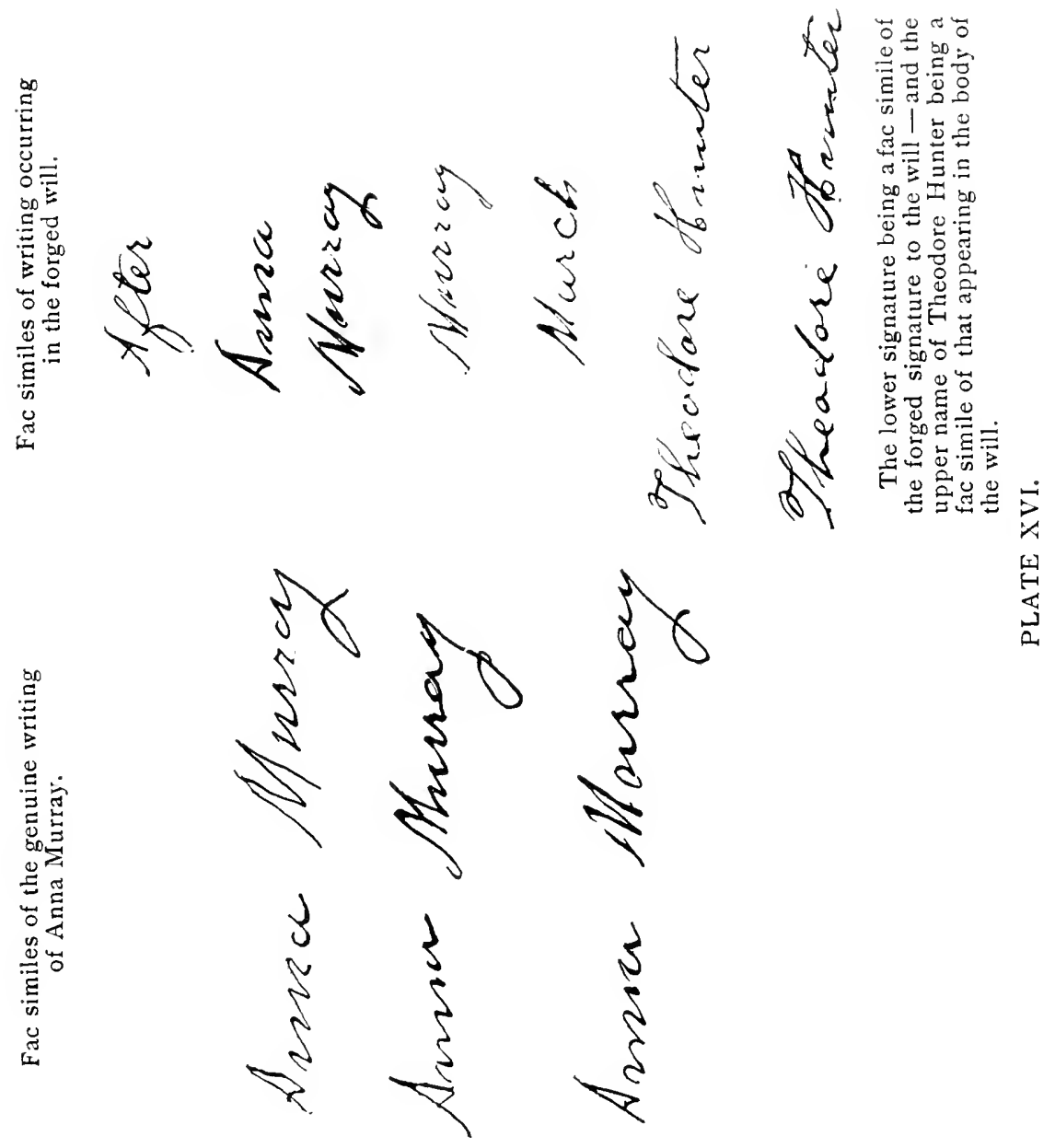


Sheodow Yleuriton

Sheodore Stounter

Ŝ́ootore Blounters

Sheorore Hounter

theortow Heunters

theodore Heunters

Theadore Dranter

PLATE XVII - Fac similes of the genuine isignature of , Theodore Hunter and the forged signature to the alleged will. 
the signatures of Anna Murray, and upon Plate XVII there are shown in fac simile the genuine signatures of Theodore Hunter, and also the forged signature to the will, the latter being that shown opposite the seal.

On examining the fac similes of Theodore Hunter's writing, and comparing them with the forged signature, the latter can hardly be said to be a simulation of the genuine writing of Hunter in any other respect than as to that resemblance which the writing of the same signature by different persons will have when compared. The form of the letters is very different in the two writings, and no effort appears to have been made to incorporate into the forged signature the habitual forms of the genuine by simulation. In the genuine signature of Hunter, the habit of the writer is strong in its personality as to the manner of producing the form of the letters composing it; while the details which characterize the method of writing it are all wanting in the alleged sig. nature to the will. Hunter wrote his name with great uniformity, and marked peculiarity as to individual habit, and the signature to the alleged will is so unlike the genuine writing of Hunter as to hardly require an expert eye to determine the forgery. But the question to be considered is, did Anna Murray write it, and can this be satisfactorily determined from the small amount of her admitted writing accessible as standards for comparison?

The alleged will contains the name of Anna Murray as occurring in two places, and there are three admitted signatures of hers from which to make the examination and formulate an opinion. If, however, it can be found to occur that Anna Murray wrote the body of the alleged will by comparing her admitted writing with it, it will very positively appear as a sequence that Anna Murray 
wrote the forged signature from the very close resemblance appearing between the forged signature of Hunter and the words Theodore Hunter occurring in the body of the alleged will, and as appearing side by side upon Plate XVI.

The words "Anna Murray" contain but seven letters considered apart from their repetition, and hence comparative form can only be found to occur in the letters "A," "n," "a," "Mur," and "y," from which to connect the signature of Anna Murray with the writing of the alleged will or the forged signature, and this would seem but little material upon which to base an opinion with the forms of but seven letters out of the twenty-six composing the alphabet found to occur in the signatures Anna Murray used as standards. This condition renders the chances of reaching an accurate conclusion as to the habit of the writer based upon the form of the letters alone very remote, from the evident fact that there are no letters in the standards with which to compare a large majority of those found in the body of the alleged will. But if the admitted writing of Anna Murray be examined microscopically, and the physical habit of the writer can be determined from the details appearing in it, then all the forms of the letters produced will indicate the habit of the writer whether this habit was employed to make the forms of letters appearing in the standards, or other forms indicative of the same physical habit occurring in the alleged will and signature.

On examining the signatures of Anna Murray as standards to ascertain the physical habit of the writer of them as to its individuality, very prominent conditions of muscular coordination are manifested with distinct definition. These features are those which designate the manner in which the pen was grasped and operated, and 
upon which primarily all analysis of writing to determine individual habit must be based, as the manner of producing the form of letters constitutes the habit, and the form is but the sequence of a series of muscularly operated coordinate acts producing it. When the admitted writing of Anna Murray is studied analytically, and with its details enlarged by the microscope, it appears that in all the heavy down-strokes of letters where above the line on which the writing is done, that there was a struggle between the index finger which bore upon the outer face of the pen as this finger curved inwardly towards the palm of the writer's hand, and the thumb of the latter against which the pen was thus moved down. wardly and inwardly. It also appears that when dem. onstratively produced in these downstrokes of the pen it becomes manifested as an angularity, although it does not always appear with the same measure of emphasis. This detail prominently occurs in the letter "A" of "Anna" in the upper signature illustrated in fac simile upon Plate XVI, and in the same part of the letters " $\mathrm{M}$ " of all the standard signatures. A close inspection of these peculiarities shows that there accompanies their production a rotation of the pen, and from the manner in which the pen-splits delineate the movement as they are shown to weave inwardly and outwardly while rotating it is plainly manifested that the pen was held nearly vertical. Finding these features to occur in all the heavy downstrokes made by the pen above the line on which the writing was done, another detail indicating this character of pen-grasp is found to occur where period-form dots are produced as parts of letters, and which, when examined microscopically, indicate that they were produced by holding the pen nearly vertical and rotating it with its points resting on the paper. One of these period-form dots 
appears at the commencement of the letter "A" in "Anna" of the upper one of the signatures illustrated in fac simile, and also at the termination of the "a" in "Anna" in the upper and middle signatures, also in the crossing of the "A" of the lower signature, also at the commencement of the first "a" in "Anna" of the latter, and at the end of the final "a" in all the signature fac similes of Anna Murray.

Continuing the analysis of the standard writing, it appears that this rotation of the pen is found to occur in all of the up-strokes of letters, and in the lines connecting the letters where tangential to the line on which the writing is done. This rotation of the pen as a manifested detail appearing in the standard writing could only have been produced as it appears, by the thumb or index finger of the writer, or by the combined action of both, and to determine from which of these two factors this impulse comes, the following details are apparent. The heavy down-strokes show this peculiarity with more emphasis than the up-strokes, and lines having an inclination to the left contain the strongest phases of its development, with the effect of the impulse more prominently marked at the upper end of the down-strokes than after the latter are continued down towards the line on which the writing was done. This fact, taken in connection with that which establishes that the thumb must have been the resisting member in all down-strokes where evidence of a struggle appears, also indicates that the thumb, instead of acting with adductor capacity harmoniously with the index finger, impeded its incurving, and caused the pen to roll along over its muscular cushion on which the pen was held.

That the second finger of the writer's hand was a subordinate factor in the production of the standards, and per- 
formed no function that is apparent, is easily determined from the entire absence of all movements of the pen to the left at the tops of letters; thus indicating that the thumb and index finger were the operating ones, and produced all the individuality manifested in the writing. Having thus ascertained the muscular factors which operated the pen by which the standards were written and that it was held nearly vertical, another characteristic is apparent in the writing of them which indicates that the index finger of the writer lay across the outer face of the pen, so that it could cooperate with the thumb in making all the lateral movement of the pen towards the right. This condition of pen-grasp is ascertained by the formation of the curls at the commencement of the first "a" in "Anna" in all of the standard signatures, the incurl or loop at the tops of the letters "a" in "Anna," the loops at the bottom of the letter "y" in "Murray" and the manner in which the offthrow from the period-form dot at the tops of the letters " $r$ " is made tangent thereto.

Reaching these conclusions as to the habit of the writer of the admitted signatures of Anna Murray, and after giving a few of the more important features upon which they are based, attention is now directed to the forged signature of Theodore Hunter.

On examining microscopically the staff of the letters " $T$," " $h$," " $d$ " and " $H$ " of the forgery in all of the heavy down-strokes there is manifested the same rotation before described as occurring in the standards. In addition to the foregoing there is found at the bottom of the letter "T" a period-form dot made by holding the pen vertically and rotating it with its points resting on the paper; and this same period-form dot is found to occur in the letters "o" of "Theodore" and at the termination of the " $\mathrm{e}$ " in the latter, just as it occurs at the termination of the letter 
"a" in "Anna" of the standards. The initial curl of the letter "u" in "II Inter" is the counterpart in form and details of production with that appearing at the commencement of the " $n$ " in "Anna" of all of the standard fac similes, and at the end of the line crossing the letter " t" in "Hunter" of the forgery there is a period-form dot made by rotating the pen with the latter held vertically. The "u" of "Hunter" is formed with its second or right-hand member having more height and with a more broadly-rounded top curve than its first member, just as has the " $\mathrm{n}$ " in "Anna" in the fac similes upon Plate XVI. The slant of the writing, the measure of curve, as well as the character and dimensions of the letters, the lines connecting the latter, and their spacing, together with the degree of pen pressure, all indicate the same conditions of physical habit in both the standards and the forgery.

When the words "Anna Murray" as appearing in the body of the alleged will and as illustrated in fac simile upon Plate XVI are compared with the standard fac similes appearing in column at the side of the others, all the characteristics of the one are prominently apparent in the other, and when examined microscopically they become even more clearly established as the writing of one and the same person and fully indicate that Anna Murray wrote the alleged will and its forged signature. The analysis leading to this conclusion extended into a more specific study of this rotation of the pen than is herein given, and it led to the determination that not only did this detail occur in the forgery and the standards, but in both writings it was attended by the same features as to character and kind.

While in many cases signatures are not the best standards to determine the physical habit of a person as to 
their writing other than signatures, in the case being considered the evidence appearing indicated that the writer produced the alleged will with the same habit that she did her signatures, and that the latter were written without signature expression. In fact the writing habit of the writer who produced the standards was so intensely individual in character, that the staff of a single letter written by her would contain strong evidences of its authorship. 


\section{THE DAVIS WILL CASE.}

This case attracted a great deal of attention throughout the country at the time of its being tried at Butte City, Montana, in August, 189I, on account of the circumstances attending the production of the alleged will, the great array of eminent counsel engaged in it, and the large amount of the estate involved, which was estimated at from seven to ten millions of dollars. Andrew J. Davis, the alleged testator, was a native of the State of Massachusetts, and was born in the year I8I9. In 1849 , under the influence of the excitement produced by the discovery of gold in California he emigrated to the latter State, and after a residence there of several years he returned to the east without having accumulated any thing. He lived several years in Indiana and Michigan, and in 1858 , he settled in Iowa, where he remained until I86I, when he moved to Montana, At the time of leaving Iowa, while having some money he was far from being rich, but while residing in Montana he accumulated money very fast by his mining and other ventures. At the time of his death in 1890 , his heirs (as he had never married) were his brothers Erwin, Calvin, John A., one sister, and the children of three deceased sisters.

About two years prior to his death he made his will, which he deposited with Mr. Knight, cashier of a bank at Helena, Montana, in which bank he was largely interested as a stockholder; he making the cashier custodian of his will. This latter will, in the presence of the cashier, he destroyed about one year before his death, and it 
was proven on the trial by the cashier who drew the will that the name of his brother, John A. Davis, was not mentioned in it. It was also proved on the trial that when the will was read over to him before signing it, he remarked that it was useless to state therein that he revoked all former wills made by him, as he had never made any other will. Soon after the death of Andrew J. Davis, his brother John A. Davis applied for letters of administration upon the estate of his deceased brother before the Probate Court at Butte City, Montana, making oath that the deceased had made no will. This petition of John A. Davis was opposed by the nephew and nieces of the deceased on the grounds of incompetency, inentally and morally; that the applicant had no responsibility, that he had never been able to manage his own business, was an imbecile and drunkard, and not fitted for so responsible a trust. The Probate Court, however, granted the petition, whereupon the contestants carried the matter by appeal to the Supreme Court of the State; this court consisting of a chief justice and two associate judges. This latter court sustained the decision of the Probate Court below; the chief justice dissenting in an elaborate opinion as to the evidenced incompetency of the petitioner, John A. Davis. As a majority of the heirs resided out of the State while preparing to take it into the United States courts, the alleged will was produced by John A. Davis, was offered for proof, and became the subject of contest.

The will offered by John A. Davis for probate, purported to have been made in Van Buren county, Iowa, in I866, some time after the alleged testator had removed to Montana, and it singularly provided for the life maintenance of T. J. and "Pet" Davis (natural children of A. J. Davis) and their mother, Miss Burgett, 
stated in the alleged will as being "all of Van Buren county; Iowa," and bequeathed all the remainder of the estate to John A. Davis, the proponent, thus ignoring the deceased's father and mother then living, and dependent upon him for support, as well as his older sister of whom he was very fond and who had cared for him in childhood. It was proven on the trial that at the time the alleged will purported to have been made, that Miss Burgett had, in fact, been married some years, and with her laughter had moved to Texas, a circumstance which the contestants claimed A. J. Davis must have been cognizant of, and the misstatement of the facts in the alleged will was an evidence that it was not his act. The case came on for trial before Judge McHatton and a jury at Butte City, Montana, in July, isgi.

The proponents argued and introduced evidence to prove that the alleged will was in the handwriting of Job Davis, one of the witnesses to it; the other witnesses being James Davis and J. C. Sconce. The two witnesses Job and James Davis were in no way related to Andrew J. Davis, the alleged testator, and were both of them dead at the time the will was produced and offered for probate. Sconce's other witness was living, and it was on the trial proved that he dallied with both sides of the controversy as to being a witness to the probate of the alleged will, and by his own evidence and cross-examination it was drawn out of him that he had signed a contract with the proponents, by which he was to receive a large sum of money in case the will was sustained; but to have a liberal per diem in any event. As will subsequently appear, it was proven by the chemical tests made of the ink with which the signatures were written, and at the instance of the proponents, that the signature of Sconce as a witness to the alleged will was written with a differ- 
ent ink from that with which the other signatures were produced, and it was proved by the testimony and the appearance of the Sconce signature that it must have been written at a different time from the others.

The alleged will was written upon a double sheet of legal cap, which had all the appearance of having been treated with a staining liquid of a coffee color before the writing was done, in the fact that the microscope showed the writing to be on top of the stain with none of the latter on top of the ink with which the document was written. The paper had evidently been treated with a hot flat-iron until it was almost charred in places, and a pot or kettle, the bottom of which was covered with soot, had been applied to the paper in two places to make an imprint thereon, after the writing had been done. These two imprints exactly coincided in measurement, indicating that they were produced by the same implement, and from their appearance it was plainly manifested that after one imprint had been made upon one face of the document, it was unfolded and another made upon a different part of it. The ink with which the writing was done had settled into the paper instead of appearing in relief upon it, the latter condition being that which indicates age; and the manner in which the writing was manifested in this respect determining it as recently written. Its color was a black, slightly shaded into blue, with every feature indicating that the ink with which it was produced was a modern analine ink. According to the alleged date of the will it was twenty-five years old, and yet the ink with which it was written did not show any fading, and was as bright and fresh as if done within a year.

The alleged will had been folded on the line in which the date appeared, and this fold was not the first fold made in it, as it did not register with the other fold lines, and 
where thus first folded both sides of the paper had been rubbed with a wet woolen rag embracing both of its sides until the paper thereat had been balled up by the wetting and rubbing, and particles of shoddy coming from the rag were found adhering to it. This rubbing had been done to such an extent as to make the date, with the exception of the figures stating the year, quite obscure. Pin-holes had been systematically punched through the paper on which the alleged will was written, and this condition of it was by the proponents proved to have been done by a child who was playing with it sonie years after the will had been made and executed; but the fact was very plainly manifested that at the time the alleged witness, Sconce, signed the will the pin-holes were there, for the pen with which he wrote caught in two places in them. While the ink with which the alleged will was written showed no evidence of having faded, according to the care the paper had received, as proved by the proponents, it had been subjected to the best possible conditions to cause it to fade. The paper had been scalloped out at the edges as if pinched out by the thumb and fingers, and these scal. lops did not occur where handling or wear would have been likely to have caused them, excepting in one instance.

The proponents introduced evidence to show that this allegred will was found in the house of a Mrs. Downey in Iowa; she was the sister of the late Job Davis, one of the alleged witnesses to the pretended will. It was also proved by her that she suggested to her son James R. Eddy, on hearing of the death of A. J. Davis without a will, that there was a will of the deceased somewhere about the house. This man Eddy was at the time of the trial apparently about thirty years old, which would have made him about five years old in 1866 , at the time the alleged will purported to have been made. $\mathrm{He}$ was 
accused by the contestants of having forged the will, which when found was in his possession, and as his mother testified, that on finding it he put himself in communication with John A. Davis.

The theory of the contestants as regards the ink with which the will was written was that it was made from nigrosine, a form of black analyne which was discovered about i 870, and they proposed while their chemical expert was in attendance to make a chemical test of the ink to determine the fact; but to this the proponents objected, and the court sustained the objection. After the chemical expert called by the contestants had returned to the east and could not have reached Butte City in time to be present at the testing of the ink, the proponents proposed the making of it, and it was done in the presence of one of the contestants' experts who was not a chemist. Hydrochloric acid, full strength, was applied to various parts of the writing upon the alleged will and the witnesses' signatures, and this reagent turned the ink red, the characteristic reaction of this reagent when applied to logwood ink, and to which the contestants' expert present assented. But the fact that it turned the ink red, and this would be the reaction it would have upon logwood ink, did not fully establish the identity of the latter, for according to the best chemical authority this same reaction would have occurred were it made from analyne black (see Allen's Commercial Organic Analysis, edition of 1889 , page I 30). One fact, however, was established that if it was a logwood ink as the proponents assumed to have proven why it should have preserved its freshness when the well-known character of logwood inks has long been established as fugitive (see Bloxam's Chemistry, edition of I 890, page 678). There was one fact developed by the chemical test thus made, that the ink with which the sig- 
nature of the alleged witness Sconce was written, was clearly demonstrated to be of a different kind from that with which the other signatures were written. To have made this test properly there should have been applied to the ink acted upon by the hydrochloric acid a supplemental test by using ammonia, which if the ink was made from logwood would have turned the red produced by the hyclrochloric acid to a deep purple.

Under a statute in force in Montana as interpreted by the presiding judge all expert evidence as to matters of opinion concerning the writing of the alleged signatures of the witnesses or that of the testator, whether they were tracings from other signatures or as to who wrote the body of the instrument by comparison were industriously excluded, but persons who had seen A. J. Davis write his name many years before were considered competent witnesses. The contestants were allowed to prove how peculiarly wrong J. R. Eddy spelt the word "give," and this and other individualisms of his writing in the alleged will, but the jury were not allowed to see the writing of Eddy for the purpose of showing that he wrote it, and to contradict the proponents who had introduced evidence to show that it was the writing of Job Davis. It will be remembered in this connection that Eddy was a mere child at the time the alleged will purported to have been made and executed.

If the Legislature of Montana could have had in view the effect of this statute as interpreted by the presiding judge, that body must have had a very poor understanding of jury intelligence in that State, and have considered it much below the ancient standard of some hundred years before, when the common-law rule became neces. sary in the fact that juries then could not read or write, for the Montana statute went even further than the com- 


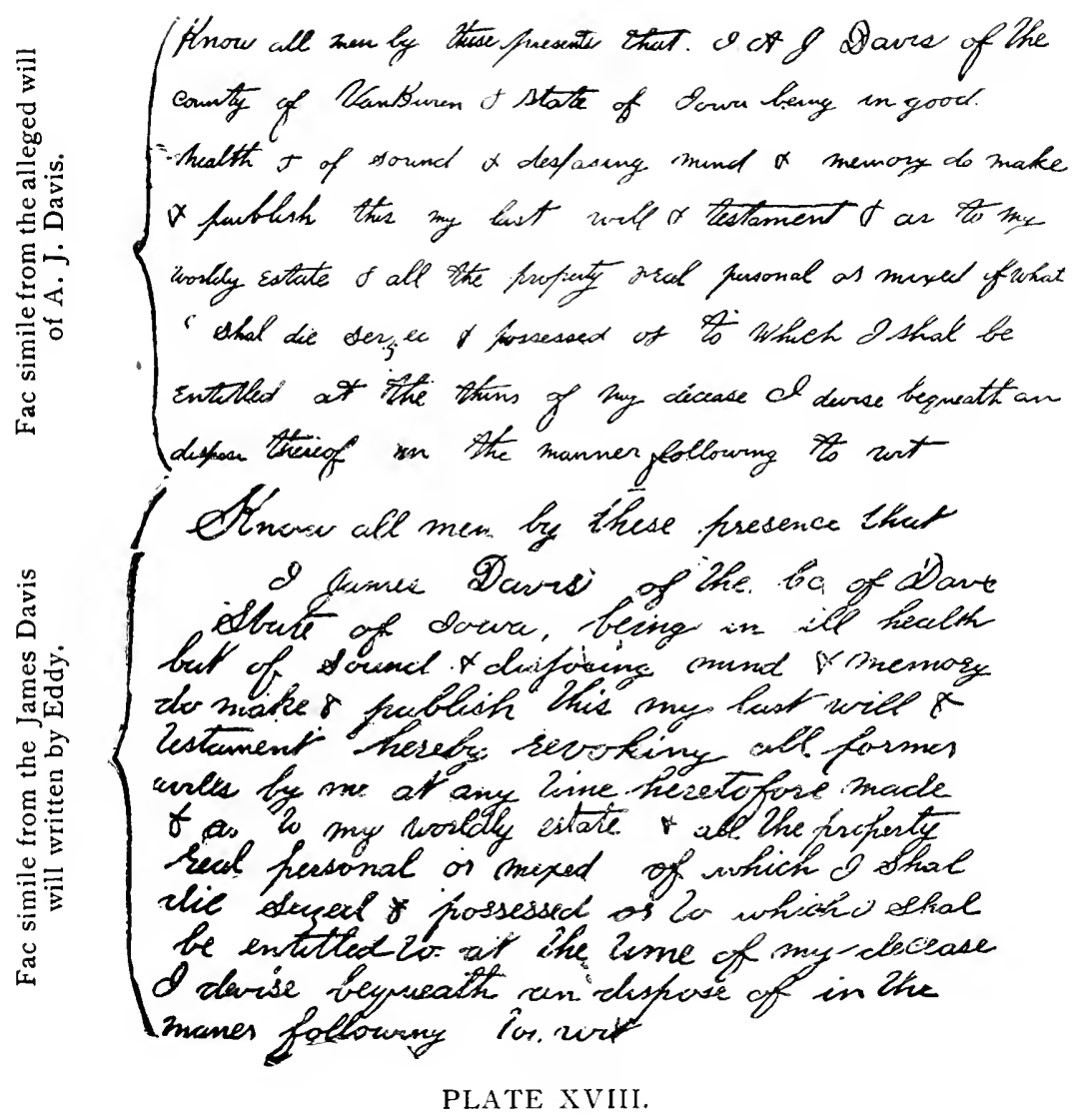




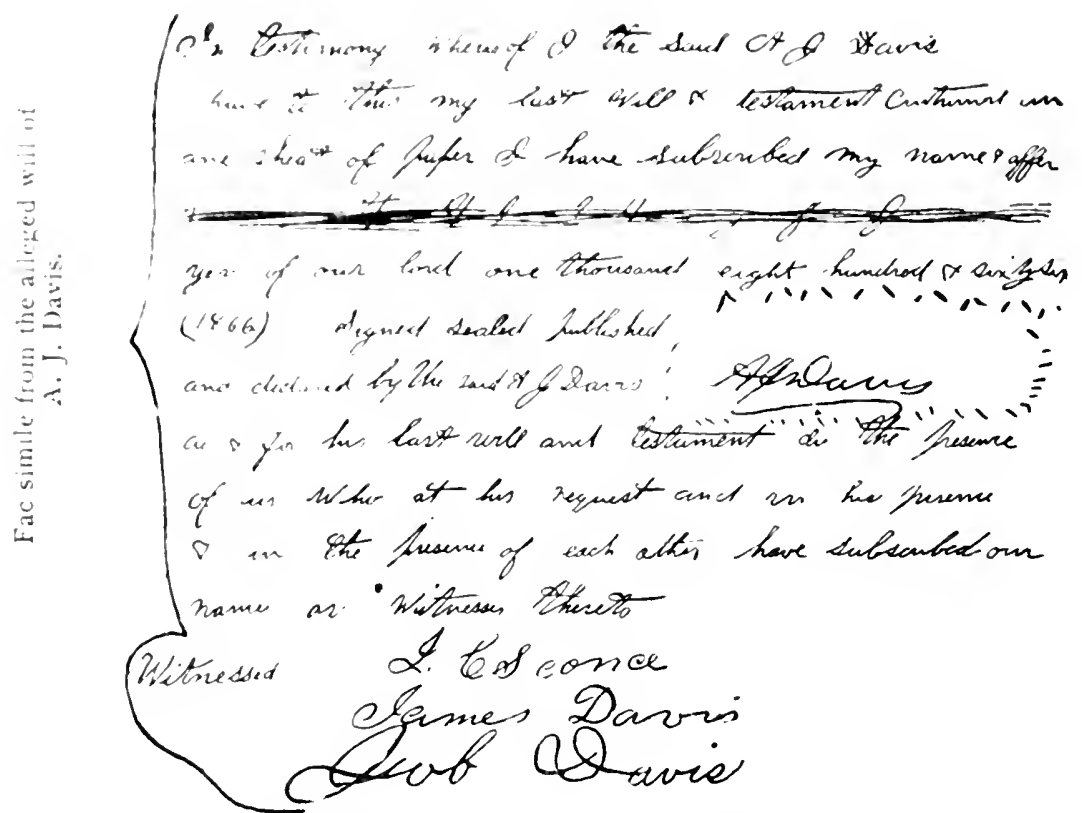

(An lestimany sohereof o the such farnes Davir huve 20 Chis my hust writ o Reskmel sontained on ane sheut of fafes I huve Hbsesibed my name $X$ offixed my seal Thes 1 he 12 vlay of Tebucing A D. 1885 "eyhtsten hunctred 8 lunty five. Siyned sealed fublished.

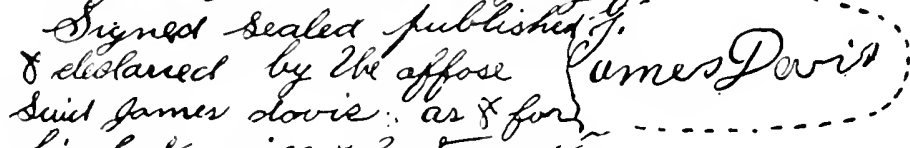
his last will $x$ hestaments in the fresendel of uss rat WH Davis his requeat of in his gohn P Pogers each other have subsereded ove

PLATE XIX. 


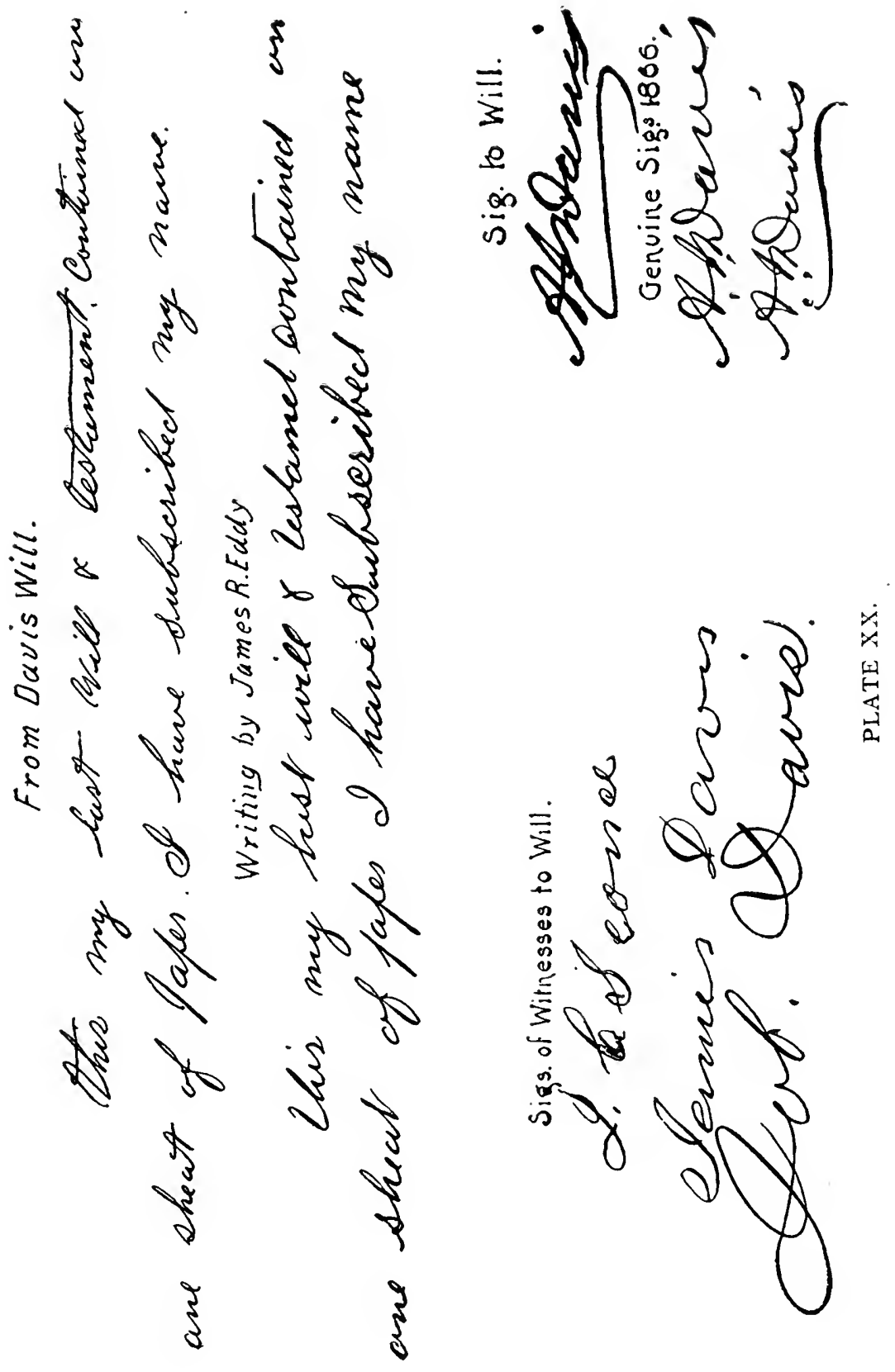


Fac-similes from Will. Fac-similes of Eddy's writing

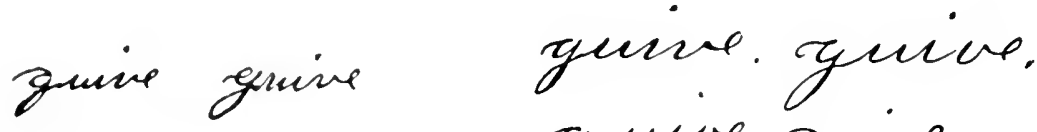
gunve guive.

moslely Estute nuosldy estate stad strat othal stral shal shal shal shal

An lestimany on Restamany wherth vhesties

my. Iny. Bny

Bny. ny. suy

my muy my Ony my ny

fropenty.

property

poperts

profert

PLATE XXI. 
mon-law rule, in the effect which the court in this case held to be the purport of the statute.

After proving the scientific education and large experience of contestants' expert witnesses in handwriting when asked if from any thing appearing in the signature of $\mathrm{A}$. J. Davis, they could tell how it was produced, on objection the question was excluded. No ingenuity of learned counsel could propose any question bearing upon the handwriting of the alleged will, as to proving the alleged signature of the testator to be a traced signature (which it very plainly was), on objection was excluded. Thus there was no evidence submitted to the jury that would aid them in reaching a conclusion upon such matters relating to the writing concerning which they had no experience, and about which they could not be expected to have any. A person who had seen A. J. Davis write his name many years before, was under the rule a competent' witness, and because the signature looked like that of the testator as remembered, and without taking into account that a forged signature must resemble that which it purported to represent, such person would testify that it was the genuine writing of A. J. Davis, and thus evidence which was only calculated to mislead the jury was all that was submitted to it under the statute as interpreted by the trial judge. The jury disagreed, seven of them siding with the contestants and five with the proponents.

The alleged will was identified as first in the possession of James R. Eddy, and as to whether he wrote it is best determined by an examination of the accompanying fac similes of the writing of Eddy, when compared with that occurring in the alleged will of A. J. Davis. Eddy was a kind of will-maker for the people of the town where he resided $\mathrm{He}$ did the work cheaply and prepared 
a number of wills for his townsmen, which came into the possession of the contestants, and it is from one of the latter that the fuc similes representing Eddy's writing are taken. Parts of the alleged will and parts of a will written by Eddy for James Davis appear in fac simile upon Plates XVIII, XIX and XX, illustrating this case and

Fac similes from alleged will of A. J. Davis.

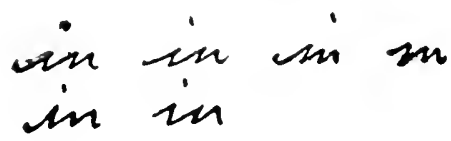

E E Entitted

$$
\text { (1866) }
$$

$\alpha \times \propto \alpha \propto \alpha \alpha$

$\propto \propto \alpha \propto \alpha \quad \gamma$

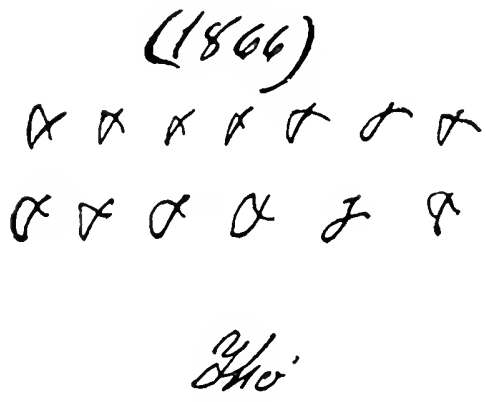

Fac similes of J. R. Eddy's writing.

(1882.) (1887)

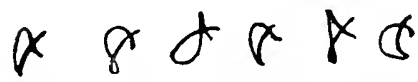
$\operatorname{se\phi } \otimes \phi x$ Whis

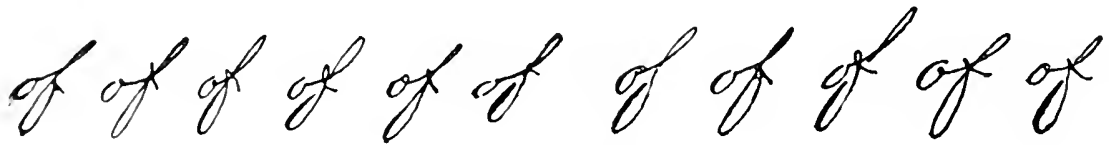

PLATE XXII.

on which plates the writing is shown in reduced size. On Plates XVIII and XIX and upon Plate XX, in the same size as the originals, there are illustrated in accurate fac simile, two lines from the alleged A. J. Davis will and two lines from another will drawn by Eddy, and also in 
the same size as the originals, fac similes of the witnesses' signatures and that of the testator to the alleged will of A. J. Davis. Upon Plates XXI and XXII there are shown specimens of the writing of Eddy taken from other wills drawn by him, arranged in column, and in another column fac similes of the same words as occurring in the alleged will of A. J. Davis.

The signature of A. J. Davis to the pretended will is plainly a tracing from its want of shading emphasis, the sameness manifested in the pen pressure, the frequent pauses made by the writer when inking over the leadpencil lines of the tracing, and the presence of the latter where not covered by the ink, showing a slow and studied movement which occurs in all traced signatures. Although the fact of its being a traced signature did not necessarily call for its comparison with genuine writing of A. J. Davis to determine it, and could be ascertained by an examination of the signature, yet proof this kind as to itself being a traced signature was objected to, and the objection was sustained by the court.

A very carefully-made analysis of the writing of the alleged will, and also the writing of Eddy very positively identified them both as the product of one and the same individual habit, and so plainly that the chances of being mistaken were too remote to be taken into account when formulating an opinion in regard to it.

For the Proponents, J. M. Woolwarti, Omaha.

W. F. Sanders, Helena, Montana.

H. W. Dixon, Butte, Montana.

W. Kirkpatrick, Butte, Montana.

H. H. Trimble, Keokuk, Iowa.

For the Contestants, R. I. Ingersoll, New York City.

Nathaniel Mrers, New York City.

E. W. Toole, Helena, Montana. 
For the Contestants, I. B. Chayberg, Helena, Montana. Rulinson \& Stapletun, Butte, Mon. D. H. PaYne, Iowa.

Statutes of the State of Montana Relating to ExiERT Testimony, i 887.

Section 105, page 526: Persons of skill shall be competent witnesses to prove that such bill or note is forged or counterfeited.

Section 617, page 223: A witness can testify of those facts only which he knows of his own knowledge - that is, which are derived from his own perceptions - except in those few express cases in which his opinions, or inferences, or the declarations of others are admissible.

Section 300, page 460: Persons of skill, or experts, may be called to testify as to the genuineness of a note, bill, draft, certificate of deposit, or other writing; but three witnesses at least shall be required to prove the fact, except in case of larceny thereof.

Section 635, page 225: When the characters in which an instrument is written are difficult to be deciphered, or the language of the instrument is not understood by the court, the evidence of persons skilled in deciphering the characters, or who understand the language, is admissible to declare the characters or the meaning of the language. 


\section{THE GORDON WILL CASE.}

The Gordon will, coming to light as it did apparently a concomitant of the prevailing epidemic conditions which led to the appearance of the Davis will in Montana, and the Dempsey will in New Jersey, after the long rest of years during which these documents purported to have slept in each instance, caused it to attract a great deal of attention from these conditions of its emergence apart from any other. Whether the appearance of what purported to be in the one instance the discovery of a long lost document had prompted the appearance of the others, or the surroundings attending the coming to light of the alleged Davis will, and the pretended Gordon will prompted the search which led to the finding of the Dempsey will, the facts of their appearance within a short time of each other, and the circumstances of their assumed age remained the same even if the suggestions prompting the details attendant upon their resurrection were alike or different. Upon the trial of the Gordon will case before the Ordinary in New Jersey, the following facts were established as to its history and the adjudication promulgated in regard to its character :

George P. Gordon died at Norfolk, Va., January 27 , I876. He was at the time of his death well known as an inventor and manufacturer of printing presses, from which he realized profits, and he accumulated a large estate. He left a widow, Leonora M. Gordon, and a daughter, Mary Agnes Gordon, by a former wife. Gordon made a will which was clated July 26. I 873 , and 
which when presented for probate before the surrogate of Kings county, New York, was contested by the widow and daughter, and rejected by the surrogate, Henry J. Cullen. The latter was appointed temporary administrator, and subsequently, on May I, 1878 , administrator of the estate of Gordon. An attempt was made by the beneficiaries of the rejected will, other than the widow and daughter, to have the surrogate grant another trial after the rejection of the will, but on submitting their new proofs the surrogate did not deem them sufficient to grant a rehearing, and the estate of George P. Gordon was settled as that of an intestate. The widow and daughter taking the estate from which, by disposition made through the trustees Henry Cullen and Josiah Porter, the contestants, received a share, amongst whom was Adeline J. Gordon, one of the proponents of the pretended resurrected will. The widow, Leonora M. Gordon, died in December, I 890, and Mary Agnes Gordon, the daughter of George P. Gordon by a former wife, died in Paris in the spring of I 890 , leaving a last will and testament by which she devised the bulk of her estate to Pauline Theresa Reitz and Samuel De Ruyssenaer, who with others became contestants of the alleged George P. Gordon will.

On the presentation of the will of the daughter, Mary Agnes Gordon, for probate before the surrogate of New York county, it was contested by the next of kin, and is still unsettled. The contest over this will of Mary Agnes Gordon attracted considerable attention and notice in the daily papers, particularly an article relating to it which appeared in the Ncw York Evening Telegram, entitled "Battling for a Fortune," which meeting the eyes of one Henry G. Adams as it appeared in proof, induced him to write to the attorneys of the contestants of the Mary Agnes Gordon will, Messrs. Black \& King of New York 
City, informing them that if they would meet him at a time and place appointed "bringing no brass band, fife or drum," that he could tell them something worth knowing. On meeting Adams the latter informed these attorneys that he, Adams, had a copy of a will which he had drawn for George P. Gordon, the original of which the latter had executed, and if the original could not be found, they could, from the copy and by him, prove its contents as that of the lost will. This proposition to attempt the proving of a lost will the attorneys did not like, and they urged him to make search for the original, which Adams assumed to do, and it resulted in his producing the pretended long slumbering original, finding it, as he alleged, in the house of his brother at Rahway, N. J., which had been formerly the residence of his father.

This alleged will of George P. Gordon, bearing date July 28 , I 868 , was admitted to probate by the Ordinary upon the petition of Adeline J. Gordon, on January I6, I89I, without notice to the representatives of the estate of the widow, Leonora M. Gordon, or those of the daughter, Mary Agnes Gordon, the only immediate family representatives of George P. Gordon having died before the alleged will was produced for probate. Soon as the probate was published, by filing the ancillary probate of the instrument in Kings county, New York, application was made to the chancellor to revoke the probate, by IV. W. Olds, executor of the widow, Leonora M. Gordon, and Henry J. Cullen, administrator of the estate of George P. Gordon, on the ground: First. That George P. Gordon was not at the time of his death a resident of the State of the State of New Jersey; and sccondly, that the instrument purporting to be the last will and testament of George P. Gordon was a forgery. Upon these proceedings the Ordinary directed the probate 
to be made in solemn form, and testimony was taken on the two points submitted by the contestants during the year 1 S92.

After a prolonged trial and the taking of a great deal of testimony, and after months of consideration, the Ordinary rendered his opinion, non-concurring as to the question of jurisdiction raised by the contestants, but sustaining their second point that the will was a forgery, and the work of Henry G. Adams. For the foregoing history of the case the author is indebted to Theodore F. Miller, Esq., of New York City, of counsel for the contestants.

Upon Plate No. XXIII there is produced in fac simile the signature of George P. Gordon, in connection with the last three lines of the disputed will, and upon Plate No. XXIV there are shown in fac simile formally produced signatures of George P. Gordon, written about the same time as the date of the pretended will, and upon Plate No. XXVI there are shown in fac simile informally written signatures of George P. Gordon.

Upon examining the writing of Gordon as appearing in his admittedly genuine signatures to business letters, and his more formally written signatures to checks and papers of importance, while to the educated eye they are all typical of the same habit, they manifest some features of difference as to the form of the letters, which to the ordinary observer might be misleading, particularly where the general appearance of the writing furnishes the only field into which the examination can go for comparison. That there are resemblances in the form of some of the letters when the genuine signatures of Gordon are compared with the disputed signature is very plain; but the disputed signature contains forms which have no resemblance to corresponding parts of Gordon's writing apart 
The Gordon Will Case.

3

$\beta$
$\vdots$
$\vdots$

롱

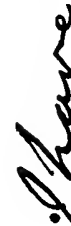

is do

40

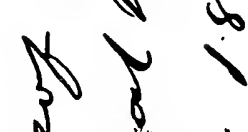

$\left\{\begin{array}{l}\gamma \beta \\ \gamma \\ \gamma\end{array}\right.$
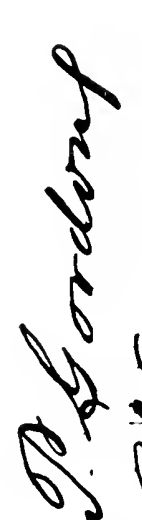

a.

$\rightarrow$

$\int_{3}^{2} 8$

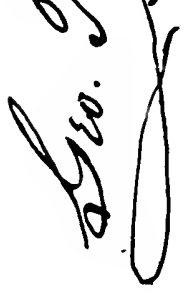

$\dot{8}$

苞

$\sqrt{\frac{30}{6}}$

 

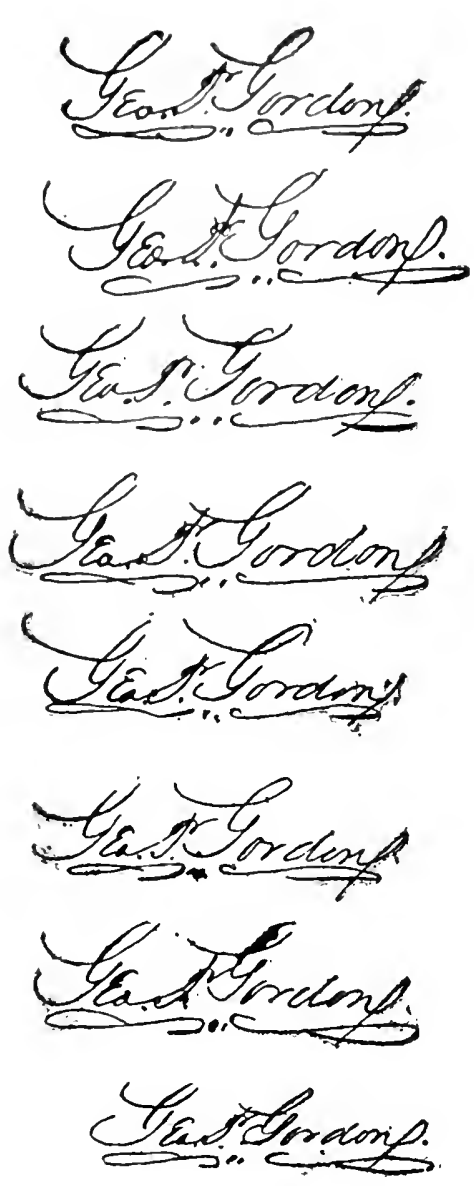
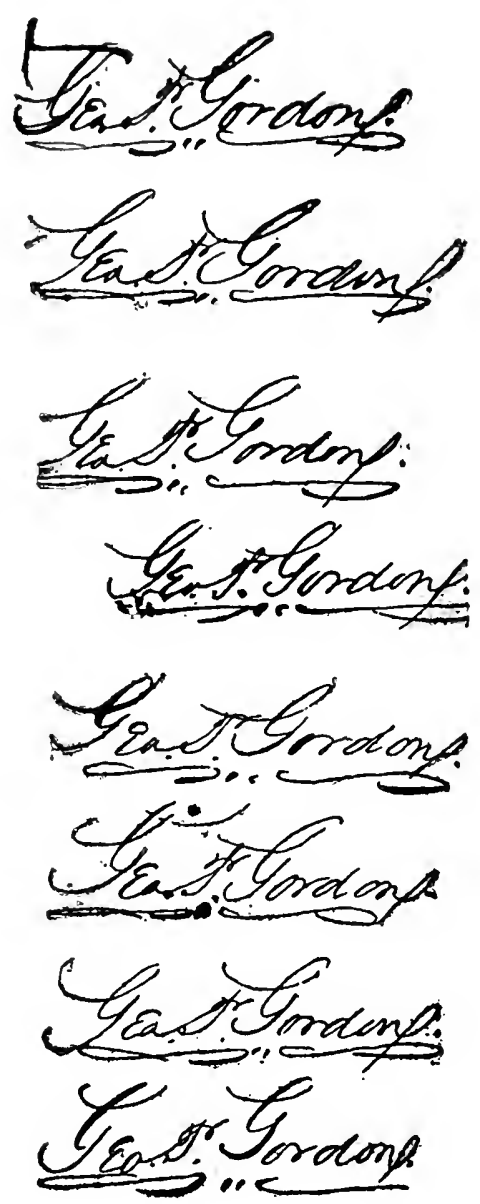

PLATE XXIV - Fac similes of formally written genuine signatures of Geo. P. Gordon to checks. 
The Gordon Will Case.

259

Gabiondme

Berg. Gordon.

Ser. If leven

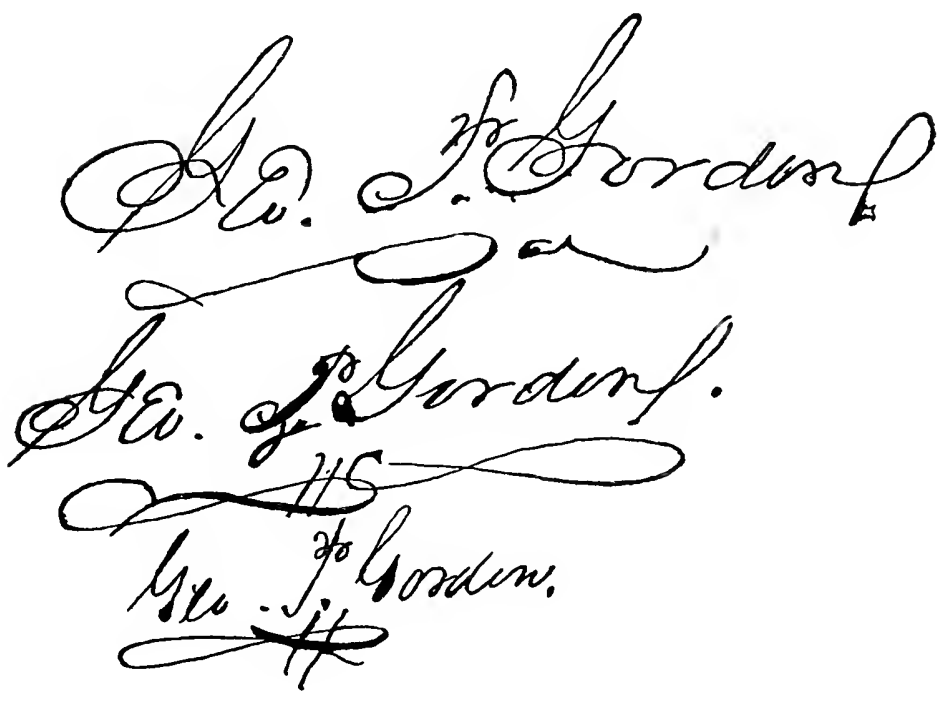

PLATE XXVI - Fac similes of informally written signatures of Geo. P. Gordon to letters. 
from that resemblance which the same letters will have, when written in the same connection by different persons. In riew of these conditions the question suggests itself: Are these like features the grenuine writing of Gordon, and the unlike portions of the disputed signature his writing done under abnormal conditions of production, or are the like portions of the signature in dispute simulations, and the unlike features the interpolations of another habit of writing, and that of the simulator of the like parts?

Understanding it to be a fact developed by experience, that persons, affixing their names as a voluntary act to papers of importance, where it is essential that the personality of the writer should be represented by the signatures, will write the latter formally and habitually; and when signing so important a document as a will, that this generally accepted rule is applicable; and knowing also, when writing is done under the influence of any excitement, abnormal conditions or want of muscular control of the pen, there will be manifested evidences of such an influencing cause apparent in the signature; the fact whether such conditions were present when writing the questioned signature can be very positively determined by an examination of it. This disputed signature when studied by an educated or uneducated eye presents no appearance indicative of being hastily written, or that the writer, at the time of producing it, was laboring under any nervous want of muscular control; on the contrary, there is a total absence of every thing indicating such a condition. Hence the features manifested in it which bear no resemblance to Gordon's writing cannot have their origin under the operation of such a cause. The fact is also apparent that the variations which are found to occur when the informally written signatures of Gor- 
don are compared with those formally produced by him, all of them are typical of each other as to the muscular coordination writing them, and the features which make the disputed signature differ from the admittedly genuine writings of Gordon are totally unlike the differences occurring between the latter when they are compared. Another fact also becomes apparent in this connection wherein the features of form occurring in the disputed signature are not typical of the same muscular coordination as those appearing in the genuine signature of Gordon in their like or unlike features. Sustaining the position thus made apparent that the unlike features of the questioned signature were not written by Gordon, there is another fact established by experience by which it is demonstrated, that abnormal conditions of nervous capacity on the part of the writer, when occurring between the powers to will and to do, tend rather to make more emphatic those peculiarities which give individual character to the signature, than to the production of new forms, and on an examination of the disputed signature those features of it other than those of resemblance do not appear as emphatic manifestations of that which is habitual with Gordon.

The features of resemblance which are found to occur when the disputed signature is compared with the admittedly genuine writing of Gordon, relate entirely to the form of parts of letters, and not to the manner of producing this form. Thus parts of the letters " $\mathrm{G}$ " of the questioned signature resemble in a small measure some of the informally written signatures of Gordon, although when compared with those of the latter formally produced, this little resemblance becomes lost in a greater measure of difference. There are no formally or informally produced letters " $G$ " appearing in Gordon's writing 
wherein the densely shaded bottom and terminal curls occur, which are so prominently manifested in the disputed signature; in fact, there does not appear in either the formally or informally written signatures of Gordon a single letter " $G$ " making even an approach to this feature so demonstratively manifested in the questioned signature.

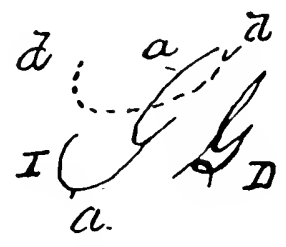

PLATE XXV.

In all the formally written signatures of Gorden to checks, the letters " $\mathrm{G}$ " are uniformly produced by two distinct efforts of the pen made disconnectedly and separately. As shown upon Plate No. XXV, where one of the letters "G" of Gordon's writing is illustrated in fac similc and designated at "I," and one of the letters " $G$ " of the disputed signature is also illustrated in fac simile and designated at "D," the one taken from the disputed signature is made by one continuous stroke of the pen, and the other by first forming the body-part indicated at "a," and then raising the pen from off the paper to return it and make the downwardly curved finishing stroke indicated by the dotted line " $d$;" and not a single formally written signature of Gordon's to a check could be found from out of a very large number, produced in any other way, although in the informally written signatures of Gordon the letter " $G$ " often appears as made by one continuous effort of the pen, and without raising it until the letter was completed.

"The curl at the termination of the letter " $n$ " in the disputed signature is very bunglingly done as a simula. 
tion of that appearing in the genuine signatures of Gordon, and as manifested in the questioned signature it indicates how very difficult it is to copy a form which is in keeping with the habit producing it, by the use on the part of the simulator of an entirely different habit of writing. In the genuine Gordon writing. from the terminal " $n$ " a broad curve extends downwardly to the right, and therefrom in lineal projection curves upwardly to be finished by a down-stroke of the pen forming a loop; the down-stroke of the pen thus actuated crossing the bottom curve near its vertical center at the base-line and in close proximity to the body-part of the letter "n," while in the disputed signature there is extended from the letter " $n$ " a nearly straight line inclining upwardly to the right, and the heavily-shaded down-stroke of the pen intersects the up-stroke at a point horizontally in line with the top of the " $n$ " instead of at the bottom, as in the genuine signatures of Gordon when formally written; thus making this terminal in a manner that was compatible with the writing habit of the simulator, but very different in form from its production when written by Gordon's habit.

The cap forming the top of the letter " $\mathrm{P}$ " in the disputed signature is made angularly in its lateral projection, and is finished with a heavily-shaded curl, while in the admitted writing of Gordon no such angularity or heavily-shaded curl appears. In the disputed signature the letter "o" appears three times, and in each instance of its occurrence it is made with a dot or period-form fin. ish at the upper end of the final up-stoke of the pen, with the latter rotated half a turn while bearing on the paper, before the line connecting the letters "o" with a succeed. ing letter is commenced. In the genuine writing of Gor. don the tops of the letters "o" are uniformly left open, 
without any apparent pen movement to close the top while finishing the up-stroke, all the closing effort occurring at the commencement of the initial clownstroke of these letters. The letters " c," "r," and in a measure the letter " l," as retouched by the pen show the best features of resemblance, and in connection with that appearing in parts of the letters "G," is all there is of likeness to the genuine writing of Gordon, unless the bunglingly. made curl at the end of the letter "n" may be said to form a part of it. These conditions so very positively indicated in the disputed signature show that where it differs from the admitted writing of Gordon, it does not manifest such variation from the latter in the same manner that the genuine signatures of Gordon do when compared with each other. These features of difference so apparent in the disputed signature tend to the conclusion that it was not written by Gordon, but by some other person who was capable of simulating parts of his writing as to form, but had not the capacity to produce simulation of all of its parts.

Pursuing the examination more in detail as to the comparative form of the letters, and their like and unlike features when compared with the genuine writing of Gordon, it appears that the capital letters in the disputed signature are made much shorter in length and relative proportion to the remaining letters composing the signature, than occurs when the capitals appearing in the genuine writing of Gordon are compared with the remaining letters of the signatures as to length. In the formally written signatures of Gordon the capitals have, with the exception of the letter " P," about four times the length of the other letters, while in the disputed signature the capitals have but twice the length of the others. In the genuine writing of Gordon, the letters " $G$ " are 
about twice the length of the letter " $P$," while in the disputed signature the letters " $G$ " and the letter " $P$ " have about the same length. These differences, as will subsequently appear, become important when determining the differing muscular habits of the writers, and the manner of forming these letters is the subject of analysis.

The foregoing description of differences and resemblances when the two writings being examined are compared mainly relate to the form of the letters, their general appearance and such features as tend to give pictorial character to the writing, and not to those minutely manifested details which determine the physical habit exercised to produce them. When comparison is made as to general appearances there is something wanting in the disputed signature to have it make the same impression upon the eye as do the admitted signatures of Gordon in this respect. Undoubtedly this effect in a measure originates from the bungling manner and studied effect which the terminal curl of the letter " $n$ " manifests itself, and the absence of a copied proportion between the length of the capitals and other letters so very strongly characteristic of Gordon's formally written signatures. This measure of indicated difference between the writings when compared was very aptly described by Expert Carvalho when he stated that "the disputed signature lacked the life of the ones written by Gordon."

Where two widely differing habits of writing are em. ployed to produce the same form of signature, one of them being that of the writer who produces the signature habitually, and the other that of one making a simulation of it, that signature produced by the latter will have features incorporated into it (where not within the capacity of the simulator's habit) which will tend to limit the measure of imitation, and the signature produced habit- 
ually will show in the forms of the letters that the latter in their delineation are in keeping with, and indicative of the habit exercised to write them. This condition will, as exemplified by analysis, be found to be strikingly manifested by the contrast apparent between the writings now being examined, where certain interpolations of the simulator's habit are used in place of those appearing in the genuine signature, from the fact that the simulator could not make them as they occur in the latter.

When the disputed signature to the alleged will is examined analytically as to the habit of the writer producing it, and by the use of the microscope it appears that the pen of the person writing it was grasped by the muscular functions of the fingers and thumb, and as thus held was operated by the flexure of these factors. When the grenuine writing of Gordon is examined by the same means and method of analysis, it is found to appear that Gordon grasped the pen with the prehensile muscular functions of the hand, and operated it when writing by the forearm movement, the hand resting lightly upon the table, as moved over the latter back and forth with the concavity of the pen facing the writer's palm. Thus two very differing habits of writing are made manifest when the one by which the disputed signature was produced is compared with that occurring in the admitted writing of Gordon. In the formally written signatures of the latter there is shown but little shading emphasis, and the pen is moved over the paper to form the signature without any flexure of the fingers and thumb, the little shading manifested being apparent in such parts of letters as could be produced by pressure of the whole hand instead of by flexure of the fingers and thumb. In the disputed signature there is strongly marked shading, as indicated by the position of the pen-splits producing it, and this was caused 
- by the flexure of the fingers and the thumb at their joints. Not only is this fact apparent, but the shading occurring in the questioned signature is very plainly marked with individual peculiarity as will subsequently appear when the analysis is proceeded with. Every pen movement manifested in the disputed signature shows that the pen was held with its concavity facing the right, and this caused the left-hand one of the pen-splits to make a deeper furrow in the paper than the other when forming the standards and curves of letters. Not only is this feature apparent, but all the curves indicate in their formation that they were made by the flexure of the fingers and thumb as moved around the pivotal point of the pengrasp, and of which, were the ellipse completed, the curve produced would form an arc.

As the analysis extends into a minute examination of the details of physical habit appearing in the genuine signature of Gordon and also that of the writer of the disputed signature, the development of two different habits become more positively established. One of the most important differences is that in which the shading emphasis of the letters "eo" and "ordon," of the disputed signature become strongly individual in its character. This feature so prominently evidenced as a part of the writer's habit which produced the disputed signature, is manifested where the pen is moved under the action of the finger impulse against the inwardly turning thumb towards the palm of the writer's hand, to form the heavilyshaded wedge-form down-strokes of the pen, and where just before reaching the bottom of the letters other than capitals, the inwardly directed Hexure of the fingers was resisted by the thumb in its adductor movement, calling for an increased measure of finger impulse to overcome this resistance of the thumb, and thus producing an irregu- 
larity or jou in the writing which is plainly manifested when the latter is magnified and examined as a trans. parency In wher words, when the fingers had curved inwardly as far as the thumb could in its adductor functionact comfortably as positioned, the thumb resisted the downwarl movement of the pen just before completing the down-stroke, and thus called for a more emphatic pressure on the part of the incurving fingers to complete the pen act, the effect of this want of harmonious action at this point, being the before mentioned irregularity or jos. In the genuine writing of Gordon there is no evilence of any flexure of the fingers or thumb at all, and consequently no such detail.

To follow up minutely and describe all the differences produced by the simulator's habit as compared with that appearing as the habit of Gordon, would hardly seem important or even necessary, so thoroughly are the prominent features of the two writings distinctly manifested, and recognizing the fact that when a person makes a copy of the signature of another, that the simulator is necessitated to use the pen habitually to have it obey the will and retain its capacity to imitate, and that the simulator cannot assume the physical habit of another person, it follows that with two differing physical habits of writing manifested in the signatures being examined, they cannot be the work of the same person.

As a summary of this analysis it appears in the writing of the disputed signature that the pen was held and operated by a coordination of muscular factors which were entirely different from that shown to have been employed in producing the genuine signatures of Gordon. That this difference in muscularly applied function resulted in typifying all the parts of the disputed signature (whether alike or unlike Gordon's writing in form and general 
appearance), with details which belonged to the simulator's habit, and were totally unlike the characteristics of Gordon's habit. That the incorporation of the heavilyshaded curls at the bottoms of the letters " $G$ " of the disputed signature were produced habitually because the broad curves of these letters as made by Gordon were not within the finger and thumb flexure capacity of the writer of the disputed signature. That the difference in the comparative length of the capitals as a feature of difference was necessitated from the limited flexure capacity of the thumb and fingers of the simulator. That the wedge-form given to the shading appearing in the simulation not only established very positively its production by flexure but gave rise to the formation of a detail which indicated a want of harmonious action between the flexure functions of the simulator's hand that was strongly personal in its character, and, finally, that there is nothing apparent in the disputed signature to indicate that it was written by the same person who wrote the admittedly genuine signatures of Gordon. That even the simulated parts when examined as to the manner in which they were formed show very positively that their production was accomplished by some other person than the writer of the genuine Gordon signature.

One of the important conclusions reached as to the signature of George P. Gordon to the pretended will by the authority officially invoked to determine its validity, was that in addition to its being a forgery, that the latter was the work of Henry G. Adams, the man who found the instrument on which Gordon's name as testator appears, and who admitted that he wrote the body of it. Without going into a recital of the moral evidence which was taken upon the trial of the case, and which tended to confirm the conclusion reached, 
the following facts appear when the writing of Adams (the man charged with forging it) is compared with the forged signature of Gordon to the pretended will, together with the signatures of the alleged witnesses to the latter, and when the names of these persons appearing as witnesses are compared with their genuine writing.

Upon Plate No. XXVII there are shown in fac simile the signatures of the pretended witnesses, and that of the forged signature of George P. Gordon to the alleged will. Upon Plate No. XXVIII there are shown in fac simile, in connection with the signatures of the pretended witnesses, a part of the alleged will, the latter being admitted to be the handwriting of Henry G. Adams, the man charged with the forgery, and upon Plates XXIX, XXX and XXXI there are shown in fac simile, genuine signatures of the persons whose names appear as witnesses to it.

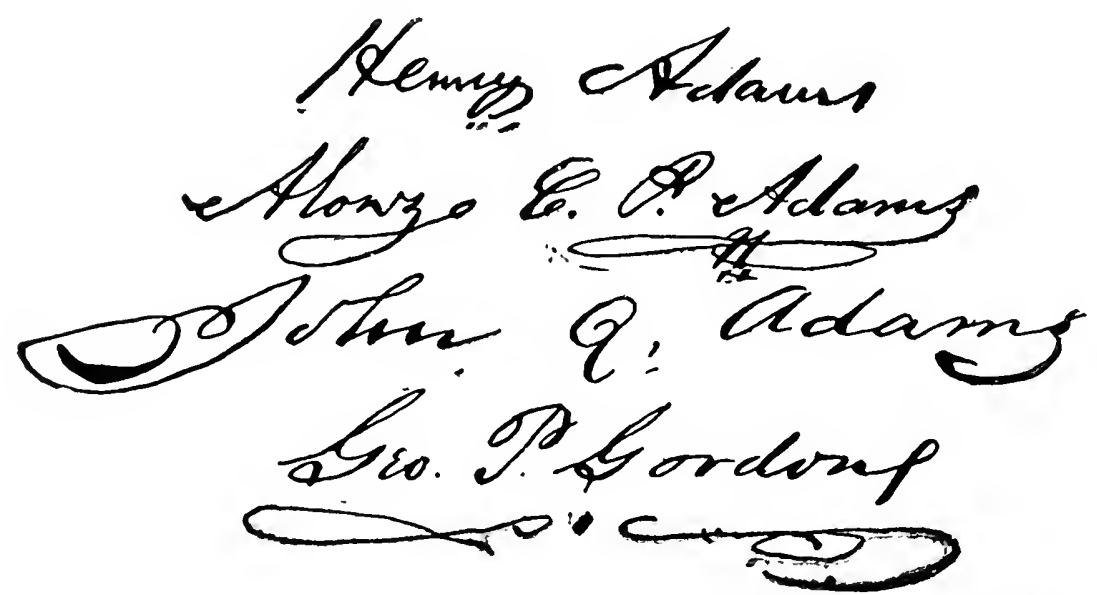

PLATE XXVII. - Fac simile signatures of the pretended witnesses and the forged signature of Geo. P. Gordon. 


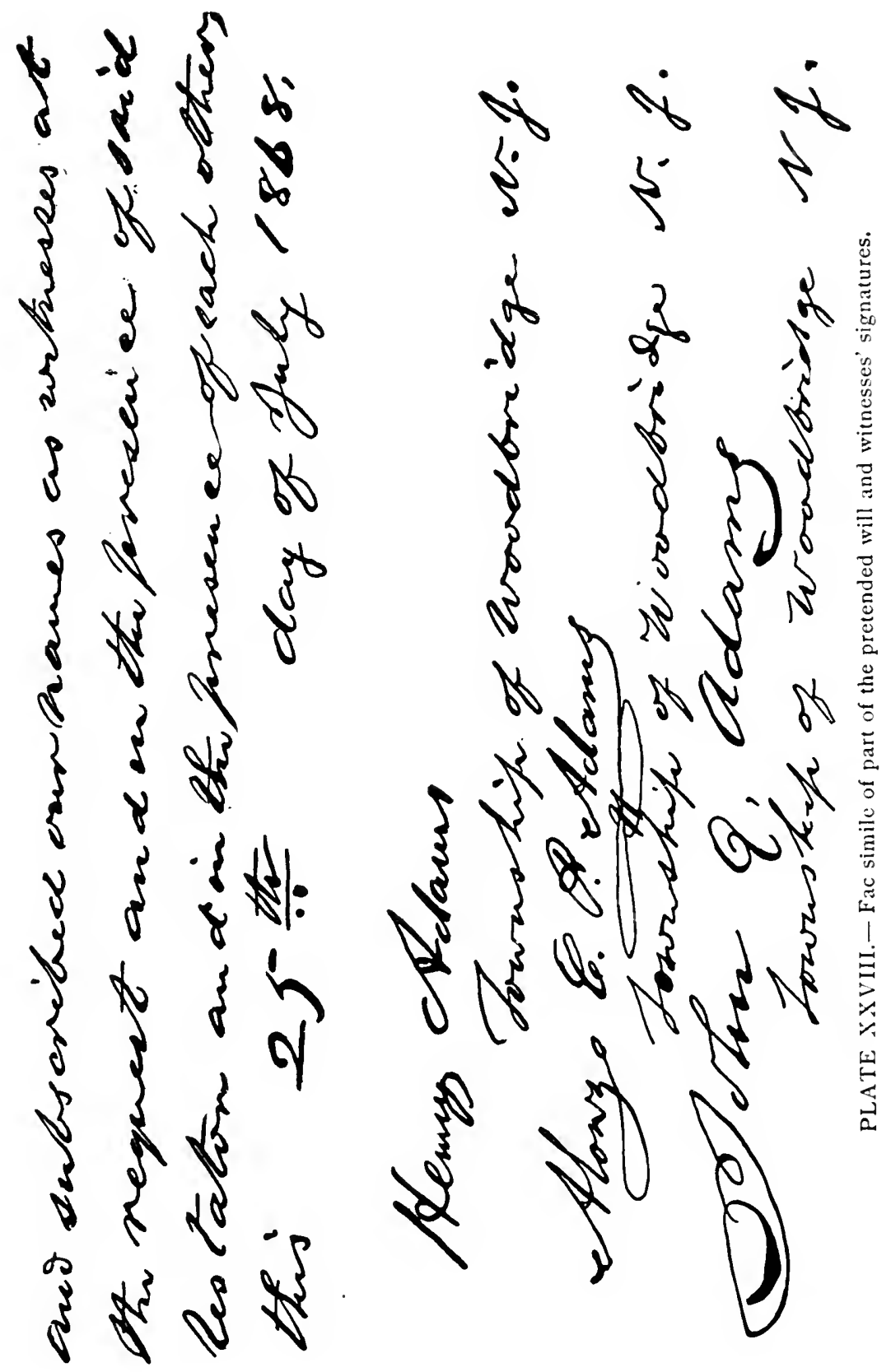


272

The Giman Will Case.

Kenny Stanes

Hency Sdawor

Heny Adarus

Aency Sdount

*. Adant

HE Halam

HAdoms

As Adame

H. Adanes

Itcury Admers

PLATE XXIX. - Fac similes of the genuine signatures of Henry Adams, one of the alleged witnesses. 
The Goriton Will Case.

273

Sterdslang

Henzo C.P.Sdams

Afongs C. O.ctomy

A.b.P. Adans

Ateretrians

te. D. Aleams

A.b. O, Alang

AC. P. Alanys

AbQ.Atrans

PLATE XXX.- Fac similes of genuine signatures of A. C. P. Adams, one of the alleged witnesses.

35 
$27+$

The Gordon Will Case.

of Q Adars

d. D: Adam

doth. Q. Clang

2. adars

C. Q. Adam

Sole D. Adams

chon: Q Adan

Shim Ba came

d. Q. Naans

Sou. Q. adan g

PLATE XXXI. -Fac similes of genuine signatures of John Q. Adams, one of the alleged witnesses.

The question presented in view of the conclusion reached by the court as to the character of the alleged will and its authorship, independently of the moral evidence produced as affecting the matter at issue, becomes: What is there in the forged signature of George P. Gr- 
don to the pretended will, the writing of the latter, and that appearing in the writing of the names appended as witnesses, which indicates that they are all the writing of one and the same person? With the forged signature of Gordon to the alleged will, and the pretended signatures appended to it as witnesses, arranged in close proximity, as illustrated in fac simile upon Plate No. XXVII, the general appearance of the writings seems to be the same in all of them. There is manifested the same slant, ellipticity of curve, the same measure of pen pressure; and when the habitually written parts of the signatures as to form are dissected out and compared with each other and the writing of Henry G. Adams in the body of the pretended will, the likeness becomes very strong in delineation.

When the writing illustrated in fac similc parts of the alleged will appearing upon Plates No. XXIII and XXVIII, is compared with that of the pretended signatures, the resemblance is not so strongly manifested as when the latter are compared with each other; yet, as will subsequently appear, they are all of them easily determined as having been produced by the same physical habit. When writing the body of the pretended will, it must be understood that the habit of the writer was exercised to produce habitual forms of letters; and when writing the pretended signatures, this same habit was employed to produce forms of letters in imitation of others which were not habitual to the simulator; hence the examination now being undertaken, instead of being directed to determine whether or not the forged signature of Gordon, considered as a questioned signature, was written by him, the investigation now must be made to ascertain whether the person who forged Gordon's name also simulated the name of the pretended wit- 
nesses, by a comparison of them with the forged signature of Gorkon and the writing in the body of the will; the difference in procedure being in the one case to compare Corlon's signature as disputed, with his writing, to see if Gordon wrote it, and in the examination now to be made, to determine whether Henry G. Adams dicl the forgery of Gordon's signature and those of the pretended witnesses, from an examination of Adams' admitted writing.

The forged signature of Gordon to the alleged will, as has been already described, was produced by a writing habit which was strong in its personal characteristics. That these individualisms appear throughout its delineation, and that they very positively did not belong to Gordon's habit of writing is apparent. But can these features of habit appearing as incidental to a simulated effort of writing be determined with sufficient accuracy to formulate an opinion which will identify the forger from an examination of writing done, when the habit so exercised in simulation is employed to produce unhabitual forms of letters? The answer to this interrogation must be, while there might be cases where the measure of accuracy attained in reaching a conclusion as to the iden. tification of the forger under such conditions would be limited, but in the case being considered there is no room for doubt, so clearly and definitely can opinion and deduction intrench itself behind the well-established facts which the habitual and simulated writing being examined presents.

The habit of the simulator who wrote the forged signature of Gordon to the pretended will as testator has been already described and in detail, and when the writing appearing in the body of the alleged will, as represented in fac simile upon Plates No. XXIII and XXVIII, 
is examined, it is found to have been written with the pen held and operated precisely as it was used when the simulation of the Gordon signature was made, and that the peculiarly manifested discordant action occurring between the thumb and fingers when producing the shaded down-strokes of letters other than capitals is more demonstratively manifested in the writing of the alleged will than when operated under the restraints imposed by the simulating intention appearing in the forged signature of Gordon.

These features of habit, it will be understood, are persistent in their manifestation, they cannot be dispensed with by intentional effort, neither can the habit making one person's writing strong in its individualisms from physical causes be assumed by another. Even in the simulation of forms of letters when well imitated they will embody the details of habit belonging to the simulator, and be wanting in those belonging to the habit of the person whose writing is imitated.

On examining the writing of the alleged will-parts shown in fac simile upon Plates No. XXIII and XXVIII, every letter evidences the want of harmonious action occurring between the thumb and fingers of the writer when forming the heavily shaded down-strokes of letters other than capitals. On examining the signature "Henry Adams" (which it will be observed in the pretended signature is not written Henry), this want of coordinate action is likewise apparent, although some of the standards of letters occurring therein have been gone over twice with the pen to make the wedge-form shading, a concomitant of this discordant action, less prominent. The same condition is manifested when the signature of Alonzo C. P. Adams to the pretended will is examined, and in the production of which the standard of the letter 
"d" has been gone over the second time with the pen, but in the pretended signature of John Q. Adams the letter " $d$ " is left as first made by the simulator with all the evidences belonging to the habit of the latter not retonched with the pen. In the forged signature of Geo. P. Gordon the pen of the writer producing it, as has been described, was held with its concavity facing to the right, operated by the flexure of the fingers and thumb, and the details which appear in the pretended witnesses' signa. tures show that the pen was held and operated in the same manner in writing them as when producing the body-writing of the pretended will and the forged signature of Gordon.

While there are forms of letters occurring in the pretended signatures which bear resemblance to those appearing in the body-writing of the pretended will, yet it must be remembered that this will only occur when the simulator unconsciously lapses into the production of habitual forms, and does not exercise the intention to produce other than the latter, and ones which resemble those which belong to the signatures being imitated. Thus when writing the pretended signature of John $Q$. Adams, and making the initial movement of the pen in forming the curl of the letter "J," the writer made it habitually as appearing in "July," on Plates Nos. XXIII and XXVIII.

It is also apparent that when writing the final "s" to the pretended signature of Henry Adams, spelled "Hemry," the simulator lapsed into his habitual form, and wrote it as appearing in "names" of line $r$, Plate No. XXVIII, and the same condition appears when the letter "m" of "Hemry" is compared with the letter " $\mathrm{m}$ " in "names" before alluded to. So the letter " $d$ " in John Q. Adams in its shading, ellipticity and slant is very close 
in its resemblance to the same letter occurring in "Woodbridge," just above the pretended signature of John Q. Adams. When the letters "o " of the forged signature of Geo. P. Gordon are compared with those appearing in the body-writing of the pretended will, they all appear to not only have the same form, but the details show that they were produced by the same habit of holding and moving the pen. All of these letters "o" were closed in at the top by the up-stroke of the pen, and the formation thereat of a period-form dot produced by rotating the pen half a turn. In the forged signature of Gordon the standard of the letter " $d$ " was made by first forming it with a wedge-form shading, and then going over it the second time to make the standard wider at the top. This standard of the letter " $d$ " was first made like the letter "l" in "seal," the second line above it, before being gone over the second time. The letter " $n$ " of the forged sig. nature of Gordon made with its first member longer than the other, which as thus produced is habitual with the writer of the body-part of the pretended will, and is particularly so manifested in the word "names" before referred to. The letter " $r$ " of the forged Gordon signature finds its habitual likeness in "presence," in line 2, of Plate No. XXVIII. In addition to these resemblances where the habit of the simulator lapses into the production unconsciously of habitual forms there is also apparent in the pretended signatures evidence of efforts made to paint them up so as to give to them a changed pictorial effect in places by the addition of prefix and suffix parts. Thus the tail of the letter "y" in "Hemry" was added after the first writing of the loop had been done and the ink of the first writing had become dry. The curl upon the initial "A" in "Alonzo" was added by a separate effort, and the awkwardly made flourish at the termination of 
the name John Q. Adams, was added after the terminal "s" had been written and the ink of the first writing had beconce dry.

When these pretended witnesses' signatures are compared with the genuine writing of the persons whose names they represent it would seem that the simulator must have copied them from memory rather than with any of the genuine writing of these persons used for the imitation, so unlike are they when compared with the genuine writing of the persons they purport to represent. To give all the characteristics of difference which are found to occur, when these pretended signatures are compared with the genuine writing of the persons which they pretend to personate in full detail would not seem important or necessary, so long as it is clearly shown that the pretended signatures were all written by one person, and by the writer of the body-part of the will and the forged signature of Geo. P. Gordon.

When the genuine writing of Henry Adams, as shown in fac simile upon Plate No. XXIX, is compared with the pretended signature of the same person upon the alleged will independently of its being written "Hemry" instead of "Henry," there is very little resemblance between them as to pen-pressure, shading emphasis, or ellipticity of curve, and they only have that likeness which the same signature will have when written by different persons using like forms of capitals. So when the genuine signatures of Alonzo C. P. Adams, as shown in fac simile upon Plate No. XXX, are compared with that appearing upon the alleged will, there is no resemblance at all beyond that which the same name written by different persons will have with the exception of the terminal "s," and so very different otherwise that where dissimilar it needs no explanation as to detail, and the same may be 
said of the genuine signatures of John Q. Adams, represented in fac simile upon Plate No. XXXI, when they are compared with the pretended signature upon the alleged will.

Each of the genuine signatures of the persons whose names appear as witnesses to the alleged will show that they were produced by a different physical habit, and the names purporting to represent them were all written by one and the same habit. Thus Henry Adams held and moved the pen with its concavity facing slightly to the left, and wrote with but little pressure upon the paper. Alonzo C. P. Adams wrote with the pen resting squarely upon the paper with its concavity facing the palm of the writer's hand, and used the flexure of the fingers and thumb in combination with the forearm movement when writing, and John Q. Adams wrote entirely with the forearm movement without the flexure of the fingers and thumb. Thus it appears that there are no parallelisms of physical habit found to occur between the genuine writing of the persons whose names appear as witnesses to the alleged will and their pretended signatures thereto which indicate that the latter were written by the persons whose signatures they purport to represent; on the contrary, all the facts which an examination of these writings reveals tend to the one conclusion, that they were all of them, including the forged signature to the alleged will, written by one and the same person, and also that the writer of them is very positively identified and established by analysis as being the same person who wrote the body of the pretended will, and finally that there are no details or features of habit indicated in the writings when examined competently which in the slightest manner sug. gest any other conclusion.

There was developed on the trial of this case a fact 
wherein a knowledge of the ink with which a writing was done became very important as affecting its age and the time at which it was claimed to have been made. There was produced by Henry G. Adams, and introduced in evidence, a document which the latter testified was an original draft of the alleged will of Geo. P. Gordon, which he, Adams, had made for the latter, and from which, as amended, he, the witness, had copied the alleged will in dispute. This so-called original draft had upon it interlineations written in red ink, which Adams testified were made at the time, and that the document as it appeared in court was, so far as the "red and black ink was concerned, just as it was originally made" when produced for Gordon's approval. This red ink interlineation was by able chemists, Profs. Morton, Leeds, Hodges, Doremus and Stebbins, found to be made from eosine, something which was not known, and had not been discovered until some years subsequent to the time when this socalled original draft of the Gordon will, as testified by Adams, had been made, and after the establishment of this fact, Adams changed his testimony and concluded that he must have been mistaken as to when it was written.

The counsel in this case were Gilbert M. Collins, of Collins \& Corbin, for the proponents, and with whom were associated Booream, Hamilton \& Beckitt, and Black \& King of New York. For the contestants, Theodore F. Miller of New York City, with Barker Gummere as senior counsel, and W. F. Abbott as Solicitor. The experts employed by the proponents were Dr. Ewell of Chicago, Rausch, McClelland and Cresson; those employed by the contestants were Daniel G. Ames and David N. Carvalho of New York city, Prof. Tollman of Chicago, Ill., Cantwell of Albany, N. Y., and the author. 


\section{N D EX.}

A

PAGE.

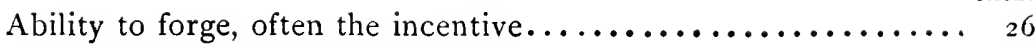

Ability to modify individual habit .................. $3^{9}$

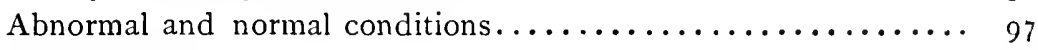

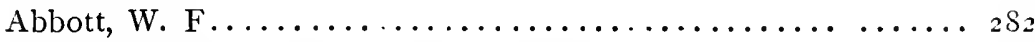

Accuracy in determining habit of pen-and-ink writing ....... 126

Accuracy attainable in determining habit in pencil writing ... $\ldots 172$

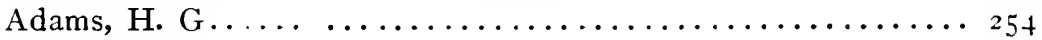

Analysis of writing explained and illustrated ............ 99

Analysis of writing made for determining individual habit.... I03, $\mathrm{I}_{4}$ Analysis of writing when results obtainable are doubtful ..... I 56 , I 5

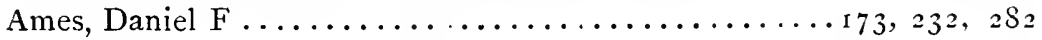
Angularity, manifested in writing.................... ${ }^{\mathrm{S}}$

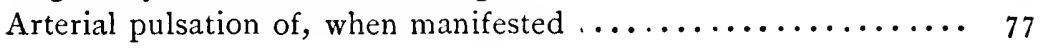

B

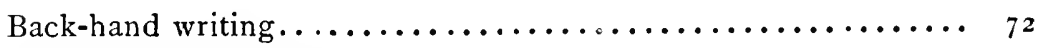

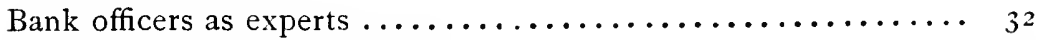

Booream, Hamilton \& Beckitt................... 282

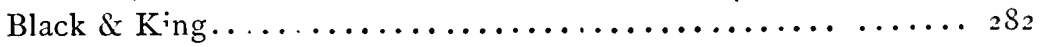

C

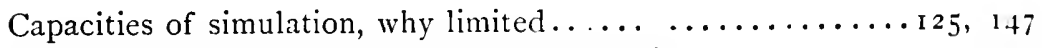

Capacities to will and to do, their individuality............ tt

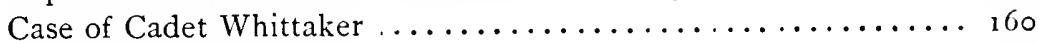

Care to be exercised in making analysis $\ldots \ldots \ldots \ldots \ldots \ldots \ldots 8_{2}$

Carvalho, David N .................. 73,2 I 3, 265, $2 \mathrm{~S}_{2}$

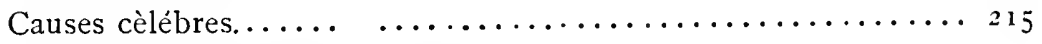

Changes in the common-law rules of evidence........... $2 \mathrm{~S}$

Characteristics of forged signatures $\ldots \ldots \ldots \ldots \ldots \ldots \ldots . \ldots \ldots$

Chabot......................... I40, ItI, I4

Character of the forgery illustrated and analyzed ........... I00

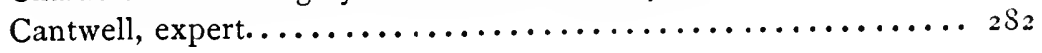


PAGR.

Children learning to write.. ................... 40

(immon-law rule ats to expert evidence............... 27

('vorlinate action of muscular functions as to personality ...... 62

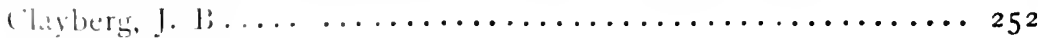

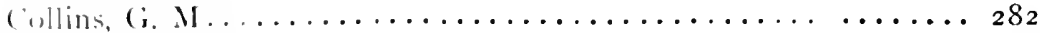

cressen, expert........................... 282

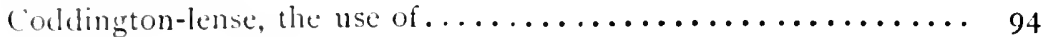

$\mathrm{D}$

1)ate of writings used for comparison $\ldots \ldots \ldots \ldots \ldots \ldots \ldots \ldots \ldots . \ldots 8_{5}$

Iavis Will Case........................... 242

Declaration of Independence, signatures to ..................... 96

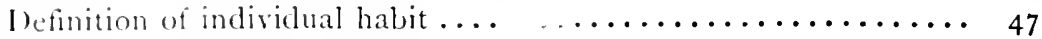

Details of hal,it why physically typical $\ldots \ldots \ldots \ldots \ldots \ldots \ldots \ldots$ I

Ietails of habit compatible with muscular co-ordination........ 56

I) tails of habit too minute to be simulated with a pen ....... I 25

Development of individual habit $\ldots \ldots \ldots \ldots \ldots \ldots \ldots \ldots \ldots \ldots \ldots \ldots$

Disease, effect of ............................ 76

Dissimulation not modification.................. I 43

I) issimulated or disguised writing $\ldots \ldots \ldots \ldots \ldots \ldots \ldots \ldots \ldots \ldots$ I 45

I) issimulating capacity, how limited............... I 47

Dissimulation, why difficult to accomplish $\ldots \ldots \ldots \ldots \ldots \ldots \ldots$ I 47

l)issimulation and the intrusion of habitual details.......... I 53

Dissimulated writing and the capacities to will and to do ..... I 55

Dissimulated writing difficult to analyze accurately $\ldots \ldots \ldots \ldots$ I 56

Dissimulated writing, when difficult to analyze ........... I56

Dissimulated writing, how determined as such........... I46

Jocuments and the effect of age upon them ............ I98

Dudley, A. K.......................... 234

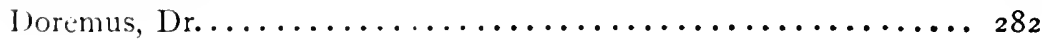

\section{E}

Eddy, James R............................ 249

Effect of differing systems of penmanship on habit......... 52

Effect of using an elastic pen and a rigid pencil ........... I 78

Ellipticity of curve as an individuality $\ldots \ldots \ldots \ldots \ldots \ldots \ldots \ldots . \ldots \ldots$

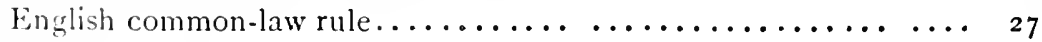

Eroine............................. 282

Ewell, Dr........................... 282

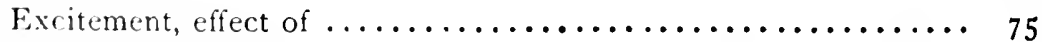

Expert evidence $\ldots \ldots \ldots \ldots \ldots \ldots \ldots \ldots \ldots \ldots \ldots \ldots \ldots \ldots \ldots$ 


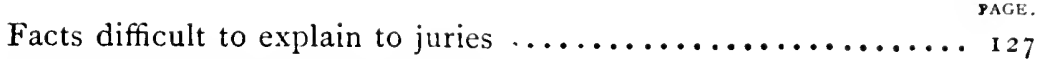

Features common to most forgeries ................ 89

Features that are generically habitual $\ldots \ldots \ldots \ldots \ldots \ldots \ldots \ldots \ldots \ldots \ldots \ldots \ldots$

Forearm movement of the pen when writing $\ldots \ldots \ldots \ldots \ldots \ldots, 7_{1}$

\section{G}

General appearances in writing, why deceptive $\ldots \ldots \ldots \ldots \ldots \ldots . \ldots \ldots$

General appearances in writing, when deceptive $\ldots \ldots \ldots \ldots \ldots . \cdots 9^{6}$

Generic features of habit $\ldots \ldots \ldots \ldots \ldots \ldots \ldots \ldots \ldots \ldots \ldots \ldots \ldots \ldots \ldots$

Generic classification of writing habits $\ldots \ldots \ldots \ldots \ldots \ldots \ldots$ r 28

Generic details, individuality of $\ldots \ldots \ldots \ldots \ldots \ldots \ldots \ldots \ldots \ldots \ldots$

Gordon Will Case ............................ 253

Gummere Baker.......................... ${ }_{28} 82$

H

Habit defined as to individuality $\ldots \ldots \ldots \ldots \ldots \ldots \ldots \ldots \ldots \ldots, 47$

Habit as a copying act.......................... 43

Habit as a reflex capacity......................... $4^{1-42}$

Hand, Kellogg \& Hall .......................... 234

Habitual and unhabitual writing. $\ldots \ldots \ldots \ldots \ldots \ldots \ldots \ldots \ldots \mathrm{r}_{4} 8$

Habits of writing as numerous as writers ............... 54

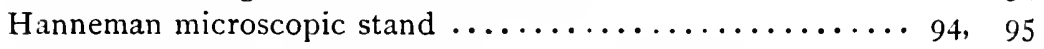

Habitual details and their appearance in simulations. ....... 154

Howland Will Case ......................... 91 18

Hodges, Prof................................ ${ }_{28} 8_{2}$

Hunter Will Case............................. 233

Individuality of generic details $\ldots \ldots \ldots \ldots \ldots \ldots \ldots \ldots \ldots, \mathrm{I}_{3} \mathrm{I}$

Individual habit of writing why developed $\ldots \ldots \ldots \ldots \ldots \ldots, 4^{\mathrm{I}}$

Individual capacities to will and to do.................. 40

Individual habit of writing defined $\ldots \ldots \ldots \ldots \ldots \ldots \ldots \ldots \ldots+4$

Individual characteristics, development of............... 49

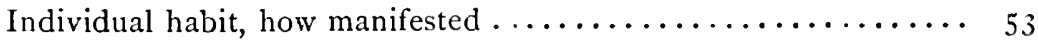

Individual muscular development................ $5^{8,} \quad 59$

Informally and formally written signatures.............. 86

Ingersoll, Col. R. I........................... 25 I

Impossibility of formulating rules for making examinations..... 55 
PAGE.

Inks, and how they show the effects of age $\ldots \ldots \ldots \ldots \ldots \ldots \ldots$ 1 88

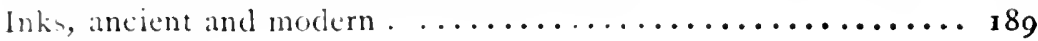

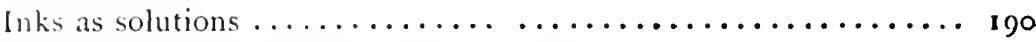

Inks containing coloring matter in suspension............ 190

Inks that are most permanent................... 192

Inks tested as to qualitative character $\ldots \ldots \ldots \ldots \ldots \ldots \ldots \ldots \ldots$ I9 $\mathbf{I}$

Inks tested with reagents ..................... 2 I 3

Inks when their fading ceases $\ldots \ldots \ldots \ldots \ldots \ldots \ldots \ldots \ldots \ldots \ldots$

Inks, how their fading indicates age............... 93

Inks, chemical testing of, when necessary ............. I96

Inks made from carbon, why not used .............. 202

Inks made from carbon, their permanency ............. 201

Inks, how removed.......................... 200

Inks tested to determine their samenesss or difference........ 199

Inks classed for testing. ..................... 2 10

Inks made from nigrosine.................... 2 I 4

\section{J}

Junius letters, handwriting of ................ 14, 40

\section{$\mathrm{K}$}

Kirkpatrick, W........................... $25^{\mathrm{r}}$

Knowledge of muscular functions of the hand and fore-arm nec-

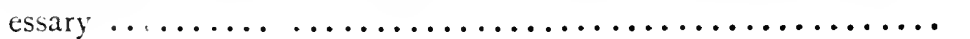

\section{L}

Limited value of evidence under the common-law rule........ 27

Lewis Will Case............................. 225

Leeds, Prof ............................. $2_{2} 8_{2}$

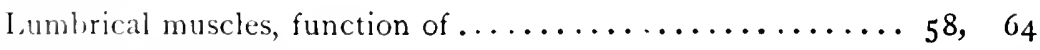

I.yman, the forger.......................... 99

\section{M}

Manner of holding the pen...................... $6_{7}$

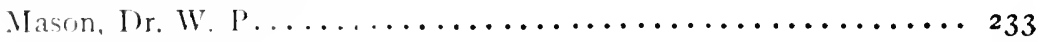

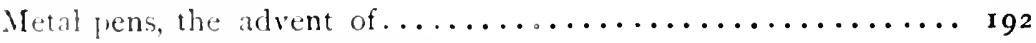

Microsope, its use a necessity.................... 94

Microscope, the use of, requires experience $\ldots \ldots \ldots \ldots \ldots \ldots .95$

Miller, Theodore F............................ ${ }_{25} 6$ 
PAGE.

Modification of individual habit of writing............... $73, \quad 138$

Modification not dissimulation................... 143

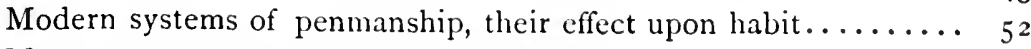

Montana statutes, as to expert evidence.................. $25^{2}$

Morey Letter Case ........................... z z

Motive feature of anonymous letters................. 150

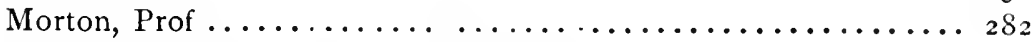

Muscular development as an individuality .............. 59

Muscular functions used when writing................. $5^{8}$

Muscular function of the hand and forearm, a knowledge of, nec-

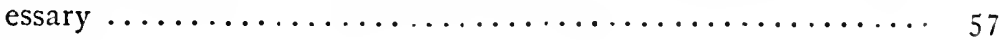

Muscular functions and their coordinate action ........60, $6_{5}$

Mc

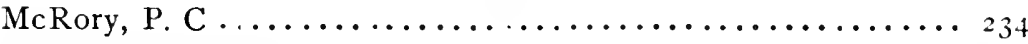

McClelland, expert. . $\ldots \ldots \ldots \ldots \ldots \ldots \ldots \ldots \ldots \ldots \ldots \ldots \ldots \ldots \ldots$

$\mathrm{N}$

Nigrosine ink............................... $21_{4}$

Normal and abnormal conditions effect of $\ldots \ldots \ldots \ldots \ldots \ldots .97$

o

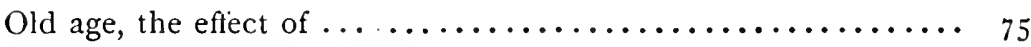

Other than signature writing....................... 134

$\mathrm{P}$

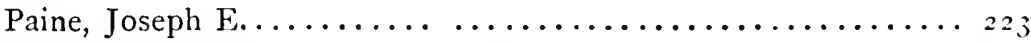

Paper and the effect of age thereon................. $197-198$

Paper, microscopic examination of.................. 197

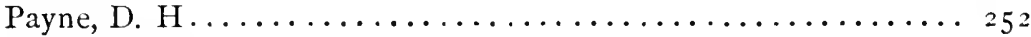

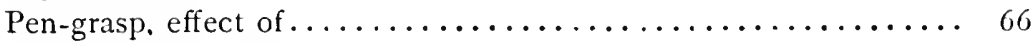

Pen-splits, the details produced by................... 68

Pen-pressure, a feature of habit . . . . . . . . . . . . . . 69

Pen-pressure, how determined................... $7^{\circ}$

Pen-and-pencil writing of same persons............... I 82

Pen and pencil, as writing implements.............. 177

Pencil writing, how differing from pen writing......... I 155 , I I

Pencil writing, details of $\ldots \ldots \ldots \ldots \ldots \ldots \ldots \ldots \ldots \ldots \ldots \ldots$

Pencil writing, when strongly habitual. ................ $18_{3}$

Pencil writing, when the writer's habit is hard to determine ..... 185

Pencil writing easily simulated, and why............. I 79 
PAGB.

Photographs for purposes of eximination.............. 99

l'iper, l) . ........................ 73

l'ueree, l'rofessor, his calculations in the Howland Will Case,as to

the chances of a person writing three times exactly alike..... 91

Proper signatures as standards. ................. 86

lulsation tremor............................... 77

$\mathrm{R}$

Kausch, expert. ........................ 282

Resemblance occurring in the writing of different persons...... $5 \mathbf{I}$

Reversion to habitual details when dissimulating........... I 49

Reflex capacity, development of ................. 42

Robinson $\&$ stapleton........................ 252

Rudimentary efforts, when learning to write............ 45

$\mathrm{S}$

Sanders, $W . F \ldots \ldots \ldots \ldots \ldots \ldots \ldots \ldots \ldots \ldots \ldots \ldots \ldots \ldots \ldots \ldots$

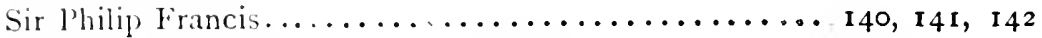

Sickness, its effect on the writing habit.............. $7^{6}$

Signatures written unwillingly .................. 87

Signature expression . .................

Signatures of the same person when exactly alike, positive evidence

of simulation $\ldots \ldots \ldots \ldots \ldots \ldots \ldots \ldots \ldots \ldots \ldots \ldots \ldots \ldots \ldots$ I

Signatures selected as standards for comparison $\ldots \ldots \ldots \ldots \cdots 34,8_{3}$

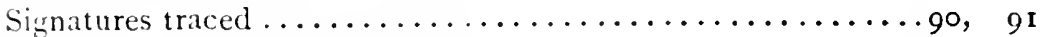

Simnatures forged, characteristics of............... 93

Signatures written with a lead pencil easily traced........... I 84

Study of writing other than signatures............... I 39

Slant or slope of writing and its ellipticity as an individuality . . . 78

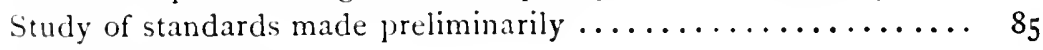

Simpson, expert....................... 173

Spinner, $F$. E., signatures of $\ldots \ldots \ldots \ldots \ldots \ldots \ldots \ldots \ldots \ldots \ldots$ I 34

Southwarth, Albert....................... I 73

Smith, ex-Judge......................... 234

Statute of Montana relating to expert evidence.......... 252

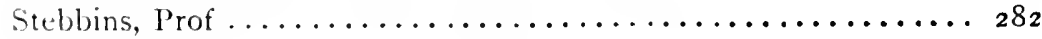

Systems of penmanship, their effect upon habit $\ldots \ldots \ldots \ldots \ldots \ldots .5$ I

T

Tests of ink when affected by age................. 2 I I

Tests of ink should be made competently............. 2 I 2

Tests of ink qualitatively made................... 209 
Tests of ink, authorities cited for making...............

Tests of ink, one test not sufficient ................... 208

Tests of ink, purity of the reagents used for making.......... 206

Tests of ink, with what implements made............... 206

Thumb as a factor in writing. ........................ $6_{4}$

Toole, E. W.................................. ${ }_{25}$

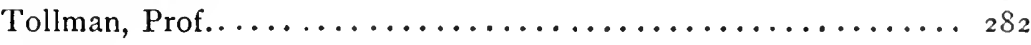

Trimble, H. H............................... $25^{1}$

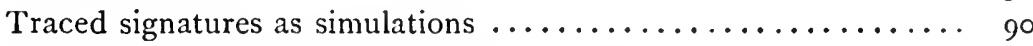

Typical variations of same habit of writing............... 8 ,

Typewriter machines and the work done by them.......... 203

\section{$\mathrm{U}$}

Unusual conditions attending the production of signatures ..... 87

Unwillingly and willingly written signatures................. $8_{7}$

\section{V}

Variation in signatures of the same person $\ldots \ldots \ldots \ldots \ldots \ldots \ldots .74$

\section{W}

Why specific rules for making analysis cannot be given....... 55

Why people write differently .................... 37

Whittaker, Cadet, case of ..................... I60

Willingly and unwillingly written signatures $\ldots \ldots \ldots \ldots \ldots .67, \quad 88$

Writing capacities, how developed.................. $4^{\text {I }}$

Writing as a reflex or mechanical capacity............... 42

Writing when done as a copying act $\ldots \ldots \ldots \ldots \ldots \ldots \ldots \ldots, 43$

Writing teachers as experts........................ 33

Writing habits as numerous as writers................. 54

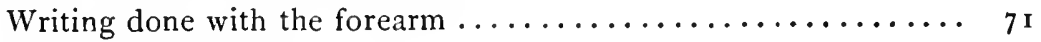

Writing backhanded.............................. $7_{2}$

Writing done in youth and old age $\ldots \ldots \ldots \ldots \ldots \ldots \ldots, 78,79$

Writing habits generically classed $\ldots \ldots \ldots \ldots \ldots \ldots \ldots \ldots, \mathbf{1}_{2} 8, \mathbf{1}_{32}$

Writing other than signatures compared with the latter...... I34, 139

Unusual conditions in the production of habitual or unhabitual

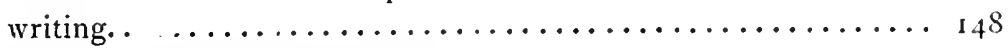

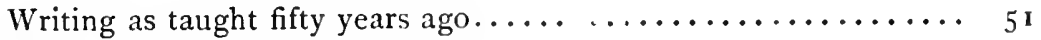

Writing habits generically classed $\ldots \ldots \ldots \ldots \ldots \ldots \ldots \ldots \ldots \ldots \ldots \ldots \ldots \ldots \ldots \ldots \ldots \ldots \ldots \ldots \ldots \ldots$

Woolworth, J. M............................ 25 I 





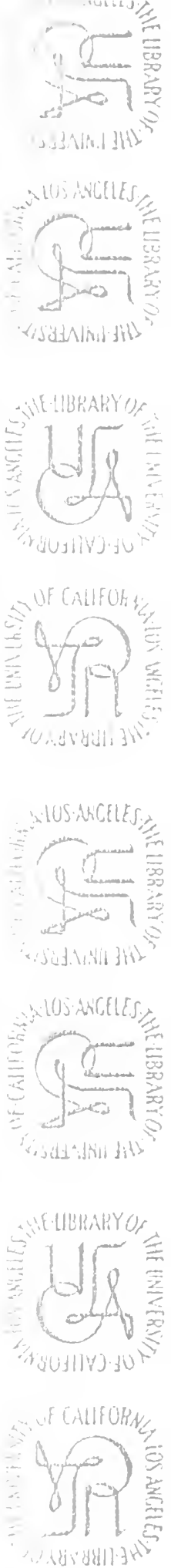


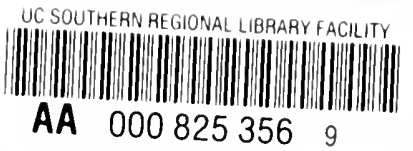


